WONDERFUL HOUSI

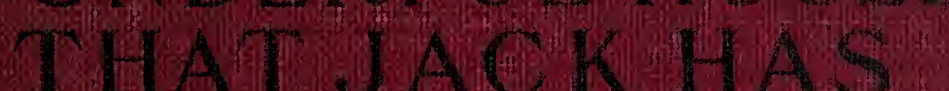
U10.

C.N. MIILARD

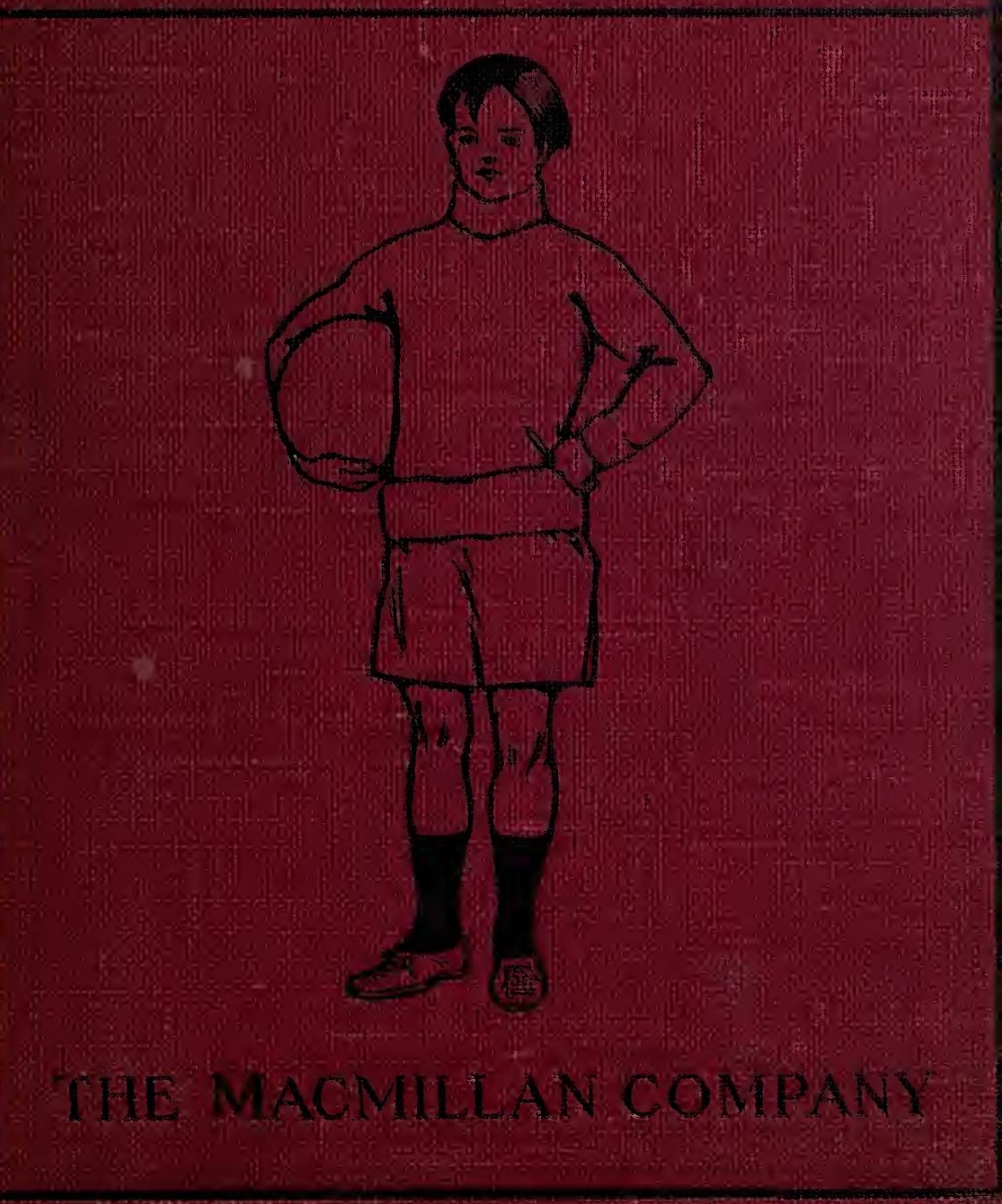


Sertrude hitchell. 


$$
x^{2}+2
$$

I.
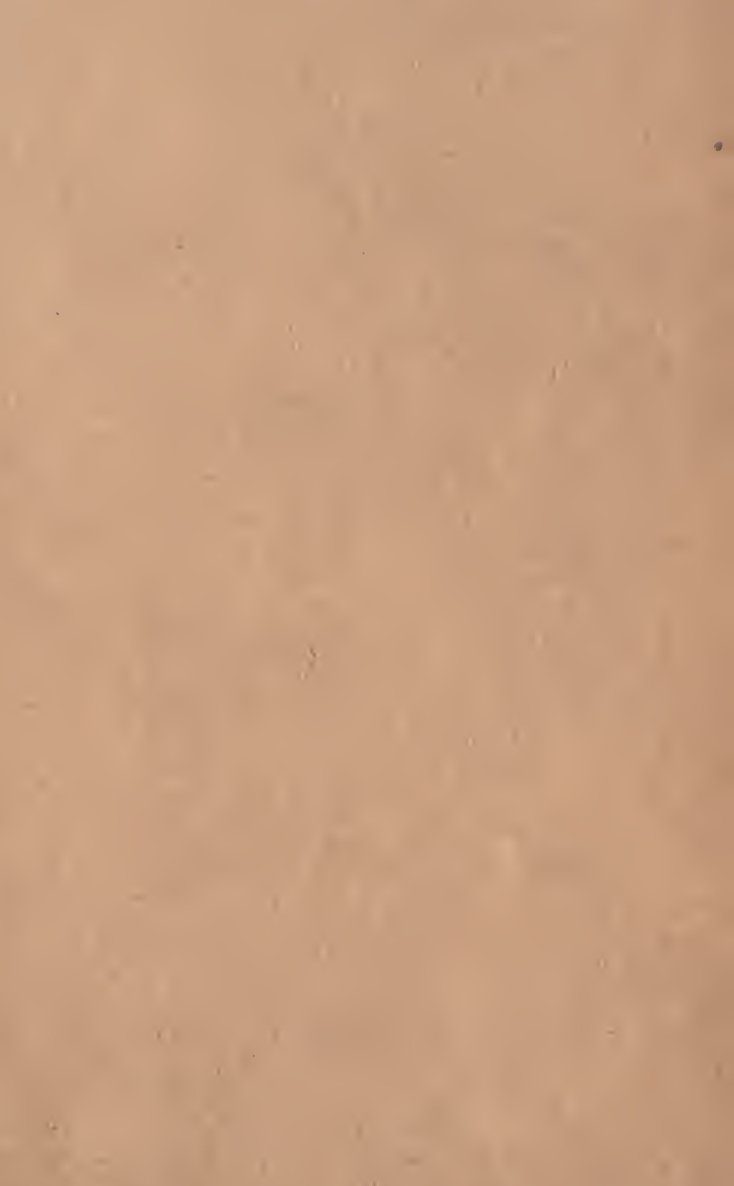

, 

THE WONDERFUL HOUSE THAT JACK HAS 


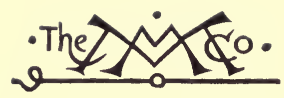

THE MACMILLAN COMPANY NEW YORK - BOSTON - CHICAGO ATLANTA - SAN FRANCISCO

MACMILLAN \& CO., Limited

LONDON - BOMBAY - CALCUTTA

MELBOURNE

THE MACMILLAN CO. OF CANADA, LTD. TORONTO 


\section{THE WONDERFUL HOUSE THAT JACK HAS}

A READER IN PRACTICAL PHYSIOLOGY AND HYGIENE

FOR USE IN SCHOOL AND HOME

BY

COLUMBUS N. MILLARD

SUPERVISOR OF GRAMMAR GRADES, BUFFALO

. PUBLIC SCHOOLS

X̛ero 19ork

THE MACMILLAN COMPANY

1908

All rights reserved 
Copyright, 1908,

BY THE MACMILLAN COMPANY.

Set up and electrotyped. Published June, 1908. Reprinted October, December, rgo8. 


\title{
Dedicated
}

\author{
To \\ MY WIFE \\ ALICE KELLOGG MILLARD \\ IN APPRECIATION OF SYMPATHY AND HELP \\ IN THE PREPARATION OF \\ THIS BOOK
}





\section{PREFACE}

The study of physiology in schools often counts very little toward building stronger and better bodies. Pupils memorize difficult technical terms, learn descriptions of processes, and study statements of hygienic facts, but passing examinations and completing the study are too often the chief results.

The following quotations were taken at random from one of the best physiology text-books in common use: "The amœba is a protozoan often found in slime at the bottom of stagnant water." "The twelve rib-supporting vertebræ are called the thoracic vertebræ." "Glycogen is found in the liver." "When - oxygen is united with hemoglobin, it forms oxyhemoglobin." "Vaso-constrictor nerves have their origin in the spinal bulb." "The opening of the left upper chamber of the heart is called the left auriculo-ventricular orifice." "The building up or constructive processes are included under anabolism, while katabolism designates the tearing down, or destructive processes."

It may be that the difficulty in learning these and numerous other technical terms prevents the excellent facts of hygiene, also included, from making the impression that they should. It is also quite possi- 
ble that at the age children usually undertake the intensive study of physiology, habits of eating, breathing, and care of the body are too firmly fixed to be changed without persistent effort, of which the great majority are incapable. Certain it is that many people who are familiar with the benefits of plain food and the bad effects of that which is indigestible do not allow this knowledge materially to affect their daily diet. Carelessness in regard to ventilation is perhaps still greater, even though the injurious effects of impure air are commonly known. In both cases the lack of care is probably a natural result of having gained knowledge of physiology and hygiene at a time or in a way that did not lead to practical application in daily habits.

The aim in the pages that follow is to present some generally recognized important facts about the care and building of the body in a way that will interest and impress children enough to help in forming daily habits most likely to insure future health and usefulness. The author believes that the reading and discussion of these facts in the fifth or sixth year of school, and again in perhaps the seventh or eighth, will greatly help in familiarizing children with the use of food, air, and water in body building. It should also impress the fact that health and strength are not due to luck, but to the wise use of these common things.

Throughout the book much is made of the fact 
that more fun, better looks, and increased power to do usually accompany improved health; for all three are powerful levers with children. That mental attainments gained at the expense of health are often of little practical use is also emphasized. Technical terms and physiological facts are not given, unless a knowledge of them will help better to impress the importance of establishing correct bodily habits. Questions that will induce intelligent word study and stimulate full topical recitations are arranged at the end of the book. A glossary giving possibly unfamiliar words is also included. Both of these features will be of practical use to teachers and parents.

Training pupils to gain power in correct oral expression is one of the most difficult problems of the school. Should this book prove an aid in this respect, it will afford the author much gratification. If the information it contains causes even one child, who might otherwise have been weak and sickly, to enjoy better health and greater usefulness, the writer will feel well rewarded.

Acknowledgments are hereby gratefully made to Dr. Charles G. Stockton, Professor of the Principles of Medicine and Clinical Medicine, University of Buffalo; Dr. John H. Pryor, formerly Superintendent, now Trustee, of the New York State Hospital for the Treatment of Incipient Tuberculosis; Dr. F. Park Lewis, President of the Board of Trustees of the State 
Asylum for the Blind at Batavia, New York; Almon H. Cooke, M.D.; Myrtle M. Massey, M.D., and Thomas C. Phillips, D.D.S., for helpful suggestions in regard to omissions and improvements. Acknowledgments are also due Francis J. Flagg, formerly Principal of School No. 25; Miss Margaret Brennan, Principal of School No. 13; Miss Ida Kempke, Method Teacher, Buffalo State Normal School; Charles P. Alvord, Principal of 'Teachers' Training School (all of Buffalo, New York); and Richard A. Searing, Superintendent of Education, North Tonawanda, New York, for careful reading and criticism of the manuscript. 


\section{CONTENTS}

CHAPTER

PAGE

I. The Greatest Treasure in the World • • 1

II. The Wonderful House that Jack Has . . 4

III. How Jack's Wonderful House builds Itself • 6

IV. Foods as Bullding Materials for Jack's House - The Proteids . . . . . . . . 8

V. Foods as Bullding Materials-Fats, Carbohydrates, Minerals . . . . . . 10

VI. How Jack's House extracts its Bullding MateRiAls-Digestion . . . . . . . . . 16

VII. How Jack's House extracts Bullding Materials From Food - Stomach and Intestinal Digestion

VIII. The Bullding Materials of Jack's HouseMilk and its Products . . . . . . 32

IX. Other Animal Foods . . . . . . 43

X. Vegetable Foods as Body-building Materials • 54

XI. Building Materials for Jack's House-Bever-

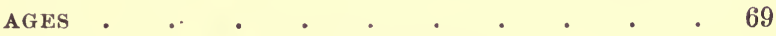

XII. Food Habits - Wise and Otherwise • • 86

XiII. The Most Necessary but Least Appreciated

Material used in Jack's House-Pure Air . 97

XIV. How to have the Best Possible Ventilation • 118

XV. Other Important Facts about Air • • • 135

XVI. Breathing Habits . . . . . . . 143

XVII. How Exercise may improve JaCk's House • • 158 
XIX. The Largest Component of Jack's HouseWATER . . . . . . . . 18:

XX. Our Wonderful River of Life and Marvelous Telegraph System - The Blood ani) the Nerves • . . . . . . . . 203

XXI. Clothing as a Protection to Jack's House . 209 XXII. How to protect our Edged Tools - The 'Teeth 221 XXIII. The Eyes and how to protect Them • . 233 XXIV. The Ears and how to protect Them . . 262 XXV. Rest and Sleep . . . . . . . . 276 XXVI. How to protect Jack's House - What to do in Emergencies . . . . . . . 283

XXVII. How to protect Jack's House from Contagious Diseases - Consumption • • • . . 295 XXVIII. The Sacredness of Jack's House • • . 311 Helps in Lesson Preparation . . • • • . . 315 GLOSSARY • • • • • • • • • • . 345

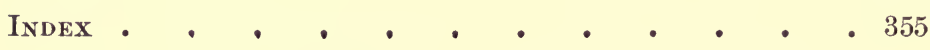


THE WONDERFUL HOUSE THAT JACK HAS 



\section{THE WONDERFUL HOUSE THAT JACK HAS}

\section{CHAPTER I}

THE GREATEST TREASURE IN THE WORLD

MaNy interesting stories have been told about gallant captains who sailed the seas, four hundred years ago, in search of treasure. Perhaps we have read of the daring adventures of men who in 1849 crossed the American prairies and mountains, in quest of the newly discovered gold in California. Some of us may know persons who are even now braving the perils of Alaska to secure this precious yellow metal; and all around us, in every city and village, we see people eagerly striving for wealth.

In fact, money seems to be the greatest treasure in the world, because it can furnish so many comforts and pleasures. Boys and girls think they want to learn to do that which will bring them great wealth. As they grow older, they dream and plan how to secure it, often neglecting a far greater treasure which most of them might obtain, but which many allow to slip away, a treasure so precious that no amount of money can buy it. 
What is this greatest treasure in the woi' $\mathrm{d}$ ? Is it something hidden away like a pirate's booty, or a miser's hoard? Must we search for it long years, and perhaps be rewarded only by accident? To secure it must we journey to distant countries, spend long, tedious years, and endure countless hardships? By no means! This wonderful treasure is simply a strong, healthy body. With it, either rich or poor may be comfortable and enjoy life. Without this best of all wealth, no one can be perfectly happy, even though he is rich, nor can he make the best use of knowledge gained in school.

In order to win this priceless possession, it is not necessary to slay mighty dragons, or to go on a perilous search for a golden fleece. Its ownership is not restricted to the highborn or the lucky. Only two things are necessary for most people to possess it. The first is to get well acquainted with our wonderful house, the body. The second, to give our bodies the same reasonable care we should give a dog or a pony, if we expected to keep him strong and serviceable.

What gives girls and boys more real pleasure than taking part in sports and games that require strength and agility? What better capital is there for men and women, just starting life's work, than to be able to labor steadily and well without the handicap of headaches or nervousness? What finer sight is there than an erect, gray-haired old man or woman, healthy in mind and body, and taking active interest 
in the affairs of life? If a good fairy were about to open a magical box of treasures, how eagerly all would crowd around to obtain some of its contents. The joys of health and strength are greater than any gift in any treasure box. We shall try to secure their precious secrets from the chapters that follow. 


\section{CHAPTER II}

THE WONDERFUL HOUSE THAT JACK HAS

Every one has read of the "Wonderful House that Jack Built," but very few know what they should about the Wonderful House that Jack Has. What makes it all the more interesting is that James, Howard, Mary, and Estelle, in fact, all of us, are house owners of the same kind. And such a wonderful house it is! Vastly more interesting than Spain's splendid palace, the Alhambra, and certainly more curious than Italy's far-famed Leaning Tower of Pisa! In fact, you might carefully study all the architecture of the world without finding anything half so wonderful.

How does it happen that many know so little about their bodies? Largely because the knowledge is so easily obtained and its importance has not been fully realized. It is said that many people living in Philadelphia have not visited Independence Hall, and residents of Buffalo who have not seen Niagara Falls are by no means few. Thousands travel miles to visit those celebrated places; and yet many living near have not had their interest aroused. We should not show such lack of enterprise in regard to our bodies, but should let the fact that they are not distant make their wonders of even greater interest. 
Of course all know this Wonderful House that Jack Has is made up of the head, trunk, and limbs. The head contains the brain, which controls and directs the rest of the body, and is most strongly fortified by the skull. The trunk has two compartments. In the upper, the chest, are the lungs and heart, well protected by the strong ribs. In the lower, the abdomen, are the stomach, intestines, liver, kidneys, and other important organs.

We sometimes wonder at the easy way the ballbearing wheels of modern machines move, but we shall see that bicycles and automobiles do not begin to be put together with such skill as are our bodies. It is not very important to know that these houses of ours contain about two hundred bones, or that our bones are covered with six hundred or more muscles. But it is very important to understand that our habits of standing and sitting, what we eat, drink, wear, and do, all affect the health and development of these bones and muscles. 


\section{CHAPTER III}

\section{HOW JACK'S WONDERFUL HOUSE BUILDS ITSELF}

A Most curious thing about Jack's Wonderful House is that it builds itself. True, it must have certain materials in the right proportion and at the proper time. When furnished with these, however, the structure it produces is stronger and more beautiful than the best architect can plan, or the most skilful carpenter construct. What are these materials? They are nourishing food, pure air, and fresh, pure water. An introduction to any of the three will not, of course, be necessary; but many of us need to get very much better acquainted with all of them. Too many people know food as something eaten at meals or at other times chiefly because of hunger. The amount taken at a particular meal often depends upon its taste. Many do not know or stop to think whether what is eaten will help or hinder the growth of their bodies.

How incompetent we should think a carpenter who used his building materials so unwisely! If he used pine where a great deal of oak was necessary, to give the building strength and durability, what poor houses he would construct! If he should make 
use of hickory and mahogany where softer timber would answer the purpose better, how much of his time and money would be wasted! Like oak, some foods give a great deal of strength and endurance, and so are much needed in the House that Jack Has. Of other foods, our bodies require only a little to assist in their growth. Still others are of very little value in large quantities, because so much labor is required in making use of them.

We know that water is needed in preparing the plaster and cement in an ordinary house. This fluid is far more important in the House that Jack Has. Indeed, this wonderful house could not get on comfortably a single day without water. Later we shall see how very useful this sparkling liquid can be made in keeping both the outside and the inside of our bodies clean and wholesome.

A carpenter could hardly tell the material most necessary for him to have always at hand. He would say that it would depend on the kind of house he was building. But in these houses of ours that build themselves, the one thing that should always be ready for use, if the best building is to be done, is pure air. We cannot have too much of it, nor is there a moment during the day that we do not need this precious material. 


\section{CHAPTER IV}

FOODS AS BUILDING MATERIALS FOR JACK'S HOUSETHE PROTEIDS

Our bodies are made up chiefly of bone, muscle, fat, blood, and nerves, with an outside covering of skin. These are constantly wearing away, and must be daily supplied by the food we eat. Besides, during the first twenty or more years of our lives, enough more good building material must be furnished to produce healthful development and growth of the various tissues and organs of the body.

If we could use food to make up bodily waste and supply necessary additions in the same way that a builder uses lumber to repair the wall of a house or stone to strengthen a cellar wall, but a little knowledge of foods would be necessary. The conditions are very different, however. Only certain components of foods are helpful building materials. These must be extracted and carried to the parts where each is needed. The rest is waste which must be cast out, as the carpenter throws aside the shavings and ends that are cut off to make the parts fit properly together.

The components of foods that are useful to the 
body are proteids, fat, starch, sugar, and mineral matter such as salt, lime, iron, and phosphorus. Proteid is derived from a Greek word which means first. It is justly entitled to this name, for it is the most important of the body's building materials. Since blood, muscle, and all the vital organs contain proteids as their chief component, we can readily understand why much of our food should be rich in this material.

What is proteid like? Is it something that only college professors and students with costly microscopes can find and understand, or is it possible for school children to get acquainted with this important substance? Strangely enough many of our old friends in the food family contain much of this useful material. For instance, the white of egg, often called albumen, is largely composed of it. Lean meat, the curd of milk (the part from which cheese is made), the gluten of flour, the legumen of peas and beans, are all good examples.

Proteids contain a great deal of an important element called nitrogen, and for this reason are often spoken of as nitrogenous foods. While proteids can take the place of fats, starch, and sugar in supplying fuel and energy to the body, these foods cannot take its place in forming new tissues. On this account we should plan always to have plenty of proteids in our food. 


\section{CHAPTER V}

FOODS AS BUILDING MATERIALS - FATS, CARBOHYDRATES, MINERALS

WHo would ever suppose that fat could be of any particular use to our bodies? It surely is not interesting to look at, and is so distasteful to some, in certain forms, that they do not eat the fat they see in meat served to them at meals. They even say, perhaps with more or less pride, that they never eat fat. Nevertheless, if they use meat as food at all, they must eat some fat, for between the fibers of lean meat there is much of this substance that is not usually seen.

It is also present in many other foods. There is much fat in the cream of milk. Fish are liberally supplied with it, and so are the yolks of eggs. Butter is largely fat and olive oil has a great deal. The various grains have some, and even nuts are rich in this element. It certainly seems odd that anything so hard and dry as grains and nuts should contain fat. Yet chemists, by careful analyses, have discovered these facts.

How fortunate it is that so many different foods, some of which almost every one can relish, are well 
supplied with this valuable food substance! In what way is it useful to our bodies? In the same manner that coal is to an engine. It furnishes energy for motion and also supplies fuel for keeping the body warm. The body could get along without fat, because proteids can supply both tissue building material and fuel. However, as one ounce of fat will supply about two and one-half times as much heat and energy as the same amount of proteid, it is usually far better to have fatty foods in our diet.

When we eat sufficient fat to furnish much of the heat and energy our bodies need, it is possible for the proteids eaten to Olive Branch and Fruit. perform their most useful work; namely, building up the tissues of the body. For this reason, fats are of great use to growing children,

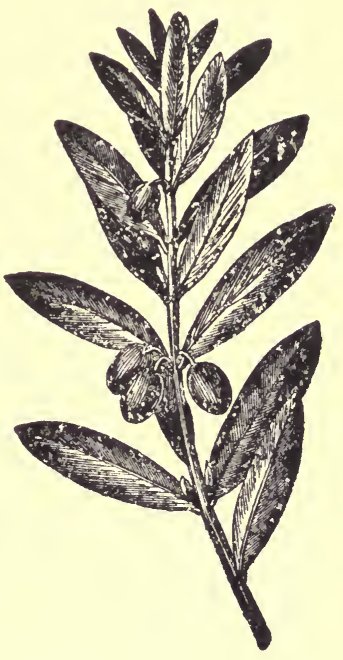
Olives and nuts supply nutritious oils. The olive is nearly black when ripe. Green olives are of no value as food. especially those that are not naturally robust and strong. Butter and cream are both very good fatty foods, and olive oil is excellent. A spoonful or more of the latter at each meal furnishes an excellent lubricant for the digestive organs, as well as a very good food. Many people have found this slight addition to their daily diet a most effective aid to health. 
Pork, lard, and other comparatively inexpensive foods all contain much fat. They are not easily digested by some, however, and it is often a mistake for such people to use them as foods to any large extent.

More fat should be eaten in cold weather than in the warm months, because our bodies need more heat. For this reason, inhabitants of the frigid zones eat what seems to us a prodigious amount of fatty foods, often several pounds of fat meat, tallow, or whale blubber in a day. For the opposite reason, people living in tropical regions eat very little fat, but much fruit, because the latter is cooling. Strange as it may seem, the Eskimo enjoys his whale blubber or pure tallow as we should broiled steak or roast turkey, and even visitors to the Arctic regions soon relish such fatty foods.

Dr. Kane, the famous Arctic explorer, says: "Our journeys have taught us the wisdom of the Eskimo's appetite, and there are few among us who do not relish a slice of raw blubber or a chunk of frozen walrus meat." A native of the frozen north would no doubt regard a breakfast of oranges and bananas with the same disgust that a dweller in the tropics would sit down to a lunch of tallow candles. The appetite of both is regulated by the need of the body for heat. Try to think of a good reason why men working at hard physical labor need more fat at all times of the year than those whose occupation requires but little exertion of the muscles. 
Two other necessary food components that furnish heat and energy are starch and sugar. They are called carbohydrates. Starch is abundant in flour, corn meal, oatmeal, and other cereals. Our familiar food friend, the potato, has a great deal of starch, and so have rice, tapioca, and other similar foods. Like fat, starch furnishes fuel for the body. We know that wood does not furnish as much heat as coal. The same is true of starch and fat. The latter furnishes about two and one-half times as much heat and energy as the former. Nevertheless, in a temperate climate from six to eight times as much starch should be eaten as fat.

Sugar is another fuel and energy furnishing food. What visions of caramels, taffy, and other candy favorites it brings to mind! Although sugar is the food children often like best, many are harmed by eating too much. It produces about the same amount of heat and energy that starch does, and, in small quantities, is an excellent food. But when much sugar is eaten, it is likely to get the digestive organs out of order and cause poor health.

Is it found in any foods except the sugar, candy, honey, sirup, and molasses with which all are so familiar? Remarkable as it may seem, milk contains a small amount, fruit has some, and beets, corn, and other vegetables are well stocked with it. Few children associate the cooked beets served at dinner with the candies and other sweets that come with dessert. Never- 
theless, even in our own country, many factories are making hundreds of pounds of sugar daily from beets.

Common salt is one of the most important minerals necessary to the body. It is contained in many animal foods, and, as we know, some is used for seasoning. It is better to put in salt during the process of cooking, as less is required to give a thorough seasoning. A small quantity is necessary to the body, but care should be taken not to form the habit of eating too much. Lime is another mineral substance which must be supplied in our food, if the bones and other hard parts are to continue healthy and strong. Small quantities of magnesia, soda, phosphorus, iron, and other mineral matter are also found in the blood and various tissues of the body. Magnesia and soda are present in most vegetables that grow underground. Phosphorus is contained in the yolk of eggs, and iron is found in all green vegetables.

We have now read about the different components of food, and their use to our bodies as building material. Shall we give these facts little or no thought, and continue to eat what happens to please our taste without regard to its benefit or injury? Certainly none of us should be such foolish builders! On the contrary, should we not make our food serve the purpose of building strong, vigorous bodies, bodies in which the active muscles, the white teeth, the ruddy complexion, the sparkling eye, - all shall tell of wisely chosen building materials and perfect health? 
The following facts about foods are especially important for us to remember. Proteids, fats, and carbohydrates should all be included in our diet, the amount being varied according to what we seem to need. More heat producing food is required in cold than in warm weather, and we can add to our comfort at any season of the year by using judgment in our choice of food. If we happen to have a dislike for one of the important food components, we should keep trying until we find some food containing it that can be both relished and comfortably digested. It is wise to eat temperately of sugars and other sweet foods that please the taste for a moment but in large quantities may do much injury.

What a great mistake it is for children to be allowed to develop and persist in a dislike of necessary foods! In the first place, they do not receive the daily body-building aid which these foods might supply. Then there are dangerous diseases in which such foods as milk and eggs, for instance, are about the only diet that can be safely used. Naturally persons having a preëstablished dislike for these cannot relish them at such a time, and so their chances for recovery are greatly lessened. Indeed, children should be made to eat staple foods, nor should they be allowed to form detrimental habits in choosing improper diet. How many cases of nervous troubles, poor digestion, and weak bodies are due to lack of proper training in these respects, experienced physicians can testify. 


\section{CHAPTER VI}

HOW JACK'S HOUSE EXTRACTS ITS BUILDING MATERIALS - DIGESTION

WE want to learn a great deal about the foods used in building Jack's house. First, however, as a help in forming correct ideas, let us see how foods are changed in our bodies to a form that can be carried to every part, and made use of where needed for repairs and additions. Compare a piece of bread with a few drops of blood, and notice how different they are in appearance. How strange it is that bread and other solid foods we eat are changed to a form in which they may be taken into the blood! To understand this marvellous process, we must know something about chemistry. "Chemistry!" grammar school girls and boys may exclaim: "Why that is one of the difficult subjects in the high school! How can you expect us to know anything about Chemistry?"

Although Chemistry is a high school subject, it has to do with many common things with which all are familiar. The dictionary tells us that Chemistry is the science which treats of the composition of substances and the changes in the composition and 
constitution of their molecules. That sounds difficult. But when we know that composition and constitution mean simply how a substance is made up or of what it is composed, and that molecules are the smallest parts of a substance, it does not seem so hard to understand.

Without consulting a dictionary, we can tell the three different forms of matter, solids, liquids, and gases. We know how sugar when heated turns to sirup, how ice and snow change to water, how heat turns water to steam, and how cold causes steam to change back to water. We have seen yeast cause the bread dough to rise, and heat make oatmeal expand. In fact, hundreds of simple experiments will show that material things are made up of different parts; and that these parts can easily be made to separate from one another and rearrange themselves in some other form, if just the right process is used.

The passage in the body through which food travels while it is being changed into body building material is called the alimentary canal. This wonderful passage is about thirty feet long. Its parts in order from the mouth are the pharynx, esophagus, stomach, small intestine, and large intestine. At various stations along this remarkable canal are situated small chemical shops called glands. In these are secreted fluids that help dissolve food, and change it into such form that it may be absorbed into the blood and become useful building material. 
The first one of these dissolving stations is in the mouth, and the fluid secreted there is known as saliva. The glands that secrete it open into various parts of the mouth and are called salivary glands. Saliva changes some of the starchy food we eat to sugar. It does not digest proteids or fats, or completely digest starch. It does, however, change starch to a form in which it is much more easily digested by the fluids in the intestines. On this account, it is especially necessary that bread, potatoes, cake, and all starchy foods should be well masticated. Proteids and fats, too, when thoroughly chewed before being swallowed, are much more readily acted upon by the digestive juices with which they come in contact later. Saliva is also said to stimulate the glands in the stomach to greater action.

When we place bread and similar solid foods in water, they soften and separate into small pieces. Warm water causes such separation more rapidly than cold. If certain acids or alkalies are added, the change in form takes place more speedily and completely. The finer the food is cut before being placed in the water, and the more the solution is mixed, the more quickly it is dissolved.

What can be learned from this simple experiment? Two most important things, if we are to build strong bodies. The first is to keep the inside of the mouth at its normal temperature while eating; the second, to chew our food so thoroughly that it will 
become separated into very small parts, and be well mixed with saliva before it is swallowed. If the temperature of the mouth is frequently lowered by cold drinks or food during mastication, or if food is swallowed before it has been well chewed and mixed with saliva, the fluids farther on in the digestive canal cannot properly penetrate it and incomplete digestion results. Consequently the blood does not receive its due supply of new material in proper form, and weakened health sooner or later follows.

Children sometimes swallow their food before it is half chewed, or wash it down with water, or perhaps soak pieces in coffee or some other liquid. Often this is done because they are in a hurry to get out to play. But what unwise builders and chemists such children are! Girls and boys who wish always to be in condition for play, no matter how old they may become; those who would build bodies that will enable them to take part actively and well in any game requiring strength and agility, should form the habit of thoroughly chewing their food.

Another great benefit that comes from properly masticating the food is that it helps to keep us from eating more than is needed. If time is taken for thorough chewing, the sense of taste is fully satisfied when enough has been eaten to supply the body's needs. When the food is hurried down, this sense is naturally unsatisfied, and more food than is required is much more likely to be eaten. As a natural result, 
discomfort and disorder are caused by the unnecessary and badly prepared building material.

Some good authorities even assert that food should not be swallowed until masticated into a liquid state. They say that in a liquid state it is best prepared for the juices of the stomach. They also claim that with such mastication too much food is not so likely to be eaten, because much more time is occupied in chewing. Persons who have persevered in this habit are most enthusiastic over the results, because of recovered health and increased ability to endure physical and mental exertion.

Boys will be interested in an experiment tried at Yale University by some young men who were active in athletics and had the habit of eating heartily, with no especial care about chewing their food. They were induced to make a special point of thorough mastication for a certain period. As a natural result of the increased length of time occupied in chewing, the quantity of food they ate was largely decreased. For this reason you might expect their activity and endurance in games would have correspondingly lessened. On the contrary, they were able to play faster, longer, and more accurately. This is certainly an excellent object lesson for all who want to do their best at games and sports requiring strength and skill.

We learn early in life to use with care any article or instrument that by cutting or burning may hurt or mar our bodies. How important it is also to 
form the habit of thoroughly chewing our food; for careless habits of eating, by overworking and clogging the digestive organs, may not only lessen our good looks, but, what is far worse, weaken our power of action.

One thing we have full power to control in the process of preparing building material for our bodies, is proper mastication. If we have not already formed this good habit, we should certainly start, at the very next meal, to make our teeth and tongue do the work of thoroughly dividing and mixing the food with saliva. From this very day, we should not allow any improperly masticated food to pass into our stomachs.

The Hon. William E. Gladstone of England was one of the most distinguished and successful men of the past century. He lived to the ripe old age of eighty-nine, and during his entire life worked untiringly as business man, statesman, orator, and author. So remarkable was the work he accomplished in the latter part of his life that he was often admiringly spoken of as the "Grand Old Man." Mr. Gladstone believed the habit of thoroughly chewing his food to be one of the principal causes of his long-continued health and strength. Many less celebrated people could give similar testimony. Thorough mastication is only a matter of habit. By taking great pains to form this habit now, our strength and usefulness in the future may be largely increased. 


\section{CHAPTER VII}

HOW JACK'S HOUSE EXTRACTS BUILDING MATERIALS FROM FOOD - STOMACH AND INTESTINAL DIGESTION

When food is swallowed, it passes quickly down through a tube called the esophagus into the stomach.

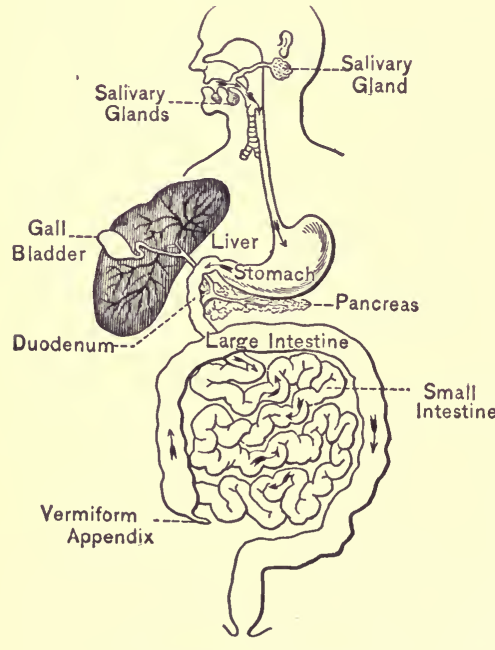

Alimentary Canal. The esophagus is directly behind another tube, the trachea, commonly called the windpipe, through which air passes to our lungs. (See cut.) An introduction to the stomach is hardly necessary. From babyhood we have heard it spoken of as full or empty, and have known that it has to do with the food we eat. Perhaps some may have even learned that when unwholesome foods get into the stomach, pain results. The cut gives a good idea of the stomach's shape, size, and position in the abdomen. 
It is a wonderfully elastic, muscular bag, having an inside lining that arlmits of great expansion. In various parts of this lining is situated the second set of chemical workshops that help to accomplish digestion. These tubes or glands secrete a fluid called gastric juice, the three most important ingredients of which are pepsin, hydrochloric acid, and rennin.

What part has the gastric juice in the wonderful process of making body building material from food? It digests the proteid parts. While starch and fat become more liquefied, passing from the stomach with other substances in the form of a grayish white substance called chyme, they are not digested, excepting the action of saliva on starch, until acted upon by the secretions of the intestines.

Must we depend upon doctors and books for the information that gastric juice digests proteids, or can we prove the fact ourselves? An ounce of water mixed with twelve drops of hydrochloric acid and one grain of pepsin will completely dissolve the cooked white of an egg in two hours, at the ordinary temperature of the stomach, which is about ninety-nine and one-half to one hundred degrees. A mixture of five grains of pepsin, eighteen drops of strong hydrochloric acid, and six ounces of water is very like a similar quantity of gastric juice. If a piece of meat is placed in this mixture and left for two hours or more, at a temperature of ninety-nine and one-half degrees, it will be changed to liquid form. 
The finer the meat is divided before being placed in the fluid, the more quickly it will be changed. If the mixture is diluted by pouring in more water, its work is less effective. As the temperature falls below the normal temperature of the stomach, dissolving proceeds more slowly and finally ceases. We can also observe that such a mixture does not affect the fat of meat or starches in the same way that it does proteids.

What should we learn from this experiment? First, to help the stomach by thoroughly chewing all food before swallowing it. Second, not to dilute the gastric juice by drinking too much water or other liquid not a food, during meals, or for some time afterward. Lastly, not to lower the stomach's temperature by swallowing large quantities of cold drinks during the hours food is therein.

For a similar reason, hard work or exercise, just before or soon after meals, should be avoided, because much exertion naturally draws an extra supply of blood to the parts of the body that are being used, thus making it more difficult for the stomach to get its due share.

If, in an experiment like the one just described, the meat is churned around rapidly in the fluid, the dissolving takes place more quickly. In the mouth, a similar mixing is done by the tongue, teeth, and jaws. In the stomach, it is accomplished by three layers of muscles, which operate in such a way that when food enters, a churn-like motion is started. 
This moves the food around and around from one end to the other, thus causing it to becorne thoroughly mixed with gastric juices. As the glands in our stomach need to secrete from one-eighth to one-tenth of our weight in gastric juice daily to carry on the work of digestion properly, we can understand why much blood is needed by the stomach during the digestion of a hearty meal.

It is not a hard problem in arithmetic to calculate how much gastric juice our own stomachs must secrete from the blood each day. If the weight is one hundred pounds, ten pounds, or about five quarts, must be secreted. Just think of it! A gallon or more of this useful fluid to be daily supplied by these busy glands! Surely even very young boys and girls can see why it is unwise to handicap the stomach by lessening its supply of blood, diluting the gastric juice, or compelling it to do more than its normal share of work.

Salt, pepper, and other seasonings are called condiments. A small amount of these, - better added during the cooking, improves the taste, and so is a healthful stimulant to the gastric glands. However, we should not get into the habit of seasoning too much. Too much seasoning over-stimulates the glands, causing more food to be eaten than the body needs. Food that is pleasing in appearance is said to cause the gastric glands to pour forth their secretion more freely than that which is not tempting. On this account, it is important to have our meals 
skilfully cooked and daintily served, and of course this is especially necessary for invalids.

It is also interesting to know that our state of mind at meal time has great influence on the appetite as well as on the nerves controlling digestion. The old saying, "Laugh and grow fat," is thought to have considerable foundation of truth. As a rule, people who go to meals having their minds occupied with work or worry, are more likely to have insufficient appetite and poor digestion than those who put such things aside for the time, and pass the meal hour in pleasant conversation. The explanation is simple. Mental exercise as well as physical requires blood. Consequently, if we are absorbed in thought while eating, an extra supply of blood is required by the brain. On the other hand, in pleasant conversation there is no special demand for blood from any other organ, so the stomach may obtain a larger share.

Besides, a happy state of mind no doubt gives a healthful impetus to the glands, just as a pleasant day is naturally stimulating to the mind and body. Being wise body builders then, it is for us to be careful in regard to all of these points. We will not swallow our food in a great rush to get out to play, because chewing it thoroughly will help us to play with greater skill and relish when the proper time comes. We will use but little seasoning, knowing that too much is hurtful. We will go to our meals with minds 
free from work and care. We will also have a joyous table atmosphere, both for the pleasure it affords and the help it gives in accomplishing the purpose of eating, which is to furnish our bodies building material in the best form for their use.

Three other fluids aid in changing food to such form that it may be taken into the blood. The first, called bile, is secreted by the liver, which is the largest gland in the body. As can be seen in the illustration on page 22 , the liver is situated in the right side of the abdomen. Under normal conditions it is said to secrete about one twenty-eighth of the body's weight in bile daily. This, in a person weighing one hundred forty pounds, would amount to about two and onehalf quarts, or five pounds.

In the same illustration we can see a curious little sac shaped like a radish. This is called the bile or gall bladder. It opens into the small intestine about five inches beyond the point where the latter joins the stomach. As chyme passes through the small intestine, the bile pours out and quickly mixes with it. Bile stimulates the flow of the two remaining digestive juices, the pancreatic juice and the intestinal fluid, and better prepares chyme to be acted on by them.

Pancreatic juice enters the small intestine at the same place as the bile. The pancreas, the gland which secretes it, can be seen in the illustration. In a person weighing one hundred forty pounds, 
it secretes about ten ounces, or a little more than a half pint daily. Pancreatic juice digests starch, fat, and proteid. We found that the lining of the stomach contained many small tubes which secreted gastric juice. In the lining of the small intestine are also small tubes that secrete the last of the digestive fluids, the intestinal juice. The fluid that pours from these tubes is supposed to aid in the digestion of proteids, fats, starches, and sugar. These intestinal glands form, as it were, clearing up workshops that help digest any food material which arrives in an unprepared state. The intestinal tubes are thought to secrete about one-half pint daily.

The quantity of the digestive fluids and the special work of each have been discovered by experiments. Many of these have been tried on dogs and other animals. Much valuable information has also been gained by doctors from patients with wounds in some part of the stomach or intestines, through which the digestive processes were watched.

After chyme has been acted upon by the digestive juices of the intestines, it becomes changed to a milky white fluid called chyle. How does chyle get into the blood? All along the inner lining of the small intestine, for a distance of about twenty feet, there are small, hair-like projections called villi. These are few in number near the stomach, but gradually become so numerous that they give the inside of the intestine a velvety appearance. These little villi 
contain blood vessels which take up or absorb the digested part of the food. As the blood circulates through the body, the building and fuel materials it carries along are made use of where they are needed.

The waste and undigested parts of the food, however, are forced out by the muscles of the abdomen and intestines. We know how necessary it is for ashes and clinkers to be removed from the lower part of a furnace fire daily. If they are allowed to remain, the fire will burn poorly and in time go out. In like manner the functions of the body become disordered if the waste and undigested materials do not pass regularly from the intestines. Often these are highly poisonous. When they remain an unduly long time in the intestines, much of the poison may be absorbed into the blood, and so-called bilious attacks, high fever, vomiting, and other troubles frequently result. These digestive disturbances are common in children, and a daily thorough movement of the bowels is the essential preventive. For several good reasons, soon after breakfast each day is the best time to attend to this important function.

The digestive glands have much to do, and we can aid them in their work by eating temperately. Enough has been learned to make us realize the foolishness of taking large quantities of unnecessary food into our stomachs. Nature has provided that these five digestive fluids will usually prepare all the food the body needs, and often even more. When they are 
continually overworked, however, they become tired, like other parts of the body, and cease to do their labor properly, unless allowed to rest. People sometimes eat unduly large meals, and afterward take medicine to help digest them. This is a very unwise habit. While the medicines may quicken digestion, and hasten the expulsion of waste material from the body, they accomplish this by stimulating the digestive glands to do an extra amount of work. Like other organs and muscles of the body, these glands have to rest longer after an extra effort, and, on this account, may not be in good condition to digest the next meal. Instead of taking medicine to whip them to overwork, a far better way is to eat very little for a few meals, thus giving the glands time to rest and get into good condition again.

While there is little we can do to help the digestion of food after it gets into the stomach, there are four things within our control which all should form the habit of attending to most carefully. The first is to select food that has the building and fuel materials we require, without being unnecessarily difficult to digest. Because a food is difficult for one person to digest, it does not follow that it will be so for others. After a food has disagreed with any one several times, it is wise to avoid it. The second is to partake of food in reasonable quantities, no matter how good it may taste. Our knowledge of body building certainly makes plain the foolishness of eating all the 
eggs one can at an Easter breakfast, or of seeing who can dispose of the largest number of pancakes at a meal. The complete mastication of food is the third thing we should make our regular habit. The fourth is giving a regular time daily for the intestines to discharge the waste products of digestion.

Little but discomfort and unhappiness can come from neglecting to form these habits. A strong, active body, ability to enjoy, power to be and to do our best, may result from forming them. What precious treasures these are to be gained so easily! Careful watchfulness for a few weeks will readily get us into the last three habits. The facts given in the following chapters will help us in selecting food that is useful building and fuel material. 


\section{CHAPTER VIII}

THE BUILDING MATERIALS OF JACK'S HOUSE - MILK AND ITS PRODUCTS

IF a carpenter were not familiar with the pine, hemlock, and other woods used in his work, what a poor builder we should think him! How much more necessary it is for us to know all that is possible about the foods we supply our bodies. Perhaps our oldest and best food friend is milk. What building materials does this useful white fluid furnish us?

While the proportion of the different materials varies according to the breed of cow and the time of year, it is usually about as follows: nearly seveneighths water, about one twenty-fifth fat, a little less proteid than fat, about one-twentieth sugar, and the remainder various mineral salts. The fat of milk forms from one-fifth to two-fifths of the cream, and the casein, of which cheese is made, is the proteid.

In spite of its large amount of water, milk is the most perfect food, because it has all the necessary elements in such form that they can be readily digested and taken into the blood. Some people have trouble in digesting milk, but if lime-water is added the difficulty is often removed. Many young babies live 
on milk alone, and when adults are sick with fever or certain digestive troubles, it is often the main food taken for a long time. This is because milk furnishes the necessary building and fuel materials with little tax on the digestive organs.

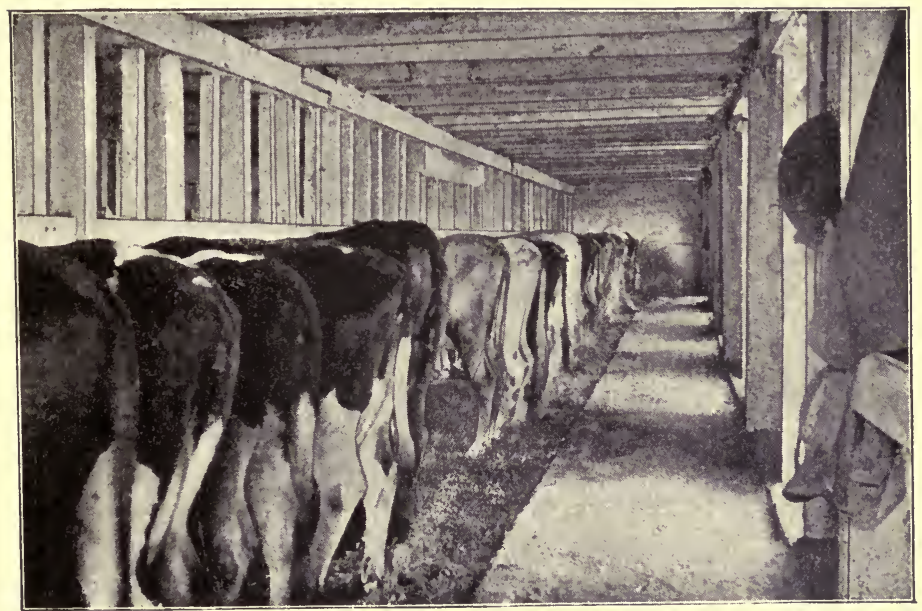

Courtesy of Revieu of Reviews

A Hygienic, but Inexpensive Dairy Stable.

Skimmed milk has lost nearly all of its fat, and should be much less expensive than pure milk. Nevertheless, it still has the proteid, sugar, and salts, and is such a useful food that two quarts, which cost about six cents, have a greater building value than a quart of oysters costing from twenty-five to forty cents. A pint of milk and a few slices of bread will furnish as much building material as a lunch of beef, vegetables, bread, butter, and coffee, and at a much smaller cost. 
As milk is so large a part of the food of invalids and children, how important it is to know that we are buying that which is pure. We should also understand how to keep it in good condition for a reasonable time after delivery. The most common ways of lessening the food value of milk are by removing a part of the cream, or by adding water or skimmed milk. The cream is removed because it brings a higher price than milk, and water or skimmed milk is added to increase the quantity. Of course, in all three cases the value of the milk is decreased.

Borax, formaldehyde, salicylic acid, and other substances are sometimes put into milk by dealers to keep it from souring. Their use is forbidden by law in many cities, because the very quality in them that keeps the milk from souring retards its digestion in the stomach. Skimmed or watered milk is thinner than pure milk, and has a bluish white color not noticeable in the former. When pure milk is poured from a glass, some of it will cling to the sides, and not run off as will water or tea.

When pure milk is allowed to stand quietly in a cool place for several hours, cream rises to the top. If the cream is not from one-tenth to one-fifth of the milk, then we may be sure its quality is inferior. There should be no deposit in the bottom of a dish from which milk has been poured. Its presence is a sign of untidiness, lack of care in handling, or the use of preservatives. 
We have heard of the countless bacteria in the air that are too small to be seen, but are always ready to enter vegetables and animal substances, if an opportunity is afforded. When food spoils, it is because millions of these tiny organisms have attacked it. If the housekeeper had been careful enough to prevent them from doing injury, the food would still be fit for use.

But how can such invisible foes be kept from doing harm? In spite of their small size, many facts in regard to these minute destroyers have been discovered. For instance, most of them can do little harm in a temperature of from thirty-two to fifty degrees, while a temperature from one hundred fiftyfive to two hundred two degrees, if maintained from fifteen to twenty minutes, readily destroys them. They require a certain amount of moisture, and on this account dried foods are not disturbed by them. They do not thrive in anything that is highly spiced, sugared, or mixed with salt, and this is the reason that materials are canned, preserved, or salted.

Few foods are so easily destroyed by bacteria as milk. What care should be taken to keep this useful food at its best? Both stable and cows should be kept as clean as possible, and the milker should wash his hands and the cow's udder before commencing to milk. As soon as the pail is filled, the milk should be strained, not in the stable, but in a cool room adjoining, after which it should be poured over a cooling 
aërator. It should then be placed in bottles or cans, and kept on ice or in cool water until shipped.

Every dairy should also have an abundance of hot water for cleaning all utensils used in handling the milk, as it removes any bacteria that may have collected on them. There should also be good food, a

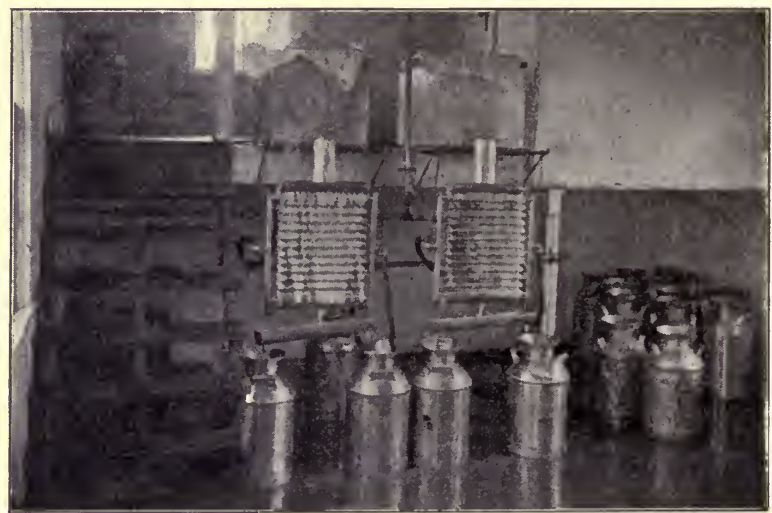

Cooling and aërating Milk - Sinton Rustic Home Dairy, Colorado Springs.

large supply of pure drinking water, and plenty of clean bedding for the cows. Light, well ventilated stables and kindly disposed attendants are also good evidence of the fact that the source of the milk supply is what it should be.

Milk that has been placed in bottles after being aërated and cooled, keeps better than that which has been placed in cans, as the bottles are more easily, 
and hence, as a rule, better cleaned. On this account, the best milk to buy is usually that which has been transported from the dairy in bottles. The next best is that which has been put into bottles after the large

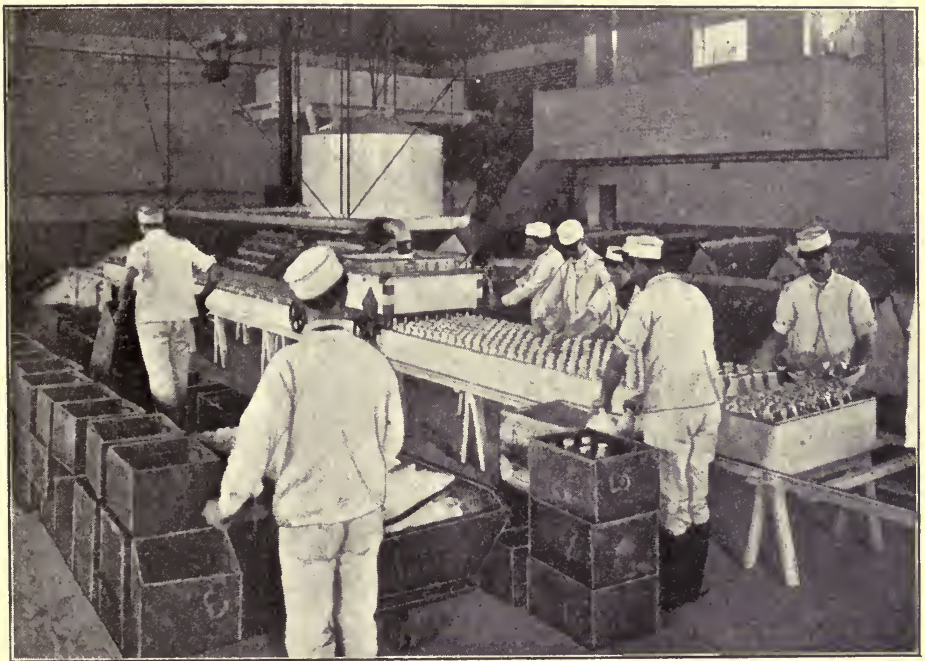

Courtesy of Reviero of Reviews.

Bottling Milk in a Hygienic Dairy.

cans of milk have been brought from the railroad station to the milkman's city dairy.

Some dealers carry their milk around in cans, dipping out the quantity which each customer wishes. What an opportunity this furnishes the ever present bacteria! A can of milk frequently opened in the warm or dusty air! Another bad feature of this custom is that the buyers first served are likely to get the greater part 
of the cream. Having a faucet in the lower part of the can is another method; but milk from such a source cannot be expected to keep as well as that which is sold in bottles. Perhaps the most dangerous

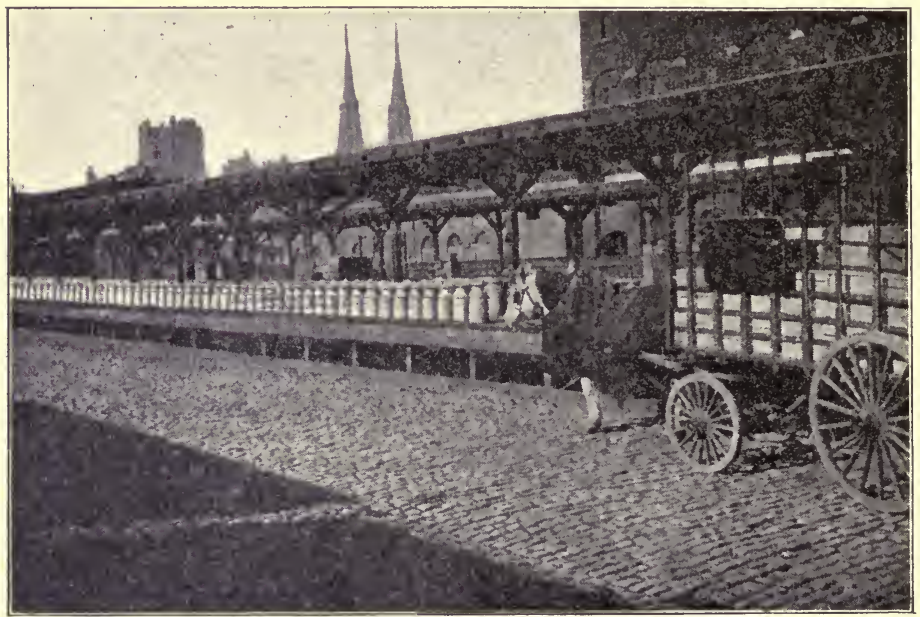

Courtesy of Health Department

Milk Station in New York City.

way to buy milk is from a grocery or other store where it is kept in a tin can under the counter, or in some place where bacteria are likely to be present in large numbers.

As soon as possible after milk has been delivered to our homes, it should be covered and kept in the coolest place in the house, when not in actual use. If the milkman comes early in the morning, before any of the family are up, there should be a covered 
box in which the bottles can be placed. A small lock-box fastened to the house near the back door answers this purpose very well.

If the milk is delivered from a can, the dish into which it is received should at once be covered and put in a cool place. As milk takes up odors more readily than do most foods, it should always be covered when placed in the ice box. If we know milk has stood for a time where it is warm, or if there is reason to fear it contains bacteria, it should be heated at once to a temperature of from one hundred fifty-five to two hundred ten degrees and kept at that point for several minutes. It can then be used without fear, and will keep for some time, if reasonable care is taken. Milk that has been kept for several minutes at a temperature of one hundred fifty-five degrees is called pasteurized. Milk that has been boiled for fifteen minutes or more is called sterilized. In the process of sterilizing, some of the good qualities of milk are lost, and for this reason the pasteurized is often better. A floating dairy thermometer is a useful article in every kitchen to aid in taking care of the milk supply.

How foolish we should think a builder who was not careful to buy lumber of first-class quality, or who did not properly protect and preserve what he had purchased. As milk is such important building material for our bodies, we should insist that it be brought to us in good condition, and then take all possible care to keep it wholesome. If in doubt as to the 
quality of milk we are receiving, it would certainly be wise to visit the dairy where it is produced. Then, if the conditions seen are not satisfactory, we should purchase from a dealer whose dairy meets with our approval.

We have now become well acquainted with our first and best food friend, and should make that acquaintance count in building strong, healthy bodies. In warm weather, a glass of milk is just as refreshing as the numerous other cool drinks, and furnishes a supply of nourishing material of which they, as a rule, have but little. When we are cold, a glass of hot milk will warm and nourish as well. A cup of milk at each meal may become just as pleasing to the taste as tea or coffee, and is far better, especially for children. An old proverb says, "A word to the wise is sufficient." Shall we let these facts about milk help us to become wise body builders?

The value of milk as a food is so well-known that the nutritious part is prepared for shipment to distant places where not enough cows are kept to furnish the supply that is required. The mode of preparing it is very simple. The milk is first placed in large heated pans where the water evaporates. Then what is left, nearly one-seventh of the original quantity, is heated to a temperature of about one hundred eighty degrees to kill any bacteria that may be present. After sugar has been added, it is put into cans or jars which are sealed tight and labeled "Condensed Milk." 
Because it will keep indefinitely, condensed milk is shipped any distance. As it contains all the building elements of the original milk, it is a valuable food.

Butter is not quite as old a friend as milk, but, nevertheless, it is a very valuable one. Happy, indeed, is the childhood recollection of a buttercup being held under the chin to tell whether we liked butter. Fortunate, too, are the little folks who do like this precious yellow food, for it is one of the most pleasant tasting and easily digested of the animal fats. "As fat as butter," an expression we have often heard, is a good comparison, for fat is as large a part of butter as water is of milk. Besides fat, butter is about one-hundredth proteid, and from nearly one-twelfth to about one-sixth water, but should not have more of these substances. Like milk, butter should be kept in the coolest place in the house. As it takes up odors very readily, it should not be left uncovered in the ice box. When these precautions are not taken, butter becomes rancid and unpleasant to the taste in a very short time.

A substance called oleomargarine, which looks like butter, is made from fats. It is valuable food, and in no way unwholesome, but, unfortunately, is often sold as butter. As it is much less expensive to make and has not nearly so fine a flavor, it is a fraud to sell it as butter. The difference can usually be told by noticing the taste and texture. If one is not sure, a good way to find out is to melt a lump of the sub- 
stance in a small tin dish. When melted slowly and then allowed to boil, oleomargarine will sputter briskly, but produce little or no foam. Butter, on the contrary, boils with little noise and produces abundant foam.

Cheese made from whole milk is composed of all the elements of the milk, except a large part of the water and the sugar, which are lost in the souring process. Cheese made from skimmed milk has less fat, is not as nutritious, and should be much less expensive. A higher priced quality is made by adding cream to pure milk. The more cream or fat cheese contains, the softer it is, and, as a rule, the more it costs.

That cheese is a valuable food for those who can digest it without difficulty, can readily be seen from the fact that one pound contains even more building material than a pound of beef. When eaten in place of meat, as it often is in France and Italy, with bread, green vegetables, and oil, it makes an inexpensive as well as a very nutritious meal. Toasted cheese is especially difficult to digest. Sometimes, when mixed with other substances, cheese is much more readily digested by some people than in the usual solid form. It is well to remove the rind before eating cheese, as unwholesome substances are said to be used to preserve it. 


\section{CHAPTER IX}

\section{OTHER ANIMAL FOODS}

EGGs are another very valuable food friend. Who has not heard the saying: "As full of meat as an egg"? Are we to judge from this fact that all the contents within the shell are valuable body-building material? Strange to say, about seven-tenths of the inside of an egg is water. The other components are about oneeighth proteid; a little less than one-eighth fat; and the remainder mineral substances, among which are both phosphorus and sulphur. It is the sulphur of an egg that tarnishes silver. The white of egg is almost pure proteid, called albumen. Nearly all the fat of an egg is in the yolk, which also contains considerable proteid.

Like milk, eggs are an especially valuable food, because the building and fuel materials they contain are in such form as to be easily made use of by the body. As heat hardens albumen and makes it less easy to dissolve, hard-cooked eggs are more difficult to digest than those that are soft-cooked. Frying eggs increases their difficulty of digestion.

Eggs spoil very easily if proper care is not taken. On this account, like milk and butter, they should be kept in the coolest place in the house. In cities there 
are large cold-storage houses in which eggs laid in the spring and summer are kept for the winter market. Where there are no such houses, eggs that are to be kept for a long time are placed in some preservative.

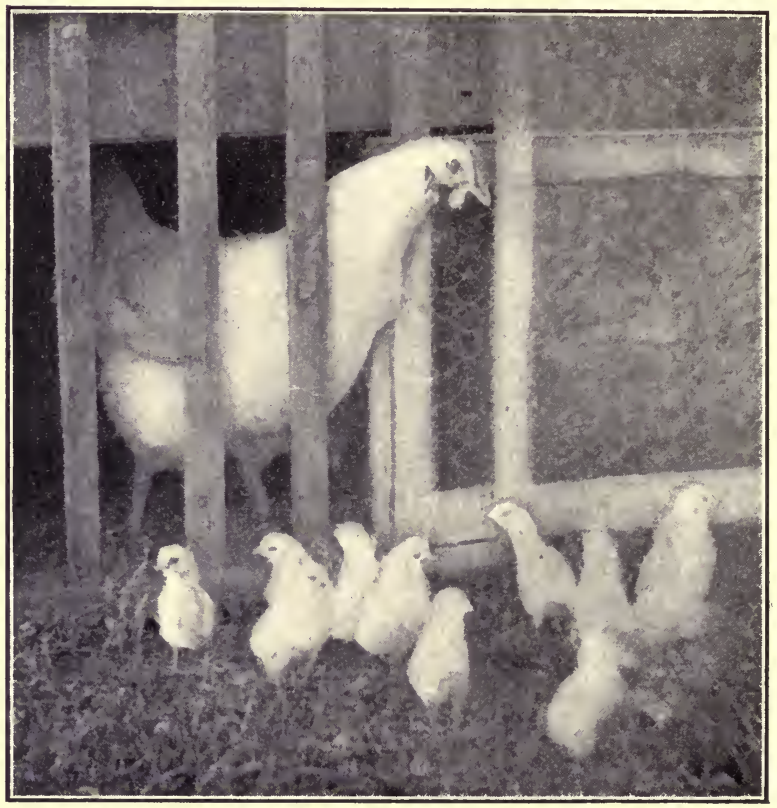

Egg Producers.

Water glass, or liquid glass, as it is sometimes called, seems to be the most effective of these preservatives. Well-known dealers claim that they have preserved fifty dozen for several months in a mixture of onetenth water glass and nine-tenths water. As eggs are such valuable building material, it is important to 
know whether they are in good condition when delivered. Candling is the method most commonly used for this purpose. An egg is held before a light, and, if fresh, will appear unclouded and almost translucent. If dark spots are visible or the appearance is clouded, it is not fresh.

As eggs grow old, the water they contain evaporates through the pores of the shell. On this account, they naturally become lighter in weight. Dealers have learned that a newly laid egg placed in a dish of brine composed of two ounces of salt and one pint of water will sink to the bottom. An egg one day old will sink below the surface, but not to the bottom. One more than three days old will float in the brine, the amount of shell above the surface increasing with age. Of course, the higher the temperature of a room in which eggs are kept, the more quickly the water in them evaporates.

When the shell is broken, a bad egg can always be told by its offensive odor. If the yolk holds together well after the shell is broken, it is usually a sign that the egg is fit to eat; but if the yolk spreads and separates, the cook may be sure the egg is too stale to be wholesome or appetizing. Although preserved eggs may pass inspection, the process often lessens their food value. On this account, invalids, especially, should be careful to buy those that are strictly fresh.

It is fortunate that eggs can be prepared in many different ways, for much use may be made of them 
without having meals lack variety. As they are said to be best for invalids when prepared soft-boiled or poached, it is likely that in this form they can be most readily digested by all. At any time, when fresh, they are a most desirable part of breakfast or lunch; and even in winter, when their cost is highest, they are not a comparatively expensive food. At such times, instead of omitting the egg or two for each member of the family from breakfast or lunch, we should be far wiser body builders to leave out of the dinner menu the much less easily digested pies and cakes of which eggs usually form a necessary ingredient.

Probably no food seems more natural body-building material than meat, because it is so similar to our own flesh and blood. What building elements does it furnish our bodies? From two-fifths to three-fourths is water, and the leaner the meat, the greater the proportion of water. From about one-eighth to onefourth is proteid, from one-fourth to two-fifths is fat, and from three-hundredths to one-twentieth mineral matter. Like milk and eggs, most meats, when properly prepared, are readily digested. Beef is probably the best of the widely used meats, because it has an appetizing flavor and a large amount of nutrition, and at the same time is not difficult to digest.

Chicken, especially the white-meat part, is said to be more easily digested than beef, but it usually costs more, for the waste parts that cannot be used for food are heavier. Veal (calf's meat) is not as nutritious as 
beef, and is said to require five hours or more to digest, while beef usually takes from two and one-half to three hours. Mutton is considered somewhat more easy to digest than beef, and, for this reason, may be better for a person with a weak stomach; but it is not quite so nutritious. Lamb furnishes less nourishment than mutton, nor is it so easily digested.

While pork is rich in fat and has a good proportion of proteid, it is, for many persons, the most difficult of all meats to digest. For this reason, it should be avoided by those who are delicate. Thoroughly boiled ham is an exception to this rule, being much used at health resorts because of its digestibility. Dried beef is more difficult to digest than fresh beef, but dried pork (ham and bacon) is digested more easily than fresh pork. This is especially true of bacon, which, when crisp and well done, is regarded as a very wholesome heat and energy-giving food.

Of course, the digestive juices can more readily dissolve tender meat than that which is tough. The tenderness of meat depends upon the character of the muscle fibers and the connective tissues that bind them together. In young and well-fed animals the fibers are thin and the tissues small in amount. As the animals grow older and are made to work, the walls of these fibers and the connective tissue become thicker and harder. Tough meat is sometimes made more tender by being cut into thin slices and pounded across the cut ends until the fibers are broken. 
While raw meat is more readily digested than that which has been cooked, civilized people cook meats to improve the flavor, and to kill any harmful bacteria they may contain. We found that in cooking eggs heat hardens the albumen, and that the harder the albumen becomes, the more difficult it is for the digestive juices. In cooking meats to the best advantage, this quality should be remembered. As albumen is distributed throughout meat, if the piece being cooked is subjected to great heat long enough, it will become hardened all through, causing the meat to be both inferior in taste and more difficult to digest. When the heat is not great enough to harden the albumen on the surface of the meat, much of the water the flesh contains escapes, carrying with it flavoring extracts and making the meat less appetizing and nutritious.

We should remember that whether meat is broiled, roasted, boiled, or fried, it should be subjected to very high heat as soon as it is placed on the stove, so that the albumen on the surface may be hardened and the juices kept from escaping. As soon as this is accomplished, the heat should be much reduced, and the meat kept on the stove only long enough for the fibers below the surface to be changed to the condition desired.

It can be plainly seen that the less meat is cooked after the albumen of the surface has become hardened, the more easily the digestive juices will be able to dissolve it. On the other hand, the more thoroughly it is cooked, the less the danger from harmful bacteria. 
As pork often contains injurious worms called trichince, which are invisible without the aid of a microscope, it should never be served rare, but always well done. Whenever there is doubt about the condition of any meat, the same precaution should be taken. If prepared at all, it should be thoroughly cooked.

How should a knowledge of the chemistry of meats guide in the preparation of soups and stews? In these it is desirable to get out all of the juices possible. For this reason but little heat is used, the meat being allowed to simmer for several hours. Meats are generally considered to be the most difficult to digest when fried, and the easiest to digest when rare-broiled or roasted.

Another useful fact to know about. meats is that cheaper cuts often contain a higher per cent of building materials than those which are more expensive. For instance, round steak usually has more proteid than sirloin or "porter-house" and much less waste. Many of the cheaper cuts from the neck or flank, when properly prepared, furnish a larger proportion of the useful food elements than others that are more costly.

As meat is such a commonly used food, it is important to be able to tell that which is not wholesome. Good beef is of a clear dark red color. It is firm and compact, contains no clots of blood, and, if it has been well nourished, is marbled with spots of white fat. The flesh of old animals is darker and drier than that of young animals, and their fat is of a yellowish color. 
A pale pink color indicates that the animal was unhealthy, while a dark purple hue is a sign that it was not slaughtered but died from disease, the blood remaining in the body.

Veal is pink in color and has tender white fibers. "Bob veal" (that which has been killed too young) may be recognized by its flabby flesh of a blue tinge. It is very unwholesome. The fat of veal is not distributed through the lean as it is in beef, and the same is true of mutton. Good meat has very little odor, and, if any is noticed, it should not be disagreeable. Tainted meat often gives off an unpleasant odor while being cooked, and is not pleasant to the taste. If meat is wet and flabby to the touch, it is not good, and should it not remain dry and firm after being kept in a cool place, it is probably not wholesome.

Bad pork is dotted with grayish white spots about the size of a bean. Dishonest dealers often cut up such pork into sausages. This practice and the ease with which sausage can be adulterated in other ways make it, to say the least, a very doubtful food. The following story illustrates this point very well. A little boy boasted that he could tell from what animals the various meats came. The veal chops at luncheon he readily assigned to the calf, and the leg of mutton at dinner to the sheep. When sausage was placed on the table next morning, the lad looked much puzzled. However, he did not wish to fail completely in the presence of the grown-up members of the family; 
and so, when questioned by an older sister as to the origin of sausage, replied, "Only the butcher knows."

There are various ideas in regard to the value of meat as a food. Some think that eating it at every meal is necessary for the greatest strength and vigor. Others believe themselves much healthier and stronger without any meat. They reason that people afflicted with certain diseases are advised to eat little or no meat. Food that is harmful to an invalid, they think, may, in time, injure a well person. Still others hold that a moderate amount, once or twice a day, in small quantities, is best, especially for brain workers.

A study of the chemistry of foods, as well as a knowledge of the remarkable powers of endurance shown by the Japanese and other people on a diet composed largely of rice, certainly proves that it is possible to be strong and well without eating meat. We also see meat eaters who appear to be enjoying the most vigorous health. Undoubtedly the best plan is for each person to regulate his diet by what seems to be true of his own body. The truth of the old saying, "What is one man's meat is another man's poison," has often been demonstrated. In the use of meat as of other foods, it is for us to learn to be either wise or foolish builders.

But what about fish? How do these finny dwellers in the water world, which so many people greatly enjoy luring from their liquid home, help in our structure? Did the Creator place them in the streams 
just to furnish us sport, or do they serve a more useful purpose as well? On the average, they are composed of from seven-tenths to eight-tenths water, one-tenth to two-tenths proteid, one-twentieth to one-tenth fat, and one one-hundredth to two one-hundredths mineral matter. We can see they contain a good proportion of the necessary building materials. This, together with the fact that they are not difficult to digest, makes them an excellent substitute for meat.

Fish caught in cold, clear, or running water are usually preferable to those from stagnant, shallow, or warm water. The kinds living in streams having a rocky or sandy bottom are, as a rule, better than those found in streams having muddy bottoms. Fish should be killed as soon as eaught. Allowing them to die slowly not only is cruel, but also, according to some authorities, makes the quality of the flesh less desirable. Some fish become soft and flabby when streams grow warm in summer, and should never be eaten in that condition.

The flesh of fish that die in the water from various causes is spongy and yellowish, and has a foul odor. Decaying fish also have a disagreeable odor, are bluish in the under part, and feel flabby and sticky. Of course these should not be eaten. Fish that have been frozen and kept for a time after being thawed out are especially likely to contain poisons called ptomaines. If the water in which fish is being washed or boiled blackens silver, we may be sure it is not fit to eat. 
Canned fish should not be left for any length of time in the can after the latter is opened, nor should it be long exposed to the air before being used as food.

The odor of fish is likely to taint other foods kept uncovered in the same ice box. While fish contains some phosphorus, there seems to be no reliable proof of the oft-quoted statement that the finny tribe is an especially good brain food. However, with the usual dinner vegetables, fish makes a hearty meal, and its use in place of meat might well be much greater than it is in this country.

Oysters are among the most popular foods taken from the water. Nevertheless, they have a comparatively small amount of the useful food components, and so are an expensive food. They are much liked for their flavor and can be made a nutritious dish when cooked in milk. Raw oysters are said to be more easily digested than cooked, and fried oysters are probably more difficult to digest than those cooked in other ways. Clams and lobsters are also comparatively expensive foods; but in shrimps one usually gets better value, because they contain a larger amount of proteid. 


\section{CHAPTER X}

VEGETABLE FOODS AS BODY-BUILDING MATERIALS

BREAD is often called the "staff of life." What building materials does wheat contain to merit this proud title? About one-seventh is water, nearly one-eighth proteid, one-hundredth sugar, two-hundredths fat, two-hundredths mineral matter, and a little more than three-fifths starch. We notice that the proportion of water is much smaller than in animal foods, and that the amount of starch is very large. Of course the fat and proteid are somewhat increased in bread by milk and other substances added in its preparation.

But what about the other grains? Are they equal to wheat in the food elements furnished? The composition of rye is very similar to that of wheat, the proteid being somewhat less in amount. Its flour, however, is likely to be infested with a harmful substance called ergot, which gives the bread a bitter taste and is poisonous. Corn has less proteid than wheat, and more than twice as much fat, but its building materials are not as readily separated from the non-nutritious parts of the flour by the digestive organs as are those of wheat. It is, nevertheless, a very useful food. 
Oatmeal contains three times as much fat, twice as much mineral matter, and only a little less proteid than wheat. In Scotland it has long been a highly prized food, the great strength and endurance of the

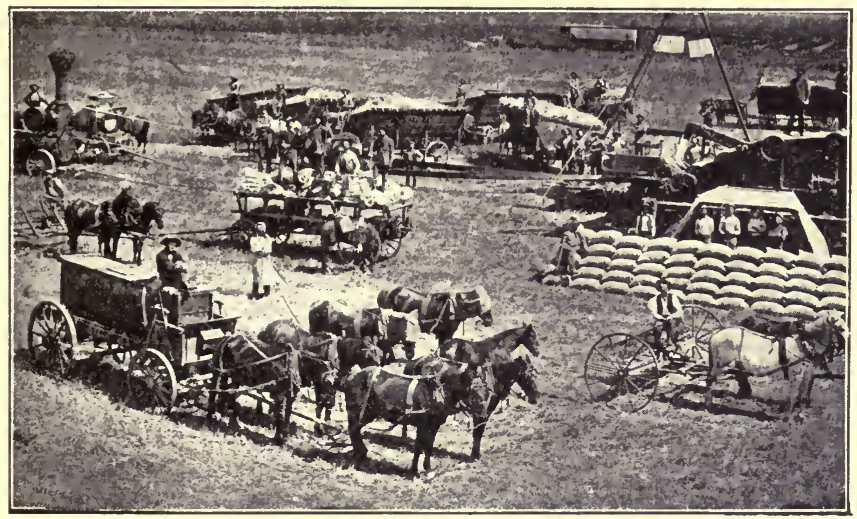

Threshing Wheat.

Scotch Highlanders being thought by many to be due to the national dish of oatmeal and milk. It is certainly an inexpensive food, and, when sufficiently cooked, an excellent body builder. Try to tell why both oatmeal and corn meal are good winter foods, and give a good reason for wheat foods being more desirable for summer use.

Rice is about three-fourths starch, less than sixhundredths proteid, and has about the same amount of fat as wheat. ' Being low in its percentage of both proteid and fat, it is the least nutritious of all the grains in common use in this country; but its 
large amount of starch and ease of digestion make it so valuable that in China and Japan it is the principal food.

Let us consider something that is really very curious about the common, everyday process of bread making. Yeast, which is commonly used to make bread dough rise, is made up of very tiny plants that are closely related to bacteria. When these yeast plants are placed in the dough, they increase rapidly, and, uniting with the sugar, produce carbonic acid gas and alcohol. The gas in attempting to escape raises the dough, making it light, and the alcohol evaporates. Yeast grows best in a temperature of from seventy to ninety degrees, the higher being desirable in winter, because of the coldness of the flour.

If the yeast is allowed to grow too long or at too high a temperature, it acquires a sour flavor. The number of hours allowed bread to rise depends upon the temperature, from five to ten being the usual number. The oven should be hot when the dough is placed within, in order that the yeast plant may be quickly destroyed. Afterward the heat should be reduced, and the bread kept in long enough to be thoroughly baked.

Baking powders are used instead of yeast in making biscuit and similar preparations. These powders contain mineral substances, which, when united with water and flour, form carbonic acid gas that raises the dough. If yeast or something similar were not used 
to leaven bread, the loaves would be heavier, much smaller, and not nearly so appetizing. After bread is baked, it should be left where it can be aërated. A wire dish in which air has a chance to circulate freely is excellent for this purpose. The bread should then be placed in a covered tin box, both to keep mold spores off and to prevent it from becoming dry and unpalatable.

Moldy bread is unwholesome and should not be eaten. Dry bread can be made more palatable by steaming or by dipping it in water and rebaking, as this supplies water in place of what has been evaporated. Flour when exposed to air absorbs moisture, in which condition mold is likely to develop.

On this account it should be kept in a covered box or barrel in a dry place. The box or jar in which bread is kept should be frequently washed out with hot water to remove any mold spores that may have collected.

Many foolish customs are the result of fashion. Perhaps one of these is the preference many housekeepers seem to have for the whitest bread. Knowing this, manufacturers naturally try to produce flour of the whitest possible brand. To do so the outside husk must be sifted out, and as these layers contain much of the proteid and the mineral components of the grain, very useful materials are not included. How foolish it would seem to put beef through some process that would separate all the fat, just because the 
lean meat might appear handsomer! And yet, from the standpoint of food value, separating the outside layers from the kernel of wheat to produce whiter flour is similar.

Whole wheat or entire wheat flour contains all the layers of the kernel ground up together. It can be obtained by grocers in the same sized sacks that are used in shipping white flour, and at almost the same expense. The coarser bran it contains is usually a helpful stimulant to the muscles of the intestines. Physicians often recommend it on this account, as well as because of its great nutrition.

Another important fact to know about bread is that the home-made article is usually cheaper and more wholesome than that which is purchased from the store. This follows because alum and other harmful substances are often added to make baker's bread light. The actual cost of the materials of a loaf of bread is estimated at about two cents. As a patent bread maker has recently been invented that greatly lessens both the time and the work of making bread, the labor required is much less than it used to be. By baking at home, money can be saved and better bread obtained. Then there is no doubt as to how and where the dough was handled, nor, in the clean home pantry, do the germs that infest the air have the opportunity that is given them in the bake shop, store, and wagons where the loaves must necessarily be placed before reaching our homes. 
But what about the digestibility of bread? Is it ever necessary to be careful about such plain food, and will a knowledge of chemistry aid our judgment in this respect? If people were always well, such information would not be necessary, but as almost every one is likely now and then to feel ill, facts about this common food may be useful. Bread a day or more old is more easily digested than newly baked bread, as the latter may cause fermentation in a delicate stomach. During the process of baking, heat changes some of the starch of flour to dextrine, or grape sugar, which is more easily digested than starch. On this account,

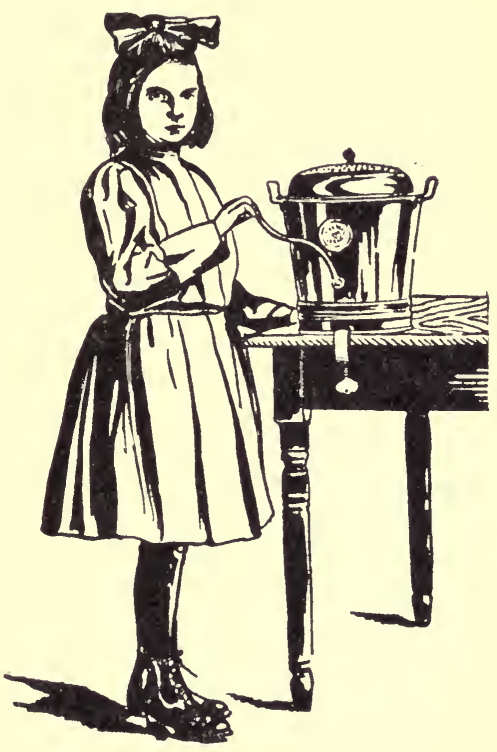

The Chautauqua Bread Mixer. A child can operate it. and because it is lighter, well-done bread is easier to digest than that which is soggy. For a similar reason, toast is a very excellent form of bread food. Another advantage of toast is that it must of necessity be chewed more thoroughly than bread before being swallowed; but this advantage is lost when it is soaked in milk or some other liquid. 
Plain, well-done bread or toast is undoubtedly the best form of body-building material prepared from flour, and much more easily digested than biscuit, muffins, and various forms of hot bread. Pancakes, pastry, doughnuts, and other cakes are probably the least digestible forms into which flour is made. While the eggs, butter, sugar, and other materials united with flour to form the numerous pies and cakes may themselves be excellent foods, the combination resulting is often far less easily digested than the single components. One reason why muffins, biscuit, and the various cakes are not as wholesome as bread, is that they cannot be cooked long enough to properly break up the starch granules as is done by the thirty or forty minutes' baking given to bread. These minute starch granules, when subjected to heat the necessary time, pop open like kernels of pop-corn. When the starch granules are not broken open in this way, they are necessarily more difficult to digest.

The best that can be said for pies and cakes is that they should be eaten only in small quantities, if at all. Usually they are in a form that does not admit of much chewing. On this account, they are often swallowed half masticated, the digestive juices in the stomach and intestines being left with an unnecessarily large amount of work to perform. To depend upon such foods for the proteid, starch, fat, and sugar our bodies need for repair and growth, is as unwise as it would be for the carpenter to make large use of woods that are 
the most difficult to be shaped and changed to the form his building needs.

Children often eat a second piece of pie or cake at meals, or buy doughnuts or other indigestible breadstuffs at the baker's shop between meals, and feel great satisfaction because for a few moments their taste is pleased. But what foolish enjoyment this is! To load our digestive organs with cumbersome food when they could get a greater amount of building material far more easily from other sources! How often it happens that people who please their palates in this way lose much of the real fun and satisfaction that come from the full enjoyment of play and work! How many times children who are naturally pleasing and bright become disagreeable and dull in school, largely because their digestive organs are burdened with indigestible food!

What a poor trade it is to spend pennies, that might buy something useful, for food that handicaps the body! How thoughtless children are to exchange the chance of doing their best work in school and having the fullest enjoyment of play for just a few moments of pleasing the taste! We should remember that bread, if simply and properly prepared, may well be called the "staff of life," for, when eaten with butter or some other food rich in fat, it furnishes a good proportion of all the building elements. We should also keep in mind the fact that flour, when made into pies and cakes, makes a weak staff, indeed, and one we should lean upon very little. 
Next to wheat, no vegetable product is more commonly used in this country than potatoes. Although they may seem one of our most valuable food friends, the amount of building substances potatoes contain is really very small. About three-fourths is water, a little less than one-fifth starch, and nearly onehundredth, salts. If a person were compelled to rely on potatoes alone for food, from twelve to fifteen pounds would be required daily. Why, then, is this tuber so commonly eaten? Simply because it grows well in a great variety of soils and climates, and also keeps in good condition throughout the winter. Besides, as its starch digests readily, and its mineral salts are valuable, the potato becomes a very useful food when eaten with meat, butter, and other foods that supply what it lacks of fat and proteid.

Much of the valuable part of potatoes is often lost in their preparation for the table. When they are pared and soaked in cold water before cooking, or placed in cold or moderately warm water to boil, there is likely to be much loss of the nutritive parts. These are best retained when potatoes are boiled or baked with the skins on. They should be put into very hot water for boiling, or into a hot oven for baking, so that the surface may quickly become hardened, and the loss of useful materials prevented. Baked potatoes are considered the most easily digested, and, whether boiled or baked, those that are of a mealy texture when served are to be preferred to the soggy 
ones. Probably fried potatoes are the most difficult to digest. The starch in potatoes, like that in flour, requires at least thirty minutes' cooking to become digestible.

Most other vegetables in common use are valuable chiefly because of their flavor and good effect on the digestive organs and blood. As a rule, they contain much water, little proteid and fat, and a small percentage of sugar, besides useful salts. For instance, turnips, carrots, and parsnips contain from eighttenths to nine-tenths water, about one-hundredth each of proteid and mineral salts, about one-half as much fat as proteid, from one-twentieth to twotwentieths starch, and from two-hundredths to sixhundredths sugar. Nevertheless, they are all highly prized for their flavor and salts.

Lettuce, onions, and celery are considered especially good for the blood and nerrous system. Spinach, dandelions, and rhubarb are regarded as healthful stimulants for the liver and digestive organs; while asparagus, carrots, tomatoes, and others are by many rated equally valuable for various reasons. All are useful in furnishing a variety of diet and in adding to the bulk of food in the intestines. As bulk helps the muscles of the intestines to perform the work of getting rid of waste material, this is an important service. Constipation, especially in children, is frequently caused because the bulk of food is insufficient. The vegetables that have comparatively the largest 
amount of building and fuel materials are the legumes. Peas and beans are the most common specimens of these used in America and Europe. In their ripened and dried state beans are about one-eighth water, a little more than one-fifth proteid, two-hundredths fat, three-fifths starch and sugar, and about threehundredths salts. Peas have a little less water and fat, but a slightly larger percentage of proteid, starch, and sugar. As legumes are so inexpensive, and at the same time so abundantly supplied with proteid, why are they not more largely relied upon for tissue-building food? Chiefly because it is difficult for some people to digest them on account of the tough outer fiber.

If dried peas and beans are soaked several hours before being placed on the stove, and are cooked a long time, this fiber does not cause so much disturbance. If, after such preparation, they are put through a colander, the fibrous part is largely removed, and what passes through may be made into broth that is nourishing and not so difficult to digest. String-beans and green lima beans are much less nutritious than the ripened dried beans, and green peas have the important food substances in considerably smaller amounts than ripe dried peas. When canned, all three lose about one-half their useful food components.

Nuts are also very nutritious foods. They contain from about one-seventh to one-fourth proteid, from one-fourth to three-fifths fat, from one-twentieth to 
one-fifth sugar and starch, and from one-hundredth to three-hundredths salts. Walnuts, almonds, and peanuts are the most nutritious varieties in common use. Like legumes, they are difficult to digest, and, as a rule, should not be eaten in large quantities. Nevertheless, their body-building value is highly esteemed, some people even claiming that they have kept in good health on nuts and fruits without other foods. Attempts have been made to prepare nuts in a form that will be more easily digested. Probably peanut butter is the most widely used of such preparations.

Although apples have from three-hundredths to eight-hundredths of proteid, and bananas as high as six-hundredths of proteid and about one-hundredth of fat, the building and fuel value of most fruits is small. As a rule, they are composed of water and from one-hundredth to one-fifth of sugar. Fruits are, however, highly prized for their delicious flavors and good effect on the digestive organs. For the latter, they are a natural stimulant, and, when ripe, may be very beneficial. Money spent for fruit, especially for breakfast, is a good health investment.

The fibrous and cellular parts of fruits are the least easily digested, but are valuable in adding to the bulk of food in the intestines. Bananas, though difficult to digest, are much used as a staple food in tropical countries, because they contain some proteid and fat as well as sugar. Under the skin of bananas, adhering to the 
solid part, is a stringy, white, fibrous substance that does not add to the flavor and is especially indigestible. Some who have not been able to digest bananas readily with this covering unremoved, find that when it is scraped off, the difficulty is greatly lessened. Apples, as a rule, are not difficult to digest and are prized for their beneficial effects. Baked apples are usually very easily digested. For many, oranges are excellent, because of their refreshing acid and ease of digestion.

Raspberries have comparatively little juice, and as their seeds may irritate the intestines, some people find it best not to eat them. Both green and decayed fruits are unwholesome and should not be eaten, as they are likely to cause serious sickness. For a similar reason, factory-prepared jellies and jams should be avoided, unless the makers are known to be reliable, as unwholesome fruits are said to be used in their manufacture. Although the digestibility of some fruits, notably apples, is improved by cooking, stewed or canned fruits are not as beneficial as fruit in the fresh state, for, as a rule, their acids have been changed, and the large amount of sugar usually added increases the difficulty of digestion.

Like legumes, fruits contain a much larger portion of nutritive material when dried than when fresh. Dried figs, dates, prunes, and grapes (raisins) are comparatively rich in food value, and, when freed from the skins and seeds, are not indigestible. Prunes, after 
being soaked and stewed, are especially prized for their laxative effect on the intestines. Dried apples, peaches, and apricots, when prepared in a similar manner, are an inexpensive and useful food for those who find fresh fruits too costly. Fruit that has been put up in tin cans should not be left standing in these after being opened, nor should it remain long uncovered in any dish. If the bottom of a tin can of fruit or vegetables bulges out, it is a sign of fermentation. On this account, the contents of the can should not be eaten, for they are unwholesome.

Is it necessary to look out for bacteria and mold in canning fruit? During the entire process, care is taken to guard against them. Both fruit and vegetables are subjected to high heat to kill all of these little destroyers that may be on them. Sugar is added to fruit, not only to season it, but also because bacteria do not readily work in substances having much sugar. Cans and jars are also covered or tightly sealed to keep out the air with its ever present destructive army.

A cool, dry part of the cellar is the best place in which to keep canned fruit, because bacteria and mold work less readily in a low temperature and dry air. A dark place is also considered better for glass cans of fruit than one that is light. Where there is not a closed fruit closet, paper is often wrapped about such cans to exclude the light. In fact, though they may not know it, the great struggle of housewives in the canning process is to exclude the invisible mold 
spores. The same thing is true in keeping fresh fruit, and for this reason it should always be kept covered in a cool place. If some of the fruit purchased is found to be partly decayed, it should at once be removed from the rest, as mold spores spread rapidly to the sound fruit.

To prevent the spreading of mold spores, oranges, lemons, and other fruits are frequently wrapped in light paper before shipment. Wiping the skin off occasionally with a cloth aids in the preservation of some fruits, because this removes the mold spores. Perhaps, when we have seen the old apple woman polishing her wares, we may have thought it was simply to make them more attractive; but she knows it also helps to prevent decay. Fruit that is found to be too green for present use will usually ripen and become wholesome, if kept for a time.

Because of its cost and health-giving qualities, fruit should not be allowed to waste. We should cherish it as a most helpful building ally, and one that will greatly assist the body in getting the most good from other foods rich in the necessary building and fuel materials. It is excellent for desserts, especially when eaten in place of the rich pastry and cake in common use. It satisfies the craving for sweets without crowding the already filled stomach with bulky foods from which our digestive organs cannot readily separate the nutriment. 


\section{CHAPTER XI}

BUILDING MATERIALS FOR JACK'S HOUSE-BEVERAGES

We have found out how most foods commonly served at the table may help keep our bodies in healthful condition. What about the familiar acquaintances, coffee and tea? Of what use are they to our bodies? No one claims that they furnish food materials, except in the cream and sugar used in their seasoning. Though tea is made from the leaves of one plant, and coffee from the seeds of another, both contain a substance that acts as a stimulant.

When properly prepared, they are possibly healthful stimulants to many people, especially when sufficient nutriment is supplied by other foods. Some have stopped using tea or coffee, because they found it made them sleepless, or injured their digestion. Others are strong in the belief that the use of one or both is very beneficial to them. The greatest difficulty, no doubt, is that many use them to excess, and, forgetting that they are only stimulants, get into the habit of depending on the cup of coffee or tea and some food not rich in nutrition to furnish strength for hours of work. Like other food questions, this is something each adult should settle for himself, being governed not by 
appetite, but by what experience shows is best for his body. As far as children are concerned, there is no question. Growing bodies need nutriment, not stimulants, and young people who care to be healthy and vigorous should not risk using either coffee or tea.

Tea leaves contain a substance called tannin, which, when dissolved in the process of making, gives a bitter taste to the liquid and retards the digestion of other foods. On this account, tea should be prepared as follows: pour boiling water on the tea leaves and allow it to remain without boiling four minutes. Then strain the liquid into a hot earthen pot. Do not allow the leaves to stay in the hot water a longer time, as the harmful tannin will be dissolved. Tea that tastes bitter should not be drunk, for this is a sure sign that it contains tannin.

But how is it with the beverage friends, chocolate and cocoa? Do they simply stimulate the body without giving building and fuel materials? They are both made from the cocoa bean, which, like coffee, is the seed of a small tree. Besides, having stimulating properties very similar to those of coffee and tea, cocoa seeds are about one-fifth proteid, one-half fat, and one-tenth starch. When these seeds have been roasted and divested of their husks, they are known as cocoa nibs. These are ground into an oily paste, mixed with sugar and flavoring matter, usually vanilla, and allowed to harden into small cakes, to make chocolate. 
Cocoa is the nibs alone, from which most of the oil has been extracted, either ground or unground, dried or powdered, or the crude paste dried into flakes. On this account, cocoa is easier to digest than chocolate,

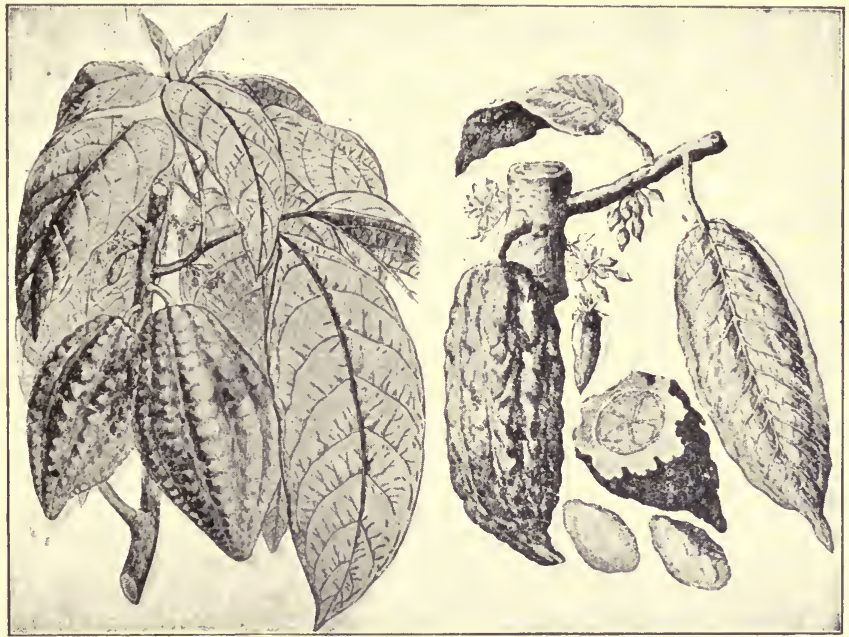

Cocoa Pods and Leaves.

this being especially true of some varieties from which about half the fat has been extracted in the course of manufacture. In making tea or coffee, care is taken to dissolve only the part that is stimulating; but in preparing chocolate or cocoa, the entire substance is dissolved in hot milk or water, making a nutritious as well as a healthfully stimulating food. Why it is wise to let such beverages displace coffee and tea can readily be seen. Few try faithfully to do so without becoming equally fond of the substitutes. 
In regard to soda water, ginger ale, pop, and the numerous so-called soft-drinks, the value of the little nutriment they may possess is usually lessened by the presence of some flavoring extracts that are difficult to digest. Unless made from pure fruit juice, such drinks are, from the standpoint of the good of the body, poor investments. The popular ice-cream soda furnishes much better value, though plain icecream is probably more readily digested. The habit of taking any of these after a hearty meal, when the digestive organs are already occupied with sufficient food, is not a wise one. By chilling the stomach they check its activity. Such drinks may also cause sour stomach.

As to beer, ale, wine, whisky, and other alcoholic drinks, the claim cannot be made that they furnish any building material to our bodies. Besides water, their most important ingredient is alcohol, which is a stimulant and in no important degree a food. People who select their diet wisely use any food or drink for one of two good reasons. First, that it furnishes the necessary tissue-building or energyproducing materials. Second, that it helps the digestive organs to make better use of nutritious foods that have been eaten.

Do alcoholic drinks serve either of these purposes? Wine is made from grapes, beer from barley, and whisky from rye. No one can dispute that grapes, barley, and rye contain helpful building materials. 
Why should not their product be similar? Our little acquaintances, the yeast plants, help to answer this question. In the process of manufacturing alcoholic drinks, multitudes of these tiny plants change the sugar of these substances to alcohol and carbonic acid gas. The carbonic acid gas passes off, and leaves alcohol and water the principal ingredients.

Then surely alcoholic drinks must help the digestive organs to make better use of other foods, or they would not be so largely used! On the contrary, it has been found that alcohol, instead of helping, retards digestion, especially of proteids. If such drinks are used to any great extent, they weaken the muscles, harden the tissues, and so derange the heart, liver, kidneys, and other important organs that a person's comfort, usefulness, ability to resist disease, and length of life may all be greatly lessened.

Some people swallow an alcoholic drink when they are cold, thinking it will warm their bodies. It does seem to do so, because alcohol makes the heart beat faster and drives blood to the surface of the body. It must soon rest from this over-stimulation, however, and the general warmth will become diminished. A cup of hot lemonade or hot milk is far better, because either warms the body without causing overstimulation and consequent reaction. A drunkard freezes easily because alcohol causes the heart to drive too much blood to the surface of the body, and so an undue amount of heat radiates from the skin. 
Few inhabitants of temperate zones ever have to endure such cold as do explorers who visit the aretic regions. Men who have been engaged in such expeditions testify that they endured the cold much better when they abstained from alcoholic drinks. In a recent interview, the distinguished explorer, Commander Robert E. Peary, said: "A man must abstain from all stimulants in the polar regions. Liquor is altogether out of the question there." Under some conditions, however, such liquors are considered useful ; for instance, when, because of disease, accident, or fainting, one's vitality is at a very low ebb and something is needed that will quickly stimulate the heart's action. Yet, like other poisonous medicines, they should be used only when prescribed by a physician.

It is not necessary to describe the effect of alcohol on the muscles and the will. Unfortunately the sight of a drunkard is too common. Nearly all have learned from observation how this spurious food, instead of nourishing or helping the body, causes the brain to lose control of the muscles and sends its victim staggering along the streets.

What reader of the morning paper does not daily learn of its degrading effect on men's wills? One person has conducted himself in a boisterous or shameful manner. Another has beaten a wife or child. Perhaps a third has been killed, or maybe has taken another person's life. And each account ends with the same explanation, "He was drunk." What community 
has not men who were once truly respected, but who have gradually fallen in the estimation of their neighbors to objects merely of pity or contempt? Why? Because alcoholic drinks, instead of nourishing their bodies or healthfully stimulating them, have simply served as a poison to paralyze the muscles and pitifully weaken both body and will! What prison does not show liquor to be the cause of the disgrace of ninetenths of its occupants? What poor-house or insane asylum but records the same unhappy tale?

The habit of using too much coffee, tea, or rich food may impair vigor, and change a man's disposition enough to make him less companionable at times. By one or both of these results, his material prosperity and that of his family may be affected. Such excesses, however, rarely lead to disgrace, and the great injury usually ends with himself. The results from over-indulgence in alcoholic drinks are far different. The person may become not only uncompanionable but brutal. Habits of work often change so that business and property are allowed to go to ruin. Wife and children, besides being overwhelmed with disgrace, are robbed of the comforts and advantages which would have been theirs, had the appetite for alcohol never been formed. No one can tell the hopes, the ambition, the sweetness, and the love that have been blighted by intoxicating drinks. What misery and despair they have caused, none can picture. It is beyond the power of words. 
But many persons use liquor daily and never become drunkards. In fact, they live reasonably long lives, and think themselves healthier and stronger because of the habit. A slight acquaintance with the chemistry of foods shows that this cannot be true. If any one who considers himself in better health because of using liquor will go without it for two months, honestly trying to find out which is better for his body, he will not hesitate to give up the habit. This he will do, not only on account of the money saved, but also because health is bound to be better when the digestive organs are spared the unnecessary burden of getting rid of liquors that are not foods. Instead of furnishing nourishment, such drinks bring on diseases which develop insidiously and cut off many useful men in the prime of life. The fact that any one needs alcohol or any stimulant except on rare occasions is, to say the least, a confession of weakness. It is borrowing at a high price, for severe penalty is sure to follow.

The digestive organs of dogs are so much like our own that the effect foods and medicines will have on men may often be judged by their effect on these animals. If it is nourishing or helpful to them, it will, as a rule, be useful to men. If any substance is poisonous to them, or lessens their strength and vitality, it is likely to have a similar effect upon people. Of course, a greater quantity is generally required to produce a corresponding effect on men because of the difference in size. 
Dr. C. F. Hodge of Clark University, Worcester, Massachusetts, has reported some interesting experiments in feeding alcohol to dogs. He selected four that were born on the twenty-second day of February, 1895. Of these two, Nig and Bum, were brothers, and the other two, Topsy and Tipsy, were sisters from another litter. Nig and Topsy were placed in a kennel by themselves and given the ordinary dog food. Bum and Tipsy were likewise placed in a kennel by themselves, but, as their names might indicate, alcohol was mixed with their food each day. They would not have eaten such food if they could have procured other, for in this respect, at least, dogs are wiser than some men.

No special difference was noticed in the occupants of the two kennels for a long time. However, in about two years, an epidemic broke out among the dogs of Worcester. Bum and Tipsy were among the first to take it, and both were very ill. For weeks they would eat almost nothing, and both were blind for several days. The alcohol was stopped, but it was only after long and careful nursing that they were restored to health. Nig and Topsy, on the other hand, were scarcely sick at all. They showed hardly any loss of appetite, did not grow thin, and suffered very little during the time they were affected.

After Bum and Tipsy had regained health, the alcohol diet was resumed. Later Dr. Hodge gave the following test to see which pair of dogs was the stronger 
and more active: each day he took them to a gymnasium, where he threw a ball the entire length of the building to see which dogs would bring it back first. The score, which was carefully kept, showed that Nig and Topsy brought the ball back twice as often as did Bum and Tipsy. Now, you would naturally think that the winners in these games would have been more tired than the losers, for they had necessarily worked faster. Each day, however, after the test was made, Bum and Tipsy showed they were far more tired than were their non-alcohol-using competitors.

Other important differences in these pairs of dogs were observed by Dr. Hodge. Bum and Tipsy and other dogs that were being fed alcohol showed little curiosity about what happened near their kennels. They also frequently exhibited timidity and fear not at all natural in healthy dogs. During the years of the experiment, Bum and Tipsy had twenty-three puppies, only four of which lived to be mature dogs. Of the others, eight were born cripples and nine were dead when born. Nig and Topsy had forty-five puppies, four of which were not allowed to live because they were deformed. The others grew up to be healthy dogs.

Dr. Hodge stopped mixing alcohol with the food given to Bum and Tipsy at the end of three years. He wanted to see if they could, in time, regain their strength and become like other dogs. Tipsy died soon afterward, but Bum grew stronger every day. 
He played as much as Nig and could even bring the ball back nearly as often. Nevertheless, during his fifth year, he began to have trouble with his eyes and was soon entirely blind. Later he had a skin disease, eczema, which lasted a long time. Bum looked and acted like an old dog. His twin brother, Nig, on the contrary, was still strong and frisky. Indeed, you might easily have taken him for Bum's grandson, so great was the contrast between them.

But these experiments were with dogs. Surely alcohol has never been shown to have similar effect upon people. Unfortunately there is abundant proof of this fact. Time and again physicians have found that both drunkards and moderate drinkers get well much less frequently from pneumonia, typhoid fever, and other dangerous diseases, because of their previous use of alcohol. Neither are they so likely as total abstainers to recover from a severe surgical operation. Such investigators as Professor Demme also assert that children of alcohol-using parents are much more likely to be born idiots or epileptics, or otherwise ailing or deformed in mind or body, than children of parents who are total abstainers.

It is a well-known fact that coaches of college crews and baseball teams insist that those under their charge shall not use alcoholic drinks during the period of training. This rule is made because their experience has shown that boys can play games with greater strength, endurance, and skill without such drinks. At the 
international athletic contests held in Athens, Greece, in 1906, the American contestants won by far the largest number of prizes. It is interesting testimony that in Germany, a country where much wine and beer are drunk, the newspapers attributed the success of the Americans to the fact that they did not use alcoholic drinks during the period of training. If one is stronger and more capable at such a time without alcohol, it is reasonable to conclude that he will be healthier and more capable at all times without it.

For a long time insurance companies have kept account of the ages of people they insure, the diseases with which they die, and their age at the time of death. Some have also recorded whether the persons insured used liquor or were total abstainers. As such records have been kept strictly for business purposes, and not to prove or disprove anything in regard to the use of alcohol, they are entitled to considerable weight. These records show that, other things being equal, persons who do not use alcohol live, on the average, from fifteen to twenty years longer than do moderate drinkers. Very old men who have used liquor for many years are sometimes seen, and people conclude that alcohol has prolonged the lives of these persons, or has, at least, not shortened them. That in such cases the length of life has been in spite of, not because of, using alcoholic drinks, these insurance records unquestionably indicate. Few people would willingly give up fifteen years of life, and yet, by continu- 
ing the use of liquor, many are thoughtlessly doing this.

But eating too much of desserts, meats, and other foods undoubtedly causes some of the same ailments and results. Why should we be more particular about abstaining from liquors than from these? If one were absolutely sure that he could use alcoholic drinks without ever becoming a drunkard, then there would be only this difference between using them and too rich foods. The rich foods contain building materials in form unnecessarily difficult for the digestive organs. The liquors have no building materials and furnish an unnatural stimulus.

However, no one is able to tell for certain whether he can keep from forming the drink habit. Parents have used alcoholic drinks for years without seeming to lose control of their appetites, while their children have become drunkards on the very threshold of life. Alcohol has the dread power of creating an appetite for itself. A person takes the first glass just to be social, or, perhaps, because it seems to be the thing to do, with no intention of forming a dangerous habit. Gradually and unthinkingly, through the unfortunate treating custom, the amount is increased to several glasses. The saloon ceases to be repulsive. Slowly and surely the appetite grows until the harmful habit becomes fixed. Perhaps it may be only daily to burden the digestive organs with liquids that may bring on disease at the end of a long period of years. Perhaps 
it is destined to hasten its victim to drunkenness and disgrace.

Beginning to drink alcoholic liquors is like starting to swim the whirlpool rapids at Niagara Falls. At any moment one may be dragged down by the eddying whirlpools and undertows. Possibly, by sheer luck, he may be carried through on the turbulent current, only to sink at the end or perhaps to be hauled out from the ingulfing torrent by helpful friends. The managers of railroads and other large corporations realize that the liquor habit is likely to affect a man's trustworthiness, and in certain positions will not employ men whom they know have the "strong drink" habit, as the following notice plainly indicates:

\section{"New York Central and Hudson River Rail- ROAD COMPANY.}

"The use of intoxicating drinks on the road or about the premises of the corporation is strictly forbidden. Their use, or the frequenting of places where they are sold, is sufficient cause for dismissal.

"C. F. Sмiтн, General Superintendent."

The Lake Shore, the Pennsylvania, the Canadian Pacific, and many other railroads, have similar rules. In fact, any employer must have greater confidence in helpers who abstain from such drinks, for it is well known that this habit is the primary cause of most of the crimes and vices. 
There are doubtless many people who take only an occasional glass at an after-theater or chafingdish party. They have no craving, in fact, not even a liking for liquor. Can there be any possible harm

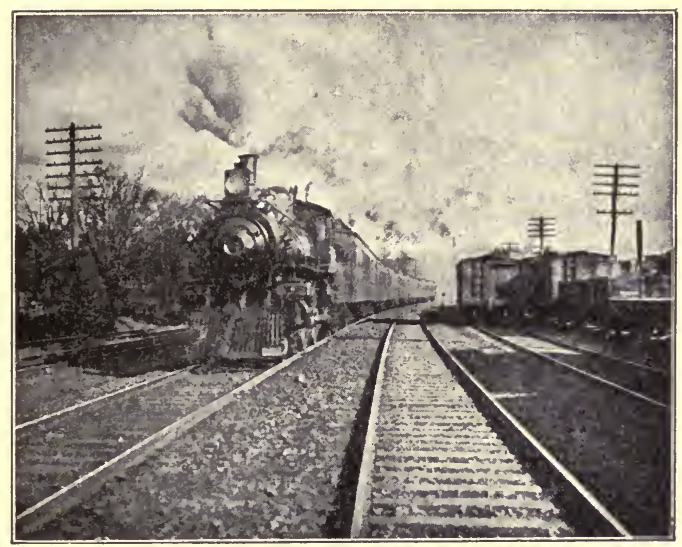

Many railway managers do not allow a man who drinks alcoholic liquors of any kind to run an engine. If you were traveling on a train, would you prefer the engineer to be a drinking man or one who never drank?

in this? They dislike to be considered unsocial, and what is the need when their digestive organs cannot possibly be deranged by such infrequent slight indulgences? Besides, with little fondness for the taste, there can be no danger of forming the habit.

Many strong, noble men have been confident of their power to resist, but when some unexpected fortune or misfortune came, have fallen victims to "John Barleycorn," chiefly because the way has been paved by previous occasional glasses. But even though a person were sure this could never happen, using 
liquors at all is dangerous on account of our influence. Persons who drink intoxicating liquors only once in a while are often of strong character and good standing in the community. Among their friends are some of weaker wills who may be started in forming the habit, because their stronger willed acquaintances, respected perhaps in church and society, drink an occasional glass. On this account, educated Christian people who now and then visit places where liquor is sold, drink it at private or public dinners, or allow it to be used on their own tables, lend respectability to a traffic they abhor. By so doing they often unthinkingly help others to misfortune and disgrace.

Young men and even young ladies sometimes partake of liquor at an entertainment for fear it might seem puritanical or impolite to refuse. But what a mistaken idea this is! No such refusal made in a quiet way but inspires the deepest respect. Why will not all young ladies, with due regard to their sex, make this one of their most sacred rules of conduct? It is the wife and the mother who are the innocent but often the greatest sufferers from the strong drink habit. If young ladies would never taste strong drink themselves, and would exclude from their companionship young men whom they know are not total abstainers, the influence of their action would be most salutary.

The law, recognizing the dangers of alcoholic drinks, makes it a misdemeanor to sell them to minors (persons under twenty-one years of age). We do not hear 
of laws prohibiting the sale of good bread, pure milk, or fresh meat; but there are ordinances in almost every city against selling impure milk or bad meat to any one. This is because, like alcoholic drinks, they may do great harm. Young people are also usually protected from the danger by the fact that few parents will allow their children even to taste liquor. The principal reason girls and boys should learn about the effects of alcoholic drinks is not that they are likely to use them, but that they may form the right ideas about their use in the future.

Knowing these facts, we should always regard alcoholic drinks with the same horror felt at the first'sight of a staggering drunkard, and resolve never to use them. May we all grow up to manhood and womanhood with these ideals and purposes firmlyestablished: To respect our minds and bodies and want them always to be at their best. To love our companions, and let no act of ours lead them to degrade their bodies or cripple their wills. To wish them and ourselves to be and to do all the good and noble things that a kind Creator has given ability for being and doing. To refrain always from handicapping our bodies by using any drink that may disease or degrade them. 


\section{CHAPTER XII}

FOOD HABITS - WISE AND OTHERWISE

Small boys and girls sometimes have much dread of terrible monsters which they hear and read about, but which never do them harm because they do not exist. A dragon which they have real cause to fear is sugar, and the dainties made from it. The very idea of anything so sweet as sugar being a dragon! How can such a delicious substance be harmful when we seem to crave it so?

Horses crave sugar just as much as human beings do. Let one taste a lump and he will follow you about eagerly for more. Why do owners not allow their horses to have all the sugar they want? Because they know that more than a little will lessen their appetite for the oats and hay that make them strong. Besides, they are aware that sugar will also get the digestive organs of these useful animals out of order. Its effect on people is similar, When eaten in small quantities, sugar is a good food, because it supplies heat and energy and digests easily. When too much is eaten, the digestive organs become clogged, and loss of appetite, headache, and other ailments result.

Is it not strange that so many parents seem to use 
better judgment in regulating the food of their horses than that of their children? Of course, this is not on account of any lack of love or interest, but because the harm done is not realized. In their desire to please and satisfy, the possible injury is overlooked. Money to spend is given, or large supplies of candy are furnished, without thinking of the consequences. How many children spend almost every penny they get for candies and other sweets! How many older people even will munch candy during an entire evening's entertainment!

Whether it is the best food or whether their bodies need nourishment at all, is not considered. Nothing is thought of but the pleasant taste. Drugs or the doctor are employed to get rid of the dull feeling or headache that may follow the next day. What caused it is often given little thought. We have read enough about body building to know that if the appetite for plain food is continually diminished, enough proteid and fat will not be furnished our bodies to supply the necessary tissues and fuel. Nor do we have to be doctors to understand that we cannot have our greatest possible health and vigor without a liberal supply of these materials. The very cheap candy so largely sold to children is especially bad, as harmful adulterants are often used in its manufacture.

Loss in health and vigor means similar loss in zest for school and play, and greater tendency to pale complexion and decaying teeth. Now let us weigh this 
sugar habit in the scales of common sense, and see if it really pays. On one side we can place, chiefly, the pleasant taste during the few moments it is being eaten. On the other, loss of interest in school, less skill and enjoyment in play, and impairment of disposition and good looks, to say nothing of pennies wasted.

How foolish it is to continue any habit at such a great sacrifice! A few pieces of candy as part of the dessert at meals may add to the body's energy. A little at any entertainment where it is served will do no harm; but let our motto be, Only a little. "Nonsense!" some children may say: "I eat candy whenever I can get it, and who can see that I am any the worse?" In the same way the carpenter might insist on using all the papier-maché he could possibly place in a house. It might be easier and pleasanter to work with, and perhaps look just as well for a time. But he knows if the building is to endure the storms of years, it must be strongly supported with stone and wood. We are building our bodies not for a day but for a lifetime. Food, water, air, exercise, and rest are our materials. Let us daily use them in the way that will make the strongest and most enduring structure.

The Bible tells of a young man by the name of Esau, who, being the oldest son, was entitled to his father's blessing and his great estate. Returning one evening tired and hungry from a day's hunting, he begged his brother Jacob to let him have the mess 
of pottage Jacob had prepared for himself. Jacob, greatly coveting his older brother's right to the father's blessing and property, saw a chance to drive a shrewd bargain. So he offered his pottage in exchange for the birthright, and Esau quickly accepted.

The birthright of almost every child is a healthy body, not for a few years but for a lifetime. Who has not felt pity for Esau because he allowed his greed for pottage to lose him a commanding position and valuable estates? Are we sure we are not giving up our birthright for a mess of pottage? A healthy, vigorous body is a far more valuable possession than the great estate Esau was to receive. Candy and rich desserts are the pottage most likely to lure away our precious inheritance. Let us hope that no readers of this book will be so unwise as Esau.

Another harmful habit is eating between meals. Healthy digestive organs are ready to take care of a reasonable amount of building material furnished them at the three ordinary meals. Like other parts of the body, they cannot work their best all of the time without rest. If compelled to work overtime, they naturally lose tone and vigor. The result is the loss of appetite at regular meals, and a general derangement of health.

If the body really needs nourishment, bread and milk, a sandwich, or even a glass of milk will supply the required strength in a form easy to digest, and will satisfy hunger as well. But we are often 
invited to evening entertainments where an abundance of indigestible food is sure to be served. How can burdening the body at such a time be avoided? Wise body builders can be careful to make the preceding meals very light ones, or be regulated during the evening by the motto, Only a little.

People often make a breakfast of a cup or two of coffee and a few pancakes liberally covered with butter and sirup. Why is this not a good start in the day's body building? The coffee, as we have learned, stimulates, but furnishes no nutriment. The flour in the cakes is in a form difficult for digestion, and so soft that it is usually swallowed without much chewing. The sirup and butter are good foods, but are likely to form altogether too large a proportion of the meal.

Remembering that the aim of wise body builders is to furnish the important materials, proteid, fat, starch, and sugar, at each meal in a form that may be easily digested, why is a lunch of egg or meat sandwiches, a glass of milk and some fruit, far better than one of bread and jam, pickles, pie, and cake? Because the former has a liberal supply of proteid in a form easy to digest. It also contains plenty of starch, and, in addition, some fruit to serve as a healthful stimulus. In the latter, the food is too largely starch, much of it in a form difficult to digest, while neither the jam nor the pickle helps the burden.

Why are broth, baked potatoes, broiled beef, toast, 
and custard better for a person who is not feeling well than coffee, boiled potatoes, fried meat, new bread, and cake? Because broth furnishes both stimulant and nourishment, while coffee only stimulates. Baked potatoes are more easily digested than boiled, and broiled meat than fried meat. Toast is the form of bread that is the easiest to digest, while new bread is the most difficult. Custard, being composed largely of eggs and milk, is both nutritious and easy to digest, while pie and cakes are bulky and more difficult.

In leaving the question of food as building material, we must remember that the kind and quantity best for our bodies depend upon both our state of health and our occupation. One who is strong and vigorous will properly digest more food than one who is delicate. Neither is it necessary for a vigorous person to be as particular about what and how he eats, though the simpler his food and the better his mastication, the longer will his fullest strength be retained. A person leading an active out-of-door life requires more food and digests food more readily than one whose work is indoors. A person doing mental work indoors naturally requires less food, and especially less hearty food, than one doing physical work.

The reason why so many brain workers suffer from indigestion is because they eat sausage, fried meats, pancakes, doughnuts, pie, and cakes, just as if they were living an active, out-of-door life, in which their bodies would need abundant heat and energy. If, 
instead, they aim to furnish only the smaller amount of energy and building material their bodies require in a form that is easily digested, the difficulty soon disappears.

All persons need more food when they are getting abundant fresh air and exercise, because more tissues and fuel are required for building and energy. However, this should not lead us to burden our stomachs with too much food, or with that which is indigestible. Such a practice is just as foolish as it would be to keep overloading a horse because of his apparent strength and willingness. Like the horse, our digestive organs will sooner or later become weakened because of the unnecessary strain.

Whether we are delicate or vigorous, whether our work is outdoors or indoors, we should keep these precepts ever in mind: "Enough is as good as a feast." The simpler our food, the better body-building material it affords. A little seasoning is golden; much seasoning is leaden. Fried foods of all kinds are usually difficult to digest, and should be avoided when possible. Additional minutes of mastication bring additional years of perfect health. An ounce of rest for the digestive organs is worth pounds of drugs and patent medicines.

But must we give up all the good things of life? some may ask, and by "good things" they mean rich foods and stimulating drinks. Suppose we consider what the good things of life really are. When we think 
of it carefully, how does pleasing the taste for a few moments, three or four times a day, really compare with looking our best, doing our best, and being our best all of the time? To look as wholesome and beautiful as is naturally possible; to play or work with our greatest skill and vim; to be in the condition of mind and body that will make us the most thoughtful and kind in our relations with others, and help us to get the fullest enjoyment out of all the good and beautiful things in the world about us; these, certainly, are the good things of life that are best worth having.

That carelessness in eating and drinking greatly lessens the possibilities for enjoyment of all these priceless good things for thousands of people, is a wellknown fact. Many physicians can testify that their busiest time usually follows Sundays and holidays, when many people indulge in the greatest excesses of eating with the least exercise and fresh air. What candid doctor will not say that too much food and drink are the primary causes of much illness and disease? Other things being equal, the health of a family in which the food is plain and not unlimited in quantity, is usually much better than it is in homes where the opposite conditions prevail.

In such families the children are not so likely to be cross and irritable. They study better, eat better, sleep better, and are even better looking, because of the simple living. Such fortunate children are not 
only enjoying the best of good things in childhood, but are also storing up the most valuable bank account for the future, - a sound, healthy, body. Without such capital, all the knowledge gained in school and college may add little to our usefulness or enjoyment. With it we can, all of the time, make the most of our ability to do and to enjoy.

History, as well as our own observation, proves the wholesome effect of simple living. Perhaps one of the most interesting examples is that of the Spartans of ancient Greece. These people settled in a part of Greece where they were largely outnumbered by the native population, and, on this account, were obliged to hold their position by superior strength and skill in arms. Nevertheless, they were supreme in that region for years, and even became the most. famous warriors among all the Greeks. This, historians say, was largely because of their simple living, which was compelled by law. "Black broth," made from vegetables similar to peas and beans, bread, and fruit were among the principal articles of food which their laws required all to eat.

Another interesting example of the good effect of simple living is related in the first chapter of the Book of Daniel in the Bible. The famous king, Nebuchadnezzar, wished to train some young men to become wise counsellors. So he directed one of his chief officers to select several "in whom was no blemish, but well-favored and skilful in all wisdom, and cunning 
in knowledge, and understanding science, and such as had ability in them to stand in the king's palace, and whom they might teach the learning and the tongue of the Chaldeans."

It was also directed that these young men were to be provided for three years with a daily supply of the king's meat and the wine which was used at the king's table. At the end of that period, all were to be brought before Nebuchadnezzar. Among the young men selected were four Hebrews, the chief of whom, Daniel, did not wish to partake of the rich food and drink which the king provided. So he requested that he and his friends might be given pulse (similar to peas and beans) and water instead. But the officer in charge replied: "I fear my lord the king, who hath appointed your meat and drink; for why should he see your faces worse liking than the children which are of your sort? Then shall ye make me endanger my head to the king."

Daniel replied: " $P$ rove thy servants, I beseech thee, ten days. Let them give us pulse to eat and water to drink. Then let our countenances be looked upon before thee, and the countenance of the children that eat of the king's meat; and as thou seest, deal with thy servants.' So he consented to them in this matter, and proved them ten days; and at the end of ten days their countenances appeared fairer and fatter in flesh than all that did eat the portion of the king's meat." When the period of three years 
expired, all were brought before Nebuchadnezzar, as had been commanded. It is related that among the entire number were none like Daniel and his three companions; and also that in matters of wisdom and understanding the king found them ten times better than all others.

It is for boys and girls to see to it that the early formation of habits of simple living helps them to become as handsome, able, and happy as possible. We should remember that possessing the truly good things of life to their fullest extent the longest possible time depends largely on keeping a healthy body; and that, odd as it may seem, the continued health of the body is dependent to a large degree on what and how we eat. Hurrying through our meals to get out to play, hastens the time when we won't care to play. Eating much food just because it pleases the taste, hurries on the years when little or nothing will taste good.

It is not necessary to be as abstemious as were Daniel and his three companions, for fortunately there are now many good foods that can be both simply and appetizingly prepared. Being wise builders, shall we not understand the food we eat, and know that it is going to assist, not hinder, our body's healthful development? If we have not already done so, shall we not start to-day to form food habits that will store up the right health capital for the future? 


\section{CHAPTER XIII}

THE MOST NECESSARY BUT LEAST APPRECIATED MATERIAL USED IN JACK'S HOUSE - PURE AIR

In a previous chapter we read that food, air, and water are the materials with which Jack's Wonderful House builds itself. Of these air is no doubt by far the least appreciated. For instance, when a picnic is planned, how carefully every part of the lunch is looked after, but how rarely the air of the crowded cars or of the place to be visited is even considered. If an evening party or banquet is being arranged, much thought is given to the menu, but provision for an abundance of pure air for each guest is often entirely forgotten.

It is certainly correct to estimate our need of a substance by our dependence on it. Let us compare air and food from this standpoint. Of which do we use the more? The air we breathe weighs many times as much as the food we eat. Which can we do without the longer? Any one can go without food a day or more and not feel any great discomfort, and persons have been known to fast for even thirty or forty days. At the most, one could exist only a few moments 
without air. Which must we have the oftener? Most people eat three times a day. While the number of breaths taken depends largely on how old a person is and whether the body is active or at rest, the average has been estimated at about eighteen a minute, one thousand eighty an hour, or twenty-five thousand nine hundred twenty a day! Resting or working, asleep or awake, a ceaseless tide of this wonderful air is continually pouring in and out of our lungs. As it is the material most needed by our bodies, we should always have an abundance at hand and be sure it is of the very best quality.

But as air is so entirely different from other substances with which we have to deal, how can we in any way regulate it? Is it not an invisible, magical something that performs its work in a good-fairy-like manner, whether we will or not? If we lived out-ofdoors, like Arabs or Gypsies, the air would certainly do its part in building our bodies as well as the very best of good fairies. Many of our hours are spent indoors, however, and so we should learn to keep the indoor air in condition to do its best work for us.

We have found that the building value of foods depends upon the proportion of certain useful components they contain. Strange as it may seem, chemists have discovered that air, too, is made up of several different components. They are agreed that about four-fifths of air is a gas called nitrogen, a little more than one-fifth is another gas called oxygen, 
and less than one-hundredth is watery vapor and carbonic acid gas. Any one who has studied chemistry will remember that water is formed of one part oxygen and two parts of another gas called hydrogen. Nitrogen, oxygen, and carbonic acid gas do not unite to form air, as do hydrogen and oxygen to form water. They simply mix or diffuse, each keeping its own characteristics. As a rule, in the free air out-ofdoors these components will be found mixed in the proportion given above, about four-fifths nitrogen, about one-fifth oxygen, and less than one-hundredth vapor and carbonic acid gas.

We found it useful to learn about the components of food. Let us see whether a knowledge of these mysterious air components is not equally valuable. As oxygen is the most useful of all, we shall get acquainted with it first. Some boys and girls may think oxygen a very difficult acquaintance to make, and may imagine a trip in a balloon or a long journey in a flying machine really necessary to know it. But what a mistaken idea! This remarkable friend is not distant or hard to reach. On the contrary, it is in, about, and all around us. About five-sevenths of our bodies, a little less than one-half of the earth's crust, eight-ninths of the weight of the earth's water, and, as we have already learned, nearly one-fifth of its air are made up of oxygen. While there are many interesting things about this useful element in the air, the most important to know, at present, is that it 
unites with the carbon of various substances to cause the burning or combustion with which all are familiar.

Of course, we know that this burning or combustion is necessary to produce the heat that warms our houses and the steam and energy that run engines and machinery. No boy or girl needs to be told that if the draughts of a stove or furnace are all closed, the fire will in time stop burning. Few are unfamiliar with the fact that if the small holes below the chimney in a lamp burner are covered, the light will go out. That both of these things happen because the air is shut off, is also well known. But that the freedom with which fire burns depends upon the amount of oxygen contained by the air that passes into it, may not be as generally understood. Oxygen in the air is also continually uniting with wood, iron, and other exposed substances, and, though heat is generated, it is not sufficient to produce flame. The rust of the iron and the decay of the wood are the results of the combustion that we see.

Why should we speak of these common, everyday things? Is it possible that our bodies are anything like furnaces or engines? Oddly enough they are very similar; and the tissues of our bodies are the coal and wood with which the oxygen, taken in through the lungs and skin, unites to produce the heat that keeps you and me warm, and the energy that gives us the power of motion. But the union of oxygen with 
the tissues of our bodies does not produce flame as in the stove or furnace, for the combustion is slow and more like that which causes rusting of iron and decay of wood. Without this useful oxygen the Wonderful House that Jack Has would be supplied with neither heat nor energy, and, as a consequence, its destruction would soon follow.

As far as is known, nitrogen passes out of the body without any change, its only apparent use being to dilute the oxygen. This, however, is a very important service. As we shall see later, if oxygen were much stronger than it is in normal air, its union with carbon would take place too fast.

But what about the carbonic acid gas, or carbon dioxid as it is often called? We have found out that less than one-hundredth of the air is watery vapor and this last named gas. Have chemists really discovered how much of the latter there is in pure air? There is such a small amount of it, compared with the whole body of atmosphere, that it does seem almost magical that an accurate estimate could be made. Nevertheless, chemists in various parts of the world agree in the opinion that there is only about one part of carbonic acid gas to every twenty-five hundred parts of air. While this gas is a deadly poison, the very small proportion in pure air has no ill effect when taken into the lungs. The best authorities, however, are agreed that twelve parts of carbonic acid gas to ten thousand of air is the upper limit of safety, and that twenty-two 
parts in ten thousand or about one five-hundredth is dangerous to breathe. Fractions with such large denominators are so difficult to picture mentally that we can scarcely realize how small an amount of carbonic acid gas in our living rooms is dangerous to health. But if we could imagine a room divided into one thousand equal parts, and one of these parts representing that amount, we should see that it is indeed very small.

Carbonic acid gas is so dense that it can be poured from one bottle to another. It is also much heavier than air. This accounts for the fact that in vats, cellars, wells, and mines where large amounts of this gas are generated, it often settles in the bottom, fatally injuring people who accidentally come in contact with it. If a lighted lamp or candle goes out when lowered into such a place, it is a sign that it would be dangerous for human heings. However, under ordinary conditions in out-of-door air, such a thing does not take place, for it is a fixed law of nature that in free air these three gases mix and keep in the proportion, four-fifths nitrogen, about one-fifth oxygen, and one twenty-five-hundredth carbonic acid gas.

In previous chapters we read that carbonic acid gas is produced by fermentation both in bread making and in the manufacture of alcoholic drinks. It is also one of the products of combustion or burning, for when oxygen unites with the carbon of wood or coal, the tissues of our body, or any other fuel, car- 
bonic acid gas is produced as well as heat and energy. Now, as this gas is poisonous, it is just as necessary that the body should get rid of what is produced by the combustion of its tissues as it is that the air breathed should contain no more than its normal amount. How the body supplies every part of its tissues with the life-giving oxygen and at the same time rids itself of the poisonous carbonic acid gas, is a wonderfully interesting story.

But before we begin this story, let us devote a moment to the remaining component of the air, the watery vapor. Although some is always present in normal air, the amount varies with the locality and depends considerably upon temperature, warm air holding a much greater amount than cold air. Any observing boy or girl knows how quickly the air takes up, or evaporates, water. Who has not seen the damp tenniscourt or ball ground soon get into fine condition for play, when the wind was blowing plenty of air over it, even if there was not a single ray of sunshine? This is because the air is like an exceedingly large sponge. Heat expands it and makes it able to hold more water, while cold contracts it, squeezing the water out in the form of rain, dew, frost, or snow.

Let us see how this thirsty habit of air is of wonderful service to our bodies. That our skin contains millions of tiny pores is a well known fact. When we exercise, sweat, or perspiration, comes out of these pores. Now all the time these tiny tubes 
are giving off moisture called insensible perspiration, because it is so small in amount we do not realize that it is passing out, and the air usually takes it up before enough collects to dampen the underclothing. As perspiration contains poisonous substances that the body needs to get rid of, it is important that the air should not be too moist to absorb perspiration readily from the body. One of the reasons we often feel uncomfortable on hot summer days when the air is full of moisture, or humidity, as it is commonly called, is because the perspiration is not readily taken up by the air. On this account, the body is disturbed, for it is not being relieved of all its poisons in the usual way. It is also very important that the air we breathe should not be too dry, for in that condition it takes up moisture that the tissues really need. This can be easily told from the parched condition of our throats when we have been long in a room that is heated by furnace air not containing enough moisture.

We are now ready to begin the interesting story of how air aids our body building by bringing in the necessary oxygen and carrying out the poisonous carbonic acid gas. The first part of this story, the passing of air through the nose and trachea, branching off by way of the bronchial tubes and penetrating into the very remotest air-cells of the lungs, can be noticed at almost every breath. In the illustrations the relative position of the trachea and lungs can be seen. The appearance of the treelike bronchial 
tubes is also nicely shown in the left lung in the figure. From books we can learn that the lungs are pink in color, have thousands of air-cells, and are extremely elastic.

The vital organs of many common animals are very similar to our own. On this account, the best way

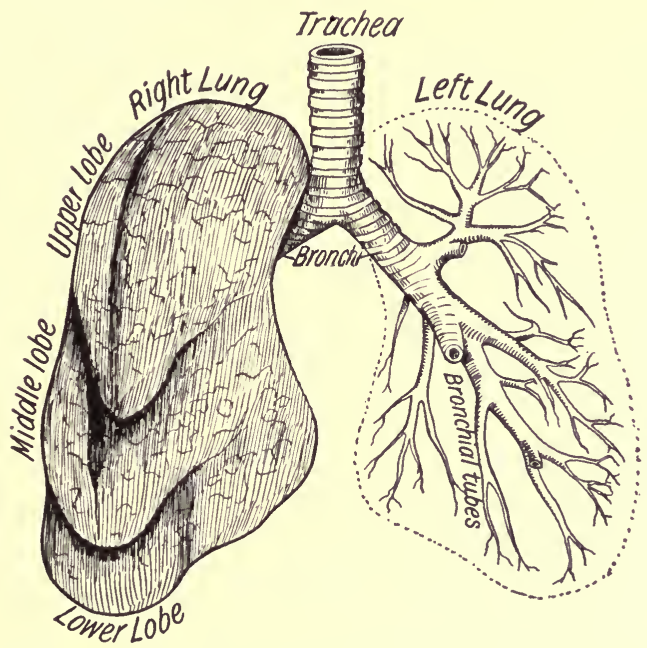

Showing trachea, right lung, and bronchial tubes of left lung.

fully to realize the vast number of air-cells and bloodvessels in our lungs and the remarkable power of expansion these two most useful organs have, is to see the lungs of some animal inflated. Children pay to see many things in museums and other places, but few of these are so curious and interesting as such an experiment. The lightness and elasticity of the lungs are 
truly remarkable. Nor can the arrangement of the cells and the wonderful network of blood-vessels be easily imagined until experiments have been made with a pair of lungs.

The story thus far is not hard to understand, for it is as easy to comprehend how oxygen gets into the lungs as it is to see how air goes through the draughts into a furnace. But how does this useful gas get to the tissues in other parts of our bodies? The answer to this question is so curious that it almost seems to take us into Fairyland. We remember how the villi in the intestines take up the digested food and pass it on to the tiny blood-vessels. In tracing these blood-vessels, we find that they gradually lead into larger and larger tubes which finally join cordlike canals.

By examining further, we discover that these canals, or tiny pipes, extend into every part of the body, but grow larger as they approach and join the heart. Opening some of these pipes, we find they contain bright red blood. Others appear to be of a bluish color and carry darker blood. The former are called arteries, the latter veins. The minute blood-vessels that connect the arteries and veins are called the capillaries.

But what makes the blood run through these tubelike canals? Some of them seem to go straight uphill. We know that when city water runs up a hill higher than its source, there are great pumps that force it to make the ascent. Can it be possible that our 
bodies are equipped in a similar way? This is exactly the case. Situated in the chest between the lungs; and a little below the neck, is a thick muscular organ called the heart. We can tell by the illustration that it is shaped like a pear, and has its small end turned downward and a little to the left. If we were to dissect a sheep's heart, which is formed like our own, we should find that it has two distinct sides, and that each side has two separate chambers. The chambers on the right side are named right auricle and right ventricle, while those on the left side are the left auricle and left ventricle.

If we could see the workings of the heart, we should observe that dark, impure blood

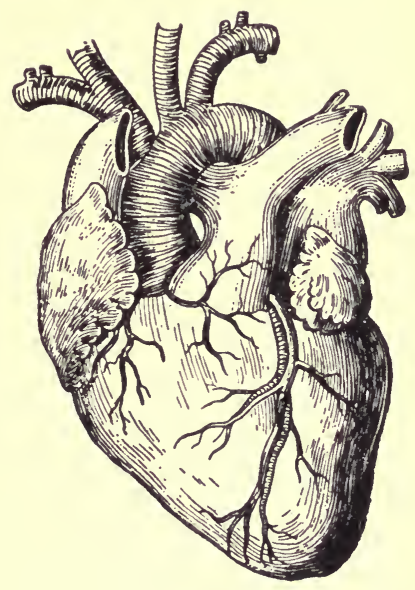

The Heart. pours through two large veins, which come one from above and one from below and lead into the right auricle. As soon as this chamber is full, the contraction of the muscles forces the blood it contains into the right ventricle. This, contracting in turn, drives it through the pulmonary artery and its many branches into the countless blood-vessels that spread all through the membrane of the five or six million air-cells of the lungs. On its journey through these capillaries the 
blood changes from a dark red to a bright red color, finally passing through the large pulmonary veins into the left auricle of the heart. Thence it is forced by contraction into the left ventricle. This chamber then contracts, forcing the blood into a large artery called the aorta, through its numerous branches, to

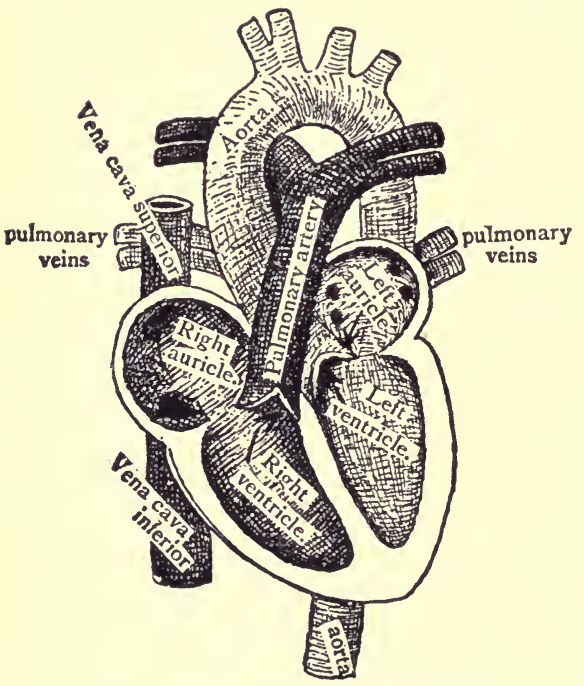

Diagram showing the course of the blood through the heart.

The vessels containing impure blood are drawn running from the pumpdarker than the others. ing stations and along the principal streets correspond to the great arteries that run from the heart. The pipes leading from the streets to the houses suggest the branching arteries, while those which carry the waste water to the sewer and the sewer pipes themselves serve a purpose similar to that 
of the veins, with this difference: the sewer pipes carry the waste and unclean. water away, but the veins conduct the impure blood back to our pumping station, the heart, which sends it to the lungs to be purified. The network of pipes that conduct a city's water supply is, indeed, a remarkable contrivance. Nevertheless, it does not begin to compare in workmanship with the wonderful blood-conducting system of our bodies; for in the latter are many more tubes of different sizes, much more delicately constructed and skillfully put together.

In pumping or forcing the blood, the two auricles contract at the same time, both ventricles contracting together immediately after the auricles. Skillfully constructed valves between the auricles and ventricles and between the ventricles and the tubes leading from them keep the blood from going backward. The passing of the blood through the arteries, capillaries, and veins back to the heart again is called the circulation (the act of traveling around). It is interesting to know that before the fact of the circulation of the blood was made well known to the medical world ‘by Dr. William Harvey of England, in 1618, it was quite generally thought that the arteries carried air. This error arose because they were always found empty immediately after a person's death.

The amount of blood a healthy person has is estimated at about one-thirteenth of his body's weight. The heart of males usually beats about seventy times, 
and that of females eighty times, a minute. The number may be greatly increased by either mental or physical exercise, and is greater in youth and less in old age. The beating of the heart is often spoken of as a pulsation, and the arteries are so elastic that they contract and relax as the blood flows through them. This movement of the walls of the arteries helps to hasten the flow of blood through them. By putting a finger on an artery the heart pulsation, or pulse, as it is usually called, can be felt and counted. The inside of the wrist below the base of the thumb is the place where the pulse is most readily felt. As the muscles are involuntary (that is, work day and night without our willing it), we can see that this wonderful little pump of ours makes about four thousand five hundred contractions an hour and over one hundred thousand a day, to keep the blood traveling on its ceaseless round through the body. The statement that the heart never rests is sometimes made, but this is not true. There is a short pause for rest between the beats.

But why cannot the heart have long periods of complete rest just like other muscles of the body? This question brings us to the second chapter of how the air assists in body building. We know how air gets into the numerous cells of our lungs. We have also seen how the dark blood is forced from the right ventricle of the heart through the pulmonary artery and into the minute capillaries of the lungs. By examining a drop of blood with a microscope, we can 
see that besides a watery substance called plasma, it contains thousands of minute disks commonly named corpuscles. Now, these tiny boats in the blood carry oxygen to the tissues of the body. On their circuit through the capillaries the blood also collects carbonic acid gas and other poisonous matter, which it bears to the lungs.

Now let us consider the marvelous change that takes place here. In the cells of the lungs is the air with its oxygen. In the capillaries, separated from the air only by the most delicate of membranes, is the blood with its freight of carbonic acid gas. The separating membrane is so thin that the law of diffusion of gases still governs. The blood gives up much of its poisonous carbon dioxid through the thin membrane, receiving in return the purifying oxygen, which at once changes its color to a bright red. The oxygen is then rapidly borne by the blood through the pulmonary vein to the left side of the heart. The beating (contracting) of the heart sends it thence through the aorta and its branching arteries to the remotest capillaries of the body.

While passing through these capillaries, the blood deposits its precious freight of oxygen wherever tissues are ready to be burned. It also collects carbonic acid gas where the oxidized tissues have produced it, and comes back to the lungs again to give up its dark cargo of poisonous gases and receive a fresh supply of oxygen in return. The many thousands of air-cells 
in our lungs can hold on the average more than a gallon of air. All the vast membrane-surface of these aircells, penetrated by its net-work of capillaries, would, if spread out flat, cover far more space than the outside surface of the entire body. These facts show us how wisely the Creator has planned for the complete purification of blood in the lungs.

Although the capacity of the lungs is from two hundred fifty to three hundred fifty cubic inches, about two hundred cubic inches usually remain in them. On the average, then, only one-tenth of the entire capacity, or thirty cubic inches (a little less than a pint), is taken in at each ordinary breath, one-fifth of this, or six cubic inches, being oxygen. It is estimated that about one-fifth of this oxygen is given to the blood through the membrane of the air-cells. A little less carbonic acid gas, together with some watery vapor, is thought to be received from the blood and breathed out at every breath. Taking air into the lungs is often called inspiring or inhaling, and forcing the air out, expiring or exhaling. Respiration is the name that includes both acts. When a person's respiration is said to be twenty-five, the meaning is that he breathes both in and out twenty-five times a minute. An exchange of oxygen for carbonic acid gas and watery vapor takes place every time men or other animals breathe.

All animals are exchanging carbonic acid gas for oxygen in this way. Everything out-of-doors con- 
taining carbon is slowly using up oxygen and giving out carbon dioxid in a similar manner. How does it happen, then, that the useful oxygen is not used up, and all animal life destroyed by the poisonous gas that takes its place? Nature has wisely provided against this calamity by having the trees, plants, and all vegetable life in daylight breathe in carbonic acid gas and breathe out oxygen. What a wise provision this is! How interesting to know that in breathing we may help to furnish necessary air material for our friends, the trees! How marvelous is the knowledge that each tender leaf and tiny blade does its humble part toward furnishing the oxygen that helps so much in building our bodies.

The growing lily which brightens the sick room with its fragrance and graceful foliage, cheers the patient by its beauty. At night, however, plants breathe a very small amount of oxygen, and for this reason or because of their fragrance they are usually taken from a sleeping room where the circulation of air is not good. In fact, at any time of day, very fragrant flowers may not be altogether beneficial to one who is ill. It should be remembered that pure air is the important requisite.

But the story of the air's part in body building is so strange. Is it really possible for us to see with our own eyes that combustion goes on readily in oxygen? Can we also find out that carbonic acid gas is a product of combustion, and that neither the tissues 
of our bodies nor other fuel will burn readily in air that contains much of the latter gas? A few simple experiments will plainly prove these facts.

In a previous paragraph we learned that a large amount of oxygen is in the earth's crust. Chlorate of potash and manganese dioxid are two solids that
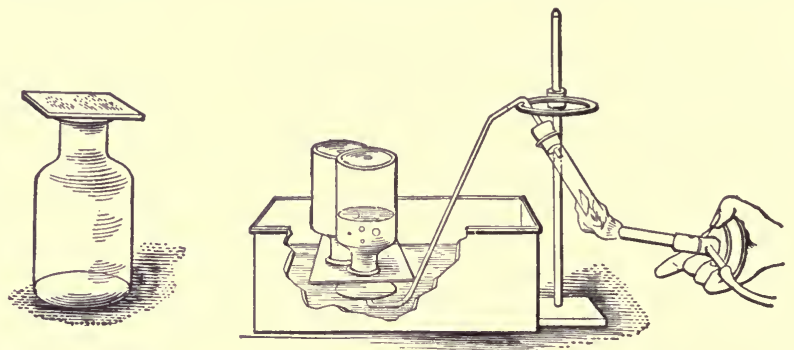

Preparation of oxygen.

contain a great deal of oxygen. Half fill a large testtube with equal parts of these substances, and, using apparatus similar to that shown in the cut, heat the test-tube over a gas-jet or alcohol lamp flame. The oxygen, being set free by the heat, will pass through the connecting tubes and fill the inverted glass bottle. Remove the bottle, being careful not to allow the oxygen to escape. If a lighted candle be lowered into the gas thus collected, it will burn with many times its ordinary brightness. Lower into a jar of oxygen a small piece of coal that has been kindled, and it will blaze up as if it were charcoal. Tie a small splinter of wood to a fine wire, and, after lighting the splinter, lower both quickly into a jar 
of oxygen, and the wire, as well as the splinter, will burn brightly. These experiments show oxygen to be a wonderful supporter of combustion, and prove how fortunate it is that this gas is diluted with a large amount of nitrogen in the air we breathe.

To produce carbonic acid gas, place powdered marble and hydrochloric acid in a test-tube. Without heating, carbonic acid gas will be set free from the marble and will quickly fill a bottle. Put a lighted candle in a bottle of this gas, and the candle will at once go out. If a mouse be placed in a jar of gas made in this way, it will quickly die unless air is let in. Thus we see that carbonic acid gas will not support combustion, and is destructive to animal life.

Pour a half-pint of lime-water into a bottle of pure air or oxygen, shaking briskly, and no change in the appearance of the lime-water will result. Try the same experiment, using lime-water and carbonic acid gas, and the former at once changes to a milky color. This is a sure test for carbonic acid gas, for any unusual amount always turns lime-water a milky color. Let us use this test in a few simple experiments to see what it will tell us of combustion and its products.

If we burn a lighted splinter in a bottle of air or oxygen and then pour in lime-water, the latter becomes milky. This shows that the burning of the splinter must have produced carbonic acid gas. If we breathe through a tube into a bottle of lime-water, the latter becomes milky, and, on this account, we know car- 
bonic acid gas must have been breathed out of our lungs.

If we breathe into a bottle for a short time and then, without allowing other air to get in, place a lighted candle or splinter inside, the light will quickly go out. This is because most of the oxygen has been breathed

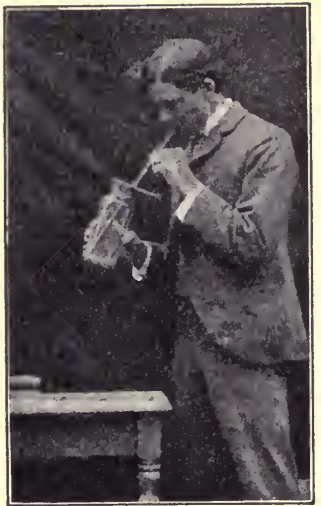

Breathing into a jar through a tube or hollow stem, passed through a card. What happens to a lighted candle inserted into the jar? Explain this.

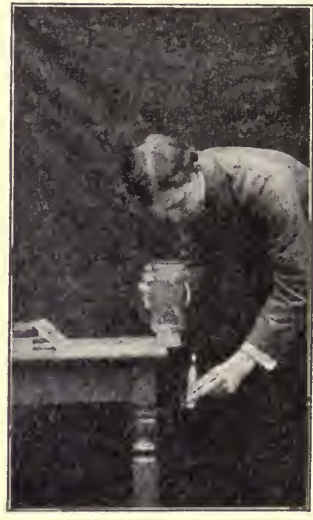

The bottle has been inverted on the table, the card slipped away, and the lighted candle lifted into the bottle to see whether it will still burn.

out, and the carbonic acid gas which has been breathed in will not support combustion. If a mouse or other small animal is placed under a glass receiver where no air can get in, it will begin to show signs of discomfort as soon as its own breathing has considerably increased the carbonic acid gas and decreased the oxygen. Its distress will grow as unrenewed air continues to be breathed. The moment fresh air is 
admitted, it will begin to revive, but if the air is not renewed, it will finally die.

From these simple experiments three facts can be readily seen. The first is that oxygen is needed in the body to burn the waste tissues and generate necessary heat and energy. The second, that the union of oxygen and our bodily tissues produces carbonic acid gas, which must not remain long in the body because it is poisonous. The third, that the body rids itself of much of this poisonous gas by expelling it with the air that is breathed out of the lungs.

It is not a very difficult problem in arithmetic to calculate the mighty task our heart and lungs perform. If, as is estimated, two ounces of blood are sent to the lungs by each contraction of the heart, and there are about seventy heart beats a minute, 201,600 ounces, or about twenty-five hogsheads, of blood are daily driven through the lungs to be purified. Breathing in thirty cubic inches of air at each breath eighteen times a minute, twenty-four hours a day, 777,600 cubic inches, or upwards of fifty-three hogsheads, of air are daily breathed into the lungs.

Are we assisting these hard-working organs in their prodigious task by doing all in our power to have the air we breathe as pure as possible? Certainly few things can count more toward health and happiness than fixing the habit of having the air we breathe as pure as conditions will permit. 


\section{CHAPTER XIV}

HOW TO HAVE THE BEST POSSIBLE VENTILATION

WE live at the bottom of a mass of atmosphere many miles high and so heavy that its pressure is estimated at fifteen pounds to every square inch of surface. Birds fly in the air as readily as fish swim through the deepest water, and we move about in it easily, because the pressure on all sides is equal. Two important laws that insure the right supply of oxygen have already been considered. The first was the law of diffusion of gases so that nitrogen, oxygen, and carbonic acid gas keep at a fixed per cent. The second was the absorbing of carbonic acid gas and the giving out of oxygen by plants. A simple experiment will help us to understand a third law that is also essential to our comfort and health.

If we blow a bladder or toy balloon partly full of air, and, after closing its opening, hold it near a hot fire, the sides will swell out just as if more air had been blown in. This is because heat expands air (makes it fill more space). But if the balloon is blown full of air and then held in a cool place, after its opening has been tightly closed, it will shrink in size, just as if air had been let out. Thus we see cold contracts air 
(makes it occupy less space). Of course, expanded or warm air is lighter than cold air and naturally rises, cooler air rushing in to fill its place. In geography, we learn that differences in altitude, the presence of large bodies of water, such as lakes and oceans, and other conditions continually cause differences in temperature. As a natural result, warm air is almost constantly rising and cooler air crowding in to fill its place, thus causing the numerous air currents and winds.

The greater the difference in temperature, the more rapidly does the exchange of warm and cold air take place. When the air inside the house is about the same in warmth as out-of-door atmosphere, very little exchange of air is noticeable on opening the doors and windows. When the difference between indoor and outside temperature is considerable, however, the currents of air passing in and out are strong. Standing in the doorway, at such a time, we can readily feel warm air passing out toward the top and cold air coming in through the lower part.

Let us see how this important law helps us to get the best material for breathing. The air leaves our lungs at the normal temperature of the body, ninetyeight and six-tenths degrees. As the air breathed out is usually warmer than the atmosphere about us, it naturally rises with its poisonous carbonic acid gas and watery vapor, cooler air rushing in to fill the vacuum caused by its departure. On this account, the 
air in the upper part of an occupied room is likely to be both warmer and less pure than that in the lower part.

We need not, then, be concerned about the air we breathe out, for it quickly rises and becomes mixed with the atmosphere surrounding us. The thing to make sure of is that the air we breathe in is pure. When out-of-doors we may, as a rule, be certain of a pure supply, for the free atmosphere usually insures quick diffusion of the air breathed out. When indoors, we should see that there is an opening for a sufficient amount of pure air to get into a room and another for the impure air to escape. The openings should be so arranged as to keep the air in motion and cause it to be continually changing. By such an arrangement the atmosphere may be kept in good condition for breathing. Replacing the foul air of a room or building with pure air is called ventilation.

But some may say: "I don't see the need of being so particular. Why is it not just as well to keep on breathing the same air over and over? There can't be much difference between the air breathed in and the air breathed out, at least we cannot see any." This is one of the important things we must believe without seeing, for chemists have discovered that the air breathed out contains one-fifth less oxygen, one hundred times more carbonic acid gas, and twice as much watery vapor as the air breathed in. And this watery vapor differs from that of the air inhaled, because the 
breathing organs send along with it many particles of fetid matter which have a noxious smell and may also contain disease germs. Not only does this unclean watery vapor pass from the lungs, but the pores of the skin are also continually giving it out.

When we go into a poorly ventilated room containing a number of people, the disagreeable odor noticed is not carbonic acid gas, though much of it may be present, for that is odorless. It is the smell from the fetid matter in the watery vapor breathed out by the people in the room. If this could be seen, we certainly should take much greater care to have a good circulation of air in dwelling and assembly rooms. It is unquestionably true that facts learned in physiology lessons and emphasized only now and then, through the sense of smell, do not make the same impression as something visible.

People who are too particular to drink from the same cup or glass others have used, often sit in close rooms breathing in foul air that they and others have breathed out, without any thought about its lack of cleanliness or the numerous disease germs it may contain. Without the slightest concern, they breathe in noxious particles of tissue that have been expelled from the breathing organs of others. Any irritation of the throat or lungs, cold, headache, or other disagreeable feeling, naturally resulting from breathing impure air, is usually charged to cold air. An effort may be made to remember when and where they were 
careless enough to sit in a draught. As a matter of fact, if enough windows had been opened to cause a good circulation of air, the breathing supply would have been kept pure and probably illness might not have resulted. Free circulation of air in a room can usually be had without forcing any of its occupants to sit in a draught. The danger from such exposure seems to be very generally understood, but if many people were only half as fearful of breathing unclean air as they are of being in draughts, vigorous health would certainly be much more common.

But if we cannot see the filth in the air, is there any way of telling whether the atmosphere we are in is fit to breathe? Certainly the sense of smell cannot be trusted. The noxious odor is quickly noticed when we first enter a room where the air is impure. However, if we remain in such atmosphere for a time, or have been one of the number present from the beginning, our nostrils gradually become used to the disagreeable odor and cease to give warning of the danger. The best plan is to get into the habit of noticing whether the arrangements for ventilating a room are such as will keep the air pure. How large a room is and whether there are openings for the air to get in and out, can usually be told at a glance.

An artificial light usually consumes several times as much air as each person. An oil lamp vitiates the air of a room much faster than an ordinary gas jet. The burning of a mantle gas-jet makes the air impure 
less quickly than an ordinary jet, and an incandescent electric light is the most hygienic of all. Strange to say, a candle makes the air impure more quickly than any of the lights mentioned. Knowing these facts, if we judge the atmosphere of a room must be getting impure, we should ask to have some windows opened.

Lucky, indeed, shall we be, if some draught-timid person does not object to the open windows before the air has had a chance to purify itself. Surely, where politeness compels us to forego trying to secure proper ventilation, it is justifiable to be excused as soon as possible from remaining in such air. At first thought, this may seem too particular, but do we not really owe it to our bodies to furnish them with fresh air? When we accidentally get into the presence of decaying animal matter that can be seen, we either have it removed or go away ourselves as soon as possible. May not furnishing one's guests foul air to breathe be even more inconsiderate than it would be to serve decayed food to eat? The latter they would easily discover themselves and let alone, with only a few disagreeable moments as a result. The former may go undetected for an entire evening, and cause hours of discomfort afterward.

When officers of schools, churches, and other public buildings realize that one of their most important duties is to see that an abundant supply of clean, pure air is furnished, it will be a great boon for all. It is, 
of course, most essential to have plenty of pure air in the schoolroom, for in it numerous pairs of lungs must be supplied with oxygen five or more hours a day. The vitality of many people may no doubt be lessened by the impure air in churches and other large assembly halls, and troublesome and even dangerous diseases may be contracted as a result. The possibility of serious injury, however, is not nearly as great as in schoolrooms, because the sessions are shorter and much less frequent.

Can it be proved that people have really been injured by breathing impure air? Two often quoted events establish this fact beyond a doubt. In the year 1756, the Nawab of Bengal, having attacked the employees of the East India Company in Calcutta, made prisoners of one hundred forty-six. At eight o'clock in the evening these prisoners were confined in a room twenty feet square, having two small windows. Soon their sufferings began to be terrible. They fought for places near the windows, trampled one another under foot, and even begged the guards to shoot. At two o'clock in the morning but fifty were living, and at daybreak, only twenty-three. Ever since that terrible night this dungeon has been known as "The Black Hole of Calcutta." As there were two windows, a few persons might have survived, even in that hot climate, but the supply of air was far too small for the number of prisoners confined.

Some years ago the steamer Londonderry, which 
had set out from Liverpool, was overtaken by a great storm. On this account, one hundred fifty steerage passengers were compelled to go into a room below the deck, and, to keep the water out, the cover to the entrance was nailed down. This unwise precaution also kept the air from getting in. "The wretched passengers were now compelled to breathe over and over again the same air. There occurred a horrible scene of frenzy and violence, amid the groans of the dying and the curses of the more robust. Finally, one of the sufferers managed to force his way on deck and alarm the mate, who was called to a fearful spectacle. Seventy-two were already dead and many were dying." All this occurred within six hours.

While other similar examples might be given, such fatal results of rebreathing the air breathed out are infrequent, because it is not usual for a large number of persons to be in such a small space. Besides, few rooms are built so tight that, in our climate, more or less exchange of air does not take place through various openings. These incidents do, however, vividly emphasize this fact: the air breathed out from our lungs will become harmful to rebreathe unless the room we are in is well supplied with pure air.

It has been estimated that three persons in a tight room fifteen feet long, twelve feet wide, and nine feet high will vitiate the air in a little more than two hours. If lights are burning, the air will be made unfit for breathing much more quickly. Twelve persons in 
a room sixteen feet long, twenty feet wide, and nine feet high make the atmosphere impure in an hour, provided there is no ventilation. Two persons sleeping in a closed bedroom ten feet long, ten feet wide, and eight feet high, make the air unfit for respiration in less than two hours. During this short period several ounces of watery vapor containing noxious waste particles of matter have been given off from the lungs and skin. If a third person should come from pure atmosphere into such a room, the odor would be almost unbearable. The sleepers' noses, however, having become accustomed to it gradually, do not warn them of the dangerous and disgusting air they are breathing.

We know people are often in close rooms several hours at a time without meeting any quickly fatal results. What, then, is the harm? Impure air dulls the senses, and also makes one physically restless and uneasy. Often when pupils are stupid and inattentive in school, the air, not the lack of brains or desire to learn, is to blame. There is no better aid to successful teaching or preaching than plenty of pure, fresh air. Wise, indeed, are the teachers and preachers who realize this fact. When the normal supply of oxygen is reduced in the air we breathe, too much carbonic acid gas and waste tissue are retained in the blood; and on this account all the organs and functions of the body are impaired, for the time being at least. When the use of such air is frequent, the vigor and 
tone of the body are naturally lessened. In such condition the numerous disease germs that infest the air are offered a good opportunity to give us colds, catarrh, tuberculosis, and many other chronic diseases.

What can we do to avoid such unpleasant results? Form the habit of having the air of rooms in which we spend our time as nearly like out-ofdoor atmosphere as possible. In summer this should be done by opening doors and windows. But even in warm weather some people keep both closed, because so much dust enters.

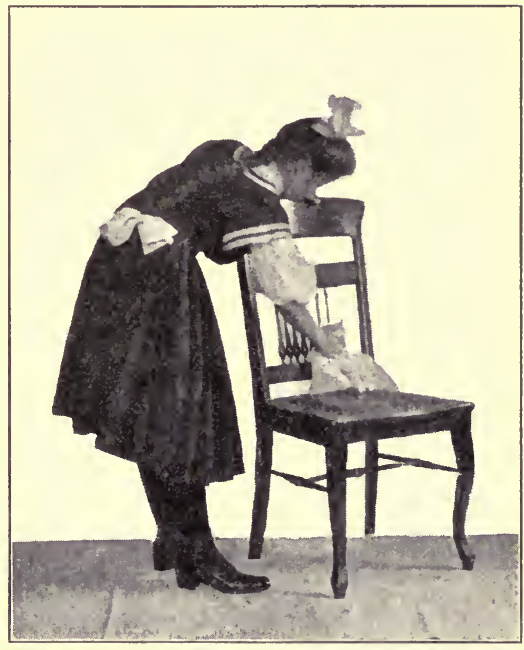

Girl dusting with a cloth moistened in liquid veneer or some similar preparation.

How unwise such a practice is! A few moments' use of a moist cloth will remove the dust, but how to make up for the vigor lost by rebreathing the breathed-out air is difficult to tell. Many persons try to do this by taking various medicines. This is, at the best, an expensive and most unsatisfactory plan. For Nature's remedies, fresh air, wholesome food, pure water, and judicious exercise, medicines are, indeed, poor substitutes. 
While sleeping, all can have the air as nearly like the out-of-door atmosphere as open windows can make it. We cannot have such air during daytime in cold weather, because artificial heat must keep the temperature warm enough for comfortable work while sitting. At night, however, with the bedclothes to keep us warm, the precious privilege of breathing the cool bracing air from outside may be ours.

Persons afflicted with the dread "White Plague," consumption, who have gone to mountain resorts to recover health, have found that the most important factors in their treatment have been abundance of pure air and nourishing food. When too weak to do much walking, such patients sit out-of-doors all day, protected from storms by verandas. This practice is followed in cold weather as well as in summer, fur coats, steamer rugs, and hot soapstones being used to help them keep warm without exercise. At night the windows are left open, summer and winter, for plentiful bed clothing and, when necessary, a hotwater bag at the feet, keep the patient warm.

Occasionally patients reach such resorts so weak that they have to be carried from their rooms to the veranda. Nevertheless, they soon become gradually accustomed to the out-of-door treatment and thrive on it. The lives of hundreds of people afflicted with this terrible disease have been saved in such resorts by the use of abundant pure air and nutritious food. Hundreds of others who have been unable to remain 
until health was fully restored, have returned to their homes and got completely well there. The enforced stay in the mountains taught them the great value of pure out-of-door air, and they made practical use of this knowledge after coming back to the duties of home and business life.

If such persons had learned fully to appreciate the great value of pure, cold air, years before, the unhappy experience of leaving business and friends for such a long period might have been easily avoided. While we hear more about out-of-door treatment in connection with consumption than with other diseases, there is no doubt about pure air being most helpful in aiding the body to get rid of any illness. The practice of having every door and window shut so as to keep air from patients ill with colds or other diseases, is most unwise. Through such precautions, the very best curative which an all-wise Creator has furnished is kept from doing its benign work.

It is needless to say that if out-of-door air works such wonders for sick people, all should have it abundantly from babyhood to old age. That neglecting to make free use of this "life-giving air from on high" until failing health or dread disease compels it, is most unwise, also goes without saying. The oxygen that helps to give the merry skater rosy cheeks, sparkling eyes, and active grace is just outside our windows on frosty nights. Why do we let it in so sparingly? Often because a warm room is wanted to dress in next 
morning. If we stop coddling ourselves in this respect and let the useful oxygen have a chance to do its marvelous part in our building during sleeping hours, we shall certainly form one of the most beneficial health habits. Every boy and girl who wants to be as strong and good-looking as possible should sleep with open windows.

How noticeably healthy and rugged are the sailors, farmers, omnibus drivers, and others whose work is outof-doors. It is a well-known fact that persons who follow such vocations, and are not addicted to the use of alcoholic drinks, usually enjoy perfect health. All, of course, cannot engage in out-of-door occupations, but, by becoming used to cold air and insisting that the supply be as pure as possible, indoor workers may enjoy much more of the same rugged health.

It is a promising sign that the benefits of out-ofdoor air are becoming more generally appreciated. The ventilation of buildings has been much improved in recent years. Hospitals adapted for out-of-door treatment have been established in several states. Occasionally we hear of people who are sleeping in cots on their verandas. In cities, the practice" of letting babies, warmly wrapped, take their naps in their carriages on the veranda or near a wide-open window, is daily growing. The good results attending all of such practices will surely extend them.

What can we do to make the air of our homes, offices, and workshops as pure as possible? When 
the heat comes from a furnace, we can be careful to see that the air supply is taken from outdoors through a cold-air box and not from the cellar. This is a good plan, because cellar air is likely to be impure, and, at the best, is not equal to the outdoor atmosphere. If our rooms are heated by stoves, there should be sufficient draught to carry off poisonous gases, and care should be taken that there are no leaking places. Coal gas forms in large quantities when coal is first put on a fire. For this reason, the drafts should be previously so arranged that the gas will go up the chimney and not get into the atmosphere of the living rooms. This gas is very harmful, because the blood takes it up from the lungs far more readily than it does oxygen.

A gas stove that does not require pipe is sold, the claim being made by some dealers that it does not vitiate the air. This claim is not true. Oxygen is used up in the burning, and carbonic acid gas results from it just as in any other combustion. Unless there is very free ventilation, such a stove is sure to make the air unfit for breathing.

It should be possible to lower windows from the top as well as to raise them from the bottom. Great care should be taken to have the transoms of school rooms open. If a few of the small ventilating windows along the upper part of street cars are kept open, there is a chance for both a free circulation of the atmosphere and the escape of the impure air from 
these commonly used vehicles. A device like the one below is good in cold weather to help in ventilating a room. The board holding up the lower sash allows air to come in between the sashes in

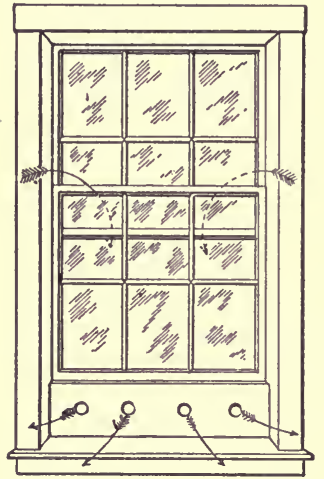

Ventilating in cold weather, keeping the lower sash of a window raised by a board.

such a way that injurious draughts will not be caused. One of the very best helps in securing good ventilation is a fireplace. The fire heats the air in the chimney, causing it to rise. The air of the room naturally crowds in to take its place, and so, if there is sufficient chance for pure air to get into the room, the atmosphere may be kept in excellent condition for breathing.

Of course, at the best, indoor air is a poor substitute for the free air outside. For this reason, every one should be out-of-doors as much as possible, earnestly aiming to become hardened to wind and weather. How many people in waiting for a car or train stay in a crowded station, breathing air fairly reeking with waste particles of tissue and microbes, just because the outdoor air is a little cold. Walking up and down while taking in deep breaths of the frosty air would give the glow of natural warmth, together with a healthful toning up of the nervous system. These, no doubt, would be followed by keener relish of the evening meal and 
sounder and more restful sleep. Perhaps, if such benefits were considered, this lack of hardihood would be less common.

Many people eagerly spy their own ailments among the thousand and one ills a new patent medicine is advertised to cure, and do not delay giving it a trial.

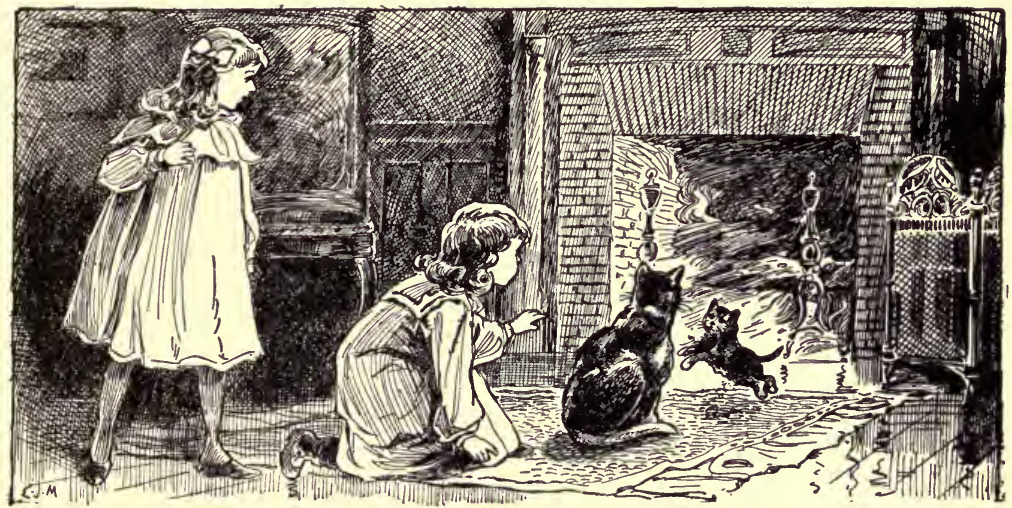

A fireplace helps in ventilating a room.

If they hear of some person who knows some one else who has a friend that has been cured by a new kind of healer, they cannot rest until this person has exercised his science or healing touch on them. But God's wonderful air, which can be had without money and without price, they shun as if it were a deadly poison.

Do we wish to belong to the fortunate class who have no need for patent medicines or other remedies? Would we be among those who thoroughly enjoy both 
work and play, and whose clear brains and ready muscles are able to meet the demands made upon them without nervousness or undue fatigue? Then let us improve every opportunity of being out-of-doors. In summer we can read on the veranda rather than in the house, and take the open car instead of the closed, when riding is necessary. At any season we can walk whatever distance time and strength will permit, to avoid breathing the close air of a crowded car. In fact, whenever we have a choice of being in or out of doors, we can always let our preference be for the free, bracing air outside.

When we are in places where the air must necessarily - be close, we should avail ourselves of an opportunity to get a few breaths of fresh air as eagerly as we should get a drink of cold water when thirsty. For instance, on a railroad trip, when it is impossible to have the car windows open, we can go to the platform at the stopping places and fill our lungs with the oxygen-laden air from outside. The car sickness and dull feeling that often attend such journeys might thus be greatly lessened. Whether in school, in church, at home, or in business, let us use our influence for a pure air supply, and be just as eager for it as if it were some high-priced elixir. Of this we may be sure: there is no elixir that begins to equal the pure air of heaven. 


\section{CHAPTER XV}

OTHER IMPORTANT FACTS ABOUT AIR

So much is said about the difference between city and country air, that we might think the latter has much less carbonic acid gas and far more oxygen than the former. Sea and mountain air have been found to contain more of a bracing form of oxygen called ozone than have other regions. The atmosphere is so vast, however, and its movements are so far-reaching that the law of diffusion usually keeps the percentage of the important elements in outdoor air very nearly normal. Yet there is a great difference in cleanliness between air in the city and air in the country. The amount of smoke and dust is far greater in city air. It also naturally follows that where so many people live, much more decaying animal and vegetable matter and other waste materials are present to give off their noxious gases.

Another important difference is the far greater percentage of bacteria or microbes in city air. In previous chapters we have learned of these little organisms as destroyers of food, but there are many different kinds. It has been found that some cause various diseases with which our bodies can become 
afflicted, and that such germs are numerous in dust and dirt. Certain harmful kinds keep alive in damp, unclean parts of a house or yard. If there were no other, this alone would be sufficient reason for keeping every part of our homes and premises thoroughly clean.

In selecting a site for a house, high, well-drained land should be chosen rather than that which is low and holds water. Soil which is sandy and soaks up rain quickly should be preferred to that which is moist and difficult for the water to soak into. Localities near cemeteries should be avoided, especially if the drinking water comes from a well or spring in such a neighborhood. Care should also be taken not to build houses near marshes or stagnant water. If a house is situated in a damp place, the land should be thoroughly drained.

Sunshine is one of the most helpful partners of pure air in building our bodies. We know how a plant that has almost died in a shady part of the yard will grow and thrive when transplanted to a sunny corner. This glorious sunshine will effect just as magical results in our building, if we only let it. Often there is nothing more beneficial to our bodies than to be out in its health-giving rays. One of the great benefits it performs is to make microbes harmless, and, for this reason, it is most essential to have our homes let in abundant sunshine as well as fresh air. If trees and shrubbery keep too much sun- 
shine away, they should be removed. The fact that they are beautiful and add to the fine appearance of the house should not save them. Healthfulness of the home is the first consideration, and even beautiful foliage should be sacrificed, if its presence makes the indoor atmosphere damp and unwholesome.

By examining the air of different schoolrooms, it has been found that microbes are not nearly as numerous in well ventilated buildings as in those of opposite character. A carpeted room which has been recently swept and dusted has been discovered to have more germs in its air than were present before the sweeping. Therefore there is an advantage in having varnished or painted floors, covered with rugs instead of carpets. The rugs may be cleaned out-of-doors, while the damp cloths used to wipe up the dust from the floors and furniture may be washed in hot water, thus destroying the germs, or at least removing them from the room. Dusting should always be done with a cloth moistened in liquid veneer or some similar preparation, when it can be done without injury to polished surfaces, for then the atmosphere may be kept free from the dust and germs which are stirred up by a dry cloth or duster.

Pains should also be taken not to let the temperature of an artificially heated room rise above seventy degrees, and a few degrees lower is even better if it does not cause discomfort. In Great Britain the temperature of schoolrooms in cold weather is com- 
monly kept from fifty to sixty degrees. Recently five hundred British teachers visited the schools of the United States, and our buildings seemed uncomfortably hot to them. One of the things some of them commented unfavorably on was the pale, unhealthy appearance of many of our school children. This, they thought, might be due to the unnecessarily warm atmosphere of the schoolrooms. Many good authorities in our own country are of the opinion that, as a general thing, an indoor temperature of sixty-five degrees is more suitable than seventy, especially in schools and other public places. As the temperature of the room rises above seventy degrees, the occupants become less active mentally and more inclined to be nervous. In this condition it is, of course, not possible to do the best work.

Remaining for some time in too warm a temperature also gets one in just the condition to take cold easily upon going into the cold air out-of-doors. It is doubtless more important to form an early acquaintance with a thermometer than with a clock. Every living or working room should contain one, and it should be consulted even more often than the familiar friend that faithfully ticks the seconds away. In schoolrooms watchfulness of temperature is especially important. If the temperature of schoolrooms had always been kept at seventy degrees or below, many cases of colds, headache, and more serious diseases would probably have been avoided. Numerous in- 
stances of disobedience and inattention might also have been prevented.

When we come from out-of-doors into a room where the temperature is too high, the uncomfortable state of the air is readily noticed. The occupants of the room, however, having gradually become accustomed to the warm atmosphere, are not aware of its condition. It would be a fine thing to equip schoolrooms and other assembling places with alarm thermometers. If such a thermometer would give notice of the harmful condition of the air so vigorously that immediate attention would be given to cooling it, much benefit might result.

Some people have an idea that if the air of a room is cold, it must necessarily be fit for breathing. For this reason, no windows are opened in their unheated sleeping rooms in cold weather. While some air will come through walls and windows when

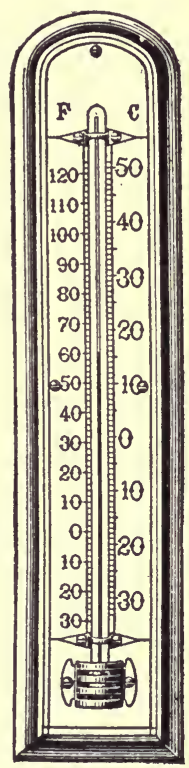

A

Thermometer. the atmosphere outside is cold enough to have good ventilation, there should be some openings through which the breathed-out air may escape and the pure air come in freely. We should remember that to have our breathing supply pure, a free circulation of air is necessary, and should arrange for it intelligently in both winter and summer.

Any one can easily be convinced of the truth of this 
statement by passing from pure air into a closed cold room in which people have been sleeping all night. The lifeless, bad-smelling air observed is the best possible argument. There is, however, foundation for the prejudice some people have against night air, especially in localities where the ground is moist. In daytime the numerous germs that breed in such ground are destroyed by the sunlight, but at night they may be present in the lower strata of air. On this account, it is usually more healthful to sleep on the upper floors of a house than on the first floor. The lower air naturally contains more dust, and for this reason is less desirable.

As has been said in previous chapters, care must be taken not to let the atmosphere of a room get too dry, for then it will take up from our bodies moisture that the tissues really need. A dry or parched feeling in the nose or throat is usually a warning that the air we are breathing needs more moisture. In caring for a furnace the water box should be filled just as regularly as coal is supplied. If this does not moisten the air sufficiently, a small basin of water may be kept before the registers of the rooms that are much occupied. An open dish of water on either a coal or a gas stove improves the quality of the breathing supply, as the air takes up some of the water.

What boys and girls cannot tell how they like the bread and eggs, the potatoes and beefsteak, that are served for breakfast or dinner? As to whether these 
shall be well or under done, seasoned little or much, each has a definite choice. Surely the left-over scraps from a former meal would not please many, unless they were prepared again in an appetizing and wholesome manner. We certainly ought to be even more particular about our air supply. Surely we should not take into our bodies air that we or others have breathed out, if it has not had a chance to purify itself by mixing with pure free air. There is good reason for being more particular about taxing our breathing organs and blood with air that is too warm than about burning our mouths with food that is too hot. Nor can any one deny that we should be as careful about breathing air with insufficient moisture as we are about eating food that is too dry.

Unfortunately our senses do not warn us of bad air conditions as readily as they do of the unsatisfactory state of our food. Safety from injurious effects of unfit air lies chiefly in the early forming of correct ideas and habits concerning this precious material. Whether our lives shall be blessed with long-continued health, strength, activity, and happiness depends largely upon the formation of such ideas and habits now.

Have we been careless in regard to this most beneficial gift of the Creator? Then we cannot start too soon to have the air we breathe clean and pure, without too much heat or insufficient moisture. Have we been spending needless time indoors? Then we 
should make it a point to be in the out-of-door air as much as we can, and, when indoors, try to have the air we breathe as near like the outdoor atmosphere as possible. Do we realize the great value of being able fully to enjoy both play and work? Do we know the deep pleasure of always being and looking our best? If so, we shall in the future let pure air have the best possible opportunity for helping our bodies attain their greatest strength and beauty. 


\section{CHAPTER XVI}

\section{BREATHING HABITS}

To breathe was the first thing each of us did on coming into the world, and we have kept on breathing ever since. Surely this is one thing that all must have done exactly right! Strange as it may seem, there are different ways of breathing, some of which are much better than others. It is also true that if any person is using one of the less effective methods, he can without doubt become healthier and stronger, both physically and mentally, by forming a better habit. Before considering the different ways of breathing, it will be well to notice the position of the lungs in the House that Jack Has. We want also to observe how well they are protected and how skillful is the arrangement by which they are easily supplied with the health-giving air.

On page 144 is shown the chest cavity, or thorax, in which the lungs are found. We notice that the thorax is a cone-shaped box with the small end at the top, ard that the outside of this box is formed by the ribs, backbone, or spinal column, and breastbone, or sternum. The twelve pairs of ribs are joined 
to the backbone, but only the upper seven are joined to the sternum. The first seven pairs on this account are called true ribs. The eighth, ninth, and tenth pairs are joined each to the one above and are

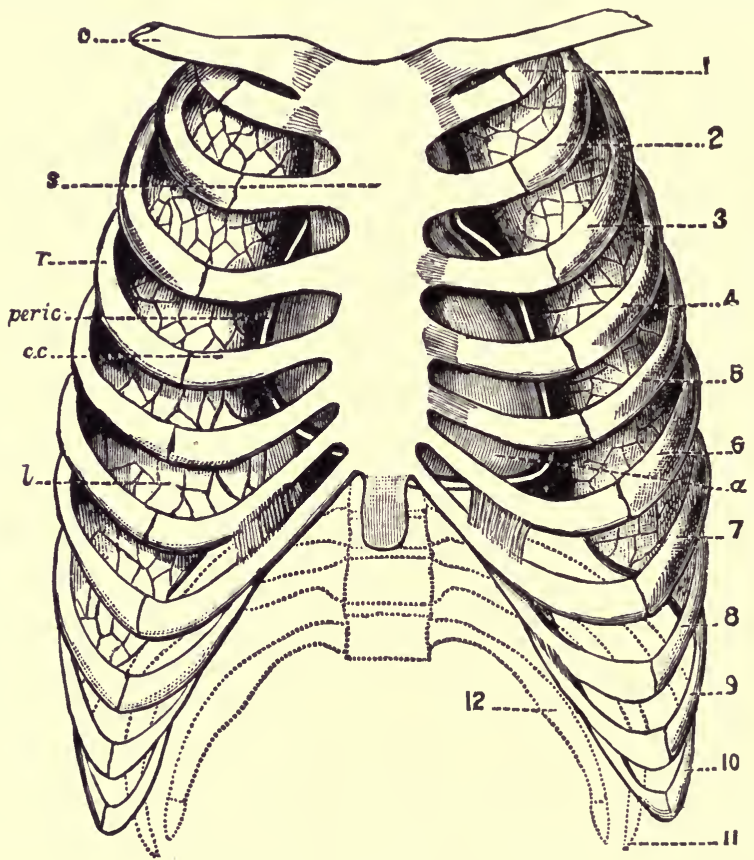

The Thorax, showing Lungs and Heart.

called false ribs. The eleventh and twelfth are not fastened at all in front, and hence are named floating ribs.

On page 145 is shown the position of the strong muscle called the diaphragm. The latter separates the chest from the abdomen. A semielastic substance 
called cartilage lies between the ends of the ribs and the backbone and between each false rib and the one above it. Between the ribs are the intercostal muscles. We can also observe that the ribs slope slightly downward from the backbone to the point where they are attached in front, and that the diaphragm, which is a very elastic muscle, is somewhat the shape of an open umbrella. Its top or convex side is toward the chest, reaching upward to about the fifth rib, and its under

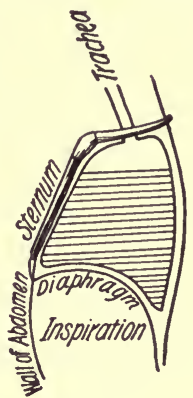

$a$

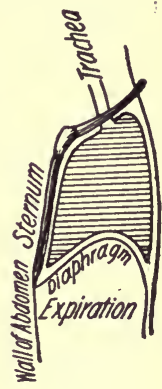

$b$

or concave side is toward Showing positions of the diathe abdomen.

Curiously enough, it is phragm, sternum, and walls of the abdomen in inspiration and expiration (Zuppke).

the sloping position of these ribs and the umbrella shape of the elastic diaphragm that enable our bodies to be easily supplied with air. The position of the ribs and diaphragm, as seen in the cut, is as they appear just after the air is breathed out. When we breathe in, the intercostal muscles draw the front of the ribs upward and the diaphragm goes downward, becoming less convex. This pushes the lower ribs outward and crowds the abdominal organs down, both movements naturally enlarging the chest cavity, thus enabling the elastic lungs to expand, so that air rushes in to fill the space. 
Now, as to the different kinds of breathing, all will agree that the one which causes us to take in the greatest amount of air with the least possible effort must be the best. Of the common habits, the one known as "high chest breathing" is the poorest. This is done by raising the collar-bone and shoulders in such a way as to elevate the upper ribs. This method is bad, because it calls for too difficult exertion and fills only the upper and smaller part of the lungs. People who have this habit are compelled to breathe very frequently to supply the air the body must have to keep in good health. The unused parts naturally become subject to disease, and shortened life results.

"Costal breathing" is the term applied when the chest cavity is enlarged by raising the ribs with the intercostal muscles. When the space for the lungs to expand is made by pushing the apex of the diaphragm downward, the breathing is said to be diaphragmatic. This is, no doubt, the easiest and best of these methods. It is, however, far better to get into the habit of forcing the diaphragm downwards and using the intercostal muscles at the same time. When the diaphragm alone is used, the upper parts of the lungs are not filled with air, and, on this account, may more readily become diseased.

When the diaphragm goes down so that we feel a good strong pressure on the organs of the abdomen, and the intercostal muscles move sufficiently to make plain the fact that new air is refreshing the upper regions 
of the lungs, we may feel well satisfied with our habit of breathing. Such a method is most excellent, not only on account of the ease with which a large amount of air is furnished to the lungs, but also because the downward pressure aids the muscles of the food canal in performing their work and stimulates the circulation of blood throughout all organs of the abdomen.

There is no greater health talisman than the rhythmic downward and upward movement of the diaphragm in our ordinary breathing. If we can feel the alternate crowding down and return to position of our abdominal organs along with this movement of the diaphragm, our breathing habit is correct. We may also be sure that we are filling our lungs and keeping the surface of the air-cells active and healthy. If, as we breathe, we cannot feel this regular rhythmic movement of the diaphragm and abdominal organs, we are not filling our lungs, nor are we furnishing our bodies with the greatest possible supply of air with the least possible effort. Children are born with this rhythmic breathing habit. They grow out of it largely through getting into bad sitting and standing positions, and through wearing clothing which is tight about the waist and abdomen. The foolishness of wearing such clothing can now be easily seen. It crowds the important organs of the abdomen and prevents the breathing muscles from doing their best work. Such clothing also keeps the digestive organs from getting the assistance that the full downward pressure of the diaphragm 
on the abdomen would naturally give them. While children's clothing is usually loose about the waist, it is often too tight about the upper portion of the chest. This is very harmful, and great care should be taken to prevent it.

Boys and girls are taught many useful things. Nevertheless, it is safe to say that if teachers and parents regarded the habit of deep diaphragmatic breathing as the most important lesson for children to learn and were watchful that neither improper position nor tight clothing should deprive them of this great boon, health and happiness would be far more common. Much is made at home of the hundred per cent and other excellent marks in their studies that children's school report cards show. If this card also recorded gain or loss in sitting or standing position, or in rhythmic diaphragmatic breathing, and even half as much attention were given to this information at home as is given to the standing in studies, what an excellent effect it might have on children's future enjoyment and usefulness.

For children just starting life's battle, it is most important to form the very best breathing habits. Furnishing abundance of fresh air to our bodies will be of the greatest help in producing pure blood, good digestion, health, strength, and all the happiness that the possession of these good things bring. Much is said in books and health circulars about guarding against disease germs. It is, indeed, wise to take such pre- 
cautions. But by far the best preventive against all diseases is the deep-breathing habit. In spite of our greatest care, disease germs may be in the air we breathe. Healthy tissues and bodily vigor are the best armor against harm from these germs. The largest possible supply of pure air in our regular breathing is the best aid to health and vigor:

The following statements are taken from an article on deep breathing in the New York Medical Journal of September 8, 1906. The article is by Dr. John H. Pryor of Buffalo, who was the first superintendent of the New York State Hospital for Incipient Tuberculosis, and who, for many years, has had wide experience in treating diseases of the breathing organs. "Very frequently breathing becomes a partial or incomplete function after childhood. Enough air is admitted to the lungs to support life in a sedentary way, but thorough ventilation becomes a rare experience.... Many women have never learned how to breathe, and the man who has given up vigorous exercise seldom fills his lungs to their full capacity. .. . The average chest expansion of all patients when they entered the New York State Hospital for Incipient Tuberculosis was two inches, and the breathing capacity was almost invariably below the standard usually required. The almost universal testimony of the patients was that they had never been taught to breathe."

Are we filling just the small upper part of our lungs by laborious chest breathing? Are we getting only 
one-half or two-thirds of the pure air we might have, because our habit of supplying our lungs is to give only a slight downward pressure to the diaphragm, or a little raising of the ribs by the intercostal muscles? Then we have surely been deprived of our rightful share of air long enough, and in a business-like way we should set about getting the largest supply with the least cost of effort. "But how can we do this?" some may ask. "Isn't breathing one of the habits born with us that our wills cannot regulate?" Certainly not! Girls and boys can form correct breathing habits if they persevere in trying to do so, and mature people can greatly improve theirs. But before we consider how this may be done, let us first give attention to one more essential breathing habit, - the importance of taking air through the nose.

The long narrow passages of the nose were designed both to strain and to warm the air. The dust particles not stopped by the numerous little hairs near the opening of the nose are arrested by the moist mucous membrane of the passages and expelled with its secretion, whenever the use of the handkerchief is required. This membrane also arrests germs, and it is likewise thought that its secretion tends to render them harmless. That one can endure breathing impure air through the nose much longer than through the mouth is a well-established fact. When people have been in the presence of some deadly fumes, those who breathed through the mouth were fatally injured, while others, 
who made use only of the nostrils, escaped with comparatively little harm. The nose certainly can make poison-laden air less harmful, and the very best air is better fitted for its work after passing through these useful passages.

The inside of the nose having the normal temperature of the body, ninety-eight and six-tenths degrees, properly warms the cold air in its journey to the delicate lung tissue. The mucous lining of the nose may also take up some vapor from air that is too moist. How skillfully the nose is constructed to be the highway of the air to the trachea and lungs, and how strange it is that so many people neglect to make use of this air-warming and cleaning contrivance of nature! Why is it not just as well to breathe through the mouth? Because the air goes in so rapidly that it is neither properly warmẽd nor freed from dust. Consequently irritation of the mucous membrane and other difficulties of the bronchial tubes result.

That the shape, size, and extent of the nose passages design them for properly préparing the air we breathe for the lungs, is just as evident as that the teeth were placed in the mouth to prepare the food we eat for the stomach. How ridiculous it would seem to see any one snuffing up food through his nose! Yet, except at times of most violent exertion, when enough air cannot reach the lungs through the nose channel, the mouth was no more intended as an air passage than the nose was designed as a passageway for food. 
But surely it cannot be harmful to breathe through the mouth when the air is not cold and we cannot see any dust in it. On the contrary, such a practice can do much harm. In the first place, although the air looks clean, it is scarcely ever free from dust. In the second place, the slight amount of resistance offered while breathing through the nose helps to keep the chest properly developed, while in mouth breathers the air gets in so easily that the chest muscles have little to do and flat chests consequently result. Then, even if no injury should result from putting the mouth to a use for which it was not intended, harm is likely to come from not using the nose as the highway for which it was made. We know that when a path or road remains unused, grass and weeds will grow up in it. So when the natural roadways of the air to the trachea, the nose passages, are not made use of, weeds in the form of polypi and other growths may spring up in the mucous membrane. These block the unused passages, and, in the worst cases, even cause deafness.

Growths called adenoids are very common in children. They plug both nostrils, causing all the evils of mouth breathing and often greatly lowering the general health. If large enough to be obstructive, they should be removed by a physician, for no child having them can thrive. Adenoids are among the most common causes of mouth breathing.

The mouth-breathing habit, whether it results from adenoids or some other cause, not only may weaken 
the senses of hearing and smelling, but also often causes foul breath and impairs the beauty of the countenance by giving the mouth and teeth a distorted appearance. Many persons seen in classrooms or audiences with mouth open and an unbecoming, half-vacant stare are naturally neither less intelligent nor less pleasing than others; unfortunately they are deformed both in understanding and in appearance by the habit of mouth breathing. Inability to use the nose necessarily causes the mouth to be held open. The deafness resulting from the adenoids or other causes naturally makes them unable to understand readily. Such persons are often given up as hopelessly stupid and uninteresting, when they might become active in mind and pleasing in appearance.

How can such a desirable transformation be brought about? By having a skillful doctor remove the adenoids or other obstruction and by seeing to it thereafter that the air is taken in through its proper channel. Even if it happen that only one of the passages is stopped up, the obstruction should be removed without delay, for none of us can afford to be without our full equipment for obtaining pure air.

The stoppage of one nostril often exists for a long time without a person's being aware of the fact. On this account, it is a good plan occasionally to test the nose passages by holding one nostril closed for a moment and compelling the breath to pass through the other. When either passage is found not to be fully 
open, and no cold or other irritation exists, a doctor should be consulted without delay.

Of course, after the nose passages are opened, it is not easy to break the mouth-breathing habit, but it can be done by any one who is in earnest. The main thing is to become fully impressed with the importance of nose breathing. In daytime one can usually think to correct himself if the old habit comes back. If the resolution to keep the mouth closed while sleeping is firmly willed, just before retiring, and this determination is persevered in night after night, the correct habit will soon be formed. When one does not succeed with this plan, the mouth may be closed with a bandage at night until the habit of nose breathing becomes established.

But what can a person do when the nose is stopped up by a cold in the head? Simply persist, even though it be with much difficulty, in breathing through the nose. By and by the pure air will not only clear a route for itself, but also greatly aid in getting rid of the cold as well. How is it in running and other violent exercise or work? Surely the larger supply of air coming more quickly through the mouth will enable the muscles to work faster and better. While in extremely violent exercise an occasional breath through the mouth may be necessary, taking the main supply through the nose is far better. For example, in running one may seem to be getting out of breath for a time, but if nose breathing is persisted in, the runner 
soon gets what is called his "second wind." On the contrary, the mouth breather, who may have seemed stronger at first, quickly gets out of breath and has to stop.

There are two reasons for this. The first, of course, is that the air which reaches the lungs of the nose breather is better fitted for its work. The second, that when air comes in through the small orifices of the nose the period of inspiration is longer, and the heart can perform its work more easily than when the larger and more direct route of the mouth is used.

Do we want to avoid the misfortune of distorted faces? Is it our desire to understand as well as our natural gifts permit? Do we wish to be as free as possible from troublesome and dangerous diseases? Would we be able to do our best in athletic games and in vigorous work? Then we must fix the habit of nose breathing as one of our most precious rights.

It is a well-known fact that mouth breathers are much more likely to have croup, enlargement of the tonsils, catarrh, bronchitis, pneumonia, consumption, and other diseases than are those who breathe through the nose. On this account, the right habit cannot be started too early.

Snoring is one of the common signs of mouth breathing. It is usual to regard snoring without particular concern. If referred to at all by other members of the family, it is likely to be in a joking manner. How much wiser and kinder it would be, if, instead 
of joking, we should earnestly impress the snorer with the importance of getting rid of the habit! Fixing the habit of nose breathing will stop the snoring and also result both in better rest and in generally improved health.

The atmosphere of houses heated by furnaces or stoves in winter is not favorable to a healthy nose, unless care is taken to provide the air with sufficient moisture. Such air takes up too much of the secretions from the lining of the nose passages, and so the dust of the air breathed in is not stopped. On this account, the mucous lining becomes irritated. Crusts are formed which are likely to crack and be torn off, injuring the tissues underneath and paving the way for germs. As such crust often itches, children scratch or pull it off. This should not be done, for germs are ever ready to attack such delicate, unprotected places, a longer period of soreness and discomfort being the natural result. When the nose passages feel dry, it is an excellent plan to inject a plentiful amount of saturated solution of boracic acid with an atomizer. This relieves the dry, irritated condition, and helps to remove the dust. Both the atomizer and the boracic acid solution are inexpensive.

A healthy nose can take care of a normal amount of dust. However, where one's employment is such that an unusually large quantity of dust is in the atmosphere breathed, a respirator to strain the air should be worn. This is especially necessary in such work as 
grinding or polishing steel or stone, in which dust particles continually fill the air surrounding the workers. Many persons, too careless or too proud to wear such protectors, either have been obliged to give up the dangerous employment or have become the victims of lung disease. Respirators, by keeping out much of the dust, make the employment less harmful. 


\section{CHAPTER XVII}

HOW EXERCISE MAY IMPROVE JACK'S HOUSE

BuT what about forming the habit of rhythmic deep breathing? Suppose we are breathing through the nose and also keeping our mouths shut except when

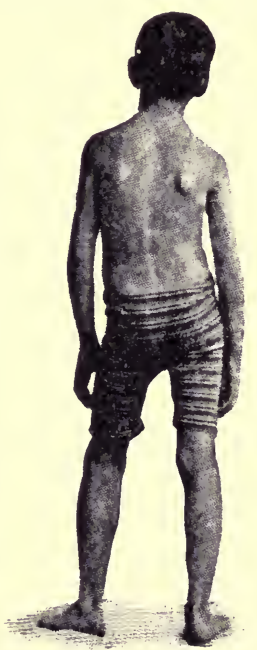

Improper position; causes spine to curve to side; raises one hip and shoulder above the other. talking and eating, what is the next step? Our aim is to take into our bodies the largest possible amount of air with the least possible effort. We know that the larger the chest cavity is made, the greater the expansion of the lungs will be, and hence the larger the amount of air that will rush in to fill the space. We have already learned that the greatest enlargement of the chest cavity is made by simultaneous movements of the diaphragm and the intercostal muscles.

Now in order to get the best and most natural movement of these muscles, the spine must be in an erect position with the shoulders well back, the chest inclined outward, and the abdomen inward. The head 
should also be well poised, being held neither forward nor backward far enough to get the body out of balance. Such is the position natural to people who are reared in an out-of-door life. The American Indian, for instance, was noted for his erect body, well-developed chest, and breathing organs. It is the unnatural, overheated, indoor life of civilized men that has led to ungraceful and injurious positions and poor breathing habits.

Some persons get into the habit of bending the spine too far back and carrying the abdomen much too far forward. This position they imagine is good, because they are conscious of not stooping. However, such a manner of carrying the body is not graceful, nor is it healthful, because it makes the best diaphragmatic breathing impossible. Carrying the chest outward and the abdomen inward is the right position, and we must not be satisfied until this is our habit. A protruding abdomen and receding chest are usually signs of weak breathing organs.

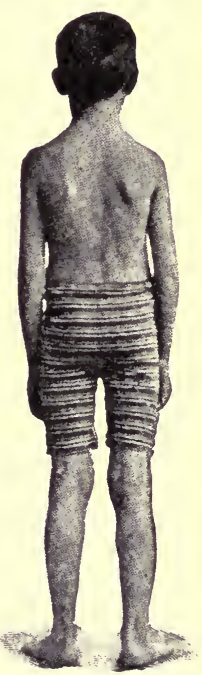

Best habitual position; chest is free to expand, and weight is easily shifted from one foot to other.

Often carelessness as to how we sit and stand is the first step toward weakening our lungs; while one of the first steps toward strengthening them is improving our position in this respect.

Sitting in school or at home in incorrect positions, 


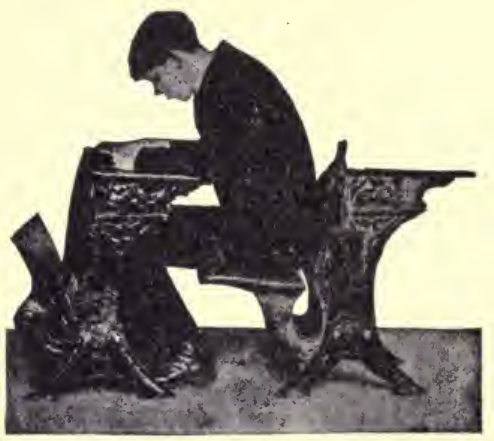

Desk too low. (Jegi.)

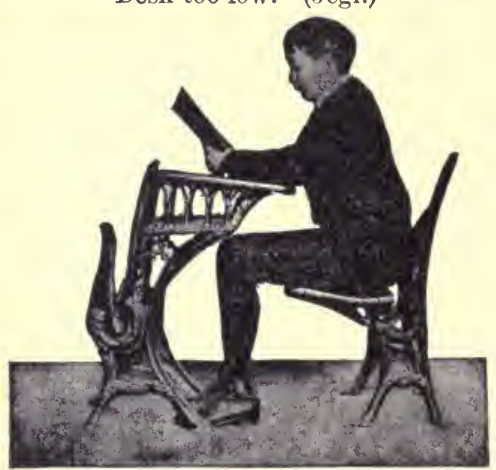

Correct position.

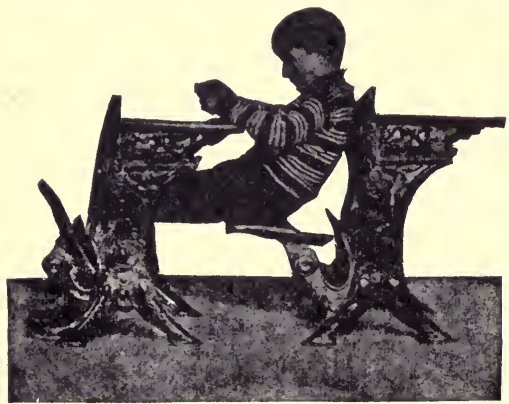

Slipping down in seat. A poor position. as are two of these children, is one of the most common causes of curved spines and poor breathing. The boy on page 163 has lowered the handles of his bicycle, thinking he could ride more easily and faster. Such a stooping position, however, hinders his breathing muscles, to say nothing of the ungainly posture. Habitually walking or standing in such position as the child on page 158, makes the body less beautiful and also starts poor breathing habits.

Notice how greatly the weak position of the children on pages 158 , 160,162 , and 163 takes away from their pleasing appearance, and how much the erect carriage of the body 
adds to the good looks of those on pages 159, 160, and 161. Erectness of the body gives an impression of strength and vigor; while the opposite position suggests weakness and lack of ambition. How fortunate it is that good health and good looks thus go hand
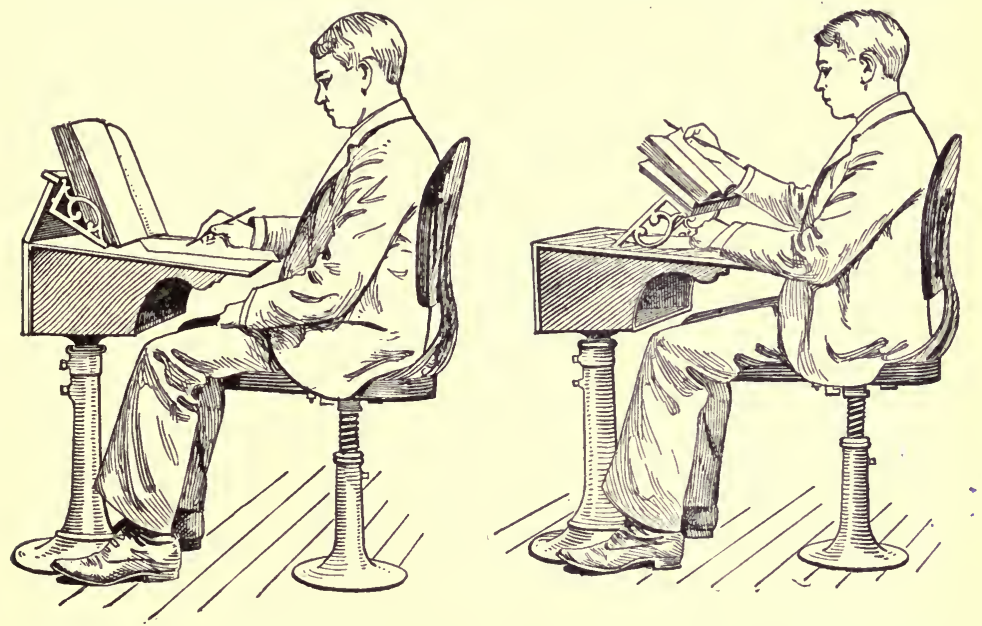

An adjustable seat and desk as used for writing. From Dr. Mosher's " Hygienic Desks for School Children," Elucational Review.

Same seat and desk as used for reading.

in hand, and that, in striving for the former, we may gain both! Careful watching and persevering will result in the habit of correct position. Such reward is certainly worth our best efforts.

But if the habits of stooping, sliding down in our seats, allowing the chest to sink in and the abdomen to protrude, have already been formed, can they be broken? The same rule applies here as in the break- 
ing of other unwise bodily habits. If we become sufficiently impressed with the necessity of making the change to persevere in trying to improve, the erect position will become just as easy and natural as was

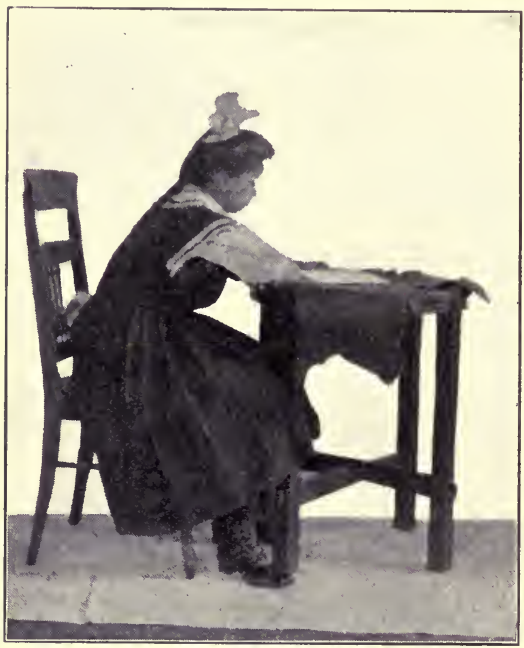

An incorrect sitting position. the weak one. It is most important to form the habit of erect position early in life, because the bones are then comparatively flexible and readily adapt themselves to a change. As we grow older, they gradually become harder and more brittle, making a change of position more difficult. It is a well-known fact that our bones break more readily as we grow older. This, of course, is because they become more brittle.

We have all seen advertisements in newspapers showing a remarkable contrast in the appearance of people before and after taking some patent medicine. If children could look forward into the future and see what a fine appearance they would make as erect, strong, and healthy men and women, or how much less pleasing they would be as awkwardly formed and 
perhaps weak or sickly, the advice to "straighten up" would certainly be given more heed.

Granted now that we have succeeded in forming the best position and breathing habits, what is the next step in making our respiratory organs furnish us the largest possible supply of air? In the first place, we must not be satisfied until we are conscious that rhythmic movement of the abdominal organs as we breathe is

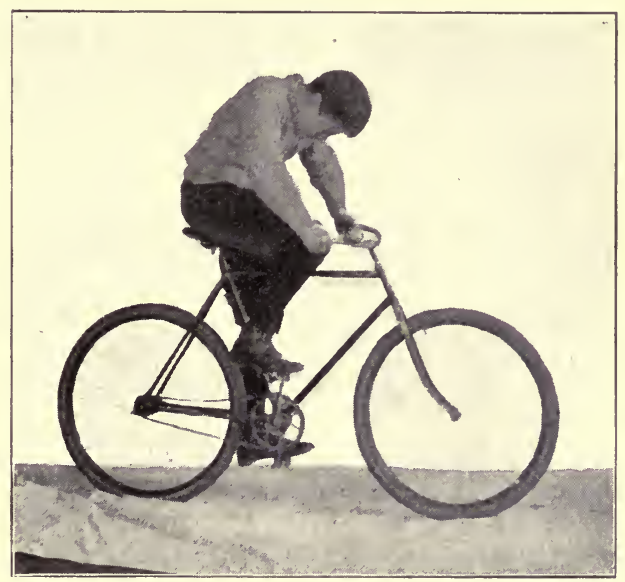

An incorrect position for riding a bicycle.

our established habit. Many give much attention to expansion of the chest. If the crowding downward of the abdominal organs is secured while breathing, the best enlargement of the chest is sure to follow. Then practising such exercises as will best develop the elasticity of the breathing muscles is the most important thing. The diaphragm, the intercostal muscles, the cartilage, the lung tissue, are all elastic and should be given abundant opportunity to grow stronger through use. The country boy helps in this development by chopping wood, pitching hay, and other daily 
chores. All children may develop these important muscles through running, skating, climbing, and the various active games that are so enjoyable. Singing or playing a flute, horn, or other wind instrument is also excellent, if the breath is taken through the nose.

But even with plenty of such exercises, practice in deep breathing is of great benefit. The following exercises are especially good: Standing erect with hands on the waist, take in long deep breaths through. the nose, and let them out slowly through either the mouth or the nose. Take in the breath in the same manner, but let it out gradually in many short successive puffs through the smallest opening in the mouth. While walking, take in long full breaths through the nose, and exhale slowly through the smallest possible opening of the mouth or through one nostril while the other is closed. It is well to avoid the practice of holding the chest long distended, for it makes extra hard work for the heart. Exercises similar to all of the above may also be profitably taken when lying flat on the back or sitting erect in a chair. In any of the positions described, variety may be added and both singing and speaking improved by using the voice with scale syllables or with vowel sounds.

The following is one of the very best exercises to increase lung power. Stand erect, holding arms by the sides. With palms downward, slowly raise hands in front and as high as you can above the head, rising on tiptoe so as to take in just as much air as possible. 
Then slowly lower hands as far as you can without bending the knees, expelling the air as the body goes downward. These movements compel great expansion of the lungs. For this reason the exercise is very helpful in developing breathing power, when practised faithfully. If the arms are forcibly crossed just as the body reaches its lowest point in this movement, complete expiration is greatly assisted. It is far more necessary for most people to practise for better expiration than for improved inspiration, for it is in the former that breathing is usually defective. If effective expiration is accomplished, the inspiration of air will naturally follow.

All exercises should be taken in pure air and, when it is feasible, with wide-open windows. One should begin moderately, gradually increasing the amount as the muscles become stronger and more accustomed to the work. It is most surprising how rapidly such exercises will develop breathing power. Where they are kept up regularly, even once a day, a gain of several inches in chest expansion in a few weeks is not at all uncommon. Gain in expansion, however, is not always due to increase in size of lungs or chest walls, but to growth in muscle or to pulling the abdominal organs up into the chest. Care should be taken to secure the right kind of development. Otherwise efforts to increase chest expansion may be easily overdone.

Each inch of expansion means greater capacity for taking into our bodies, every time we breathe, this 
useful air with all the benefits it can bring. The engine that propels an automobile is spoken of as one, two, three, or more, horse-power, according to its possible strength and speed. Other things being equal, our power to play, to do, and to enjoy, can be estimated by the quantity of purifying air with which we supply our bodies. Shall it be only one horse-power, when by care and practice we can readily make it more? Such low power in an automobile would not satisfy us, if we could honestly obtain one of higher power. What foolish body builders we should be to estimate our own gain in power so lightly.

Do we wish to equip our bodies with their greatest possible air power? The prescription is easy to remember. Fully appreciate the power to be gained. Intelligently set about gaining it. Keep striving for it unceasingly. Even ten deep breaths every night and morning will cause remarkable progress. A deepbreathing exercise at odd times during the day, when walking, is good. The same exercise upon going into the out-of-door air for a few moments' change after long-continued work or study indoors, will always be refreshing and beneficial. Above all we must not be satisfied until rhythmic deep breathing is our regular habit.

Breathing out all the air we can, immediately after leaving a close street car, a theater, or other crowded room, and then refreshing the lungs with several long deep breaths of pure air is also a good practice. 
Upon discovering that unclean food has been taken into our mouths, how quickly we eject it! We know that the atmosphere of crowded rooms must be more or less unclean and poisonous. Certainly, then, we should quickly expel all we can of the foul air that may be retained, and eagerly refresh the lungs with extra quantities of pure air.

Breathing exercises are not usually necessary for adults engaged in hard physical labor, especially if their employment be out-of-doors. However, those whose work is largely mental, or persons who are weak or not well developed, can improve greatly by practising them. Growing children can, by such practice, store up capital in the form of healthy, capacious breathing organs that will furnish them a most bountiful supply of life's very best form of wealth, good health. But some children may say, "I am growing stronger and broader chested as the years go by, and my general health is excellent without giving these matters any particular attention." Some are fortunate enough to have such good bodies, and while deep-breathing exercises might make them even stronger and healthier, there may be no great need of care and practice for them.

For children who are naturally delicate, however, training in regard to position and exercises for the development of the breathing and other muscles is a most valuable part of education too often neglected. Small chests, flat chests, and even deformity due to 
rickets, a disease which is more common than is supposed, may be remedied by deep breathing. How encouraging it is for weak, sickly children to know that with plenty of nourishing food and abundant exercise

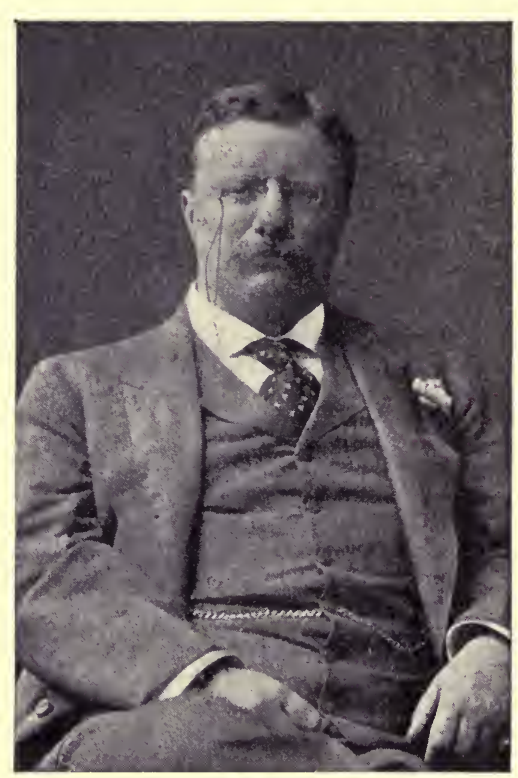

Theodore Roosevelt. out of doors, they may grow to be healthy and vigorous. What a satisfaction is the knowledge that many of the world's most useful men were children from whom little was expected because of poor health, but who, by careful living and by persevering in out-ofdoor exercise, developed into vigorous manhood. One of the most notable of such examples is that of our energetic and distinguished President, Theodore Roosevelt. Though fond of active games in childhood, he could not play as vigorously as did many of his companions, because of lack of strength. Realizing that much of the enjoyment in life was derived from being able both to work and to play one's best, he determined to make himself strong and vigorous. With this purpose, he gave much time to out-of-door 
games and sports. Even after completing his college course, he spent many months on a Western ranch, where a large part of the day was passed in the saddle.

"What a waste of valuable months for a college graduate!" one might say at first thought. But let us see what kind of an investment it was. Persistence in out-of-door games during school and college life laid the foundation for good health, while the ranching experience developed iron muscles and a vigorous constitution. As Assemblyman, Police Commissioner of New York City, Assistant Secretary of the Navy, Colonel of the Rough Riders, Governor of New York State, Vice-President and President of the United States, this rugged health has been most useful capital. The hardships of war in the tropics, the strenuous exertions of speech-making tours, the vast responsibilities of the presidency, have all been undertaken without shrinking and performed with preëminent success. No task has been too irksome, no undertaking too vast, for his buoyant mental and physical life.

What has given him this great capability for successful achievement? No doubt the college training has been of great value, but the underlying foundation was the physical and mental reserve power stored up during the years of devotion to active, out-of-door life. Another valuable lesson that the life of our universally beloved President teaches is that of the benefit derived from regularly keeping up out-of-door 
exercise. It is said that this is the one thing he will not omit. How often have we read of the daily horseback rides, the tennis and boxing matches, the long cross-country walks! These and occasional hunting trips have preserved vigorous health and enabled him fully to enjoy the arduous duties of his various offices and to keep in touch with many other important interests besides.

The famous author, Sir Walter Scott, is another well-known example of the beneficial effects of out-ofdoor life. On account of extremely delicate health,

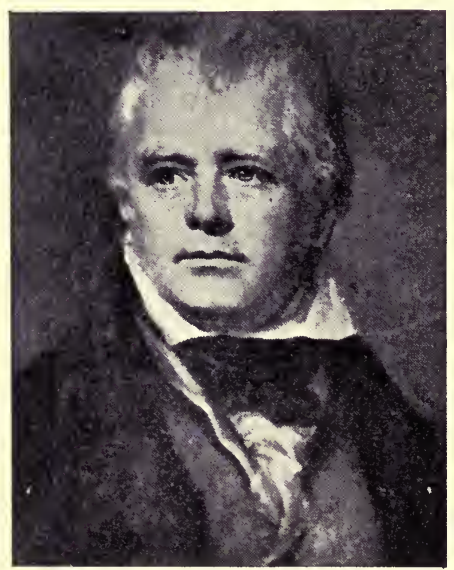

Sir Walter Scott. a large part of his childhood was spent in the outof-door country air, where he developed a deep fondness for walking and riding through the beautiful highland regions of Scotland. Although lame from babyhood, the early years in the open air helped him to build such a vigorous body that in school he was noted for activity and endurance. During the first thirty years of manhood, his literary labors were prodigious, the English reading world being delighted with story after story from his pen. Nevertheless, his health did not suffer, because of the rugged constitution with 
which the years of life in the open air had equipped him, and his continued devotion to brisk daily rides and walks.

At the age of fifty-five, through the failure of a publishing house with which he was connected, a debt of $\$ 600,000$ was suddenly thrust upon him. Many friends urged that he relieve himself of this crushing load by going into bankruptcy, and depend upon his popularity to cause people soon to forgive such action. But Sir Walter Scott said, "No!" The years of devotion to out-of-door exercise had equipped him with rugged honesty as well as rugged health. With the lofty courage of the most chivalric knight in his own stories, he declared that if God gave him health, the debt should be paid in full, and that no one should lose one penny on his account. Henceforth his great aim in life was to pay this vast sum of money by the work of his pen. During the ensuing years almost every waking moment was spent in writing, story after story being published and gaining wide popularity.

An ordinary man could not have endured such strenuous mental labor. His constitution had grown so strong, however, through years of devotion to active exercise in the bracing air, that he was able to keep up this terrible pace nearly five years, before paralysis compelled him to stop. He died a few months later, happy in the thought that the sale of his books would soon wipe out the debt; but leaving his friends and admirers sar in the belief that, had the old habits 
of daily exercise in the open air been kept up, his life might have been spared many years. What an inspiration for sickly boys and girls is the life of this great poet and novelist! Devotion to out-of-door life enabled him, a puny lad, to become one of the bestknown English authors. The character developed under such circumstances helped him to furnish an example of devotion to high ideals of honor and duty that will be an inspiration as long as the records of his noble life exist.

The careers of these two eminent men certainly prove the truth of the old sayings: "The child is father of the man," and "As the twig is bent, the tree is inclined:" Children who would live the happiest and most useful lives, should, like them, cultivate a fondness for out-of-door exercises, and persist in gratifying that love all their lives. Nor is this a hard thing to do, for what gives more pleasure than active exercise in the bracing air? What delight there is in the games themselves, and how the exercise sends the blood bounding through the veins, filling every fiber of our bodies with new life and vigor!

Do we wish to have bodies both strong in action and powerful in resisting wind and weather? All may not have such opportunities for out-of-door exercise as Theodore Roosevelt or Walter Scott had in boyhood. Still there are some forms that are possible for everybody. Either city or country children can scorn to ride to school or any other place, if there 
is time to run or to walk. Certainly, unless the weather is too rainy, this practice will be found beneficial. "But should we not ride in the warm street cars on cold winter days?" city children may ask. By no means! The colder the air, the more bracing it is. Boys and girls who hurry on foot to school, breathing in the exhilarating oxygen, both save the car fare and store up for the day's work vitality and power that no amount of money can buy. Fortunate are the children who, because their parents cannot afford the necessary car fares, get a larger supply of precious oxygen! Unfortunate indeed are those children whose well-to-do parents do not realize that by enabling their little ones to avoid exertion in the cold air, they are unthinkingly depriving them of a great benefit!

Again, all of us can have.our work out of doors whenever that is feasible. When obliged to stay indoors, we can also make sure that the atmosphere of the room is as pure as possible. Furthermore, all can form the habit of getting out of doors for some active exercise whenever freedom from work and other conditions permit, aiming to cultivate such a love for some open-air game or sport, that we shall keep it up regularly as we grow older. Horseback riding is good, if we can afford it. Tennis, golf, base-ball, skating, and many others are excellent. That is the best for each which can be undertaken most readily, for it is the one most likely to be kept up regularly. Although, other things being equal, a game having 
the element of contest is better than exercise which is not a test of skill, yet even a brisk walk will suffice when more absorbing exercise is not possible.

Walking is certainly far better than no exercise at all, and is even to be preferred to games in gymnasiums, because the air in the best-ventilated of such rooms cannot be as beneficial as the pure atmosphere outside. Active, out-of-door exercise is an excellent thing for adults, because it keeps the heart and breathing muscles strong and in good condition. Men and women who do not continue some such exercise after entering business life, in time get out of breath quickly when some sudden physical exertion is necessary. This is because the heart and other muscle tissues have become enfeebled from lack of use. Such a condition can easily be avoided by regular, active exercise.

Let us then persist in forming a love for out-of-door life, both for the joy it will afford and the larger usefulness it is bound to give us. We may not all become authors so celebrated as Sir Walter Scott, or warriors, authors, or statesmen so distinguished as our versatile and beloved President Roosevelt. Nevertheless, no matter how humble our calling, honest, useful lives are possible for all. If, like these two great men, we improve the opportunity to make our bodies vigorous and strong, like theirs, our lives will become more honorable and useful than would otherwise have been possible. 
In the Century Magazine of June, 1907, the famous Australian singer, Madame Melba, gives the following testimony, which should be of especial interest to girls :

"For perfect singing, correct breathing, strange as it may sound, is even more essential than a beautiful voice. No matter how exquisite the vocal organ may be, its beauty cannot be adequately demonstrated without proper breath control. . . Phrasing, tone, resonance, expression, all depend upon respiration; and, in my opinion, musical students, even when too young to be allowed the free use of the voice, should be thoroughly taught the principle of breathing.

"Indeed, the science of taking breath is a study peculiarly suited to the years of childhood and adolescence; for, apart from other considerations, there are few things so conducive to good health as good breathing. And, owing to the greater elasticity of the human frame in the time of youth, the chest is then more easily developed and expanded. Any exercises that give strength to the diaphragm are of especial value, since this is the chief muscle of inspiration. Expiration, however, is not so easily controlled as inspiration, and on that score calls for the most careful practice. . . .

"Of course robust physical health is of paramount importance. Without it a great vocal career is absolutely barred. . . I I admit that there is much in a singer's life conducive to this physical robustness, as, for example, the vigorous use of the breathing 
apparatus. . . Plenty of fresh air, plain food, a reasonable amount of exercise, and eight or nine hours' sleep are all necessary to the young singer, whose larynx is quick to reflect the general physical condition.

"At the same time common sense and individual temperament should be the best of all health rules. I myself always suffer in a steam-heated apartment; I consider the general overheating in America a menace, and never allow the temperature of my rooms to rise above sixty degrees; while at the same time the whole range of my apartments is continually freshened with pure air.

"The singer should aim at becoming a hardy plant rather than a hot-house plant. I know that a girl with a voice receives a painful revelation of the delicacy of her vocal organs when she passes from a superheated room to the low temperature of a winter's day outside. But I consider dry feet far more important than the wrapping up of the throat on raw, slushy days." 


\section{CHAPTER XVIII}

\section{ADULTERATED AIR - TOBACCO}

We have learned how much pure bracing air has to do with the enduring strength of the House that Jack Has, and how the dust and smoke of cities often hinder its best building work. How unwise it seems for people knowingly to adulterate the air their bodies are using! And yet many do so through the practice of smoking. Tobacco, the substance most generally used by smokers, is called a narcotic because of its peculiar effect on the nervous system. The fact that severe sickness usually follows the first use of tobacco is good evidence that it is naturally poisonous to the human body.

Undoubtedly many tobacco users have lived to a good old age. That they might have been healthier and longer lived without the tobacco is quite probable. It is also a well-known fact that many of the most useful old men of the world have been abstainers from tobacco. Many smokers who have become alarmed at getting out of breath quickly through any unusual exertion, have found, on consulting a physician, that they had a "Tobacco Heart." This name is applied 
to the too rapid and irregular beating of the heart which is sometimes caused by the narcotic effect of tobacco on the nerves. In such cases, if smoking is given up for a time, the heart's action soon becomes normal; but, if the harmful habit is continued in spite of such warning, serious injury may be done. Often men whose employment makes very little physical exercise necessary, have not realized the weak condition of their heart until refused life insurance on this account.

In a magazine article published February, 1897, Professor J. W. Seaver, Director of Yale University Gymnasium, gave some remarkable information concerning students who were tobacco users. For nine years he had kept careful record of the age, height, weight, chest girth, and lung capacity of all students who entered that university. He also recorded whether they had used tobacco before coming to college. According to his records, the smokers who entered Yale during that period averaged fifteen months older than those who were non-users of tobacco. This would certainly seem to prove that the tobacco habit hinders boys from making their best progress in school.

The measurements he made of the students who entered, showed that while the smokers were, as a rule, somewhat heavier, their average height and lung capacity were both considerably smaller. Now as they were, on the average, fifteen months older, they 
naturally should have been both taller and of greater lung capacity.

Professor Seaver also kept accurate record of the physical development made by the young men while they were attending college. To find out what effect tobacco might have in this respect, he grouped them into three classes; namely, those who never used tobacco, those who had used it for at least a year, and those who used it irregularly. His records showed that those who never used it increased in weight about one-tenth more than those who had used it for a year or more, and nearly seven-hundredths more than those who used it irregularly. In height, the gain of the non-users was nearly one-fourth more than that of those who had smoked a year or more, and a trifle over one-tenth more than that of the irregular user. The gain in girth of chest for the non-users was slightly more than one-fourth greater than that of the irregular smokers. But the gain in lung capacity for the nonsmokers was greatest of all. In this respect they were more than three-fourths ahead of the year or more smokers, and almost one-half better than the irregular smokers.

Did the non-smokers also show greater ability as students? Out of the hundred men who took the highest rank at Yale while Professor Seaver was keeping these records, only five were smokers. The other ninety-five never used tobacco. Of all the students taking rank below this hundred, however, three-fifths 
were smokers. Dr. Hitcheock of Amherst College has obtained similar figures from records kept of students who were gaining an education there. Surely any boy who wants to be able to do his best, either in play or at study, can make Professor Seaver's conclusions the very best of reasons why he will not begin to use tobacco in any form.

Indeed, the bad effect of tobacco on the physical and mental development of boys is so well known that the law mákes its sale to children a misdemeanor punishable by fine or imprisonment. And such an act should receive the severest punishment, for tobacco, especially in the form of cigarettes, stunts children's growth. It also dulls their minds, and makes them listless and inattentive. Boys often commence smoking in the belief that it will make them appear manly. On the contrary, it takes away from their manly appearance by causing unnatural pallor and thinness. Besides this, its effect on their wills may be so weakening that often boys who would not otherwise have stooped to anything low or impure, disgrace themselves and their friends by doing mean and vicious things.

The odor of tobacco is very penetrating, being noticeable in both the clothes and the breath of its users. Smokers and their immediate family and friends get accustomed to this odor, but it is frequently disliked by others. One of the unfortunate things about the smoking habit is that those who 
are fond of tobacco sometimes forget that it may be offensive to others, and smoke in public conveyances or meeting places without considering that others present may prefer not to have the air made less pure by ill-smelling smoke.

The habit of chewing tobacco is probably much less common than smoking, but it has all the bad features of the latter and is certainly much more offensive. That smoking tobacco is an expensive and more or less untidy habit cannot be denied. That we often meet with men who wish they had never started the habit, and rarely, if ever, find one who does not regret having burned his money up in this way, are facts well worth considering.

The following conclusions may be readily made from the above facts. Genuine lovers of cleanliness should avoid a habit that may cause them to be offensive to others. Genuine lovers of pure air should not begin a practice that will interfere with their getting the fullest enjoyment of this best gift of nature to their bodies. Genuine lovers of perfect health should beware of a custom that has injured many others, and may weaken their bodies. Most important of all, boys should shun the tobacco habit as they would smallpox or other dangerous disease, for it may easily do undeveloped bodies even greater harm. Surely all should remember that air is the most important element in body-building. We would not think of adulterating the bread we eat by mixing 
182 THE WONDERFUL IIOUSE THAT JACK HAS

tobacco with its flour, nor should we be any less particular about the air we breathe. When asked if smokers were desirable members of his polar expeditions, Commander Robert E. Peary replied: "As for taking a man with me who is dependent on the use of tobacco, I should as soon think of taking a man who had to have pie." 


\section{CHAPTER XIX}

THE LARGEST COMPONENT OF JACK'S HOUSE - WATER

WATER is the largest component of the Wonderful House that Jack Has. How much this common liquid has added to our pleasure since babyhood! In summer, we have sailed tiny boats and gone swimming in it. In winter, many a merry hour of skating on its frozen surface has been our delight. How often, when we have been tired and thirsty, it has revived and strengthened us! We, perhaps,

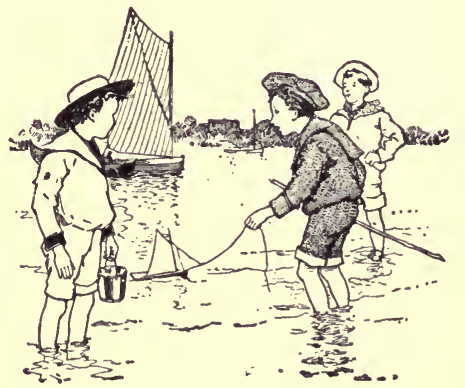

Sailing tiny boats. have never thought why a glass of water is so refreshing, though the pangs of thirst have told in no uncertain way that it is absolutely necessary to our health and comfort.

If two-thirds of a house were wood, and a certain amount were worn off each day, the portion lost would have to be replaced, or it would soon tumble down. Now, strange as it may seem, chemists estimate that 
at least two-thirds of the human body is water. Blood is nearly four-fifths water, and flesh, cartilage, and even bone, all have a share. In fact, if all the water were to be pressed out of the tissues of a healthy person weighing one hundred twenty pounds, the substances remaining would not altogether amount to more than forty pounds.

As the body is continually giving out water through the skin, lungs, and kidneys, it must frequently receive a new supply to keep up the normal proportion of two-thirds. A dry, parched feeling in the mouth and throat is a warning that the proportion of moisture has been reduced below the normal amount, and that the loss must be supplied if we are to feel comfortable. From our study of foods, we know that bread, meat, and vegetables all contain water, and that a part of the body's need for this fluid is supplied by them. The various liquids drunk during the day furnish the remainder.

Why are we, as a rule, thirsty so much more often in summer than in winter? Simply because the greater amount of water lost in perspiration must be supplied. For a similar reason, we drink more freely when working or exercising than at times of slight activity. At night there is normally the least craving for water, because the body, being in a state of rest, loses but a small amount through the pores of the skin.

But water performs other important services in Jack's House. We know that it is used to soak up 
dirt from soiled clothing. Making other substances become a part of itself in this way is called dissolving, or taking into solution. Notice how much salt, sugar, or other substance a glass of water can take into solution. This is an interesting experiment that all can try. It is because of this dissolving power that water is so useful in cleaning floors, furniture, and anything else that is soiled. On account of the same quality it is able to carry away waste and filth from our homes through the sewer pipes.

A great deal of water must be used in bathing, if we are to keep our skin clean and wholesome. It is also just as necessary to make free use of this dissolving liquid to keep the inside of our bodies in a clean, healthy condition. In studying about How Jack's House Builds Itself, we found that it must get rid of certain harmful acids, poorly digested materials, and other waste products. Water is an important aid in getting these out of the body. As it is able to soak up dirt from clothes and carry waste through sewer pipes, so it can take up acids and other injurious or useless substances, and carry them from the body through the kidneys, lungs, and skin. It may also be of great assistance to the intestines in getting rid of the solid waste products of digestion.

Any boy knows that a bicycle runs its best when all the parts are thoroughly clean. Like the bicycle, our bodies can perform their best service when kept thoroughly clean in all their parts. Drinking freely 
of pure water is one of the greatest helps in accomplishing our inner house cleaning. In a previous chapter we read that drinking too freely of water at meals may be an injurious practice, because, if cold, it is likely to lessen the supply of digestive fluids, and, if taken in too large quantities, it may over-dilute them.

But a glass or two of water just before retiring at night, or two or three glasses a half hour or more before meals, especially before breakfast, are most effective in keeping the inside of our bodies clean and healthy. At such times the work of stomach-digestion of the previous meal is nearly or entirely completed. The water helps to cleanse the various organs and tissues through which it is carried, and also stimulates the kidneys to remove injurious products from the blood. Thus, this liquid, so commonly used to clean the outside of many things we can see, is equally useful in cleaning the inside of our bodies which we cannot see. There are people who get into the habit of drinking little or no water except what is in their coffee or tea. Some insidious disease forces them to consult a physician, when they discover what a serious mistake they have been making and how much benefit they might have derived from drinking a plentiful supply of pure water.

But what about the temperature of our drinking water? Is that of any particular consequence? It certainly is, for the stimulating effect of water depends 
upon whether the difference of its temperature and that of the body is great enough to affect the nerves and muscles. When it is enough colder or warmer than blood heat to stimulate the lining of the mouth and stomach, the nerves and muscles along the digestive canal are affected in a similar way. In fact, if the intestines are not regularly and freely discharging the waste products of digestion, a cup or two of cold or hot water a half hour or more before breakfast is often a most effective help. Of course, water should not be hot enough to burn, and refreshingly cool is better than ice cold. When either very hot or very cold, it should be drunk slowly.

Hot water will take more materials into solution; but many prefer cold water, because of its pleasant taste and its tendency to give the lining of the digestive canal a more vigorous tone. We all know how refreshing cold water is to our hands and face, and can readily understand why it may have a similar effect on the mucous lining of the digestive organs. How much better it is to assist the cleansing of the inside of our bodies by the abundant use of water, than by taking patent medicines and other drugs! The drugs whip the glands into pouring out extra large amounts of dissolving fluids. As a natural consequence, they must rest to recover from such unusual exertion, and so are not fully ready to take care of the next meal when it reaches them. The water, on the contrary, simply affords a natural stimu- 
lant, and by softening the contents of the digestive canal, it aids in the expulsion of waste.

There may, of course, be times when medicine is necessary to help in our internal house cleaning; but it should be prescribed by a physician, or at least be something of well established value in the household. The habit of taking doses of any kind should be carefully avoided. Our bodies are wonderful self-oiling, self-cleansing machines. Furnish them an abundance of air, water, exercise, not too much food, and sufficient rest, and they are likely to continue strong, clean, and healthy. These are the natural ways to build and repair them. Medicines should be rarely used unless a doctor advises. Of this we may be certain: if we learn to make the right use of these common building and repair materials, we shall be so strong and well that spending money for medicine will rarely be necessary.

Let us review our knowledge of this useful liquid. Where does it come from? Is it all alike and equally beneficial? We have all seen steam come out of the teakettle and condense into water again as it strikes the cold surface of the window. Water that is condensed from steam is called distilled water, and it is very pure, for whatever mineral or other substance might have been in solution before the steam was formed, was left behind.

That greatest of all fires, the sun, is constantly causing moisture to rișe from that greatest of all tea- 
kettles, the ocean, and from other bodies of water as well, the salt and other substances in solution of course being left behind. When clouds of this moisture come in contact with cold currents of air, condensation ensues, and water falls to the ground in the form of rain, hail, or snow. Rain would be as pure as distilled water, if it did not bring along ammonia, dust, and other substances that are in the air. How clean and pure the air seems just after a hard rain storm! This is because the rain has given it a thorough cleansing.

Much of the water that falls from the clouds drains into small streams, and finally reaches the ocean. A considerable quantity soaks down into the earth, however, collecting in some rocky region through which it cannot pass. Here it forms the sources of various wells, or bubbles out of lower ground in the form of springs. In passing through the ground, the substances brought with it from the air are filtered out, but it often dissolves others in the earth through which it passes. Water that has taken up considerable lime or other mineral matter in passing through the earth is called hard water. That which has very little mineral substance in solution is called soft water. Some waters have taken up salts, sulphur, or other mineral matter that gives them valuable medicinal qualities, and so sanitariums are built near such springs, and their waters often have a large sale.

Why does the housewife prefer soft water for wash- 
ing? Because it has less mineral substance in solution, and hence more readily takes up dirt from soiled clothes. For a similar reason, soft water is often preferred for drinking, and distilled water, as far as dissolving power is concerned, is better still. The salts of lithia in-

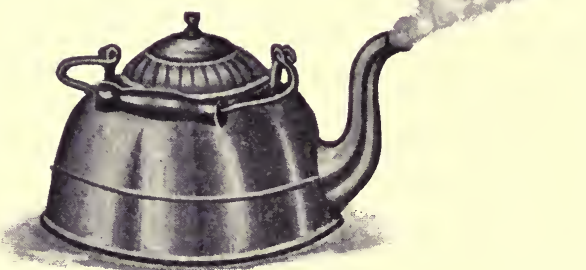

A good way to kill germs in drinking water - boil twenty minutes. crease the dissolving powers of water, and, on this account, much lithia water is drunk.

One thing on which all are agreed is that water polluted by waste material from the human body should be avoided. Such water may come from wells situated near out-houses or cemeteries. This waste material may be in city water when the source of supply is some river or other stream into which sewage is drained. The danger most to be feared from drinking such water is typhoid fever, because the germ of this disease is often in the waste that passes from the intestines of human beings. When there is any reason to fear that the drinking supply is polluted from sewers or any other source, it should be boiled about twenty minutes after the steam begins to rise. This will kill all germs. Another bene- 
fit from boiling drinking water is that some of the substances in solution are deposited, both the clearness of the water and its dissolving power being improved. Filters are also often used to purify drinking water. When we consider that thousands of deaths from typhoid fever occur yearly, the necessity of being careful about our drinking water can be easily appreciated. The whole world marveled at the comparatively small number of deaths from disease in the Japanese army during the Russian-Japanese war. When a new camp was pitched, the drinking water was examined, and if disease germs were found, it was purified before being used for drinking. This precaution prevented much sickness.

Drinking water should not be cooled by putting in ice that has been cut from sewage-laden streams, as freezing does not necessarily kill typhoid fever germs. When the purity of the ice is in doubt, placing a bottle of water on the ice is a safer way of cooling than putting ice in the water. Water that has remained in water pipes all night should not be drunk, as it may have dissolved lead, which is poisonous. By allowing it to run a few moments before the teakettle or pitcher is filled, danger from this source is avoided. Water very readily takes up gases or bacteria that may be in the air, and for this reason should not be left long uncovered when it is used for drinking. Such care is especially necessary in the sick room.

Why is it better to force drinking water from a well 
with a pump than to draw it in a bucket? Because when a bucket is used, the top of the well is more or less open, but a tight covering is possible around a pump. It is also a good plan to have the surface surrounding the top of a well slope away from it. Such grading causes the waste water to drain off instead of flowing quickly back into the well and perhaps carrying impure substances with it. Melted snow does not make as pure drinking water as a good supply from underground, because the substances taken up during its passage through the air have not been filtered out by the earth. The same thing is usually true of stored rain-water.

Thus far we have considered the value of water to the inside of the body. Let us now see how it performs another very useful service in helping to keep the outside clean and healthy. And what an interesting outside covering the skin is! Its outer or thin layer, called the epidermis, is the part that is raised by a blister, and its chief use is to protect the under layer, called the dermis or true skin. The under side of the epidermis is uneven, and the cells of which it is composed are constantly working up to the surface and being shed. The dermis with the underlying fat serves as a protection to the body.

The skin contains two sets of tubes called the perspiratory glands and the oil glands. The perspiratory glands are small tubes lying deep in the true skin or the fat beneath. An outlet, or duct, runs from each 
in a spiral manner to the surface of the skin. It has been estimated, that if all these glands, which a body of average size contains, were placed end to end, they would reach twenty-eight miles. What a remarkable arrangement this system of glands is! How important it is that they should always be in the best condition for work can be judged from the fact that with the kidneys and lungs they form the sewers through which the water of the body and any substances that it has taken into solution are discharged. Great pains are taken to prevent the sewer pipes of a dwelling from becoming clogged, and when for any cause they are stopped up, no time is lost in clearing away the obstruction. That we should be even more particular with the sewer pipes of our bodies can be easily understood.

It is well known that waste water given out through the pores is commonly spoken of as sweat or perspiration. On warm days or when we are exercising violently, perspiration can be seen or felt on the skin. At other times the pores of a healthy skin give out water, but in such small quantities that it is called insensible perspiration. Like watery vapor from the lungs, it sometimes has a disagreeable odor which is noticed after perspiring freely. Though the water evaporates, substances that it had in solution remain on the skin or underclothing. But what other use have these miles of pores? They perform another great service in so regulating the body's heat that in health it 
normally remains at a temperature of ninety-eight and six-tenths degrees, without regard to weather, rest, or exercise. Suppose there were a stove that would increase or decrease its heat to remain ninetyeight and six-tenths degrees, regardless of the temperature of the room in which it was placed, what a fine invention it would be thought!

The pores of our skin are the safety valves in helping Jack's House to be just such a stove. We know that insensible perspiration is continually passing from the body. Now when our body's temperature rises above ninety-eight and six-tenths degrees because of heat or exercise, these glands pour out so much additional perspiration that all the heat not needed to keep up the normal temperature is expended in evaporating this water from the skin. How necessary the work of these glands is to our life and comfort, may be judged from the fact that if the skin were covered with any substance that would stop up all the pores, death would soon follow.

Of what use are the oil glands? They secrete a fluid that lubricates and softens the skin. If oil and the scales that are shed by the skin are allowed to collect on its surface, they form a covering which tends to obstruct the pores and interfere with the proper performance of their work. When such a condition is allowed tocontinue, the kidneys and lungs are given an abnormal amount of labor in getting rid of the liquid waste of the body. As a natural con- 
sequence, one or both of these important organs may in time become diseased, especially if one's work is not in the purifying out-of-door air. Some persons try to improve their complexions by applying powder or paint; but as such a practice tends to obstruct the pores, it is likely to prove an injury instead of a help to the appearance of the skin.

It is generally known that bathing is the best way to keep the perspiratory glands open and healthy. But how often should baths be taken? We have learned that insensible perspiration, oil, and scales are being constantly given off by the body. It is evident, then, that daily bathing of the entire body is essential for cleanliness and health. Many people wash their hands and face several times daily, because dust and dirt show on them, but are not as careful about parts of the body that are not visible. Surely when one considers that the skin is giving off impurities continually, the need of bathing the entire body at least once a day is plain. Who has not seen a baby enjoying its daily bath? How carefully the watchful mother bathes the little one each morning, and how much the babe is helped in gaining health and strength! The morning bath is truly a custom that may be continued always with great profit.

Baths are spoken of as tepid, warm, hot, or cold. We shall now learn about the value of each, and when and how to take it. Tepid water cleanses the skin, but, as it is neither hot nor cold, has little stimulat- 
ing effect. Warm water cleanses more quickly and thoroughly than tepid. It also induces more blood to come to the surface of the skin, without greatly stimulating the action of the heart. For this reason, it has a quiet, soothing effect on the nervous system, being useful not only in cleansing the skin, but also in helping to bring restful sleep. People troubled with insomnia often find that a warm bath just before retiring is an excellent help in gaining a good night's sleep, for uneven circulation or too much blood in the head is often the cause of sleeplessness.

Hot water cleanses the skin more readily than warm, and also has a much greater effect on the heart's action. On this account, it is not as restful to some people, making them wakeful if taken just before retiring. A hot bath causes a profuse flow of perspiration. Consequently it relieves the body of impurities, and, if taken in time, often prevents a cold. Where there is not opportunity for a full tub bath, soaking one's feet in hot water will frequently ward off a cold, and will likewise prove a valuable aid in inducing sleep. Usually the best time for warm or hot baths is just before retiring at night, or at least two or three hours after meals. If they are taken near meal time, the extra supply of blood drawn to the surface of the body may hinder digestion.

Cold baths do not cleanse the skin as well as the other kinds that have been mentioned. However, when taken daily, and followed by thorough rubbing, 
as they always should be, they keep the skin in excellent condition, especially if one also takes a hot bath once a week. Some gymnastic exercises to stimulate the circulation should precede a cold bath. Wetting the head, face, neck, and arms with cold water before getting into the tub is also a wise precaution. This is likewise a good thing to do before going in swimming, even on the warmest days. Daily cold baths cleanse the skin and are an excellent means of gaining strength and vigor for the entire body. In the morning before breakfast is the best time to take them. Their first effect is to drive blood from the skin to the interior of the body. One's breathing becomes deeper, first quickening but afterward becoming slower. On getting out of the bath, the arteries near the surface of the body dilate, causing the skin to grow red with blood. The bather then experiences a delightful feeling of warmth and exhilaration. This is called the reaction, and without it the practice would prove harmful.

It is wise to begin the habit of taking cold baths in summer, for the body gradually becomes used to cold water as the fall and winter months follow. When convenient, the best plan is to get into a tub of cold water; but where this is not feasible a sponge bath is a good substitute. After cold water has been applied to the entire surface of the body, the skin should be vigorously rubbed with a coarse, dry towel. A cold bath of any kind is not complete without such rubbing. 
The friction thus caused aids in the cleansing, improves the circulation, and also helps to give tone and life to the glands. The cold shower bath is excellent, but few have such a privilege at home.

The bath in a tub of cold water gives a greater reaction and is more stimulating than either the sponge or the shower bath. One of the greatest benefits from cold baths is the power they give to resist cold. Those who take them do not often have the common malady known as a cold. Their bodies, having become accustomed to sudden changes of temperature, are not easily affected by draughts. It is a fact that persons in delicate. health, threatened with consumption or other serious disease, have helped to make themselves strong and vigorous by taking the morning cold bath. It is safe to say that those who have become accustomed to this healthfully stimulating practice would willingly give up any physical pleasure of the day rather than the morning bath. That so few people make use of this simple health giving custom is either on account of the time and trouble necessary, or because they do not appreciate how much real joy and zest it might add to each day's living.

The practice of cleansing the body by baths that cause a copious flow of perspiration is very general. Sometimes this is done by going into rooms filled with steam. These are called Russian baths. Often air of a very high temperature is used instead of steam. The latter are known as Turkish baths. 
Both cause a free flow of perspiration, that of the Turkish bath being greater, as dry air naturally takes up moisture from the skin faster than air that is full of steam. After the bather has stayed in the steam or hot air room until he has perspired sufficiently, he is thoroughly rubbed. An attendant then cleanses his skin with soap and tepid water. After going into the steam room cold water is applied, and after a thorough rubbing, he is ready for a good night's sleep. Probably all large cities of the United States have one or more public baths of this kind. That they are very beneficial both in cleansing and in stimulating the body can be judged from their large patronage.

What is known as the cabinet bath is an excellent home substi-

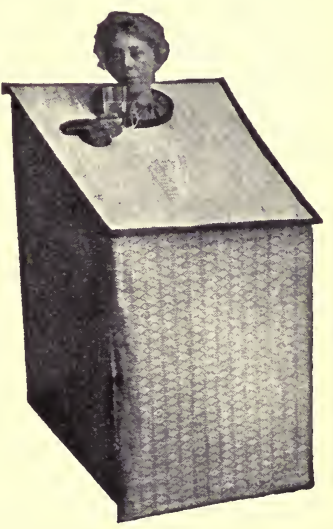

Vapor Bath. tute for the Russian bath. The cabinet is large enough comfortably to inclose a person in a sitting posture. It is usually made of rubber cloth and has an opening in the top through which the bather's head protrudes. A chair is put inside the cabinet and an alcohol lamp having a small basin of water over its flame is placed underneath. After getting inside the cabinet, the bather arranges the fastenings so as to keep the steam from escaping and stays until the desired amount of perspiration has flowed. After com- 
ing out, the cleansing process is continued with soap and tepid water, usually followed by a cold sponge bath and energetic rubbing with a coarse towel. In this, as in other warm baths, perspiration flows more freely if several glasses of water are drunk just beforehand. Wood alcohol should not be used as the fuel for such a bath, for its fumes are said to be injurious, especially to the eyes.

The cabinet bath has several advantages in comparison with the public Russian or Turkish. The only expense is a few cents for the alcohol burned, while the public baths usually cost seventy-five cents or more. A person in the cabinet bath breathes the pure, normally heated air of the home bath-room. In the public baths, the air breathed is necessarily very hot and sometimes not pure. While one may not have an attendant to give the strenuous massage received at public baths, he may derive benefit from performing this work for himself. Children who play hard out of doors, or adults doing active physical labor, usually perspire enough without such baths. For persons engaged in work requiring chiefly mental effort, a weekly bath of this kind, especially in the colder months, is very beneficial. It purifies, rests, and strengthens the entire body. It is also one of the very best beautifiers of the skin and complexion, because it stimulates the pores to an active, healthy condition.

How many other benefits of this useful liquid friend 
might be mentioned! Cold water quickly takes the numbness out of frozen hands or feet. Drinking a bowl of hot or tepid water will often relieve a headache by carrying the offending substance from the stomach or causing it to be ejected. A bottle of hot water placed next to any part of the body suffering from pain or congestion often brings quick relief. These simple water remedies, so easily prep ared, are frequently as effective as costly medicines, and far better, be-

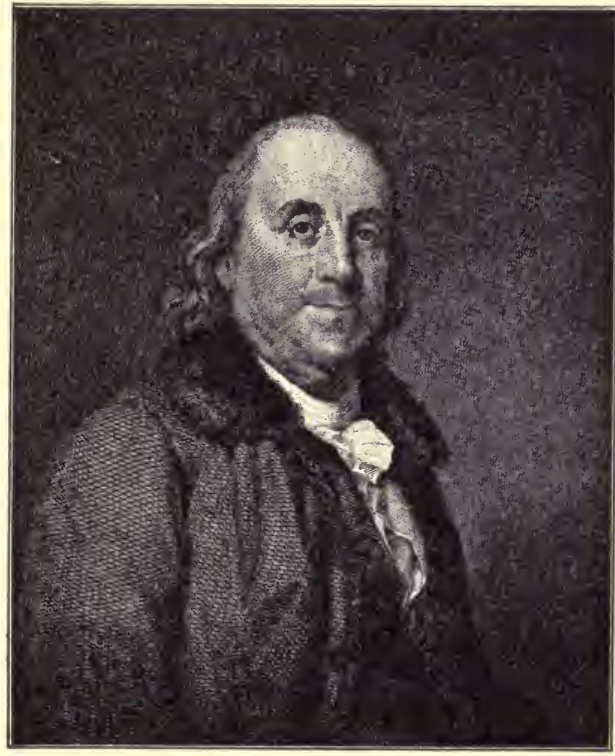

Benjamin Franklin.

cause they do not unduly tax the body. - In these and in many other ways that might be mentioned, water helps to protect our bodies by keeping them in good condition.

A familiar advertisement of a toilet article says, "The first step away from self-respect is lack of care in personal cleanliness. The first move in building 
up proper pride in man, woman, or child is a visit to the bath-tub. You cannot be healthy, or pretty, or even good, unless you are clean." Perhaps a better ending would be, "You cannot be your healthiest, prettiest, or best, unless you are clean." Surely the old saying, "Cleanliness is next to godliness," should always be remembered and unceasingly practiced.

In his interesting autobiography, Benjamin Franklin tells of some fellow-workmen in a London shop who drank much alcoholic liquor, thinking it made them strong. These English workmen were greatly astonished to find that the "Cold-Water American," as they had deridingly dubbed him, because he drank no strong liquor, easily carried printing "forms" that they could manage only with the greatest difficulty. He also relates how he told them that they could get much more strength from eating a penny's worth of bread than from a quart of liquor that cost ten times as much. This great statesman and philosopher taught many useful lessons, but none that were wiser or more practical. Truly, this common, sparkling liquid is one of our strongest and best building allies. As the days and weeks go by, we can, if we will, let our knowledge of its usefulness help to keep us healthy, happy, and wise. 


\section{CHAPTER XX}

OUR WONDERFUL RIVER OF LIFE AND MARVELOUS TELEGRAPH SYSTEM-THE BLOOD AND THE NERVES

We have learned how to aid Jack's House in building and repairing itself, and why we should always keep it clean and wholesome. Now in what ways may this wonderful house be protected from the various hurts and diseases that are likely to come? As a first step toward an understanding of this important question, let us get better acquainted with our wonderful river of life.

What is our wonderful river of life? The blood, of course, because it carries building material and oxygen to every part of the body, and takes away carbonic acid gas and other poisons that would destroy life. If our only way of getting food were from the delivery wagon that brings it to the door, the amount we could have at our daily meals would depend upon what this food vehicle brought, and how regularly it came.

In a similar way, the amount of building material the various parts of our bodies receive, depends entirely upon how freely and regularly this wonderful red river 
of life brings such material and carries away the waste products. As long as a normal supply of pure blood continues to come to any part of the body, that part will be warm, healthy, and vigorous; but it will weaken or die as the usual amount lessens or fails altogether.

In a previous chapter we read that the passing of the blood from the heart through the arteries, capillaries, and veins back to the heart again is called the circulation. We also learned that the pumping or beating of the heart is the force that propels the blood, and that its passage is helped by the elastic arteries vibrating along their course.

The arteries have small muscles that by relaxing and contracting allow these blood canals to grow larger or smaller, thus increasing or decreasing the amount that flows through them at any particular time. Exercise of any part quickly increases the supply of blood there. This follows because muscles, when active, require a larger amount of blood than when at rest, and the arteries expand to allow the increased supply to come. Rubbing or massage also stimulates the free flow of blood in the part of the body to which it is applied, for friction tends to relax these little controlling muscles. Hot-water bags or hot cloths are good remedies in colds or other congestive troubles, for applying heat to any part of the body also causes the arterial muscles to expand and allow a larger supply of blood to pass.

On the contrary, cold, by contracting the arterial 
muscles, lessens the blood supply of the surface of the body. Wet garments, too, have a similar effect, because some of the heat of the body next them is used in evaporating the water. On that account, the temperature of the skin is lowered, the amount of blood being made less, as the cold contracts the arterial muscles. Binding the arteries by wearing tight garters, belts, corsets, or other clothing is a hindrance to free circulation that all can avoid. How foolish we should think a hungry person who obstructed his walks or doors so that little or no food could be brought to him by the delivery man! Keeping blood from the hungry tissues by wearing tight clothing of any kind is just as unwise.

An acquaintance with our marvelous telegraph system is another important step toward a better knowledge of how we may protect Jack's House. How curious! Have we really anything like a telegraph system in our bodies? We certainly have, and a more remarkablé one than has ever been made by man. The central office is the brain, and the main wire, the spinal cord. This wire is protected by the vertebræ of the spine (backbone) through which it runs. Numerous smaller wires, or nerves, branch off from this all along its course, dividing and subdividing until every part, of the body, no matter how small or how distant, is reached. Sub-stations, called ganglia, are situated in various parts of the body, being especially numerous in the back. 


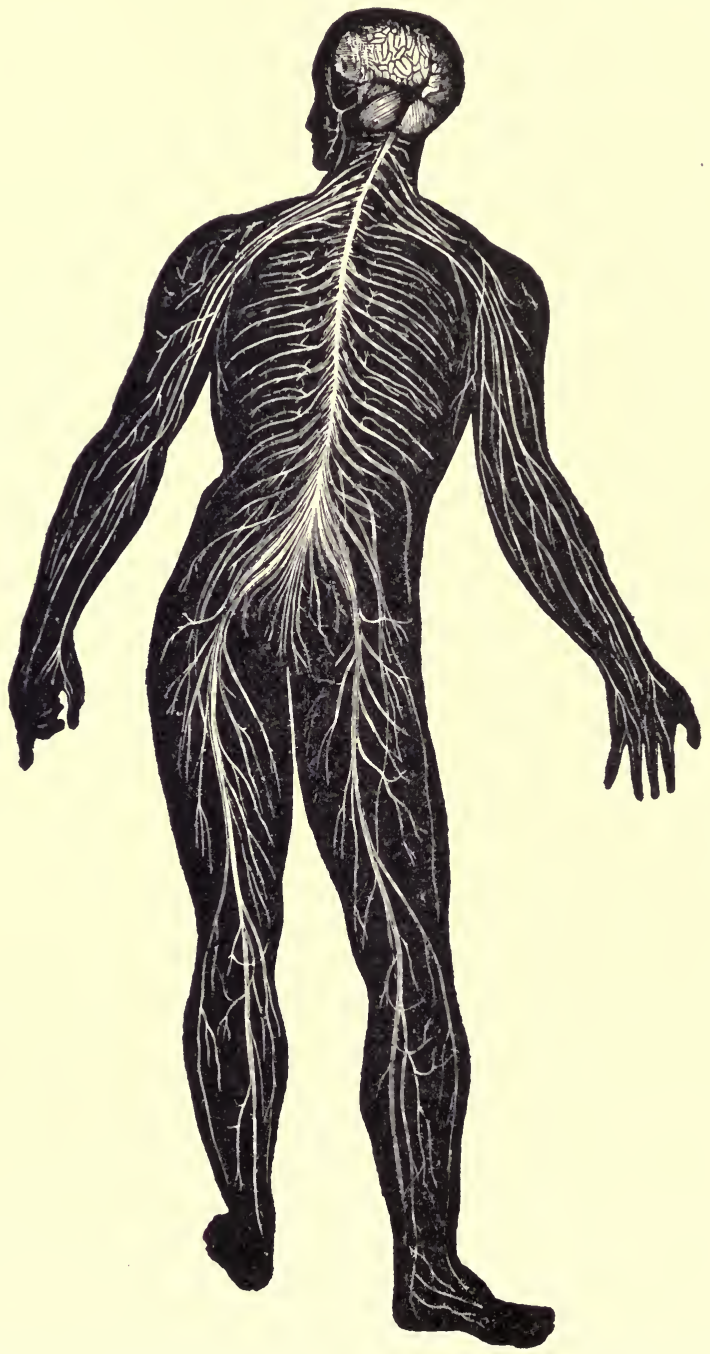

The general arrangement of the nervous system (viewed from behind). showing the brain, the spinal cord, and the chief nerves that branch from it. 
The next time you have chicken for dinner, separate the vertebræ of its neck, and notice the pithy cord extending through the center of these bones. It is the chicken's main telegraph wire, or spinal cord, which is very much like ours in appearance, though, of course, smaller.

The brain, the ganglia, and the spinal cord with the thousands of nerves extending from it, form what is commonly called the Nervous System. When we see, hear, or smell anything, the nerves of the eyes, ears, or nose carry the information to the brain. When a feeling of heat, cold, pain, or any other sensation is received, the brain is at once made aware of the fact through the nerves near the surface of the body. Nerves accompany blood-vessels everywhere in the body. They help control the blood supply by telegraphing to the brain the needs of the various parts, and carrying back to the arterial muscles the command to relax or contract.
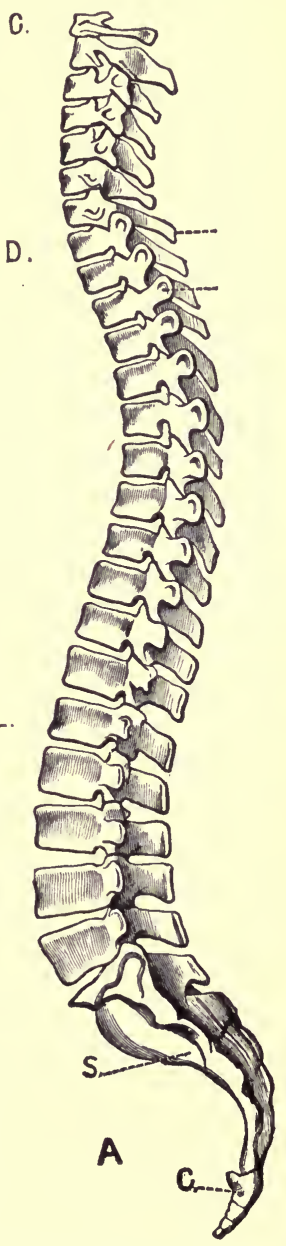

Knowing how the brain controls The backbone or spinal all the muscles and other organs, column-side view. 
we can realize the importance of the nervous system and be very careful to protect it. Although nature has strongly fortified the brain with the skull, and the spinal cord with the backbone, yet we should take especial care to guard these regions from injury. I hard blow or a fall might cripple one for life. 


\section{CHAPTER XXI}

\section{CLOTHING AS A PROTECTION TO JACK'S HOUSE}

THE normal temperature of our bodies, ninety-eight and six-tenths degrees, is almost always higher than that of the surrounding air. On this account, the heat made by the union of oxygen and bodily tissues would generally escape too quickly, if there were no outside covering to prevent. The fur of animals and the feathers of birds sufficiently regulate the passing of their bodily heat. Man, having only a thin, delicate skin for an outside covering, must conserve the warmth produced by combustion in his body by means of clothing.

People often speak of wearing apparel as warm or cold, but clothing does not give warmth of itself. Its power to keep us warm depends entirely upon how slowly or how rapidly it allows the heat generated in our bodies to pass away. Feathers and fur are very poor conductors of heat, and make very warm clothing. Dry air not in motion is also a very poor heat conductor. Consequently cloth having numerous air spaces makes warm clothing, while fabrics so closely woven as to contain but a small number of air spaces are better 
conductors of heat, and hence make cooler clothing. Because of the non-conducting power of dry air, two or more thin garments or quilts are warmer than one of thickness equal to all the others. For a similar reason, a loose garment is warmer than a tight-fitting one.

Woolen naturally contains numerous air spaces, and so is warm clothing. Cotton, linen, and silk, being usually more closely woven, are cooler clothing. When any of the last three is woven into a mesh-like cloth containing numerous air spaces, it is much warmer clothing than in the ordinary close weave. Darkcolored cloth absorbs the sun's rays to a much greater extent than fabric of light color, and, for that reason, is warmer. These facts explain why fur and woolen material are so generally worn in cold weather, and light-colored cotton and linen in the warm months.

In a previous chapter, we read how the numerous pores of the skin are continually giving out perspiration containing bodily waste and impurities. On this account, most civilized people wear next to the skin underclothing of such weight and texture that it can be easily and frequently washed. Undergarments should not allow heat to pass off too quickly from our bodies. Neither should they prevent its passing to such a degree that any portion of the body will become uncomfortably warm. Underwear should also take up moisture readily and permit its rapid evaporation. This is important, because, as moist air is a 
good conductor of heat, damp garments quickly cool the surface of the body. Underclothing should also be capable of frequent and thorough cleansing on account of the impurities taken up from the perspiration.

The fabrics commonly used in manufacturing underwear are woolen, cotton, and linen. Many think woolen best for a cold, damp, or changeable climate,

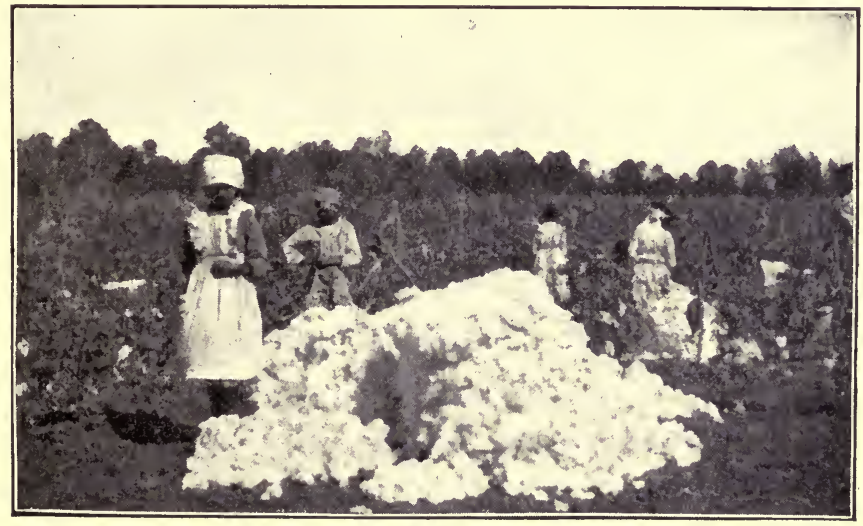

Picking cotton.

because it is a poor conductor of heat, and does not cause colds by suddenly chilling the body through too rapid absorption and evaporation of perspiration. A generally admitted objection to woolen undergarments is that they shrink in boiling water, and so cannot be as thoroughly cleansed as other fabrics. Even when carefully washed in tepid water, they gradually shrink. Shrinking makes woolen fabric 
less porous, till it becomes a sort of felt, and is consequently less desirable for underwear.

Many persons do not like woolen underwear, because its fiber irritates their skin or because it keeps them uncomfortably warm. Cotton is a fabric often substituted. Unlike woolen, it can be thoroughly cleansed in boiling water without shrinking. Being of closer weave than wool, it is a better conductor of heat, and hence makes cooler clothing. It also has the advantage of being cheaper. Cotton mesh underwear is warmer than the ordinary close weave on account of the many spaces it affords for dry air.

The so-called Linen Mesh underwear is very popular with many who have worn it. Numerous air spaces make this cloth an excellent regulator of bodily heat. The claim is made that it absorbs and evaporates perspiration much more readily than either woolen or cotton, and for this reason interferes less with the natural functions of the skin. People who have changed from thick woolen to linen mesh, even in the coldest months of the year, testify that it is entirely satisfactory as regards warmth, and that they have been much less subject to colds than they were when wearing woolen. It can be cleansed in boiling water without shrinking, but is not as durable as either cotton or flannel of the ordinary weave. It is also more expensive than either. Nevertheless, few who have worn linen mesh underwear would change to woolen or cotton, for their gain in health and 
comfort more than counterbalances the extra expense.

Underclothing worn in daytime should not be kept on at night. If the garments worn next the skin during the day are hung at night where air, coming in at the open window, can do its purifying work, they will be cleansed of much of the impurities taken up from the perspiration during the day. For a similar reason the nightclothing, and the bed clothes as well, should be thoroughly aired in the morning.

Many people make the mistake of having too much covering over them when in bed, and of wearing too heavy underwear or outer garments when dressed. By using lighter covering, and less or thinner clothing, such persons become more comfortable and healthy, because both the air and the skin have a better chance to do their important work. The habit of "bundling up," especially the head and neck, is very unwise. People who do this have a continual dread of draughts, and are frequently afflicted with colds and sore throat. Few who have tried the sensible plan of giving the air and skin a fair chance go back to heavy clothing and the bundling process. If, for the sake of keeping an overcoat from soiling a linen collar in the colder months, a neck scarf is necessary, it should be of light weight and never fastened tight enough to prevent free circulation of air.

While old persons and very young children need more clothing than others, it is a fact that many little 
children, especially, are often much too warmly dressed. Of course this is done with the kind intention of more carefully protecting them; but, other things being equal, children who cannot afford unnecessarily thick and cumbersome clothing, are more likely to be healthy and vigorous than those whose supply of clothes is unlimited. An old proverb in regard to eating says, "Enough is as good as a feast." The same is just as true of clothing. With light, thoroughly cleansed underclothing and enough outer garments to keep the skin warm, one can be both healthier and happier than if clothed in the richest furs and velvets.

The head is a part of the body that boys often clothe too warmly. Nature has provided hair to protect our heads, and ordinarily there is need of little else. Baldness, which is so common among men, is thought to result largely from wearing hats that fit too tight or are too heavy. These interfere with the free circulation of blood in the scalp and also keep air and sunshine from cleansing and giving vigor to the roots of the hair.

Fond parents buy fur and other warm caps for children, aiming to provide the best possible protection from the cold. Their little ones proudly wear them, sometimes perhaps with the feeling that they are very fortunate to possess such warm caps. Parents do not realize that the unusual weight and warmth of this expensive head-gear may cause the early thinning and perhaps even the entire loss of the covering nature 
so bountifully provides. If they did, they would, no doubt, furnish hats and caps that give both blood and air a good chance to circulate.

If boys wish to escape future baldness, it is wise to begin taking good care of the hair while very young. Why is it unusual to see a woman who has become bald? Largely because the hats girls wear from childhood are so light that they do not bind the head enough to interfere with the circulation of the blood, nor do they keep out the air. From this fact boys can certainly learn that their hair will be benefited by going without hats as much as possible, and wearing those of very light weight when any covering for the head is necessary. The oft-quoted "Blue Coat School" of London, England, furnishes an excellent example. One of the customs of the boys of this school is not to wear any head covering. It is claimed that the health of the pupils is not injured, and that baldness among its graduates is unknown.

Such an extreme measure is probably unnecessary, but its result in the case of the "Blue Coat" boys, should teach the value of wearing very light hats. Stiff, or "Derby," and high silk hats are among those that do the most damage. As good style permits soft felt "Fedora" hats, except on special occasions, the heavy stiff hats need be worn but rarely. In childhood, the small, light cap or hat should at all times be preferred. Free circulation of the blood, and giving a chance for air and sunshine to reach the scalp, help to prevent 
excessive dandruff, which is one of the chief causes of baldness. Brushing the hair vigorously once or twice a day with a brush that may be readily cleaned, and washing the head thoroughly about once in two weeks with good soap and water, are also excellent aids in keeping the scalp healthy.

Cold water every morning will not harm the hair, if a vigorous rubbing follows, but the habit of frequently plastering it down with a wet brush may be injurious. Oiling one's hair daily is also likely to do more harm than good. Vigorous brushing or rubbing will bring out the natural oil, and if the supply of the latter is not sufficient, a little vaseline rubbed in once or twice a week is the least expensive and best substitute.

Boys with hair so thick and luxuriant that they comb it with difficulty, give no thought to the possibility of future baldness. The idea that they may ever be bald like some of their elders, seems too improbable to think about seriously. Yet no doubt the very men whose heads appear so unnaturally shiny had just as thick hair in boyhood.

Year by year, as the circulation in the scalp grew weaker, and the air and sunshine came less in contact with the roots of the hair, its growth became less vigorous. The dandruff increased in quantity, and gradually hairs began to drop out. Finally a period arrived when the hair began to fall out in larger and larger quantities, and in a few years baldness was the 
result. This, in brief, is the story of the loss of hair that almost every person who is bald could tell. If the question was ever given any attention in childhood the thought was, "With my thick hair I can never be bald!" How incorrect such a conclusion is, many grown men can testify.

It is right that all should try to retain any gift of nature that improves the appearance. The loss of much hair from the head certainly does not add to any person's good looks. Health in the scalp and hair, as in any part of the body, helps to give an impression of youth and vigor. Every boy owes it to himself to form the habit of looking out for the health of his hair early in childhood. If he inherits a tendency to baldness, wearing light head covering, brushing and cleansing the hair, and daily rubbing the scalp may all prove valuable preventives. In fact, care in these respects has helped men to save their hair after scalp disease had got a very good start. How fine it is to see an old man with the head covering nature gave him in childhood, changed perhaps in color, but still vigorous in growth! Any boy who has the good sense to help nature preserve her own, may keep his hair thus vigorous and abundant, if he lives to old age.

We should also learn to be wise in clothing the opposite extremities of our bodies, the feet. The ground is an excellent conductor of heat, for which reason, in cold weather, material that is a poor conductor 
should separate our feet from the earth. Neither shoes nor stockings should be any heavier than is required to keep the feet warm and dry. It is important to have shoes fit perfectly. When they bind or chafe in any way, the free circulation of both blood and air is interfered with, annoying corns or bunions often being the result. Shoes that are too large are likely to chafe the skin and be uncomfortable.

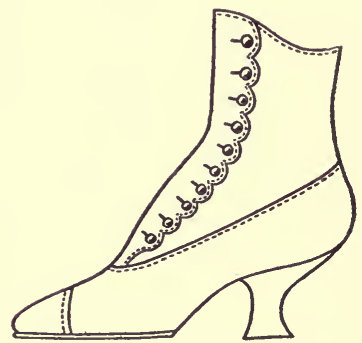

An unhygienic shoe.

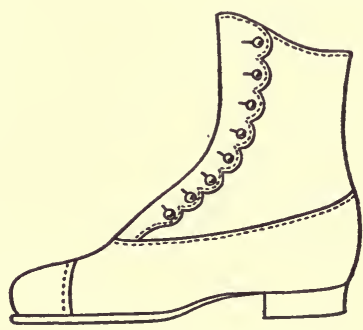

A hygienic shoe.

Shoe leather should always be pliable, and the more porous it is, the more healthful it will be for the feet, provided the latter are kept warm and dry, because a better circulation of air is possible and greater activity of the skin results. On this account, patent leather shoes, which are non-porous, are not good for continuous wear. Rubbers should be worn in damp or stormy weather. They should not, however, be kept on longer than is absolutely necessary, for, not being porous, they prevent free circulation of air. Children sometimes sit for hours in school with their rubbers on, and even adults frequently neglect to remove theirs 
while in church or at an evening entertainment. Both young and old should avoid such an unwise practice anywhere.

Shoes that lace are more hygienic than button shoes, or the style called "Congress," because they give the air a better chance to circulate. For a similar reason, low shoes, when the weather will permit, are the best of all. Shoes should be neither box nor narrow toed in form, but should conform to the natural shape of the feet.

High heels are injurious because they place the body in an unnatural position. Low broad heels are far handsomer and much more hygienic. Extension soles are good because they protect the feet. While wearing extremely thick heavy shoes may often enable one to do without rubbers, it does not seem wise to burden the feet all of the time that they may be protected some of the time. It is certainly far better to wear shoes heavy enough to protect the feet properly at ordinary times, and then put on light rubbers when stormy weather makes extra covering necessary. Where the feet sweat easily and are tender, frequent changing of stockings and bathing in cold water give both relief and strength.

Children are often so careless as not to avoid getting their feet wet. They even purposely wade or run through pools of water on their way to and from school. The fun and excitement of splashing through the fascinating water seem too enticing to resist. But 
how little fun there is in the croup, colds, and fevers that often follow! How many good times are missed through being kept in the house by such unnecessary illness! Active girls and boys would not voluntarily choose to shut themselves up in the house away from the jolly fun of out-of-door sports. They simply do not consider the consequences of such carelessness. Nor is loss of pleasure the only result, for chronic colds, catarrh, or even more serious troubles are likely to follow, if the careless wetting of feet and clothing is often repeated. 


\section{CHAPTER XXII}

HOW TO PROTECT OUR EDGED TOOLS - THE TEETH

A GOOD carpenter is careful to keep his edged tools in the best possible condition for preparing building material. What part of Jack's House serves a purpose similar to the carpenter's sharp tools? Any child can easily guess the teeth. In a previous chapter we learned the importance of thoroughly chewing our food, and how much possible future illness and discomfort might be prevented by forming that habit early in life. All can see that well-formed, healthy teeth look better than those that are irregular or decayed. We also know that these ivory-like tools in our mouths are useful in giving distinctness to speech. For these and many other reasons we should protect our teeth so well that they will be efficient servants as long as we live.

But are not the form and regularity of our teeth natural characteristics that we cannot help to regulate? Are not these useful tools bound to decay in time, and, for this reason, is there any use in trying to prevent it? Fortunately care and attention at the right time will aid in keeping teeth from being irregular, and daily cleanliness will protect them from 
decay. But to understand this, we must first learn some important facts about their structure and history.

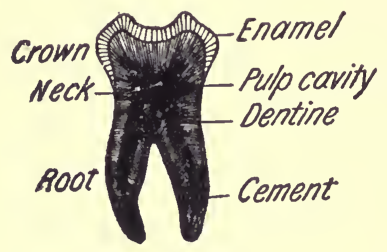

Showing the structure of a tooth (Zinns).

The part of a tooth outside the gum is called the crown, and the part within the gum is named the root. The white covering on the outside of the crown is called enamel, and, being the hardest substance in the body, is well fitted to protect the tooth from injury. Underneath the enamel and forming the principal part of the crown is the dentine, which is a hard substance, but not so hard as enamel. Both the roots and the crown are hollow, the space inside containing the nerve and the blood-vessels.

Our first or temporary set, twenty in number, are often called milk teeth. Few need to be told that these are followed by a permanent set of thirty-two. The cut on p. 224 shows both milk teeth and the permanent set. The teeth of the lower jaw are similar to those of the upper in both temporary and permanent sets.

The cut below shows how appropriately the various teeth are named. Incisors mean cutters, and from their shape it can be seen that these four teeth in each jaw are well adapted for cutting. Canine means doglike, and we observe that the two teeth in each jaw bearing that name resemble the teeth of a dog. Next to the canines on each side are the bicuspids. Cusp means 
point, and $b i$ means two, and each of the bicuspids has two noticeable points or projections. A glance at the twelve largest teeth in the permanent set shows how well they deserve the name of molars, which means grinders or crushers. The last molar on each side of both jaws is often called a "wisdom tooth," because it

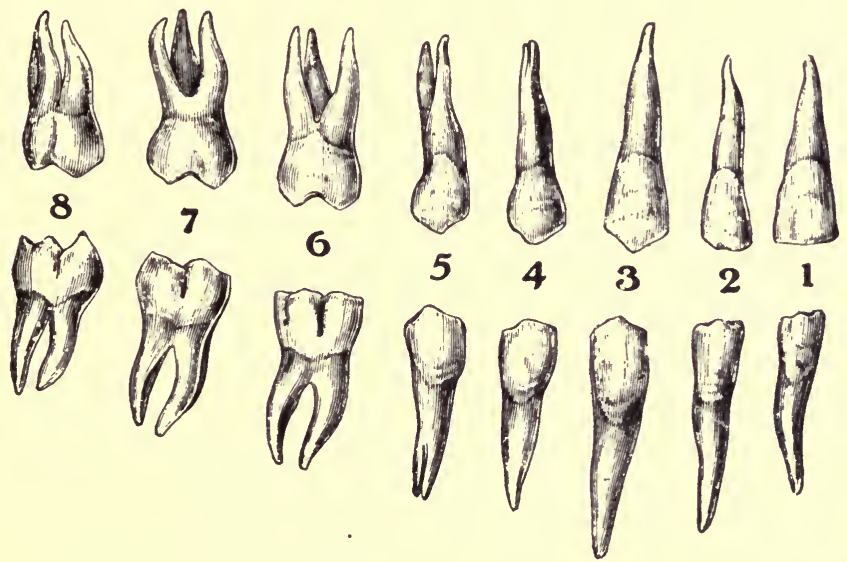

Form and names of permanent teeth. 1,2, incisors ; 3 , canine; 4, 5, bicuspids; $6,7,8$, molars.

usually appears when one is from sixteen to twentythree vears old, - several years later than the others.

How fine it would be if our teeth always kept as white and healthy as they are on making their first appearance! How much more pleasing they would look, and what a vast amount of bother and discomfort might be saved! Let us see what causes teeth to decay and how we may help to prevent it. But surely this is too difficult for any one but dentists 
and physicians to understand! On the contrary, the causes are very simple. The protective covering, enamel, is largely composed of lime and other minerals that dissolve in acid. Food decaying in the mouth produces acid that dissolves some of the enamel with which it comes in contact, thus laying the weaker dentine open to similar attacks.

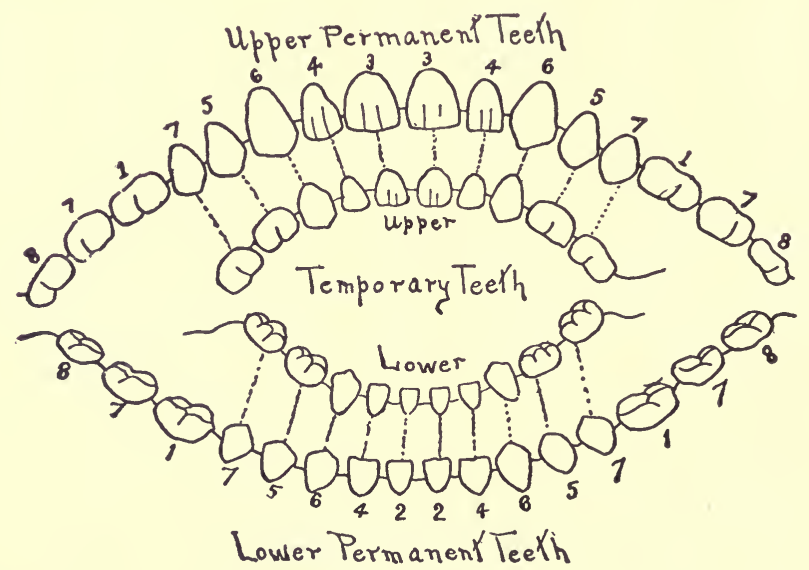

Temporary and permanent teeth.

Knowing these facts, it is certainly plain that we should thoroughly clean our teeth after each meal, or, if this is not possible, at least once a day. If only one cleaning a day is convenient, just before going to bed at night is the best time. The following is an excellent way. Rinse the mouth with water, using the tongue and muscles of the face to force the cleansing liquid about. Next crowd dental floss (waxed silk thread) between 
the teeth to remove all food particles that may have lodged between them. Rinse the mouth again, and then use a tooth-brush, moving it from the roots up and down rather than crosswise. The latter motion, instead of removing the food particles, is likely to deposit them between the teeth, which is the very thing to be avoided. Rinse the mouth again with water, and usually the teeth will be thoroughly cleansed.

A tooth powder recommended by a reliable dentist may be an excellent help in the cleansing process. However, as some preparations are said to be harmful, none should be used unless one is sure it will not do injury. Plain precipitate of chalk makes an inexpensive but excellent tooth powder.

Using dental floss is a very important part of teeth cleaning. If only a brush is used, food is likely to remain between the teeth, especially when the latter are close together. White linen machine thread No. 35 is cheaper than dental floss, and answers the purpose even better, except when one's teeth are too close together to admit it. In such cases, running the thread over wax may cause it to slip between the teeth readily. Sometimes persons who use a tooth-brush three or four times a day wonder why, in spite of their care, frequent visits to the dentist are necessary. Often it is because the cleaning they have done has not removed the food particles from between the teeth. The use of dental floss or thread and a little 
more rinsing would have made a better job, and very likely have prevented much of the trouble.

Limewater, milk of magnesia, water in which some bicarbonate has been dissolved, or some specially prepared mouth wash may be profitably used for the last rinsing. All are alkalies and neutralize acid,that is, they make the acid powerless to have any solvent effect upon the teeth. If used just before retiring, they help prevent decay during the night. Where the tooth powder used leaves a slightly alkaline reaction, that of itself will usually be sufficient. Plain precipitate of chalk, being alkaline, fulfills this purpose.

But even with the best care daily, all decay may not be prevented; and as a diseased tooth may infect those adjoining, much injury may be done. Having one's dentist examine the teeth at least once in six months is an excellent safeguard. Usually a charge is not made if an examination shows no work is necessary; and if cavities are discovered, the more quickly they are filled the better. How foolish some people are to put off visiting the dentist because they dread the possible pain! If one goes when the cavity is first started, the dentist's work may cause little or no pain. The larger the cavity and the nearer it gets to the hollow part of the tooth, the more painful the filling process may be.

If a cavity continues uncared for long enough, a peculiar sensation is felt when cold water or food comes in contact with it. When the nerve becomes exposed, 
the pain is so great that going to the dentist is usually a necessity. The result often is that the patient, dreading the pain and bother of the filling, or thinking that the tooth is too far gone to warrant the expense of such work, has it pulled out. By having the teeth examined twice a year, and going to a dentist as soon as there is reason to believe a cavity has been started, such misfortunes may be prevented.

A hard, yellowish substance called tartar often collects on teeth. If allowed to remain, it will crowd the gums away and cause the teeth to become loose. Besides it makes the teeth look unclean and is likely to cause an unpleasant breath. Tartar will often collect in spite of the most careful brushing. For this reason we should have the dentist remove it twice a year when the teeth are examined.

But acid is not the only eause of tooth disease. Building material supplied by our wonderful river of life, the blood, must contain lime and other salts needed to replenish all parts of the teeth. Unless our food contains such materials, the blood cannot furnish them. Bread and breakfast foods made of entire grain are especially well stocked with these salts. White-flour foods do not contain them, because the coarser parts of the grain which have this mineral matter are not utilized in their manufacture. Milk, eggs, meat, vegetables, - in fact, nearly all foods described in previous chapters as wholesome and nourishing, are good teeth builders. Non-nutritious or 
indigestible foods, especially candies or other sweets, should not be eaten much by those who wish to have good teeth.

Like all other parts of the body, our teeth, to be healthy, must have good circulation of the blood. Active exercise helps their circulation just as it does that of any other organ of the body. This is an excellent reason for thorough mastication, as well as for eating foods that require a great deal of chewing. An adult who lives largely on soft foods is likely to have poor teeth from lack of proper exercise, if for no other reason. It is a mistake to cut up food in very small pieces for a child after its teeth are able to do their work properly, and the little one can be made to understand that he must chew food thoroughly before it is swallowed. Parents sometimes neglect to give any instruction to children who are beginning to eat solid food, and themselves set the example of too rapid eating. Some even reprove young members of the family who have the habit of eating slowly.

How fortunate are little folks whose parents insist on thorough mastication of food from the beginning! Habits formed early are likely to remain through life. Proper exercise will result in healthier teeth and great benefit to the digestive organs. The habit of overeating will not be formed, because, if food is thoroughly chewed, the sense of taste is satisfied when enough has been taken to supply the real building and fuel needs of the tissues. Another good point to know is that 
when teeth show weakness and seem not to be well nourished, rubbing the gums a few times a day will often improve the circulation and result in general benefit.

But surely it is not necessary to bother about keeping the milk teeth clean, when, at the most, they serve such a short period! This is a mistaken idea which many people have. The milk teeth should be kept clean from the beginning. They should also be frequently examined by a dentist, and any cavities promptly filled. What a waste of time and money such care seems to be! Not so, when we consider the damage that may follow if they are allowed to decay or are removed too early. The upper central incisors usually come into a baby's mouth about the fifth or sixth month. The other milk teeth keep coming gradually, the second molars, which appear from the twenty-first to the thirty-sixth month, being the last. The first of the permanent set, the sixth-year molars, appear, as a rule, about the sixth year. They usually come before any of the milk teeth are lost, and, for this reason, are often thought to be temporary. However, if the number counted in either jaw is more than ten, one may be sure the new arrival is a permanent tooth.

The incisors, bicuspids, canines, and second molars of the permanent set come in from the seventh to the thirteenth years. As all the permanent teeth come in, the roots of the first teeth are gradually absorbed 
by the blood, while their crowns are forced out as the permanent teeth appear. From these facts we can see that several of the second set of teeth may be in the mouth before all of the first set have been removed. So, if the latter are allowed to decay, the disease may be given to the newly arrived second teeth and great damage done them. Too great pains cannot be taken with the sixth-year molars, for dentists find that these are often the first to become diseased. Carelessness with them may cause much trouble in the future.

The regularity of the permanent teeth may also be changed by losing the milk teeth before their natural time. How may this happen? Let us imagine a case. Because one of a child's canine teeth has been allowed to become badly decayed, it is pulled. Now the first bicuspids of the permanent set are pushing their way through, but, since there is a vacant space next to them, they crowd out in that direction, as it is the path of least resistance. This tooth getting out of position may cause others to change their direction, and so the set of second teeth is much less regular and beautiful than it might have been had the milk teeth received proper care.

Some little children, while teething, get comfort from continually sucking a thumb or something similar. Parents allow this because it helps to keep little ones from being fretful. The practice should not be permitted, for, by pressing the teeth, it causes an ill- 
shaped mouth. The habit of constantly sucking in the lower lip is harmful for a similar reason. Sucking the thumb may be prevented by tying something around it that will make it too large to be admitted to the mouth. To stop lip sucking, doctors sometimes insert a piece of rubber between the lips and teeth. As we have learned in a previous chapter, the habit of constant mouth breathing also causes a similarly deformed appearance. It is now possible to have an irregular set of teeth straightened by a dentist. Of course this should be done as soon as possible after the principal permanent teeth have come in.

Thus far we have read about what to do to keep the teeth clean and healthy. Let us now consider some things not to do. Cracking nuts with our teeth or biting any substance harder than food should be avoided. Biting thread is an injurious habit which girls especially need to guard against. The great force exerted to bite the thread often injures the enamel of the under teeth. Such use of our edged tools may break the enamel and cause serious injury. Pins or any metallic substances are likely to scratch the enamel and do permanent damage. For this reason, picking the teeth with any sharp or pointed metal is unwise. In a previous chapter we learned that heat expands and cold contracts air. Both have a similar effect on the enamel of teeth. On this account, a hot food or drink should not be immediately followed by one that is cold, and vice versa. When expansion and con- 
traction follow each other too closely, the enamel is often injured.

Medicines containing iron or acids often injure teeth, and, for this reason, should be taken through a tube. The fact is, unless the doctor pronounces the liquid harmless to teeth, this is a good precaution in taking any medicine. Another thing builders of good teeth will especially avoid is eating much candy or other sweets, for this practice is likely to dissolve the enamel. The noticeably bad teeth of people who frequently eat candy is the best proof of this statement. Smoking or chewing tobacco also discolors the enamel of teeth. This is another excellent reason for not forming either of these habits.

How much beautiful, healthy teeth are admired! How greatly such edged tools may aid in keeping the body strong and well! How they add to the fine appearance of those who have been wise enough to preserve them! No person is so handsome or so homely that good teeth cannot improve or poor teeth lessen his attractiveness. No one is so strong that his health cannot be weakened by diseased teeth, nor so weak that sound teeth may not be a source of strength. Are we wisely building and preserving our permanent teeth? Surely any who are careless of edged tools that do such important work are, indeed, foolish builders. 


\section{CHAPTER XXIII}

\section{THE EYES AND HOW TO PROTECT THEM}

THE special senses, seeing, hearing, touching, tasting, and smelling, might be called the windows of Jack's House. These are all of great use to our bodies, but nothing takes more from the real joy of living than the loss of sight. Not to see our friends and the beautiful world about us! Not to be able to run, play, read, write, or do any work that requires seeing! Think how heavily time would hang, and what would be taken from every hour's pleasure by such a misfortune! How much is lost even by seeing indistinctly, or by being limited as to our amount of reading and other close work! We need only try to do something with the eyes closed to realize how dependent we are on them every waking moment. In fact, the eyes are so valuable that our highest success and happiness in life depend largely upon how much and how well they can be used.

To keep any machine in the best condition for use, we should know the important things about its structure and working; and the same is true of our eyes. 
This page shows a view of the eye as it would appear if cut into two equal parts, as one might divide

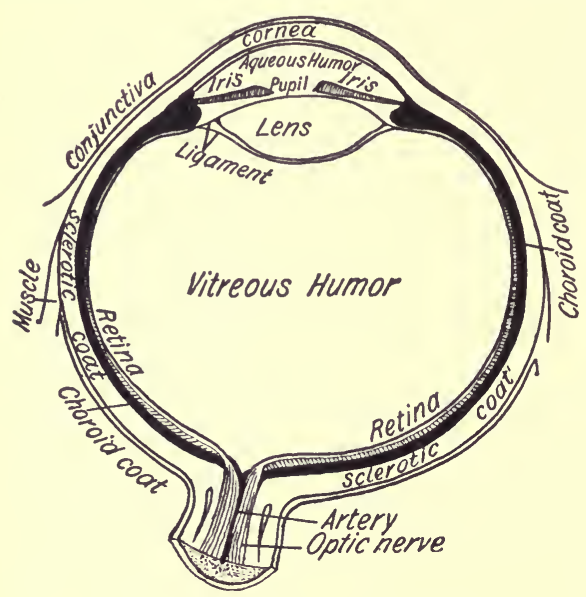

A Section through the Eyeball.

an apple, and if the flat, cut surface were held up to view.

By examining it we can see that the eye has three coats, two humors, and a lens. The sides and back of the outside coat, marked sclerotic but commonly known as the "white of the eye," are strong and opaque and serve as a protection. The front part of the outside coat, the cornea, fits into the sclerotic or white somewhat as a watch crystal is set in its case. It is strong like the white, but differs in being transparent.

The second or middle coat contains many bloodvessels and pigment cells. It serves to absorb superfluous light. The back and sides of this middle coat are called the choroid. Its front part, the iris, gives color and beauty to the eye, and is the curtain that softens the light entering it. When babies are born, the iris is usually blue, but it often changes to harmonize with the complexion of the person, a brunette, as a 
rule, having dark eyes, and a blonde, eyes of a light color.

By looking into a mirror we can see a little hole in the iris which lets the rays of light pass into the inner eye. This little round door, called the pupil, is controlled by some wonderful muscles which have the power of contracting, or making it grow smaller, when the light is strong, and expanding, or making it become larger, as the light grows weaker. All may have noticed that on coming suddenly into bright light, the eyes squint. This results from the quick effort of the muscles to protect the eye.

In the cut on page 234 we notice that in front of the iris is the aqueous (watery) humor, which seems to keep the cornea bulged out. Back of the iris we also see a convex-shaped humor called the crystalline lens, which performs the same work as the lens of a camera, for its office is to bring the rays of light to a focus on the retina. The latter, we observe in the same illustration, is the innermost coat of the eye. We also see that between the lens and the retina there is the vitreous humor. This is a jellylike substance, occupying about four-fifths of the interior of the eyeball. It is colorless and transparent, and besides maintaining the form of the eyeball, helps to protect the sensitive retina. The optic nerve, which the picture shows extending from the back of the eye, transmits to the brain the impressions received by the retina.

Comparing the eye to a camera helps us to under- 
stand how we see. The pupil of the eye serves the same purpose as the little hole in the camera which is uncovered to let in the light while a picture is being taken. The crystalline lens of the eye corresponds to the glass lens of the camera, and the retina to the sensitive plate or film on which the impression or picture is taken. This sensitive plate or film is taken from the camera, and the picture developed or brought out. But in our eyes, the optic nerve transmits each impression received on the retina to the brain, so the same sensitive plate, the retina, is used all the time.

Perhaps we know that after the sensitive plate, or film, has been taken out of a camera, and developed so that the picture is visible, it is called a negative. We may also be familiar with the fact that a negative will not be clear unless the rays of light entering the camera are brought to a focus exactly as they reach the sensitive plate or film. The same thing is true of the eye. Vision is not clear and distinct unless the rays of light are brought to a focus exactly on reaching the retina. If they are focused before or after reaching the retina, sight is more or less blurred.

When we are gazing at a distant object, if our eyes are neither nearsighted nor farsighted, the rays of light entering the eye are focused on the retina as seen in the cut on page 237 without effort on our part; but if we look at near objects, as in reading and writing, an effort of the eye is necessary to focus the 
rays of light. Otherwise they would reach the retina without coming to a focus at all.

Rays of light from a distance enter the eye in parallel lines, but the natural convex shape of the crystalline lens in a normal eye brings them to a focus on the retina. Rays of light from small objects do not enter the eye in parallel lines, but an effort of the muscles is necessary to make the crystalline lens convex enough to bring these divergent rays to a focus on the retina. The eye has muscles that do the important work of making this lens become more convex when it is necessary. The more convex a lens is,

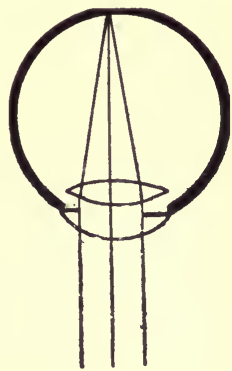

Parallel Rays focused on the Retina. whether it is the natural one in the eye, or a glass lens in spectacles, the greater is its power to bend divergent rays to meet at a point.

When a normal eye looks at distant objects, these muscles are at rest, because the convexity of the crystalline lens is sufficient to focus the rays of light on the retina. In looking at near objects, however, as in reading, writing, sewing, and every kind of work requiring close examination, these muscles are brought into use. Although they are involuntary (that is, they work without our willing it), effort is required to keep the lens adjusted for work which has to be held close to the eyes. On this account, it is restful to the eyes when using them for such work, oc- 
casionally to gaze off as far as possible into the distance, for during such an interval these muscles are completely relaxed. Forming this habit is one of the best ways to help keep the eyes strong and vigorous, for occasional complete rest has the same good effect on them that it has on other organs of the body.

Another muscular effort necessary in using the eyes for close work is convergence. By this is meant turning the eyeballs inward so that both may look at the same object at the same time. By holding a small object three or four inches from the eyes and looking at it closely, the effort to turn the eyes inward can be distinctly noticed, and, if continued, the act will soon become painful. Whenever the range of vision for close work changes, both of these sets of muscles have to accommodate the form of the lens and the position of the eyeballs to correspond with the size and position of what is being examined.

The ability of the eye to make these changes is often spoken of as its power of accommodation. In health, these muscles in a normal eye work together in perfect harmony ; but if either set becomes weakened, they do not work well together, and weak or painful sight is the result. From these facts, it can be readily seen that the usual cause of weak sight in persons having otherwise normal eyes, is that these muscles have been made tired and sensitive by overwork. Now, the accommodation muscles in normal eyes are 
not used in looking at a distance, and they must be employed in close work. Therefore if one's eyes feel weak and painful, the very best way to improve and cure them is to do the least possible amount of close work, and frequently use the eyes in distant vision. If, while studying; we look away into the distance during the necessary periods of thinking, the eyes will be rested and the thinking power improved at the same time.

The following points should also be carefully observed by all who would protect and preserve their eyes. See that the light for reading, sewing, and similar occupations is always sufficient, and that it falls properly upon the work. Do not use the eyes for close

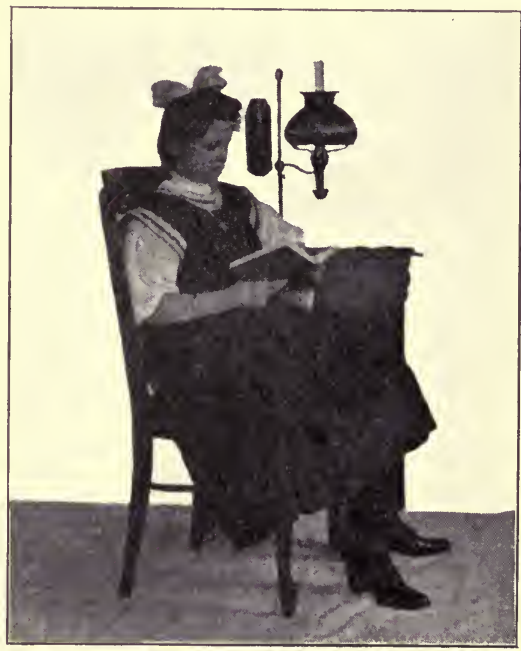

Correct Position for Reading. work while facing either the sun or artificial light. The light should come from behind and above, and, when one is writing, preferably from the left side for those who are right-handed, as a shadow is cast by any object coming between our source of light and the surface at which we are looking. We should not 
do close work by bright sunlight, as it is likely to injure the eyes. When one's eyes feel uncomfortable because of the reflection of intense sunlight from sand, snow, or any other light surface, the protecting power of the iris should be supplemented by wearing colored plane glasses. Where such care is not taken, eyes may become so irritated and sensitive that it is necessary to remain days or weeks in a dark room. Even blindness sometimes results from such exposure.

One should not wear colored glasses where intense sunlight does not make it necessary, unless so advised by an oculist, for the eyes may be weakened by such subdued light. It is also unwise to do close work by twilight, since the changing light necessitates rapid change in the accommodation of the eyes. Besides, the light often becomes insufficient before the fact is noticed.

Any light used in reading should be strong and steady, because a flickering light makes the muscles work unnecessarily hard. Artificial light is much more trying than daylight. On this account, when our eyes feel weak and tired, we should use them as little as possible in the evening. A complete rest from such occupations, even for a day, will often give great relief. It is much easier for the muscles of accommodation, if any close work we are doing is kept in a firm, steady position. For this reason, reading while riding on a car or any moving vehicle is trying to the eyes, as the jar resulting from the motion con- 
tinually changes the position of the book or paper, making frequent change in accommodation necessary. One should at least be particular to read only good print at such a time.

An erect position of the body is best for close work. When we read in a stooping position, the circulation of blood in the eye is interfered with and vision is made more difficult. For the same reasons we should be careful not to let what we are reading lie flat on the table or desk but should always hold it up toward the level of the eyes. This is a very important caution to keep in mind. One has but to compare the ease of reading in the two positions to realize how very much harder it is for the eyes when the book or paper lies on the desk. Short-sightedness and other disorders may be started by neglecting to be careful in these respects.

The habit of reading while lying down, especially by artificial light, may be the cause of much serious eye trouble, for in this position the muscles are given far more difficult work than they would normally have. We should also be very careful not to use our eyes for close work when, because of illness, the rest of the body is in a weak condition. It is not reasonable to expect the muscles of the eye to be strong at a time when the other muscles of the body are weak. For a similar reason, delicate children should not begin to attend school until they grow strong, because the muscles of the eye, like the rest of the 
body, are weak. If, when in this condition, the eyes are given the extra strain that naturally attends school work, they may easily be permanently injured.

From every standpoint it is far better for weak, sickly children to postpone entering school until they become well and strong. The time lost by so doing will soon be made up, and they will not be crippled for life by weakness of the eyes. Many people with painfully weak sight could trace it either to reading while recovering from some illness, or to entering school when they were weak, sickly children. Girls sometimes injure their eyes by doing needle-work on dark materials by artificial light. Such work is very trying to the eyes, and should be done only by daylight. Another practice of the feminine sex that may prove injurious is that of wearing veils, especially those that are thick or spotted. Surely few will dispute that anything in the way of style or appearance gained by wearing such articles would indeed prove costly, if it injured in the least the precious power of seeing.

In a previous paragraph the importance of screening the eyes from the glare of intense light was mentioned. One should take special pains not to expose his eyes to a very bright light after having been in darkness, for, in spite of the contraction of the pupils, severe injury and even blindness have been known to follow. Sometimes it is necessary to adjust a very bright light, 
but, in doing this, one can protect the eyes with the other hand. We should be careful not to look through a microscope or any other optical instrument for too extended a time, as it is very trying to the eyes.

When our eyes feel uncomfortable, they should not be rubbed with the warm hand, but bathed in cold water. Rubbing is likely to add to the irritation, while cold water cleanses and refreshes. On rising each morning, or after a nap, bathing the eyes in cold water is an excellent practice. Cold water has the same bracing, refreshing effect on the eyes that it has on other parts of the body, and so the bath furnishes an excellent stimulus for any work that is to follow.

Especial care should be taken with the eyes of infants. Shortly after birth their eyes are sometimes sore and give an unpleasant discharge. At such times a physician should always be consulted and his directions should be faithfully followed, or blindness may result. It is estimated that one-tenth of all blindness is due to lack of attention to this discharge from the eyes of infants. In a recent report, Dr. F. Park Lewis, President of the Board of Trustees of the New York State Asylum for Blind Children at Batavia, states that of one hundred forty-nine patients in that institution, thirty-nine per cent or almost fourtenths were blind because this discharge of their eyes in early infancy was neglected. The right solution applied at the right time will stop the discharge and save the eyes. Parents would not neglect to call a 
physician at such a time if they realized the possible danger. Care should also be taken that none of this discharge gets to the eyes of other members of the family, as the disease is contagious. The eyes of young babies should at all times be screened from strong light, for, as the tiny beings are too helpless to protect themselves, the delicate tissues of their eyes may be greatly injured.

Some diseases are accompanied by a discharge, which, if it comes in contact with the eyes of other persons, will cause the same disease. The cloths used to cleanse the eyes or wipe the faces of persons having such a discharge should on this account be washed separately or burned, and, of course, no one else should use them. This is one reason why it is dangerous to wipe one's face on a towel in a public place. We do not know what disease others who previously used the towel may have had, or what injurious germs we may take from it. Of course, where individual towels are available, as they now are in the public rooms of many good hotels, such danger does not exist. Any disease of children's eyes causing a discharge should receive the immediate attention of a physician. This is a matter which may possibly have such serious consequences that parents should not, under any circumstances, neglect it.

As distant vision rests the eyes, and near vision causes greater exertion, care should be taken not to make their work unnecessarily difficult by holding 
what we are reading too near. The printed page should not be held nearer than is necessary to make the print perfectly sharp and distinct. Type not readily made out when held eighteen inches from the eyes, should not be read continuously even by persons who are not nearsighted. The spacing and the paper are also important, as well as the size of the type. If too little space is left between words, they appear to run together, thus making the print indistinct. White, glazed paper may be injurious because of its glare.

Other things being equal, books and newspapers should be chosen in which the print is readily legible. A few cents more for reading matter of such character are indeed well invested, because of the strain that is spared the muscles of the eyes. One of the very best things about penmanship as now taught in our schools is the benefit both teachers and pupils derive from the greater ease with which written exercises can be read. By acquiring a plain, legible style of handwriting, we certainly do both ourselves and our friends a real kindness.

But we must protect our eyes not only by not using them improperly, but also by keeping them from being injured by substances that may accidentally get in from outside. The bony socket of the eye, the eyebrows, the eyelashes, and the eyelids all help to protect from outside injuries. The tear gland is also of great assistance in this respect. When small particles of dust get into the eye, the tears will often wash 
them down into one corner from which they can be easily taken with a handkerchief.

After getting a particle of dust or a cinder into the eye, close the lid for a moment to allow the tears to collect. Then take hold of the centre of the upper lid with the thumb and finger and draw it forward so as to lift the lid from the eyeball, and pull it down over the skin of the lower lid, and the intruder will often be deposited thereon. Should a metallic particle lodge in the eye, it can often be removed by a strong magnet.

In case any foreign substance is not promptly removed by these methods, an oculist should be visited at once. Much discomfort and even serious permanent injury may follow if this is not done. One of the greatest sources of danger to children's eyes is the use of the percussion caps which are so popular about the Fourth of July. Pieces of these caps often fly into the eyes of the one who explodes them. The fun realized from the noise made does not begin to make up for the possible danger.

While working in places where splinters of metal, stone, or wood are likely to strike the eyes, men should wear spectacles with strong plane glasses. Such glasses are also good protection against getting sparks or cinders in the eyes during railway traveling. Riding with one's back to the engine is another good way to keep cinders from getting into the eyes. Sometimes when the eye has been irritated for a time by 
a cinder or other foreign body, the uncomfortable feeling will keep up, and the eye appear inflamed, even after the removal of the cause; but usually the discomfort and inflammation soon disappear. A little saturated solution of boracic acid dropped into the eye is an excellent remedy in such cases. Because of its soothing qualities this lotion is very healing to the eye when sore or inflamed from any cause. If the inflammation continues, however, an oculist should be consulted without delay.

But dust and cinders are not the only things from outside that may cause injury to the eyes. A particle of quick-lime, mortar, or any strong acid may do great harm. When either of the first two substances has fallen into the eye, it is well to drop sweet oil in as soon as possible, and then to syringe out the eye with warm water to wash away all particles of the lime. When strong acid gets in, a safe remedy is to drop in some milk, and then syringe the eye with warm water. Although a weak solution of soda-water or other alkali would be the best antidote for acid in the eye, a person not a physician might do injury by having such a solution too strong.

Wood alcohol, and other liquids made from it, which are often used for cooking or heating purposes, are dangerous to the eyes. People have been made blind by accidentally drinking even small quantities of these preparations. Cases have also been reported where blindness or other serious injury to the eyes has resulted 
from working in a small or poorly ventilated room with shellac or varnish that has considerable wood alcohol in its composition. Burning wood alcohol or any of its products in a cabinet bath, or for light or heat in a bedroom, has been known to injure the eyes. Harm results from such uses, because the fumes are taken into the body through the lungs. Wood alcohol as fuel for a chafing-dish may cause injury to the sight, unless great care is taken.

As some form of wood alcohol is now often used as a substitute-for grain alcohol in patent medicines, Jamaica ginger, and various flavoring extracts, there is likelihood of injuring one's eyes by making too free use of such liquids. This again emphasizes the fact that water, air, and food are the only safe remedies for people to take without the advice of a physician. Beware of quick-lime, acids, wood alcohol and any of its products, is a safe rule for all who would wisely protect their eyes. The danger from any one of them is so great that an oculist should be visited as soon as possible after the best known immediate relief has been given.

It is needless to say that fresh air, pure water, nourishing food, healthful exercise, and anything that tends to improve the general health is good for our eyes, while impure air and water, improper diet, and lack of exercise lessen their power. One of the very best things for weak eyes is plenty of sleep, for the muscles are given complete rest for a long time, 
and by going to bed early the trying artificial lights are avoided. The following is a good motto to remember:

Early to bed, not too early to rise,

Is an excellent balm for tired eyes.

But how foolish it seems to be careful of so many things concerning such little organs as the eyes! Ask a person with weak eyes for his opinion, or get the next blind man you meet to tell what he thinks about it. What would they not give for your eyes! What care they would take of theirs, if through any good fortune the lost power of seeing should be restored! A fact well worth considering in this connection is that a distinguished authority, Dr. Cohn of Breslau, estimates that of one thousand cases of blindness only two hundred twenty-five were unavoidable, while four hundred forty-nine were possibly preventable, and three hundred twenty-six were positively avoidable. As far as our eyes are concerned, the old adage, "An ounce of prevention is worth a pound of cure," is most true. Let us use the full ounce of prevention, and thus avoid the unhappiness and discomfort of the necessary cure.

If all were born with perfectly formed eyes, the ounce of prevention might be sufficient to keep these organs healthy and useful servants for a lifetime. But all do not have such good fortune. On a previous page, we read that to have distinct vision, the rays of light entering the eye must be brought to a focus on the retina, as seen on page 237. Now some people 
are born with eyeballs so deep from front to rear that the rays of light are brought to a focus before

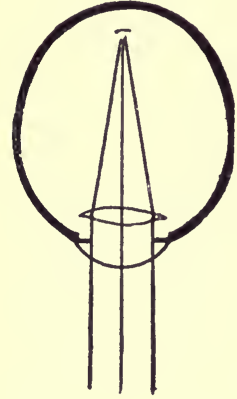

Parallel Rays focused in front of the Retina. reaching the retina. In such eyes, the accommodation muscles are of little use. In truth, they are even worse than useless, because, when exercised, they make the lens more convex, tending to focus the rays of light sooner, thus increasing, instead of lessening, the difficulty. Such a condition is called nearsightedness.

To make vision clear for nearsighted people, it is necessary to prevent the rays of light from being focused too quickly after entering the pupil. This is done by placing before the eyes glasses so hollowed out that they are thinner at the center than at the edges. Such glasses are called concave. By correcting the defective form of the eyeball, they prevent rays of light from being focused before reaching the retina, thus making vision distinct.

Nearsight is not always inherited, but unfortunately is often caused by children's stooping over books or holding them too near the eyes while reading or studying. Such position interferes with the normal circulation of blood in the eye, thus weakening the tissues. As the latter are very soft and plastic in childhood, such long continued improper position gradually changes the form of the eyeball, at the same time 
affecting the focusing power. In such cases, vision is hazy and indistinct unless one's work is brought very near. If children persist in holding books abnormally near when reading, it is a sure sign that they are nearsighted, or that such trouble is developing. If when a slightly concave glass is placed before their eyes vision becomes more distinct, it is quite certain that the advice of an oculist should be sought.

Some years ago the government of Germany, alarmed at the large number of young men unfit for military service because of shortsightedness, ordered an investigation. The expert oculists who conducted this investigation reported that the principal cause of the prevalence of shortsightedness was that so many children were stooping over their books while studying in school. The government thereupon ordered that iron frames which would prevent such stooping position should be fastened to the desk of any children showing a tendency to form such a harmful habit. The decrease of shortsightedness in Germany, since that time, is ample proof of the wisdom of the government in starting such a practice.

Because of the increased amount of close work required by lessons, nearsightedness may be noticed at any period from the time a child enters school until about the age of twenty-three. Few cases develop at a later period in life, for the eye tissues, like those of the rest of the body, gradually become tougher and less plastic as we grow older. The same reason ex- 
plains why many persons are obliged to put on glasses at about the age of forty-five, for the lense of the eye has become so inelastic it cannot be controlled by the muscles as it formerly was. Complete rest from close work will sometimes cure cases of nearsightedness at the beginning, and glasses will usually correct those that are not curable by rest. Whether the trouble is temporary or permanent, an oculist should be consulted, for the child's future comfort and working power are deeply concerned.

Farsightedness is a defect of the eye exactly the opposite of nearsightedness. In this the eyeball is so flat or shallow that, in spite of the assistance of the

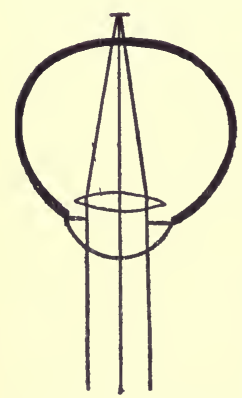

Parallel Rays focused behind the Retina. muscles of accommodation, the rays of light reach the retina before being focused, as seen in the cut. On this account, vision is blurred and indistinct. A farsighted person does not see clearly and easily at any distance. Street signs are not discerned readily, written work on the blackboard is made out with great difficulty, small type cannot be read quickly or accurately, nor can distant objects be seen as well as by others who have properly formed eyes. In farsightedness the lines on the eye-test cards in common use cannot be read at the ordinary distances. If convex glasses placed before such a person's eyes improve the vision, that is good evidence of farsightedness, 
We remember that a normal eye does not need to use its accommodation muscles when looking at distant objects, but only in reading, writing, and other close work, requiring extra focusing power. However, a farsighted eye must exert itself to focus the rays of light at all distances, and so there is no rest for the muscles except during sleep. Of course the remedy for farsightedness is convex glasses, just the opposite of the concave lenses that are used for nearsightedness. How convex the glasses should be made depends upon how faulty the formation of the eye may be. That is a matter for the oculist to determine.

A common defect usually due to unequal curvature of the cornea is called by the long name astigmatism. Usually this condition dates from birth, though it may not be troublesome enough to attract attention until the eyes are put to considerable use in reading, study, or similar oc-

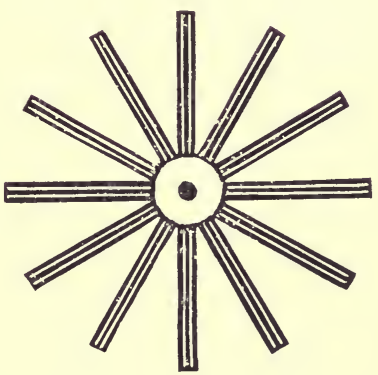

Test for Astigmatism. The Lines should appear of Equal Blackness. cupations. This defect in the form of the eyeball causes inability to see horizontal and vertical lines equally well. On the eye-test card, there are diagrams having lines of equal blackness radiating from a center. If, when this test card is at a distance of about twenty feet, any of these lines appear less 
black to the eyes than others, it is regarded as evidence of astigmatism.

This defect is a hindrance to clear and easy vision, as letters are made up of lines running in different directions. Its cure is in the use of glasses that correct the defect in the form of the eye. Neither the concave glasses helpful in nearsightedness, nor the convex lenses that relieve farsightedness, will be of any use. In fact, if neither of the above glasses gives the desired ease and clearness of vision, it is almost a sure sign that one's trouble is astigmatism. The relief and comfort following the use of the properly fitting glasses is so great that one feels his oculist is, indeed, a benefactor.

There are important parts of the eye that have not been mentioned in this chapter. Many interesting things concerning these useful organs have also been purposely omitted, for the aim has been to give only names and facts necessary to such an understanding of our eyes as will enable us to keep them in the best condition for service. There are also many disorders of the eyes to which no reference has been made. The three defects that have been described are the most common ones that the use of glasses will permanently correct, and many others that have not been mentioned result from a lack of correction of these.

For example, squint or cross-eye is often caused by farsightedness or some other defect too severely overtaxing certain sets of muscles. Squint usually starts at 
a time when children begin to occupy themselves with near objects. At first it is noticeable only when the eyes are examining something near at hand. Then it is occasionally observed when a more distant object is looked at, especially if the child, because of sickness, is less equal to the strain than usual; and finally, one or both eyes remain constantly turned in toward the nose. Parents often think the squint is a result of some sickness such as measles, or scarlet fever, as these diseases frequently occur at about the time squint is developed. While such sickness may act as an exciting agent by weakening the patient so that his eyes are less able to bear the strain, the real cause is a defect in focus due to improper formation of the eye. Squint or cross-eye should receive attention at the earliest moment possible.

When a person has squint, it is difficult for him to use both eyes at the same time, and so the eye affected gradually becomes diseased, and, in time, accurate vision in it may be lost. At the commencement of squinting, if the child is old enough, the trouble may be cured by wearing glasses that correct the defect. If the oculist thinks it too late for glasses to correct the trouble, he may restore the normal position of the eye by the simple operation of cutting the affected muscles. This can be done very quickly and with but little pain. After such an operation, there is danger of the squint's returning, unless glasses are worn that correct the improper form of the eye. Besides bring- 
ing on loss of sight in the eye affected, squint also lessens one's good looks. Any one having this trouble ought to be very thankful that it can be cured so easily.

Do we seem not to see as well as the average boy and girl with whom we associate? Have we a dislike for reading and other occupations requiring use of our eyes on near objects? Do headaches and other uncomfortable feelings result from our study and similar work? Then it is quite probable that our eyes need attention. Either rest is necessary, or they have some defect which only glasses can remedy. Nor should we feel any hesitation or shame about trying to find out the existence of such defect or weakness or any foolish pride about letting others know we have it. As a rule, it is not something for which we ourselves are responsible, and it may be present in the very young or very strong, as well as in the old or the weak.

"We don't want to wear glasses because they make us look old!" some children may say. How foolish such an idea is! How little the question of looks really amounts to, compared with the great misfortune of future weak sight or possible blindness! How very small, indeed, is such a consideration, when we know that going without glasses means only half seeing things or seeing with difficulty, and naturally prevents us from doing our best either at play or at work! How trifling is the question of looks when, without glasses, 
we may never form a liking for reading and other occupations that add so much to the joy of living! Especially are all these things true, when we realize that one of the greatest elements of beauty in the eyes is the ability to keep them wide open and to look frankly at those with whom we are conversing. Those with weak or defective eyes usually cannot do this without the aid of glasses.

"But it isn't the looks we care for, it's the bother!" others may say. Something a bother that helps a boy to throw or hit a ball more accurately, or that aids a girl to draw or play with greater dexterity! Something a bother that gives greater eye power for everything during a lifetime, and may prevent much sickness and discomfort as well! People who have long been under the treatment of a doctor for stomach troubles, headaches, or nervousness have had these ailments disappear, after the glasses that corrected their eye defects had been worn for a time. The undue strain on the nerves and muscles of the eyes had affected other parts of the nervous system, which naturally recovered their normal condition when the eye strain was relieved by glasses.

Why is it better to wear spectacles than nose-glasses, provided an oculist tells us our eyes need correction? That they are much less likely to be mislaid or broken, is a very good reason. The chief advantage, however, is that they keep their proper position before the eyes. Nose-glasses are frequently put on at an angle different 
from that which the oculist intended, and so the full benefit from the lenses is not received. Another danger is that they are not always put on at the same angle, thus giving the muscles the extra strain of accommodating themselves to different positions. Since spectacles will prove less expensive and more serviceable, they are certainly far better than nose-glasses for most persons, even though they may not seem quite as pleasing. All know we can see through dusty windows much less clearly than through those that are clean. The same thing is true of eye-glasses. On this account they should be frequently cleaned.

The service our eyes will perform, when properly protected and cared for, is truly marvellous. And yet, no doubt, there are many who have never had the full enjoyment of seeing. Mr. Francisque Sarcey, who was born with the defect of nearsightedness, gives the following interesting account of his experience: "One day, for fun, I got hold of the large silver spectacles my father used to wear, and put them on my nose, as children will do in play. That was fifty years ago, yet the sensation experienced is still vivid in my memory. I uttered a cry of astonishment and delight. Before that day I had never seen the foliage which arched above my head, except as a large, compact, green sheet, through which no ray of light penetrated.

"All at once I saw with surprise and rapture that there were openings in the dome through which the light penetrated; that the foliage was composed of 
separate leaves not soldered to one another; that the sun's rays filtered through and played among them, illuminating some and leaving others a darker shade of green. What astonished me most, and caused an enchantment of which I cannot speak even now without emotion, was that, through some holes in the foliage, I suddenly perceived far-away bits of blue sky. I clapped my hands, and was in ecstasy! I was mad with admiration and joy. I could not rest until they gave me a pair of spectacles. I felt a sort of intoxication in looking about me. All the objects I had hitherto believed to be of indistinct outline assumed for me new and singular appearances. Views unfolded themselves to my eyes and were an inexhaustible source of discoveries and wonder, for things that had previously appeared all confounded with one another, now seemed to detach themselves and recede from or approach the eye."

Are we missing all or even a small part of the joy glasses revealed to Francisque Sarcey? If so, what a pity that such misfortune should continue a day longer than is absolutely necessary. If, because of having to hold print abnormally close to our eyes, lack of power to see at a distance as well as our comrades, or other difficulty or discomfort of sight, some defect is suspected, how foolish we shall be to lose any time in finding out and correcting it. If our eyes have normal accommodation, they will be able to read fine type at twelve inches in good daylight. 
Every doctor and almost every school now has an eye-test card and every home can possess one. All the lines on these cards should be read easily and accurately with each eye, while the other is closed, at the distances indicated in figures above them. The horizontal, vertical, and oblique lines radiating from the same centers in the cards should appear of equal blackness. In all eye tests, it is important to try each eye while the other is covered, for, if they do not see alike, it is a sign that attention is needed. Perhaps the teacher or principal can test our eyes with one of these cards, but if not, some one who can should be consulted.

Should defects be discovered or suspected from such an examination, or if, for any other reason, we suspect their existence, we should go to an oculist without delay. But perhaps we may live where there is no oculist. For what better purpose can a visit to a city be made than to have full power and comfort restored to our eyes? Nor need the question of expense long delay, for what person cannot earn the necessary funds to secure the blessing of improved sight, if he sets out in real earnest to accomplish that end? Cities often have infirmaries where persons who cannot afford to pay may be cared for by well qualified physicians, but none except the very poor should make use of this opportunity.- Indeed, all should be anxious to pay for such a precious possession as the full power of seeing, and there are few oculists who will not allow a reasonable time for payment. 
Do we now fully appreciate the blessing of good sight? Then we shall ever be on the alert to guard and protect our eyes. We shall remember that sufficient light from above and behind us in doing close work, rest from close work, and especially rest from close work by artificial light, are among the principal things to be careful about in our daily life. We shall not forget that while weak eyes may be greatly helped by rest and careful treatment, defective eyes can be permanently remedied only by the proper glasses. On first meeting a person, we often decide largely by his eyes whether he is interesting, fun-loving, bright, or soulful. In fact, eyes are often spoken of as windows of the soul. Weak or defective eyes cannot be the truest mirrors of our inner selves. By proper care, we can have them both look and see their best. May we ever strive to make our eyes reflect the best that is in us, and bring in the best that is around and about us. 


\section{CHAPTER XXIV}

THE EARS AND HOW TO PROTECT THEM

THE ears are also very important windows of Jack's House. Just how much good hearing contributes to our usefulness and pleasure, no one can fully appreciate

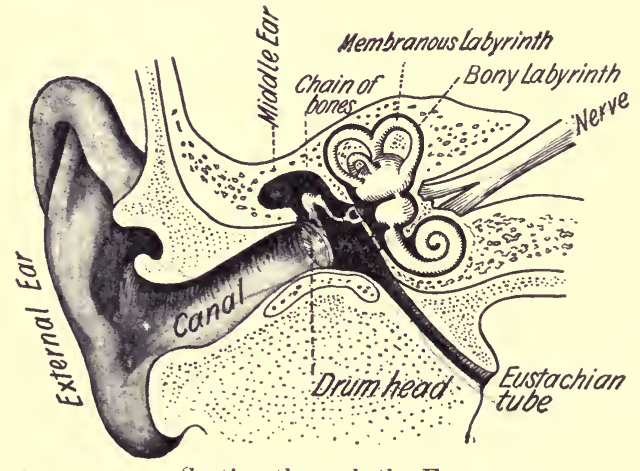

Section through the Ear. until he becomes deaf. There are occupations in which only persons having the ability to hear well can be employed, and, to be fitted for these, our ears must be in healthy condition. Indeed, there are few lines of work in which inability to understand readily in conversation is not a handicap, hence even slight deafness may be a hindrance in almost any business. But the worst feature of slight derangement of hearing is that it may gradually lead to greater or even to total deafness. 
One can partly realize the greatness of such a calamity by trying to think how much would be removed from life, if the voices of the friends we love and the various other sounds that are dear to us were never again to be heard as we know them now. What foolish house-owners we should be, not to do all in our power to prevent such a misfortune from coming into our lives! We shall now consider some facts about the structure of our ears and the process of hearing that may help us more intelligently to protect and preserve this wonderful sense of hearing that God has given us. While there are many interesting things that might be mentioned concerning the ears, only what is necessary for a clear understanding will be given.

The ear has three divisions, - namely the outer, the middle, and the inner ear. The outer ear consists of the auricle (the visible outside part that is usually called the ear), and the auditory canal, which we can see leading from the auricle to the middle ear, or drum. This canal is about one and one-fourth inches long, and the skin lining it contains the earwax glands. These glands secrete a bitter sticky wax which catches dust and usually stops insects that may enter. This wax is of great importance, for as long-as the outer end of the canal is covered with it, the skin will not itch and the ear will be comfortable. Besides being a protection against dust and insects, earwax also prevents the growth of mold. The skin of the auditory 
canal grows outward, carrying with it any worn-out skin and superfluous earwax. Consequently, the ordinary daily washing of the auricle and the outer opening of the auditory canal is sufficient. Trying to swab or dig out more of the wax may do injury by packing it in or by wounding the drumhead. The auditory canal is slightly curved. On this account an insect or a flying missile cannot go straight against the drumhead.

The latter is the partition between the auditory canal and the middle ear or drum, and is commonly spoken of as the "ear-drum." However, it is no more entitled to that name than is a part of anything to be called by the name of the whole. The drumhead is circular, about one-fourth of an inch in diameter, and extremely thin. The cavity of the middle ear or drum is about half an inch in height and width, and from onetwelfth to one-sixth of an inch deep. It contains the three tiniest bones of the body, which join together so as to form a chain or bridge from the drumhead to the inner ear. In the front part of the drum cavity is an opening into a little passage, called the Eustachian tube, leading to the throat. This tube is of great importance, for through it the middle ear gets its supply of air. The inner ear is a shell-shaped hollow in one of the bones of the skull. It contains a fluid and has a lining from which float delicate nerve endings.

Now let us consider how we hear. When anything has been set into vibration, at a certain rate of rapidity, waves of sound travel from it just as ripples of water 
pass from the place in a stream where a stone has been thrown. It is estimated that sound moves through air at the freezing-point at the rate of one thousand ninety feet a second. When a wave of air reaches the head, part of it is taken up by the auricle, and directed into the auditory canal, where it sets the drumhead in motion. The drumhead imparts this motion to the chain of little bones that connects it with the middle ear. The movement of the bones sets the liquid of the inner ear in motion, and nerves attached to the floating soft parts of the inner ear carry the impressions thus received to the brain.

So we see that the following are three of the things that are essential to good hearing. The auditory canal must be kept open and unobstructed. The drumhead must be in proper position and condition to respond to vibration. The chain of bones must be free to move forward and backward in response to the vibrations of the drumhead. Let us now give attention to a few common causes of disorder of these important parts, and find out how we may try to prevent them.

The auditory canal may be obstructed by impacted earwax, by some object or substance that has accidentally got in, or by something that has been placed in for a certain purpose and forgotten. The earwax obstruction, as has been stated, has usually been packed down by trying to swab or dig out an undue amount. Trying to get out only what may be removed by wash- 
ing and thoroughly drying the auricle and the outer orifice of the auditory canal, will usually obviate trouble from this source. In rare instances an excessive accumulation of wax can be removed only by syringing. Such accumulation is sometimes large enough to cause deafness in the affected ear; but syringing, by removing the wax, restores the hearing. One can easily imagine the great relief of the patient, especially if he has imagined something far more serious to be the trouble. A physician should do the syringing.

There is little need of the great alarm often caused by getting a foreign body into the ear. Whether it be a live insect or an object without life, slight discomfort, or, at the most, a partial blocking of the auditory canal, is the worst immediate effect, for the drumhead will prevent anything from getting into the inner or middle ear where harm might be done. However, such foreign bodies should not be allowed to remain an unduly long time, as they may produce irritation and serious injury. If the auricle is drawn upward and outward to straighten the canal as much as possible, and the head is inclined to the side of the affected ear and gently shaken, the object will often drop out. A light held close to the auricle of the ear will sometimes attract an insect from the auditory canal.

When this fails, gently syringing with some lukewarm water while the head is inclined to the side affected, may cause the object to come out with the returning water, A small syringe sold by druggists 
for such purpose should be used, and always operated gently. The water should not be syringed directly in, for this might drive the object still farther on, but it should be directed toward the walls of the canal. To get rid of live insects, the auditory canal should be filled with warm water, which will quickly destroy them. Under no circumstances should an attempt be made to pick out such foreign bodies with a wire or similar instrument, for greater damage may be done in this way than the object could possibly cause. If the two simple means described fail, a physician should be consulted.

The drumhead may be punctured by instruments carelessly used to poke out foreign bodies, or by pencils, hairpins, or something similar accidentally thrust into the ear. It may receive too severe a shock from a loud report near by, through loud shouting into the ear, or by a sudden severe blow on the ear. Even picking one's ear with a pencil or any pointed object is dangerous, for, by playfully jogging the elbow, some one may cause the drum to be punctured. The foolishness of suddenly shouting into the ear to startle a person, and the cruelty and danger of boxing any one, especially a child, on the ear, can be readily understood.

When we are going where loud explosions are expected to take place, the drumhead may be protected by a covering. It may also be well to remember that if one swallows at the instant an explosion occurs, the Eustachian tube will be opened, and air will be sent into 
the middle ear with sufficient force to assist the drumhead in warding off the shock. The danger from loud explosions is one that should be carefully guarded against, for severe shocks to the nerves often cause temporary or even permanent injuries to the ears.

But one of the gravest and most common dangers is the stoppage of the Eustachian tube, for such a stoppage cuts off the middle ear's supply of air. Then, when the air it contained before the stoppage is absorbed, a vacuum is created, and the air outside the drumhead naturally breaks through it to fill this vacuum. The result is that hearing becomes permanently deranged because of the puncturing of the drumhead and the change in position of the chain of bones.

The lining of the Eustachian tube is simply an extension of the lining of the throat and nose. Consequently, colds, catarrh, adenoids, and kindred troubles are common causes of the stopping up of the Eustachian tube, because anything that affects the inside of the throat naturally passes to the inner part of this tube. Continuous mouth breathing, by irritating the lining of the throat, may also cause the Eustachian tube to become stopped up. If there is any derangement of hearing after or during a cold, an aurist should be at once consulted. Parents should watch their children carefully for evidence of the ears being affected, for deafness is so insidious that often it is not suspected until accidentally found out by a physician.

The same harmful result frequently attends certain 
children's diseases, such as measles and scarlet fever. The latter being especially dangerous, the slightest symptoms of pain or of sounds in the ear should be reported to the attending physician without delay. In the case of young children who give evidence of pain, but are not able to tell where it is, a finger may be pressed below the auricle, and, if the pain is in the ear, the fact will be made evident by the child. These statements make it plain that wise protectors of the ear should do all they possibly can to avoid catching colds. This, in brief, means that all should make abundant use of pure air and cleansing water, and avoid handicapping their bodies with too much food or improper clothing.

Deafness and unusual sounds in the ear are signs that the Eustachian tube may be stopped up. Sometimes a vigorous blowing of the nose will open the tube and give relief. Where this fails, or, as in the case of an infant, is impossible, a doctor should be consulted. Care should be taken to test the hearing of infants frequently, especially if they have had measles, scarlet fever, or similar diseases, or have suffered much with colds. Children who become totally deaf are likely also to become dumb, for, not being able to hear others speak, they never learn to talk in the ordinary way.

Earache may often be cured by placing a hot-water bag, or cloths wrung out of hot water, back of and below the auricle. Breathing into the ear will sometimes quiet a slight attack of earache, the warmth of the 
breath having a soothing effect. One should not pour sweet oil, glycerine, or similar liquids into the ear to cure earache, unless advised to do so by a physician. Although such fluid, if heated, may relieve the pain for a time, it is likely to become rancid and furnish soil for the growth of harmful mold.

A discharge of pus from the ear may always be considered a symptom so dangerous to the sense of hearing that an aurist should be consulted. Such discharge is usually thin and mild in its character at first. If allowed to continue, it becomes greater in quantity, very irritating, and of a most disagreeable odor. Its cause is usually severe inflammation of the outer or middle ear, a condition which often follows an attack of scarlet fever or measles. When the discharge is from the middle ear, the inflammation has brought about a puncture of the drumhead. Even when the inflammation is in the outer ear, there is danger of puncturing the drumhead, if the trouble is not relieved. Displacement of the chain of bones and impairment of hearing usually follow permanent injury to the drumhead. Nor is impairment of hearing the only danger. Such inflammation may extend through the middle and inner ear to the brain and even cause death.

One of the things boys like best to do is to go in swimming, though few realize that too frequent and too careless visits to the old swimming hole have caused many a lad to be handicapped for life by poor hearing. Jumping into the water from high places 
without holding the nose may forcibly send this liquid through the Eustachian tube, causing irritation of the middle ear. When water remains in the auditory canal after swimming, heat of the ear is required to evaporate it. Colds and inflammation are likely to follow such a condition, for the ear is very susceptible to colds.

The ears may be protected by holding the nose when jumping or diving. Having the head above water as much as possible during the swim, and getting all of the water we can out of the ears after the bath, are both wise precautions. A good way to get the water out is to stand on one foot and kick backward strongly with the opposite leg, while the side of the head is inclined downward. Of course, for the time being, there may be more fun in jumping and diving all we like, staying in the water as long as we want to, and dressing without thought of the health of our ears. However, few will question that even such good fun got at the expense of hearing power is a very poor bargain.

Cotton plugs may be worn in the ears for a short time without doing any harm; for example, while in swimming. They should not, however, be kept in for any extended period, especially while within doors. One's hearing may be injured by the continuous clatter of machinery. On this account, boiler makers and men doing similar work are often made deaf. Such misfortune may be avoided by wearing ear protectors. 
Hearing is also sometimes injured by substances being forcibly snuffed up the nose, as some of the liquid or powder gets into the Eustachian tube, causing inflammation. Atomizers that spray gently will do no harm, but a quantity of liquid or powder forcibly impelled or snuffed up the nostrils can do little good to the nose or throat, and may cause injury to the ears. Taking too much quinine is another cause of deafness. This drug is often used in cases of colds or fevers, and, when long continued, sometimes causes loss of hearing. In tropical countries, where it is largely used as a remedy for fevers, many persons can be found whose hearing has been impaired by its use.

One of the greatest dangers of deafness is that the affliction comes on so gradually that it is often not noticed or considered seriously until ordinary conversation becomes difficult to hear. This follows naturally, because persons slightly deaf are likely to think that their inability to hear is due either to their own carelessness or to the indistinct speech of others. These faults they try to correct by the most eager listening, as well as by watching the lips of those with whom they are conversing: and the latter, noticing that they are frequently misunderstood, raise their voices a little or speak more distinctly. This mutual help prevents, for a time, a discovery of the real source of trouble. As the idea of being deaf is disagreeable, friends hesitate to call attention to anything about which they think one may be sensitive. For these reasons the danger- 
ous condition of the ears is often not realized until it is too late for much relief.

There have been discovered many cases of stupid and disorderly pupils who, when the cause of deafness had been removed, became bright and intelligent. Having only partially heard, they could not fully understand, and hence seemed to be stupid and unruly. Not realizing that they were not hearing as well as others, they did not know that the help of a physician should be sought. This emphasizes the importance of testing the ears of school children. Both wasted time and much unhappiness may be saved by such tests.

But suppose we are attending schools where ear tests are not given, how may we find out whether our hearing is defective? The low-spoken voice should be heard at a distance of twenty feet. A watch having a loud tick may usually be heard about three feet, and one with a low tick from twelve to fifteen inches. All such tests should be made with one ear, while the other is covered. If the ear fails to hear these sounds, or if for any other reason we think our hearing is not normal, there should be no delay in consulting an aurist.

Frequent earache, pus or odor from the ear, continued roaring or other unusual sounds in the ear, are all dangerous warnings that should never be long unheeded. Inability to breathe through both nostrils is also a sign that the advice of an expert should be sought. When attended to in time by one who is competent, these often do not result in permanent 
harm, but by neglecting them or experimenting with patent remedies, precious hearing power may be lost.

Some people are not concerned about deafness in one ear. They seem to think either that increased power in the other will make up the loss, or that they can get along well enough with one good ear, and that it is not worth while to bother about the other. This is a great mistake. Even if there is no chance of restoring the lost power to the diseased ear, the same difficulty may occur in the good ear, and deafness in both result. No pains or trouble should be spared to restore the affected ear to a state of health. Very likely deafness may exist for years in one ear, while hearing in the other remains perfect. On the other hand, the possibility of the healthy ear becoming affected is always present, and the slightest cause may bring about such a grave result.

Altogether too little attention is directed to the disabling effects and the unpleasant features of deafness. The groping of the blind always excites sympathy. The inability of the deaf to understand unfortunately seldom makes much impression. It does not require great imagination to feel for those who are blind, because the pathos of their loss is so self-evident. But few are moved fully to sympathize with deaf persons, since their loss and discomfort are not so noticeable. Very deaf persons speak in abnormally loud or in extremely low tones, because they cannot hear themselves. Often they are troubled by roaring and other unnatural 
sounds in the ears that must have an unpleasant effect on the entire nervous system.

They are also sensitive and shy, frequently imagining that others are having fun at their expense, and even becoming morbid and melancholy as a result of their affliction. We have learned how even slight carelessness may cause some or all of these great misfortunes. May the knowledge we have gained lead us to keep our ears healthy and serviceable as long as we live. 


\section{CHAPTER XXV}

\section{REST AND SLEEP}

"You must not burn the candle at both ends," is a caution often heard. In other words, work and play must be followed by sufficient rest and sleep, or serious consequences will result. During sleep the brain and all other parts of the body rest and regain lost strength. Therefore, if we do not sleep enough, the body cannot be in its best condition, for it has not had a chance to get fully rested.

But how much sleep is necessary? That depends on one's age and various other conditions. A very little baby usually sleeps a large part of the day. Growing children need from fifteen to nine hours daily, the number decreasing as age advances. Adults should sleep from eight to ten hours. Provided our bedtime is early enough, it is a safe rule to sleep as long as we are naturally inclined. If we awake fully refreshed and rested in a shorter time than is ordinarily needed, that period is sufficient. However, it is very unwise to decide, after a short experiment, that we can get along well on an unusually small number of hours' sleep. While for a time there might be no serious consequences 
from such a practice, loss of strength and vitality is quite likely to come if it is continued. It is far wiser and more economical, in the long run, to exceed rather than to cut short the sleeping hours ordinarily considered necessary. When we feel ill or nervous, it may even happen that quietly resting in bed a few hours or days will completely restore our strength.

Certain conditions help the body to gain the greatest possible benefit from sleep. The first is a plentiful supply of pure, cool air. One may sleep all night with windows closed, because of wintry atmosphere outside, and yet feel languid and nervous in the morning. This is because the large amount of carbonic acid gas in the room during the latter part of the night has had a depressing effect. A person may not wake once through a hot summer's night, and still not be rested next day, for, even with wide-open windows, there may not have been sufficient circulation of air to keep the atmosphere pure and bracing. A sleepingroom having two or more windows should always be preferred to a chamber with but one, as good ventilation is much more easily secured, especially in summer.

Then there should be just enough bed clothing to keep the body comfortably warm. An unnecessarily heavy covering is too warm, and does not afford sufficient chance for air to circulate near the skin. Usually it is well to sleep with the head on a low pillow. A firm, compact mattress is also more hygienic than the feather and straw ticks that were formerly in com- 
mon use. Of course we should not sleep with bed clothing over the head if we want to breathe pure air. "Early to bed and early to rise" is unquestionably a good motto, for it is more natural to sleep at night than by daylight. While nearly all healthy persons can get accustomed to almost any conditions, quiet surroundings are more favorable to restful sleep than are the opposite. Habit is a powerful factor in sleeping as well as in other things the body has to do. On this account it is well to have a regular time for retiring and rising. We shall then not be troubled with wakefulness when we go to bed, nor shall we need an alarm clock in the morning. Sleeping and waking at the right time will become simply a matter of habit.

It is perhaps needless to say that sleeping with a person who has a contagious disease is dangerous. Another fact not as well understood is that children should not sleep with invalids or with very old persons. With no apparent cause, children who do so have gradually become weak and sickly. If, on account of a doctor's advice, or for any other cause, the practice of sleeping with the older person is discontinued, the child has usually regained health and vigor. Wherever it is possible, it is well, for many good reasons, that children should sleep alone.

As a rule, growing children are not troubled with insomnia (sleeplessness). Their difficulty, as far as sleep is concerned, is to wake up at the required time in the morning. Adults, however, sometimes get into 
a state of serious sleeplessness. Perhaps they lie awake a long time after going to bed, or maybe wake up far too early in the morning. Possibly the wakefulness continues through the greater part of the night. The body's reclining position and lack of effort may be restful to their muscles, but their brains get little rest without sleep. People thus affected may continue their regular duties for a long time. They cannot, however, work with their accustomed skill or vigor. Nor, if regular habits of sleep are not restored, can they escape the nervous prostration or other breakdown that is sure to follow.

Sleeplessness is thought to be caused by some disorder of the circulation. It may be too much blood in the head. Perhaps some digestive difficulty causes an uncomfortable accumulation of gas, or there is some nervous irritation. Plain food and fresh air purify the blood and strengthen the circulation. Hence both are conducive to sleep. It is also true that indigestible foods and impure air help to bring on sleepless conditions. Hard study or other difficult or exciting mental work just before retiring, draws an extra supply of blood to the head, and so it should not be done by any one inclined to wakefulness. For a similar reason, worry, which is a common cause of sleeplessness, should be carefully guarded against. Forget both work and worry is a good rule for any one to put into practice on retiring at night.

It also naturally follows that anything which draws 
extra blood from the head to the other parts of the body tends to prevent being wakeful. Light exercise, a warm bath, or soaking the feet in warm water are among the most useful practices of this kind just before going to bed. Some also find that a glass of hot milk or other simple food taken at bedtime accomplishes the same purpose, as it calls blood to the stomach. However, neither rich food nor a hearty meal late at night is conducive to restful sleep.

People whose occupation requires chiefly mental effort are much more likely to be troubled with sleeplessness than those engaged in physical labor. Therefore such people should not neglect to take enough physical exercise to keep their circulation even and active. In fact, whatever tends to keep the body in a normal, healthy condition induces restful sleep. Notice how peacefully a little child sleeps. Not a muscle is tense. If you try to lift him while sleeping, he is almost as limp as a rag. By fully relaxing the muscles in a similar way, adults, too, may help to bring sound sleep.

Pupils sometimes sit up late at night studying for next day's examination. They try to cram all possible information into their minds, expecting to be better prepared for the questions. Why is this an unwise investment of time? Simply because the brain does an extra large amount of work without having a sufficient chance to get rested. How much more sensible it is to give the brain its usual rest! Then nervousness will not prevent memory and reason from doing 
their best next day, for the brain will be clear and strong.

In some cities much is heard about children's breaking down in health. Parents and doctors frequently say school work is to blame for this. They declare there are too many studies or that too much home study is required. Nevertheless, the difficulty is often one that can be corrected only at home. It may be due to lack of nutritious food or to incorrect eating habits. Often the trouble is too much candy. Perhaps there is not enough out-of-door play before and after school, or maybe the sleeping-room is kept too warm or is not well ventilated. Very often, instead of going to bed at nine o'clock or before, dancing school, theater, or parties cause sleep to be postponed until a much later hour than usual. How wise are the parents who insist that if such pleasures are indulged in at all during the school year, they shall be allowed only on Friday or Saturday nights.

Young men and women sometimes have the foolish notion that they can study or work till very late at night and resume the same or other work very early in the morning. They are young and strong and perhaps have rarely been ill. They are ambitious to excel or to advance rapidly. "Surely no one so strong and well can be injured by the loss of sleep," they think. Unfortunately many have found that thus burning the candle at both ends did not pay. Knowledge got at the price of health profits little. 
Grades skipped at school through cutting off needed rest at night are a poor bargain when, as is often the case, nervousness and ill health are among the consequences.

About three hundred years ago, Cervantes, a wellknown Spanish author, made one of the characters of his most famous book say: "Now blessings light on him that first invented sleep. It is the cloak that covers men's thoughts. It is meat for the hungry, drink for the thirsty, cold for the hot, and heat for the cold. It is the money that purchases all the pleasures of the world cheap. It is the balance and weight that equals the shepherd with the king, the simple with the wise." Carefully study the meaning of this quotation, and decide whether the same benefits might not be justly claimed for sleep to-day. An American poet, John G. Whittier, includes "Sleep that wakes with laughing day" among the greatest joys of the barefoot boy. By remembering the value of such sleep, and daily allowing ourselves a reasonable amount, can we not keep it among our precious possessions? 


\section{CHAPTER XXVI}

HOW TO PROTECT JACK'S HOUSE-WHAT TO DO IN EMERGENCIES

JACK's House may receive hurts that ordinarily do no lasting harm, but, if not taken care of properly, are likely to cause permanent damage. It may also meet with injuries so severe that to know what to do until a doctor comes is of great value. While many go through life without having such misfortunes, persons in every occupation are liable to them. Certainly any one who knows how to do the right thing at the right time may be of great service; and, by being careful, all may prevent their own slight injuries from becoming serious.

Cuts are among the most common injuries to the body. As a rule, if not deep, the blood soon thickens over such wounds, and healing is only a question of time. If the wound is made by something dirty, or if the surface under the skin is left exposed to the air, germs may get in that will cause inflammation and serious trouble. It is wise immediately to cleanse such wounds, and then wrap them up with gauze or muslin cloth. When they are neglected, long-con- 
tinued inflammation and soreness may ensue and sometimes even blood poison may develop. Blood poisoning has often compelled the amputation of a part or a whole of an arm or a leg, and is not an infrequent cause of death.

Cuts are sometimes deep enough to sever a vein. Persons thus injured should lie down and have clean, cold, damp cloths pressed firmly against the wound. This will often stop the bleeding or cause it to be retarded until some one comes who knows just what to do. If the doctor's arrival is long delayed and the loss of blood seems alarming, a bandage may be fastened on firmly enough to stop the flow of blood. It should not, however, be placed between the wound and the heart. The dark color and the steady flow of blood

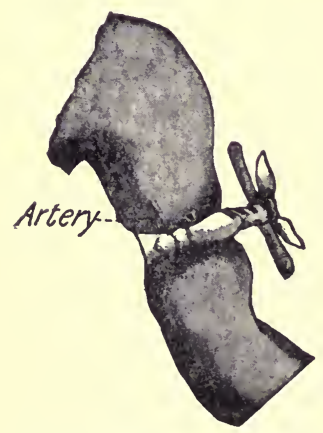

Knot twisted on Artery above Cut. indicate that a vein has been cut. When an artery has been severed, the blood is of a bright red color and comes out in jets.

When a wound is deep enough to cut an artery, if it be in an arm or a leg, the following is an excellent way to stop the bleeding. Make a pad of a towel or something round and hard tied in a cloth. Bind this with a handkerchief around the limb near the wound and between it and the heart. If such a bandage does not stop the bleeding, loosen the 
handkerchief enough to slip in a strong, round stick. This may be twisted around until pressure stops the flow of blood. The stick may be kept from untwisting by tying it to the injured limb. This is called a Spanish windlass or tourniquet and by it one can get great pressure. Holding a wounded arm above the head will help to stop the flow of blood. If one of the lower limbs is eut, lying down on the ground or floor and supporting the limb on a chair or something of equal height will be helpful. A physician should always be summoned in case of severe bleeding, for the judgment of an inexperienced person as to whether an artery or a vein has been cut might not be safe.

When companions are present, and the hurt is where a tight bandage will not be effective, one should thrust a clean cloth against the wound and press hard, while another hastens for a doctor. If a person receives a severe cut while out of doors alone, one of the best plans is to press the cleanest cloth he has against the wound and hold it there firmly until he finds assistance. Of one thing we may be certain, bleeding from any wound must be stopped, or our wonderful river of life will be exhausted and death will ensue. Instead of being frightened or fainting at the sight of blood, we should have the good sense to check its flow until some one can stop it. Pressure will usually do this, if enough is used at the right place. Bleeding from the nose may often be stopped by sitting upright, bathing the head and neck with 
cold water, or applying cold to the nose. If these simple remedies fail, a doctor should be sent for without delay.

Sometimes a severe blow does not break through the skin, but wounds the soft tissues below it, causing bleeding and discoloration under the skin. What is commonly spoken of as a "black eye" is a familiar example. To such a bruise, apply hot water first and afterward cold. When a cut is wide, the edges should be fastened close together so that a scar will not be left to disfigure the skin. A doctor should put some stitches in such wounds, for otherwise a scar is likely to remain.

Another common injury to our bodies comes from the effect of too great heat. The simplest and best home remedy is to bind on powdered baking soda with damp cloths. Sweet oil or vaseline may be applied later. When the burned surface is large, a physician should be immediately summoned, as the danger of serious results is often great. When clothing accidentally takes fire, the best thing to do is to smother the flame by wrapping oneself up in a quilt, coat, or any other heavy covering that is at hand. This keeps the air away, and fire cannot burn without air. To become frightened and run is the very worst mistake to make, because it gives the air the very best chance.

Burns from oil of vitriol or other strong acids should be treated with limewater, soda and water, or a so- 
lution of any other alkaline substance that can be obtained most quickly. Water containing vinegar, lemon juice, or other readily obtained acid should be applied to burns caused by lye, lime, or other alkalies. These are the best remedies to use in such cases, because acids and alkalies neutralize each other; that is, they make each other incapable of having the effect that each might have alone. Severe burns caused by either are so serious that no time should be lost in getting a physician. Children should never touch electric wires, for serious injury and even death may result from coming in contact with them.

Sunstroke is another injury from heat to which Jack's House is subject. It usually occurs on a hot, muggy day. Often it is preceded by pains in the head and a general feeling of oppression which result finally in a loss of consciousness with heavy, labored breathing and very dry, hot skin. The patient should be taken to a cool place, and his clothing should be removed. Sunstroke is often followed by permanent injury to the mind, so a physician cannot be too quickly summoned. Absence of perspiration in the presence of great heat is often the cause of sunstroke. Therefore, while one is perspiring freely, such misfortune is less likely.

People are sometimes exhausted by heat when the cause is not sunstroke, but the depressing effect of long-continued high temperature on the system. This is called heat exhaustion. In such cases the skin 
is moist and cool, instead of hot and dry. As in sunstroke, a physician should be obtained as soon as possible.

But our bodies may be injured by cold as well as by heat. What relief can be givén when they are frost-bitten or frozen? When only a small part, such as an ear, a nose, or a toe is affected, rubbing with snow or with cloths wet in cold water, or, as in the case of the hands or feet, placing the frozen part in cold water is an excellent help. When a larger portion of the body is frozen, rubbing, blankets, extra clothing, warm drinks, and, where the person still retains the power of motion, exercise, may all be helpful. Care should be taken, however, not to bring the sufferer into a warm room, for the blood-vessels of the frozen part are choked and swollen, and, when heated suddenly, are likely to burst, causing unnecessary suffering and bothersome wounds. After the circulation has been restored, vaseline, sweet oil, or other healing lotions will be beneficial.

In a previous chapter we learned why the lungs must receive a regular supply of pure air, and we can readily understand that life will not continue if breathing stops. Drowning is one of the common accidents that stop breathing. As even the best swimmers may be in danger of this misfortune, all should know how to give aid at such a time. The two things necessary are to remove anything that may obstruct the entrance of air, and to reëstablish the movements 
of the chest that take place in the act of breathing. While waiting for a doctor, wipe out the mouth of the rescued person as far back as you can reach with a finger covered with several thicknesses of cloth, to remove anything that may be obstructing the mouth or windpipe. Strip off any clothing that may hinder breathing. Then turn the patient on his face, and, grasping him under the abdomen, quickly jog him up and down to expel the water from the breathing passages. To further assist this end, rest the patient's face on his arm with a large roll of clothing under his abdomen, and, placing a hand on either side of the small of the back, press heavily.

Then turn him on his back, and if breathing has not commenced, give him several hard slaps over the pit of the stomach. Artificial respiration should now be immediately tried. What is known as "Sylvester's Method" is generally regarded as the best.

After wiping out the mouth and expelling the water as previously directed, place the patient on his back, with a large roll of clothing under his shoulders.

Then pull out his tongue and have another person hold it to keep it from going back to obstruct his windpipe. If no helper is at hand, the tongue may be held out by a rubber band fastened under the chin. Another way is to push a pin, needle, or some other sharp instrument through the tongue about half an inch from the tip. This will rest against the upper and lower lips and keep the tongue from falling back. 
Then, kneeling behind the person's head, grasp his arms halfway between the elbows and wrist, draw them quickly and steadily up over his head until his hands touch the ground behind, and keep them there about two seconds, as in the cut. This motion, by

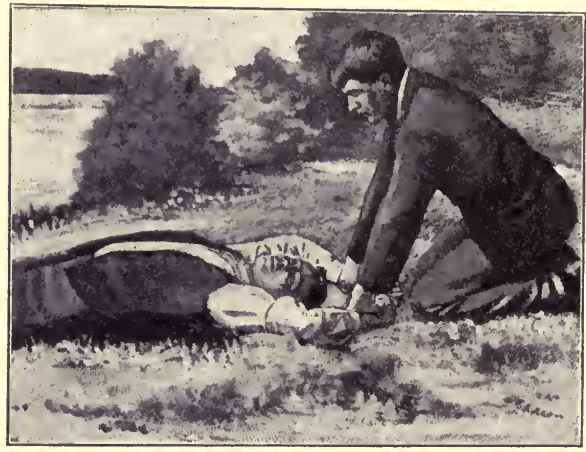

Artificial Respiration-First movement: Inspiration. drawing the ribs upward, expands the chest and causes air to enter. Then move the arms back until they rest against the sides of the chest, the forearms a little on top, pressing them firmly downward and inward against the chest for about one second, as on page 291 . This contracts the chest cavity and forces the air out. These movements should be continued alternately about sixteen times a minute, until natural breathing is restored. Care should be taken to avoid too rapid artificial respiration, for that is a common mistake. From fourteen to sixteen times a minute brings the best results.

The first feeble attempts at natural breathing should be aided by timing the artificial breathing to it, and may be stimulated by applying ammonia to the nose 
and dashing cold water on the chest. While artificial respiration is being carried on, another person may be massaging the legs of the patient, being careful to rub toward the heart. Warm sand, clothing, hot water, or anything else that is available may be used to make the body warm. Small doses of hot drinks and other stimulants may also be given, when they can be swallowed without difficulty. The instructions of the doctor in regard to where to move the patient

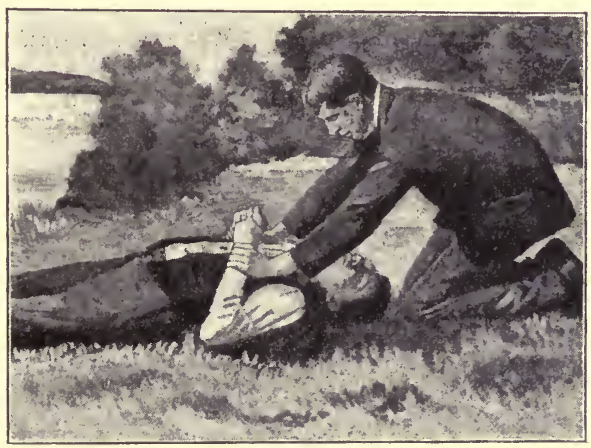

Artificial Respiration - Second movement: Expiration.

and when it will be safe to leave him alone should be strictly followed, because, for some time after such an experience, breathing may suddenly cease with little or no warning. Although a person may have been under water a half-hour or more, the restoration of breathing should be attempted, and should not be given up until a physician pronounces recovery impossible.

Breathing may also be stopped by gas or smoke, by hanging or choking, and by hard substances getting into the windpipe. In case of gas or smoke, removal from the cause is the first step. If gas has been 
escaping, a match should not be lighted nor a lamp brought in, no matter how dark a room may be, for injury by explosion is almost sure to follow. After a suffocated or strangled person has been removed to pure atmosphere, the same methods for restoring artificial respiration may be used as in the case of one apparently drowned. Where something has got into the windpipe, one of the quickest methods of relief is to turn the person head downward and give some quick hard slaps between the shoulders. This is likely to dislodge the obstruction and cause it to fall out. If it does not, a doctor should be immediately sent for, as prompt and skillful action is necessary.

A person's fainting often produces needless excitement. As the cause of such condition is too little blood in the brain, the thing to do is to make it easier for a normal supply of blood to reach the brain. On this account the best position for one who has fainted is flat on the back with the head a little lower than the feet, so that the heart does not have to overcome the resistance of gravity. Any clothing about the neck or body should be unloosed, while smelling salts are held to the nose and water is sprinkled on the forehead.

Unconsciousness also results from severe blows on the head, diseases of the brain, and shocks to the nervous system resulting from accidents and various other causes. A good rule to follow until a physician arrives is to lower the head and give stimulants when- 
ever the face is pale, as this usually indicates the need of more blood in the head; but to raise the head and not give stimulants when the face is flushed, for such condition indicates too much blood in the head. When an unconscious person's skin is cold and clammy, heat should be applied to the entire body, especially to the region of the stomach and heart. An abundance of pure air is always necessary for any one in an unconscious condition, so it is a mistake for others to crowd around and keep the air away.

Another common injury to Jack's House comes from poisoning. Any substance is poison that when taken into the system tends to destroy life or impair health. Poisonous drugs or medicines sold at stores must bear a label containing a picture of a skull and cross-bones and marked "Poison." Such bottles should never be kept where children can get at them. Sometimes poisoning results from eating meat or fish in certain stages of decay. Ice cream, cream puffs, and other foods also occasionally contain poisons called ptomaines.

First of all, a physician should be sent for when poisoning is suspected. As a general rule, the best thing to do while awaiting his arrival is to induce vomiting by drinking large quantities of warm water. If the poison taken is known to be an acid, some alkali, such as limewater, baking soda, tooth-powder, soap, or even plaster from the walls, may be put into the water. If it is an alkali, some convenient acid, such 
as vinegar or lemon juice, should be used. Copious draughts of milk, raw eggs, or flour and water may be given after the vomiting to lessen the bad effects of the poison on the digestive organs. Where pallor or coldness of the skin is present, heat and stimulants may be used, but usually a doctor will have taken charge before this condition exists.

There are also many plants that are poisonous to the body. A good rule for all is not to eat the berries or any other part of a plant or shrub not absolutely known to be harmless. The berries may appear tempting and perhaps seem pleasant to the taste. The root of the plant may be very similar to some well-known cultivated vegetable, and yet either the berries or the root may be very poisonous.

Perhaps few plants give boys more bother and discomfort than poison ivy. It is an ornamental vine, bearing its leaves in clusters of three and gracefully spreading over the neighboring ground and shrubbery. Its grayish white colored berries are poisonous, but it is not through these that its mischief is usually done. The whole plant has the power when touched, or sometimes when even approached, of exciting a swollen, irritated condition of the skin. In case of such poisoning, witch-hazel and other healing lotions have a soothing effect. 


\section{CHAPTER XXVII}

HOW TO PROTECT JACK'S HOUSE FROM CONTAGIOUS DISEASES - CONSUMPTION

IN a previous chapter we learned how minute plants are destructive to foods. There are also tiny plants and animals that are injurious to our bodies for the reason that they cause disease. Consumption, pneumonia, diphtheria, typhoid fever, malaria, influenza, and colds are some of the common diseases that are due to these tiny plants or animals. These minute organisms do not thrive, as a rule, in healthy, vigorous body tissue. But if they get into an organ or some part of the body, when, on account of exposure, over exertion, lack of nutrition, loss of sleep, or any other cause, it is not able to resist, then, multiplying rapidly, they produce disease.

The rapidity with which certain of these organisms can multiply under favorable conditions is most remarkable, specialists estimating that one can increase to a colony of several millions in twenty-four hours. In consumption, pneumonia, influenza, and colds, the organisms are in the lungs or air passages, and so are ejected with expectoration. In typhoid fever they are present in the intestines, and pass out with the 
waste from the bowels. In smallpox, scarlet fever, measles, and some other diseases they are contained in particles given off from the skin. They may get from one body into another in milk, water, or solid food. After being dried, these organisms become so light as to float easily in the air. Hence they may be taken by one in the same house with a sick person, or carried on clothing from one house to another, and in some diseases infect persons living in the latter.

A fly alighting on some substance or object containing disease germs may take them up and deposit them on food, and of course a person eating the food will get the deposit in his stomach. The very best way to protect the body against such enemies is to keep it in vigorous health, for then they are not likely to do harm. As we have learned, the very best way of keeping such health is to be wise in our use of pure air, water, nourishing food, exercise, and rest.

Since there are times when we may be unable to resist attacks of disease germs, it is wise to do all that is possible to destroy any that may come from a person having one of these diseases. Boiling water, steam, solutions of carbolic acid, and formaldehyde are some of the agents commonly used for this purpose. During the period in which there is danger of contagion, the patient should usually occupy an upper room of the house away from other members of the family, and as few as possible should wait on him. 
If the disease is one in which infection from expectoration is possible, all sputum should be deposited where it can be soon destroyed. There have been invented small covered spittoons holding paper cups that are excellent in such cases. The expectoration is deposited in the paper cup, which should be renewed daily or oftener, the old one being immediately destroyed by burning. If an ordinary spittoon is used, it should contain a five per cent solution of carbolic acid (three teaspoonfuls to a glass of water), and should be washed daily in boiling hot water. There are also patent pocket flasks that patients may carry with them when away from home, but these must be frequently disinfected. When a patient is coughing, small particles of expectoration often fly into the face of an attendant or into the surrounding atmosphere. A paper napkin or cloths that may be immediately burned should be held in front of the mouth to prevent the disease from spreading in this way. As expectoration dries very quickly on cloths, they should not be carried in the pockets, but should be burned at once.

In typhoid fever, the bed-pan and similar articles should contain a solution of carbolic acid. These should also be frequently cleansed in boiling water. This precaution is likewise a good one to take in diseases where the infecting organism comes from the surface of the body. All clothing used by the patients or those attending them should be handled by itself 
and washed in boiling hot water. Dishes and other utensils for food should also be reserved for their especial use, and should be washed separately. In short, every possible precaution that may help to prevent infection should be taken.

At the beginning of the illness, all rugs, draperies, pictures, contents of bureau drawers, and any other favorable lodging places for germs should be removed. During its continuance the room should be cleaned by wiping up the dust with cloths moistened in a solution of carbolic acid, and these should afterward be burned. All instructions given by the doctor in regard to burning bedding and other articles, and disinfecting and redecorating the bedroom, should be faithfully followed, as some germs may be able to cause disease for months afterward.

Probably all villages and cities have a health officer. One of the most important duties of this official is to see that due precautions are taken to prevent the spread of diseases. Physicians are required to report cases of contagious diseases to him, and he notifies school principals of the houses in which such diseases exist. Children from these homes are then compelled to stay out of school until they bring a permit stating that danger of contagion is past. Pupils are excluded from school on account of mumps, whooping cough, and all diseases of the skin and eye, as well as diphtheria, smallpox, scarlet fever, and measles. In the most serious of these diseases the families are 
warned not to attend church or other public gatherings, and, as far as possible, not to mingle with others during the period of danger. In cases of smallpox, scarlet fever, and diphtheria, placards are placed on the patients' houses to warn the public that the dangerous disease is within. Such cards must not be removed until the health officer or one of his assistants is satisfied that there is no longer danger of contagion. These officers are also expected to see that there is proper disinfection of the room and premises afterward.

While some people have had smallpox, scarlet fever, or measles two or three times, having had any one of them once seems, as a rule, to make one immune from a second attack of the same disease. It is well known that we can protect ourselves from smallpox by vaccination. In many cities, children must be vaccinated before they enter school, and again in four or five years. It is also wise to be revaccinated later in life whenever one is where a smallpox epidemic prevails.

Some children and parents try to evade vaccination. This seems a very foolish thing to do, because results show that its benefits have been great. In the year 1900, the deaths in the United States from smallpox, according to the census returns, numbered three thousand four hundred eighty-four. If the rate had equalled that of England and Wales before the discovery of vaccination, the number would have been two hundred sixteen thousand. In the latter two 
countries, before vaccination was discovered, the number of deaths from smallpox annually averaged about three thousand to a million inhabitants. Less than a hundred years later, in 1890, their records showed that the deaths from smallpox for an entire year were only fifteen. In Germany, where the vaccination of infants is compulsory and children must be revaccinated at the age of twelve, smallpox is almost unknown. A few days of sore arm or leg and some little discomfort are the only unpleasant effects usually following successful vaccination.

Unfortunately people are often very careless about mingling with others in public places when some member of their own family has a contagious disease. The neighbors and acquaintances of such inconsiderate folk should not hesitate to avoid them nor to report their names to the proper authorities for such negligence. We get out of the way of a mad dog quickly, nor do we consciously allow ourselves to be burned by fire. Surely we should be just as particular to protect our bodies from contagious diseases which may do even greater harm. Rules of health departments are made by men of wisdom and experience for the benefit of the entire community. All should obey their instructions without hesitation and as faithfully as possible.

Certain diseases, such as smallpox, usually make one very ill rapidly, and their danger is well known. Consequently the advice of a physician is, as a rule, 
quickly sought, and his instructions are carefully obeyed. But there is a contagious disease far more common, to which but little heed is often given until too late. This disease, tuberculosis of the lungs, commonly called consumption, is so fatal throughout the civilized world that it is often spoken of as "The Great White Plague." Statistics show that about twelve deaths out of every hundred occurring in the United States result from this disease. In New York State during the year 1899, the deaths from consumption alone were thirteen thousand four hundred twelve, while the total number from smallpox, typhoid fever, diphtheria, croup, measles, and whooping-cough was only six thousand seven hundred eighty-three. These figures unquestionably show the terrible danger from "The Great White Plague" and why our bodies should be more carefully guarded against it.

The following information concerning this greatest body destroyer may help in protecting our bodies from its ravages. While there is a type called quick or galloping consumption, which develops with great rapidity and often ends fatally in a comparatively short time, this form is not common. In the great majority of cases the progress of the disease is slow, lasting for months or years, and, along with the periods of temporary improvement, there is, without proper care, gradual progress to a fatal issue. As we have learned, the bacilli must have got their start at a time when the body's vitality was lowered because of some 
illness, too long-continued over-exertion, lack of nutrition, loss of sleep, or some other condition that tends to make one less able to resist attack.

The usual beginning place of the bacilli's work is in the topmost part, called the apex, of either one or both lungs. If the disease is not arrested, it spreads to other parts of the lungs. Should the vitality of the patient not be restored to such a degree that the bacilli cannot go on with their work, lung tissue will be destroyed, cavities will be formed, and finally death will result.

Occasionally an early warning of the disease comes from the spitting of blood. More commonly, however, its progress is so slow and insidious as to escape notice for a considerable time. The patient's friends may observe his gradual loss of flesh, and he himself may be conscious of becoming weak and tired more easily than was usual with him. He has a persistent cough, either at intervals during the day, or perhaps only at night and on rising in the morning; and his reply to the inquiries of solicitous friends is that he never had a cold hang on like this one. There may be occasional slight pains in the chest, shoulders, and back, though these often do not occur or are not noticed.

Feverish symptoms, indicated by rise of the body temperature above its normal point, ninety-eight and six-tenths degrees, in the afternoons and particularly in the evenings, may be present from an early period. 
This daily rise in temperature, together with the persistent cough and loss in flesh and strength, are such marked signs of consumption that no time should be lost in having a physician give the lungs and expectoration a thorough examination. Every home should possess a clinical thermometer (the small kind used to take the body's temperature), which some members of the family should learn to use. Such a thermometer is placed under the lower part of the tongue and left there three or four minutes, the lips being kept tightly closed. If, when it is taken out, the mercury has risen higher than ninety-eight and six-tenths degrees it is evidence of fever.

The higher the temperature the greater the fever, and the more serious the condition of the sick person. Any one whose temperature is above normal is not in fit condition for work. If, after rest, such temperature continues, especially when other alarming symptoms are present, a doctor should be consulted. A temperature of one hundred four degrees is very high. A person becomes delirious at one hundred five degrees, and at one hundred six degrees death may ensue. A temperature below normal should also receive attention, if found afternoons or evenings. The temperature of a sick person is likely to be lower in the morning, and higher towards evening, than at other times. A record of a patient's temperature at various times of the day is one of the most important sources of information by which physicians watch the progress of 
the disease and judge whether the patient's condition is growing more or less favorable. The beating of the heart at a rate higher than normal is also an indication of fever. For this reason, it is important that some member of the family should be able to find out the pulse rate. The pulse and the temperature are two things by which necessity for the immediate attention of a doctor may largely be judged in any disease.

Besides the daily rise in temperature, there are three other marked signs of consumption that sometimes cause little alarm. These are gradual loss of appetite, increase in the amount of expectoration, and night sweats. The night sweats, perhaps, start mildly in the early stage of the attack, but often become so copious that a patient's sleeping garments are wet with perspiration in the morning. Such unnatural perspiring should be remembered as a very serious symptom of the progress of consumption. Under no circumstances should any one having night sweats neglect to put himself under a doctor's care. Allowing such a warning to go unheeded nearly always means another victim for "The Great White Plague." There are sometimes other symptoms of this disease, but the points that have been mentioned are especially important for all to know, because they frequently do not arouse any particular concern.

How may this dread disease be prevented from spreading in a family or neighborhood? The main thing is to keep the bacilli in the patient's expectora- 
tion from infecting other people. For this reason, all the precautions mentioned on pages 297 and 298 should be taken. (What were they?) Especially should patients be careful to keep their mouths covered while coughing, so that particles of phlegm may not fly off into the air or the faces of attendants. Persons having consumption should sleep alone. Men consumptives should be smooth shaven, since it is difficult to disinfect either beard or mustache. Neither should those ill with this disease kiss or be kissed. If possible, the windows and doors of a patient's house should be well screened to prevent flies from spreading the germs.

That the bacilli of consumption may infect others may be judged from the fact that twenty-four deaths from this disease in one house and one hundred two in one block have been traced to the same source. Some years ago, after one member of a family had died from consumption, others, and occasionally all, followed. With due care taken to destroy bacilli, it has frequently happened in recent years that but one member of a family has been affected.

The great decrease in the number of cases of consumption in regions where particular care has been taken to teach people how to prevent its spread is another strong proof of the wisdom of those precautions. The United States census of 1900 shows that in the region where registration is compulsory, the death rate from consumption was one-hundred eighty-seven per 
one hundred thousand of population. In 1890 the same region reported two hundred forty-five and fourtenths per one hundred thousand. In Prussia, for some years before 1887, the death-rate from consumption had averaged about three hundred ten to every one hundred thousand of population. Through changes in the care and treatment of patients, the rate has gradually decreased, until, in 1900, it was two hundred ten to every one hundred thousand. These figures furnish arguments altogether too strong to be allowed to go unheeded. Although the precautions advised may seem unreasonable, yet, if occasion demands, we shall be wise to use them as far as possible. In dealing with consumption, at least, we are safe in assuming that facts are facts and that figures don't lie.

Why does the law often impose a fine for spitting in street cars and other public places? There probably are in every large city many consumptives who do not know that they have this disease and who mingle freely with others. Many other persons with colds, influenza, and similar ills having bacilli in the expectoration are also often in public places. Knowing these facts, concern for public health as well as public cleanliness should prompt all to obey this law, and to insist that others do the same. Healthy people should observe such regulations just as cheerfully as those who know that they are sick. Then those affected with disease, but not aware of it, will have no excuse for being heedless. 
No doubt the improved methods of treating consumption, as well as the pains taken to prevent its spread, have had much to do with the decreasing deathrate. Formerly any one having the disease was supposed to be fated to die. Drugs were used to stimu-

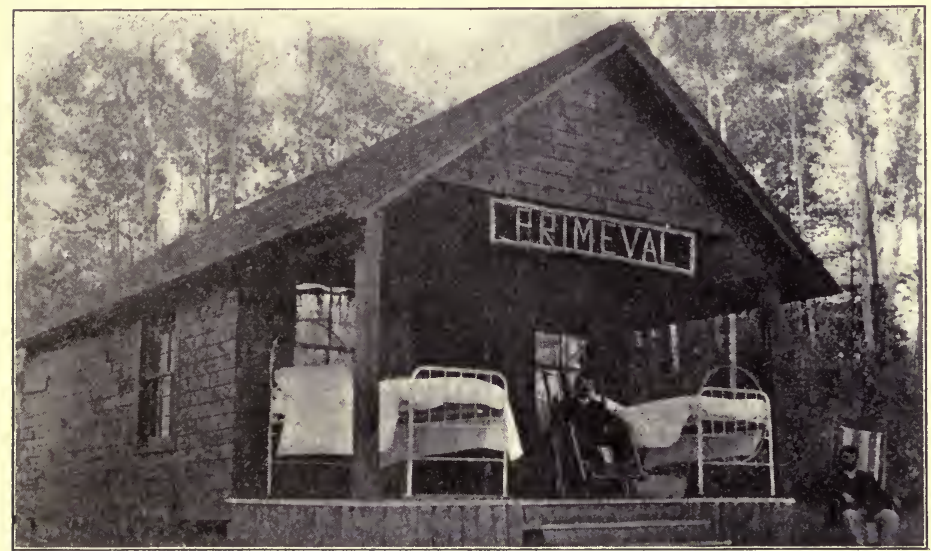

Raybrook Sanitarium, Adirondacks. - Sleeping out in Summer.

late or ease the patient, but with little or no hope of effecting a cure. Now, this dread disease, if not too far advansed, is regarded as curable; though it is generally conceded that medicines, and especially patent medicines, are valueless. Many patients, who might have recovered had they consulted a doctor at the outset, lose their lives because of a period of trying various patent remedies, which can only deceive and delay. The aim is to increase the patient's vitality to such an extent that he will be able to resist the 
inroads of the bacilli and in time destroy them. An abundance of pure air and nourishing food are the chief factors relied upon.

While some simple tonic is often used to stimulate the digestive organs, if they are not working well, this is discontinued as soon as the need for it ceases. Milk, eggs, bread, butter, and fruit are among the foods that are considered the most beneficial. A tablespoonful or more of olive oil is often taken at meals, as it lubricates the bowels and is an excellent food as well. Cold dry air and sunshine are considered very useful in fighting this disease. For this reason, patients are often sent to regions of high altitude or long-continued bright weather. Where this cannot be afforded, all possible outdoor air at home is the best substitute.

In this country, the Adirondack Mountains in New York State, as well as the highlands of Colorado, Arizona, and other states are localities which are beneficial for consumptives. In such regions patients are advised to be out of doors during the daytime, and to sleep at night with their windows wide open without regard to temperature. The amount of food that one can digest under these conditions is astonishing, from a half-dozen to a dozen eggs, and from one to two quarts of milk a day being often taken, in addition to three hearty regular meals. Very little except easy walking is done until the daily rise in temperature has ceased. Then light exercise is commenced with the advice of a physician, and system- 
atically increased with the gain in weight and general condition.

Frequent baths, followed by brisk rubbing to keep the third lung, the skin, in active condition, are very useful. If the body is gradually accustomed to cold water, the morning cold bath may be of great value. In brief, much that is given in the chapters on food, air, water, and exercise may be profitably reread in this connection. One point generally agreed upon is that alcoholic drinks of any kind hinder, rather than help, a patient's recovery. It

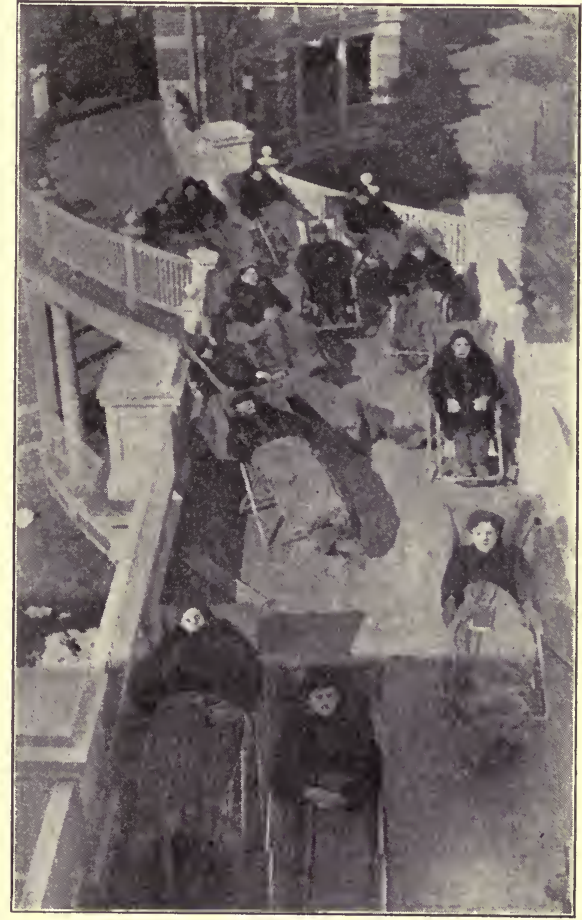

Raybrook Sanitarium, Adirondacks. - On the Porch in Cold Weather. is also true that any one who has previously been addicted to the use of such drinks is less likely to recover because of that habit.

The tubercle bacilli also attack other parts of the 
body. The lungs are so often the place affected, however, that consumption and tuberculosis of the lungs are generally regarded as the same thing. Who are likely to be attacked by this dread disease? While no person is immune, and no one can be said to be fated, statistics show that the following are especially vulnerable: persons who work in impure air or where there is much irritating dust; persons who are narrow-chested or round-shouldered; persons who do not employ deep breathing; persons who are subject to frequent colds or catarrh; persons whose ancestors or relatives have had the disease; persons not well fed or fully nourished, - especially those living in dark, poorly ventilated rooms.

Do we belong to any of these classes? If so, let us be watchful that ours is not one of the deaths credited to this great destroyer. Taking up an out-of-door occupation; developing our greatest breathing capacity; in every way making the best use of food, air, water, exercise, and rest; even planning to spend life in the most favorable climate, - these are among the effective weapons to be employed in our defense. How thankful all should be that having or escaping consumption is not a matter of luck or inheritance, but simply a question of keeping up strength and vitality! 


\section{CHAPTER XXVIII}

\section{THE SACREDNESS OF JACK'S HOUSE}

GoD has given this world many wonderful and beautiful things, but the most wonderful and beautiful of all is the human body. This gift is always wonderful because of its many different parts, each so skillfully fashioned, so perfectly adapted for service, and whether large or small, strong or delicate, so necessary for the highest good and usefulness of the whole. Of our bodiẹs it may well be said:-

"Nothing useless is or low,

Each thing in its place is best,

And what seems but idle show,

Strengthens and supports the rest."

This gift may not always be beautiful in form and features, but, however plain these may be, persevering effort will cultivate a gracious bearing, which, with wholesome cleanliness, abundant health, a kindly spirit, and sincere sympathy, will make it capable of the greatest usefulness. When we see the beautiful things in the world about us, how splendid it is to realize that man is the most wonderful of all the Creator's works! How inspiring to know that we have been 
made after His image, and that, with proper care and training, we may become strong and noble in body and mind! What a charge to keep we have, and with what care and prayerfulness we should guard and shape so precious and sacred a gift!

But if full-grown oaks are to be straight, strong, well-proportioned, and sturdy, they must not be bent and weakened when saplings. So if the joyous, healthy, active boys and girls of to-day are to become happy, vigorous, well-poised, and capable men and women of the future, they must train these wonderful gifts to achieve their highest and best possibilities. In the preceding chapters we have read how to make food, air, water, exercise, and rest serve the best growth and development of these bodies God has given us. These are rules easily remembered and readily made our habit of living, if only begun early enough. While fleeting pleasure may attend their transgression, the truest joy and highest satisfaction accompany their keeping. "More to be desired are they than gold, yea, than much fine gold: sweeter also than honey and the honeycomb. Moreover by them is thy servant warned: and in keeping of them there is great reward."

How truly these words used by the Psalmist in describing the laws of the Lord may be applied to the simple laws of health! If we regard our bodies as precious, sacred gifts, which, keeping pure and clean within and without, we try to shape and develop to their highest and best, then we can more proudly and 
hopefully offer up the daily prayer: "Let the words of my mouth and the meditation of my heart be acceptable in Thy sight, $O$ Lord, my Strength and my Redeemer." With our bodies thus in full harmony with what our kind Heavenly Father would have them, it will surely be less difficult to keep our lips and minds in accord with His teachings. May a part of our daily prayer ever be: Kind Father in Heaven, I know my body is a sacred gift from Thee. Guard it this day from accident and harm. Give me wisdom to keep it sound, strong, and serviceable. Help me to preserve it clean, pure, and undefiled. 


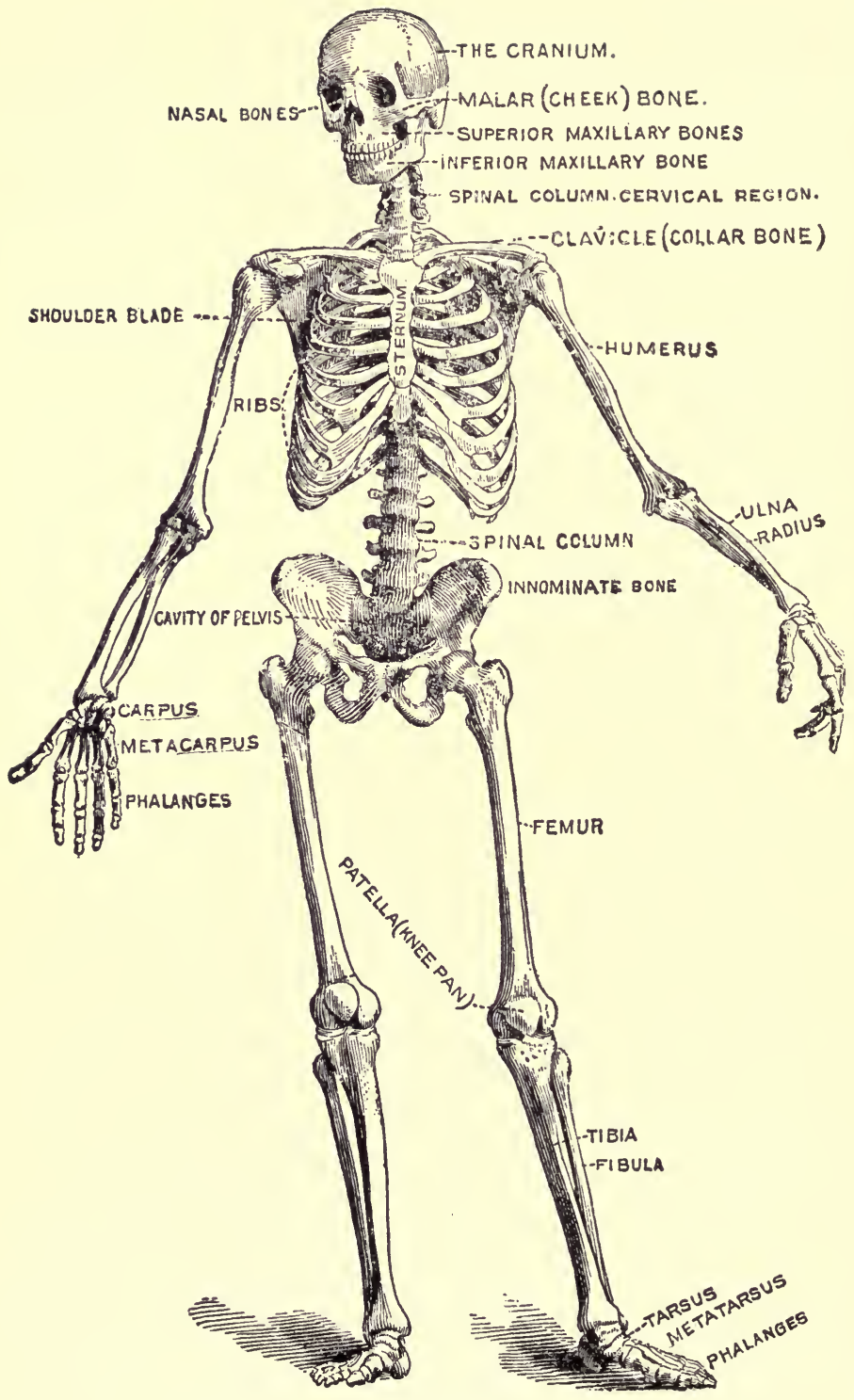

The Skeleton, showing Names of Bones. 


\section{HELPS IN LESSON PREPARATION}

DURING the study period pupils should prepare complete answers to the following:-

\section{Chapter I}

1. Why does money seem to be the greatest treasure in the world? 2. What is the greatest treasure in the world, and why? 3. Tell the two things that are necessary for most people to possess a strong, healthy body. 4. (Note: Synonyms are words that have similar meanings. Antonyms are words that are opposite in meaning.) Give synonyms of gallant, perils, precious, striving. 5. Tell the meaning of pirate's booty and miser's hoard. 6. Give antonyms of tedious, comfortable, erect. 7. What is meant by without the handicap of headaches and nervousness? By the word contents, page 3 ?

\section{Chapter II}

1. Give the meaning of vastly, far-famed, and architecture, page 4. 2. Explain why many people know so little about their bodies. 3. Give a synonym of each of the following words, page 4: importance, realized, residents, celebrated, enterprise. 4. What part of the body is called the trunk? 5. Tell what is said about the brain. 6. What organs are in the chest, and how are they protected? 7. Nention some organs that are in the abdomen. 8. Give the meaning of the following words: fortified, compart- 
ments, page 5. 9. Tell some facts about our bodies that are of the greatest importance for us to know.

\section{Chapter III}

1. Mention the materials with which Jack's Wonderful House builds itself. 2. Give the meaning of the following: right proportion, architect, construct, nourishing food, page 6 . 3. For what purpose, besides satisfying hunger, should we eat food? 4. Why are some foods like oak? 5. Tell why some foods in large quantities are of very little value to our bodies. 6. On page 6 , what is meant by the following: an introduction, chiefly, particular? 7. Explain the meaning of the following words: incompetent, durability, construct, require, large quantities, pages 6 and 7 . 8. What is said about water? 9. Tell what is said about pure air. 10. Give the meaning of an ordinary house, comfortably, and sparkling liquid, page 7. 11. Give an antonym of pure, page 7 .

\section{Chapter IV}

1. Of what are our bodies chiefly made up? 2. Give two reasons why we must supply our bodies with food. 3. Give the meaning of components and extracted; of substances, mineral, and organs, page 8. 4. Name the components of, or substances in food that are helpful building materials. 5. Give the meaning of proteid, and state why it is justly entitled to its name. 6. Mention some common foods that contain proteid. 7. Why should we have plenty of proteids in our food? 8. What is a microscope?

\section{Chapter V}

1. Give the meaning of distasteful and fibers, liberally supplied, various grains, and chemists, page 10. 2. Give 
the meaning of energy, naturally robust and strong, excellent, page 11; comparatively inexpensive foods, and large extent, page 12. 3. Tell the meaning of inhabitants, prodigious, whale blubber, Arctic explorer, disgust, appetite is regulated, etc., physical labor, occupation, page 12. 4. Of what use is fat to our bodies? 5. Name five foods having much fat. 6. State what is said of olive oil. 7. Tell why it is a mistake for some people to eat much pork. 8. Explain why more fat is needed in cold weather than in warm weather. 9. Compare the diet of an Eskimo with that of an inhabitant of the tropies. 10. Give antonyms of similar and remarkable, page 13. 11. Name some foods in which starch is found. 12. Compare fat and starch as to the amount of heat and energy each furnishes the body. 13. Why should sugar not be eaten to excess? 14. Mention five different foods in which sugar is found. 15. State five important facts given about foods on page 15. 16. What two good reasons are given for not allowing children to persist in a dislike of necessary foods? 17. Give the meaning of preëstablished dislike, chances for recovery, staple foods, improper diet, experienced physicians, page 15.

\section{Chapter VI}

1. Give an antonym of correct, different, and solid, page 16. 2. What are the three different forms of matter? 3. Give the meaning of expand, rearrange, process, situated, and absorbed, page 17. 4. About what is the length of the digestive canal? Name its parts. 5. What are salivary glands? 6. Mention three uses of saliva. 7. Why should our food be thoroughly masticated? 8. Explain why children who eat rapidly in order to get out quickly to play, make a mistake. 9. Why does properly masticating our food help to keep us from eating more than is needed? 
10. Give the meaning of good authorities, liquid state, persevere, enthusiastic, exertion, eating heartily, induced, activity and endurance in games, more accurately, page 20.11 . Tell about the experiment of the athletes at Yale University. 12. Give the meaning of admiringly, principal, less celebrated, page 21. 13. Tell what is said about Mr. Gladstone.

\section{Chapter VII}

1. What is meant by alimentary canal? 2. Where is the esophagus? 3. Where is the windpipe? 4. Give the meaning of elastic, of great expansion, ingredients, page 23. 5. What component of food does gastric juice digest? 6. Explain the meaning of diluted, less effective, and experiment, page 24. 7. Mention three things that we can learn from the experiment in digesting meat. 8. Why should hard work or violent exercise just before or immediately after meals be avoided? 9. Tell how the muscles of the stomach assist digestion. 10. Give synonyms of calculate, compelling, normal, page 25 . 11. What is said about the use of seasonings? 12. Give the meaning of state of mind, controlling, considerable, foundation, insufficient, absorbed in thought, page 26. 13. Explain how our state of mind at meal-time influences digestion. 14. Give the meaning of table atmosphere, accomplishing, page 27. 15. Why should we have a joyous table atmosphere? 16. Tell three important things about bile. 17. What is said of pancreatic juice? 18. What foods does the intestinal fluid digest? 19. Explain the meaning of quantity and information, page 28. 20. Give the meaning of projections, numerous, velvety, page 28. 21. What are villi? Tell their use. 22. Give the meaning of become disordered, regularly, unduly long, essential, preventive, page 29. 23. Give antonyms of careful and 
reasonable, page 30.24 . Tell the four things in regard to digestion concerning which we should be careful to form correct habits.

\section{Chapter VIII}

1. Mention the building materials usually found in milk. 2. State why milk is the most nearly perfect food. 3 . Give the meaning of adults, tax on the digestive organs, skimmed milk, and expensive, page 33. 4. What are the common ways of lessening the food value of milk? 5. Give antonyms of retards, thinner, inferior, untidiness, page 34. 6. Give the meaning of opportunity, afforded, attacked, invisible, moisture, thrive, page 35 . 7. What care should be taken to prevent bacteria from destroying the food value of milk? 8. For what purpose is hot water useful in dairies? 9. Mention other evidences of a good dairy. 10. What is the best milk to buy? The next best? 11. Why is it not well to buy of a dealer who dips the milk from tin cans? What is probably the most dangerous way to buy milk? 12. When and why should milk be put in the coolest place in the house after it is delivered? 13. Give antonyms of foolish, important, page 39. 14. Tell how condensed milk is prepared. Give meaning of indefinitely and original, page 41. 15. Why is the expression, "as fat as butter," a good comparison? 16. Tell why butter should not be left long uncovered, and why it should be kept in a very cool place. 17. Give the meaning of precautions and rancid, page 41. 18. Tell why it is a fraud to sell oleomargarine as butter. How may the difference between oleomargarine and butter be told? 19. Explain from what cheese is made, and why it costs more to make some kinds than others. 20. Why is cheese a valuable food? 21. With what is cheese often eaten in France and Italy? 


\section{Chapter IX}

1. Tell what you have learned about the components of an egg. 2. Which are more easily digested, soft-cooked or hard-cooked eggs? What effect does frying have on the digestibility of eggs? 3. Where should eggs be kept? Why? 4. Explain what candling eggs is. 5. Why do eggs become lighter as they grow older? 6. Tell how one may usually judge without tasting, if eggs are too stale to be appetizing. 7. Give the meaning of comparatively, expensive, omitting, menu, page 46. 8. Mention the body-building materials in meat. 9. Why is beef probably the best of the much-used meats? 10. Compare chicken with beef; compare veal with beef. 11. What is said about mutton and lamb? 12. Tell what you have learned about each of the following: pork, ham, dried beef, bacon. 13. How is tough meat sometimes made more tender? 14. Give antonyms of civilized, harmful, advantage, page 48 . 15. Why, when meat is being cooked, should it be at once subjected to great heat? 16. Why should pork always be thoroughly cooked? 17. Tell how to prepare soups from meat. 18. How may you tell that beef is good? 19. How may bad veal be recognized? 20. Why are sausages often a doubtful food? 21. Tell why some people think it best to eat only a moderate amount of meat. 22. What proof have we that it is possible to be well and strong without eating meat? 23. What is the meaning of finny dwellers in the water world, sport, substitute, preferable, stagnant, pages 51 and 52 ? 24. Tell three things page 52 teaches about fish as food. 25. When are fish not good food? 26. What is said about oysters as food? About clams, lobsters, and shrimps? 


\section{Chapter X}

1. Tell the food materials in wheat, and state how it compares with animal foods in respect to these. 2. What is said about rye? About corn? About oatmeal? 3. Compare rice with wheat as to the amount of starch, proteid, and fat contained. Mention countries in which rice is the principal food. 4. Give the meaning of consider, curious, close'y related, attempting, evaporates, destroyed, and reduced, page 56. 5. Explain about the use of yeast in breadmaking. 6. Give the meaning of mold spores, unpalatable, page 57. 7. Tell why flour should be kept in a dry place. 8. Why should the bread jar be frequently washed out with hot water? 9. Define fashion, preference, included, page 57. 10. Tell what Entire Wheat Flour is, and why it is often recommended by physicians. 11. About what is the actual cost of the materials of a loaf of bread? 12. Why is homemade bread better than baker's bread? 13. Give antonyms of plain, aid, ill, lighter, page 59. 14. Which is more easily digested, newly baked bread or bread a day or more old? Well-baked bread or that which is soggy? What is said about toast? 15. Name some of the least digestible of the flour preparations. Explain the reason. 16. Tell why it is unwise to depend on such foods as pie and cakes for the building substances our bodies need. 17. Why is it a poor exchange for children to spend their pennies for cakes and other sweets? 18. What is said of the building substances in potatoes? Why are potatoes such a widely used food? 19. Give the meaning of preparation, moderately warm, and nutritive, page 62. 20. Explain how to prepare potatoes for the table and best retain their nutritive substances 21. What is said of baked potatoes? Of fried potatoes? Which are more easily digested, those that are mealy, or those that are soggy, 
after being baked or boiled? 22. Give synonyms of flavor and prized, page 63. 23. Why are vegetables highly prized as food? Name some vegetables that are considered especially good for the blood and the nervous system. 24. Name some that are healthful stimulants to the liver and other digestive organs. 25. Tell the meaning of variety of diet, bulk, insufficient, page 63. 26. What vegetables contain a large amount of proteid? 27. How may peas and beans be made more easily digestible? 28. What is said about string beans? Lima beans? Green peas? Canned peas and beans? 29. Why are almonds, walnuts, and peanuts good body-building foods? What is said of their digestibility? 30. What components are usually found in fruits? Give two fruits that contain some proteid. Why are fruits a highly prized food? 31. Tell how bananas may be made more easily digestible. 32 . Why are stewed and canned fruits usually not as beneficial as fresh fruit? What is said of dried apples? Of fruit put up in tin cans? 33. How may we guard against bacteria and mold when canning? 34. Explain how to keep fresh oranges, apples, etc., from decaying.

\section{Chapter XI}

1. Give the meaning of beverages, beneficial, and diffculty, page 69. 2. Tell from what coffee is made. From what is tea made? What do both contain? 3. Why should children drink neither tea nor coffee? 4. What is tannin? Tell the best way to prepare tea, and why. 5 . Why are cocoa and chocolate much more nutritious beverages than coffee or tea? 6. Tell what is said about the numerous "soft drinks." Why should ice cream soda not be taken immediately after a hearty meal? 7. Give the meaning of multitudes, ingredients, and derange, page 73 . 
8. What is said about alcohol as a food? 9. Explain why alcoholic drinks do not warm persons who are cold. What does Commander Peary say about alcoholic drinks? 10. Give the meaning of spurious, degrading, boisterous, community, gradually, page $74 . \quad 11$. Tell the meaning of less companionable, material prosperity, excesses, overindulgence, brutal, overwhelmed, and blighted, page 75 . 12. Compare the effects of too much food on the body with the effects of too much alcoholic drink. 13. Tell why a little alcohol each day is a hindrance rather than a help to the body. 14. Give the meaning of insidiously, page 76 . 15. What dogs were selected by Dr. Hodge for his experiment? 16. What effect had the epidemic on Bum and Tipsy? On Nig and Topsy? 17. Tell about the experiment with the dogs in the gymnasium. 18. Tell other bad effects of alcohol on Bum and Tipsy. 19. What is said about users of alcoholic drinks getting well from dangerous diseases? 20. Why are college boat crews and ball teams not allowed to use alcoholic drinks during the period of training? 21. Give the meaning of international, contestants, capable, recorded, total abstainers, prolonged, unquestionably, indicate, page 80. 22 . What do insurance records show about the average length of life of those who use and those who do not use alcohol? 23. Tell the meaning of desserts, abstaining, unnecessarily, unnatural, page 81. 24. Give synonyms of threshold, dread, creating, social, repulsive, page 81 . What dread power has alcohol? 25. Explain why beginning to drink alcoholic liquors is like starting to swim the whirlpool rapids at Niagara Falls. 26. Who are not employed by railroads in certain positions of trust? 27. Why have many strong men fallen victims to "John Barleycorn"? 28. Tell why it is wrong for educated Christian people to visit places where liquors are sold, or to allow liquor to be 
used on their tables, even though they are temperate in its use. 29. Give antonyms of prohibiting, protected, right, page 85. 30. Tell the four ideals and purposes mentioned on page 85 .

\section{Chapter XII}

1. Why are horses not fed all the sugar they want? 2. Why should we eat sugar only in small quantities? 3. Give the meaning of consequences, page 87. 4. Why is cheap candy especially harmful? 5. Tell why the sugar habit does not pay. 6. Give the meaning of papiermaché, supported, enduring structure, page 88. 7. Relate the story of Jacob and Esau. 8. What is likely to lure away our most precious inheritane ? Give the meaning of greedy. 9. Tell why eating between meals is a bad habit. 10. Give the meaning of liberally, nutriment, page 90 . 11. Explain why our occupation should, to some extent, regulate both the kind and quantity of our food. 12. Why do so many brain-workers suffer from indigestion? 13. State the food precepts given on page 92. 14. Mention the good things of life that are really best worth having. 15. What are often the busiest times for physicians, and why? 16. Give antonyms of valuable and usefulness, page 94. 17. Tell what is said about the Spartans. 18. Relate the incident of Daniel and his three companions. 19. What is the effect of hurrying through our meals to get out to play? Of eating much food just because it pleases the taste?

\section{Chapter XIII}

1. Give synonyms of previous, appreciated, banquet, page 97. 2. Compare air and food from the standpoint of our need of each. 3. About what is the average number of breaths taken per minute? Does a baby take 
more or less than the average? ceaseless, tide, continually, page 98.

4. Give the meaning of 5. Mention the principal components of air. 6. About what part of pure air is oxygen? 7. Why does a furnace fire or a lamp light go out when the draughts are closed? our bodies are like furnaces and engines.

8. State how produced by the union of oxygen and the tissues of our bodies? 10. What component of air serves to dilute the oxygen? 11. State the proportion of carbonic acid gas in pure air. 12. What amount of carbonic acid gas in air is the upper limit of safety? Give the meaning of imagine and representing, page 102. 13. How can you judge whether or not the air of a vat or well is dangerous to breathe? 14. What poisonous gas is produced by the union of oxygen and the tissues of our bodies? 15. Which has the more moisture, warm air or cold air? 16. What is insensible perspiration? 17. Explain why we often feel more uncomfortable on moist summer days than we do on days that are hotter but not as moist. 18. Give synonyms of penetrating, remotest, relative position, page 104; of extremely, vital, inflated, museum, and elasticity, page 105. 19. Give the meaning of comprehend, tracing, approach, and contain, page 106. 20. What are the capillaries? 21. How many separate chambers has the heart? What are they called? 22. Of what use is the heart? 23. In the water system of a great city, what corresponds to the arteries of our body? What to the veins? 24. How is the blood kept from flowing backward? 25. What is meant by the circulation? 26. Tell what is said about the number of times the heart beats per minute. 27. How is oxygen carried from the lungs to the tissues of the body? How is the carbonic acid gas brought from various parts of the body to the lungs? 28. Where does the blood exchange its carbonic acid gas for oxygen? 29. Give the 
meaning of on the average and purification, page 112 . 30. About how much air will the cells of the lungs hold on the average? About how much space would the surface of the air cells of the lungs cover if spread out flat? 31. Define inspiring or inhaling, expiring or exhaling, respiration. 32. What exchange of gases should take place every time we breathe? What is meant by the capacity of the lungs? 33. Why is it that oxygen is not all used up? 34. Tell how you know oxygen is a wonderful supporter of combustion. 35. Give three proofs of the fact that carbonic acid gas will not support combustion. 36. What effect has lime-water on pure air? On carbonic acid gas? What proof have we that burning a splinter in a bottle produces carbonic acid gas? That breathing into a bottle also produces carbonic acid gas? 37. Describe the experiment with the mouse and the glass receiver. 38. State the three facts proved by these experiments.

\section{Chapter XIV}

1. Give antonyms of heavy, deepest, simple, essential, page 118. 2. Describe the experiment with a bladder or toy balloon. 3. How can we tell that warm air is lighter than cold air? 4. Name some conditions that cause differences in temperature in the atmosphere. 5. Tell how the fact that warm air rises helps us to get pure air to breathe. 6. How will the temperature in the upper part of an occupied room usually compare with the temperature of the air in the lower part? 7. Why are we usually sure of pure air when out of doors? 8. Define ventilation. State what openings are necessary for the good ventilation of a room. 9. Compare the components of the air breathed out with those of the air breathed in. 10. Tell about the watery vapor that is given out from the lungs and the skin: 11. Give the meaning of disagreeable, odorless, fetid, page 
121. 12. What is said about people who are too particular to drink from the same cup another has used? 13. Why cannot the sense of smell be trusted to detect the bad odor of the air in a room of which we are one of the occupants? 14. In order to protect ourselves from foul air, what should we get into the habit of noticing? 15. How does the amount of air consumed by an artificial light compare with the amount a person will use? 16. What artificial light consumes the least air? What light consumes the most? Compare a kerosene lamp with a gas jet; a gas jet having a mantle with an ordinary gas jet. 17. Give the meaning of justifiable, accidentally, undetected, page 123. 18. Why is furnishing impure air for our guests to breathe even worse than serving them decaying food to eat? 19. Give synonyms of confined, terrible, survived, page 124. 20. Relate the incident of the "Black Hole of Calcutta." 21. Give the meaning of steerage, compelled, frenzy, violence, contriving, spectacle, page 125 . 22. Tell the story of the steamer Londonderry. 23. State why such fatal results of rebreathing air that has been breathed out are infrequent. 24. What fact do the "Black Hole of Calcutta" and the Londonderry incidents emphasize? 25. Mention several bad effects of breathing impure air, page 126. 26. State why it is unwise to have doors and windows closed in summer time to keep out the dust. 27. What are Nature's remedies? 28. How can we have pure air while sleeping? 29. Tell about the treatment of consumptives at mountain resorts and sanitariums. 30. Give antonyms of occasionally, gradually, abundant, nutritious, completely, practical, pages 128 and 129 . 31. What has an enforced stay at mountain resorts taught some people? 32. Why is the practice of having the doors and windows of any sick person's room closed usually unwise? 33. Give synonyms of needless, wonders, spark- 
ling, sparingly, coddling, page 130. 34. How may indoor workers enjoy more rugged health? 35. Give some evidences that the benefits of out-of-door air are becoming more generally appreciated. 36. From where should the air supply of a furnace be taken? Why? 37. Why should the draught in the pipe be wide open when coal is being put on a furnace fire? 38. Why are gas stoves without pipes dangerous? 39. Tell why windows should be lowered from the top. 40. Explain how a fireplace helps in ventilating a room. 41. Why should all try to be out of doors as much as possible? 42. State why it is unwise to stay long in crowded depots and other public waiting places, if one can just as well be in the open air. 43. Give the meaning of ailments, delay, shun, page 133. 44. How may we be among the fortunate class that have no need for patent remedies? 45. Why should we be more eager for pure air than for any high-priced medicine?

\section{Chapter XV}

1. Name three of the principal differences between city and country air. 2. In which are disease germs comparatively numerous? 3. Tell several things one should consider in selecting a site for building a house. 4. State some of the benefits of sunshine. 5. What should be done with trees and shrubbery that keep too much sun from the house? 6. State the advantages of having varnished floors and rugs instead of carpets. 7. The temperature of an artificially heated room should not be allowed to rise above what point? Why? 8 . Tell what the British teachers thought about the temperature of our schoolrooms, and why. 9. Why is watchfulness of the temperature of schoolrooms especially important? 10. State why cold air is not necessarily pure air. How may we prove the 
truth of this statement? 11. What is the danger of having the air of a room too dry and how may this be prevented? 12. Tell why we should be just as particular about the air we breathe as about the food we eat.

\section{Chapter XVI}

1. Describe the thorax or chest. Draw a picture of it. 2. What strong muscle forms the base of the thorax or chest, and what does this muscle separate? Describe the diaphragm. 3. What is cartilage? 4. What and where are the intercostal muscles? 5. Describe "high chest" breathing; "costal" breathing; "diaphragmatic" breathing. 6. What is the bes method of breathing? 7. How may we tell whether or not we are employing rhythmic deep breathing? How does such breathing aid digestion? 8. Give the meaning of alternate, effort, prevents, assistance, page 147. 9. State two of the principal causes of getting out of correct breathing habits. 10. Why is the deep breathing habit one of the most important lessons for all to learn? 11. What is one of the very best aids to health and vigor? 12. Give the meaning of function, sedentary, vigorous, universal, testimony, incipient, tuberculosis, page 149. 13. Tell what Dr. Pryor says about breathing. 14. What was the almost universal testimony of patients at he New York State Hospital for Incipient Tuberculosis? 15. For what were the long, narrow passages of the nose designed? 16. State two important uses of the secretion of the nose passages. 17. Tell why it is not just as well to breathe through the mouth. 18. Give the meaning of resistance, page 152. 19. How does nose breathing benefit the chest? Give the meaning of obstructive, page 152. 20. Tell what is said about adenoids. 21. What effect may the stoppage of the nose passages have on hearing? On one's appearance? How 
may these be remedied? 22. How may we make sure that we are breathing through both nostrils? Why should we be certain of this fact? 23. Give the meaning of firmly, determination, persevered, bandage, page 154. 24. Tell why it is better to breathe through the nose as much as possible when exercising violently. 25. What is said of snoring? 26. What care must be taken in order to have the atmosphere of a heated building favorable to a healthy nose? 27. Tell how too dry air affects the nose passages. 28. What simple remedy will often relieve the dry condition of the nose passages? 29. Explain the benefit of a respirator in some trades.

\section{Chapter XVII}

1. Describe the position of the spine, shoulders, chest, and abdomen when the body is in the sitting or standing position most favorable to deep breathing. 2. Tell why bending the spine backward and carrying the abdomen outward is not a good position. signs of weak breathing organs?

3. What are usually ungainly, posture, habitually, erect, carriage, impression, suggests, pages 160 and 161. 5. How may habits of incorrect position be broken? 6. State why habits of correct position should be formed early in life. 7. How does the country boy usually make his breathing muscles strong? How do most children help in developing these important muscles? 8. Describe the breathing exercises given on page 164. 9. Describe the last breathing exercise given. Try it. 10. State why it is usually more important to practice for better expiration than for improved inspiration. 11. In what kind of air should such exercises always be taken? 12. Tell why gain in chest expansion does not always indicate increase in size of lungs 
or chest. 13. By what may we usually estimate our power to play and to work? 14. Why is it a good plan to breathe out all the air we can immediately after leaving a crowded car or room? 15. Who have the greatest need for practicing breathing exercises? 16. Tell about President Roosevelt's health in boyhood. 17. How did he make himself strong and vigorous? How has he in his years of responsibility kept in the physical condition that enables him to do such a large amount of mental work? 18. Who was Sir Walter Scott? Tell about the benefits of out-of-door life and exercise for him. 19. Mention ways we may help ourselves to gain such benefits. 20. Why should every person keep up some active physical exercise? 21. Relate what Madame Melba says about correct breathing. 22. What is her idea about the proper temperature of a room? 23. Tell what she means by saying a singer should become a "hardy plant."

\section{Chapter XVIII}

1. Why is it thought that using tobacco is naturally poisonous to the human body? 2. Tell what is meant by a "Tobacco Heart" and how smokers sometimes discover they have that difficulty. 3. Give the meaning of chest girth, progress, page 178; of accurate, physical development, irregularly, page 179. 4. In Professor Seaver's experiment, how much older on the average were the smokers who entered Yale than the non-smokers? Compare the development of the smokers and non-smokers during their college course. 5. What is said about the ability both showed in mental work? 6. Give the meaning of stunts growth, listless, pallor, page 180. 7. What effect does the use of tobacco have on the growth of children's bodies? What effect on their wills? 8. Give antonyms of offensive and ill-smelling, page 181, 9. Give the four 
conclusions that are stated on page 181. 10. What did Commander Peary say about taking on his Polar expeditions men who were dependent on tobacco?

\section{Chapter XIX}

1. Tell what is said about the amount of water in the human body. 2. Why must the body frequently receive a new supply of water? State how this need is supplied. 3. Explain what is meant by taking into solution. 4. Tell how water is helpful in cleaning the inside of the body. 5. How may drinking water with one's meals be harmful? 6. Mention times of the day that are favorable for drinking freely of water. 7. What is said about the temperature of water? 8. Tell why drinking freely of water to help cleanse our bodies is usually much wiser than taking patent medicines. 9. Why should the habit of dosing with medicines of any kind be avoided? 10. What is distilled water? 11. Explain what causes rain. 12. How does rain differ from distilled water? 13. Tell about the formation of wells and springs. 14. Why does the housewife prefer soft water for washing? 15. Give the meaning of polluted and sewage, page 190. 16. How may water that is suspected of being polluted be made safe to drink? 17. State a good reason for being careful about the quality of our drinking water. 18. Tell what is said about the Japanese. 19. What is the safest way to cool water for drinking, and why? 20. Tell why a pump is better than a well. 21. Of what use is the epidermis? The dermis or true skin? 22. State why the perspiratory glands are like the sewer pipes of a house. 23. Besides furnishing an outlet for perspiration, what other useful service do the perspiratory glands serve? 24. Tell the use of the oil glands. How may they obstruct the skin? 25. Show how the 
practice of trying to improve the complexion by applying paint and powder may be harmful. 26. State how often baths should be taken, and why. Why should we be as careful about having all parts of the body clean as we are about the hands and face? 27. Compare tepid and warm baths. 28. How may a hot bath help to relieve a cold? 29. How may warm water be an aid to sleep? 30. Mention a good time to take hot baths. When should hot baths not be taken? 31. With what is it well to precede cold baths? 32. Describe the effects of cold baths. 33. What is the reaction? How can we tell if the practice of taking cold baths is harmful to us? 34. Mention the best time of the year to start the cold-bath practice. Explain the benefits of energetic rubbing after taking cold baths. 35. Tell some of the benefits of cold baths. 36. State the difference between Russian and Turkish baths. 37. What are some of the advantages of a cabinet bath? 38. In what way is it beneficial to drink several glasses of water before taking a cabinet or other hot bath? 39. Why should wood alcohol not be used as a fuel for a cabinet bath? 40. State why baths that cause a profuse flow of perspiration are more necessary. in winter than in summer. 41. Mention other benefits of water, page 201. 42. Relate the incident concerning Benjamin Franklin.

\section{Chapter XX}

1. (a) Define the circulation. (b) Tell why it is necessary to keep the circulation of blood normal in every part of the body. 2. Mention several things that cause the arterial muscles to relax. What makes these muscles contract? 3. Tell how tight clothing may hinder the circulation. 4. Describe our marvellous telegraph system, naming the central office, the main wire, etc.

5. How does our 
telegraph system work, page 207? 6. Why should all be especially careful not to injure the head or back?

\section{Chapter XXI}

1. Tell why human beings in cold or temperate climates need clothing. 2. Name several substances that are poor conductors of heat. 3. Why are two or more thin quilts warmer than one quilt of thickness equal to all the others? Why is loose clothing warmer than that which is tight? 4. Tell why woolen is warm clothing. 5. How does cotton-mesh clothing compare in warmth with closely woven cotton? Why? 6. Why should underclothing be capable of frequent and thorough cleansing? 7. Give the advantages of and the objections to woolen underclothing. 8. State the advantages and disadvantages of cotton underwear. 9. Tell what is said of linen mesh. 10. State the benefits of airing our underclothing at night. 11. Why is it not best to wear too much clothing daytimes or to have too much over us while sleeping? 12. What is said about neck-scarfs? 13. Why is it unwise for parents to dress their children too warmly? 14. Mention the harm of wearing too heavy hats or caps. 15. Why is it unusual to see bald-headed women? 16. Tell about the "Blue Coat School" boys. 17. Mention several things boys should do to help prevent baldness. 18. Tell how baldness of the head usually develops, page 216. 19. Why should shoe-leather be pliable? What is the advantage of porous leather? 20. What is said about patent leather shoes? About rubbers? 21. State the advantage of laced shoes; of low, broad heels; of medium weight soles. 22. Tell how to relieve tender feet. 23. Why should all avoid getting shoes and stockings wet? 


\section{Chapter XXII}

1. Give some advantages of well-formed, healthy teeth. 2. What is the crown of a tooth? The root? What is the enamel? The dentine? 3. How many teeth are in the temporary set? In the permanent set? 4. Describe the incisors; the canines; the bicuspids; the molars. What are the wisdom teeth? 5. Tell what causes teeth to decay. 6. Describe a good way for thoroughly cleansing the teeth. If this is done but once a day, what is the best time? 7. Explain the benefit of using dental floss. 8. Why is it well to follow the cleansing of our teeth with an alkaline mouth wash? 9. What makes an inexpensive but excellent tooth powder? 10. How often, at least, is it well to have one's dentist examine the teeth? 11. Explain why it is foolish to delay going to a dentist when we know we have a cavity in a tooth. 12. Tell what tartar is, and why it should be removed. 13. State with what the blood must supply our teeth in order to keep them healthy. What foods supp'y such materials to the blood? What foods do not? 14. Of what benefit to the teeth is active exercise? 15. Why should the first, or temporary teeth, be kept clean and free from decay? 16. Explain about the sixth-year molars. 17. Show how losing temporary teeth before their natural time may cause the permanent set to be irregular. 18. What harm may come to the teeth of a little child from allowing it continually to suck its thumb, or something similar? How may this be prevented? 19. By whom can an irregular set of teeth be straightened? When should this be done? 20. Explain the possible harm from cracking nuts; biting thread; picking the teeth with a pin, knife, or any sharp instrument; following hot drinks or food with cold, or vice versa. 21. Why should medicines containing iron or 
acid be taken through a tube?

22. Describe the harm that may come to the teeth from eating candy; from using tobacco.

\section{Chapter XXIII}

1. What may be called the windows of Jack's House? 2. Describe the white of the eye. 3. Tell what is said of the cornea. 4. What and where is the iris? What purpose does it serve? 5. What is the pupil of the eye? 6. What part of the eye performs the same work as the lens of a camera? 7. Tell what the retina is, and to what part of a camera it corresponds. 8. In order to have vision of the eye distinct, where must the rays of light come to a focus? 9. If our eyes are neither nearsighted nor farsighted, on what part of the eye are the rays of light focused when we look at a distant object? 10. When we look at near objects, what is necessary in order to bring the rays of light to a focus on the retina, provided our eyes are normal? 11. Why are the muscles of a normal eye at rest when a person is looking at distant objects? Why must its muscles always work when one is looking at near objects? 12. Why is it restful to the eyes occasionally to look off into the distance when we are doing close work? 13. Tell what is meant by convergence, page 238. 14. State what is usually the cause of weak sight in persons having otherwise normal eyes, and tell a good way to cure it. 15. Give the points mentioned on pages 239 and 240 that we should be careful about while reading. 16. When and why should colored glasses be worn? Why should they not be worn at other times unless advised by an oculist? 17. Give two good reasons why we should neither read nor sew by twilight. 18. Why should we not read by a flickering light? 19. When should we not do close work by artificial light? Why? 20. Tell why read- 
ing while riding in a car is trying to the eyes. 21. State why an erect position of the body is best for the eyes while we are reading or studying. 22. Why is it well not to have what we are reading lie on a desk or other flat surface? 23. What is said about reading while lying down? 24 . Why should one not read when the body is weak from illness? 25. Give a good reason why delicate children should not commence attending school until they become strong, page 241. 26. Tell why one should not sew on dark materials by artificial light. 27. Why should thick or spotted veils not be worn? 28. State why we should be careful not to expose our eyes suddenly to intense light. 29. What is said about using a microscope, page 243 ? 30. Why is washing the eyes in cool water when they feel uncomfortable better than rubbing them? 31. Who should always be consulted when there is a discharge from an infant's eyes? How much of all blindness is said to be due to lack of attention to such condition of babies' eyes? 32. What proportion of the children in the Batavia Asylum for the Blind are there because of attention not having been given to such discharge from their eyes when they were infants? 33. What care should be taken that none of such discharge gets into the eyes of other people? 34. State why the eyes of infants should at all times be screened from strong light. 35. Tell some other things to be careful about in regard to our reading, page 245 . 36. Mention one great benefit of legible writing. 37. Tell how to get a particle of dust or a cinder out of the eye. 38. If a cinder is not removed by such attempts, why should an oculist be at once consulted? 39. Why are percussion caps a great source of danger to children's eyes? 40. How may workmen protect their eyes? 41. What should be done when quicklime or mortar gets into the eye? When an acid gets in? 42. Tell what is said 
about the dangers to the eye from wood alcohol and substances made from it. 43. Why may patent medicines, Jamaica ginger, etc., injure the eyes? 44. State why one should avoid using a towel that persons having a disease may have used. 45. Why is plenty of sleep good for the eyes? 46. Tell the estimate Dr. Cohn makes in regard to one thousand cases of blindness, page 249 . 47. State why concave glasses correct nearsightedness. 48. Tell how school children often bring on nearsightedness. 49. Describe the experiment in regard to nearsightedness which the German government made. 50. Give some good evidences of farsight. What kind of glass corrects farsight? 51. To what is astigmatism usually due? How may it be recognized, page 254? When neither concave nor convex glasses correct the eye's defect, what is usually the difficulty? 52 What is the usual cause of squint or cross-eye? Tell why it should be immediately attended to. 53. Mention some warnings of the fact that our eyes probably need glasses to correct some defect. 54. Give some good reasons why it is very foolish for children not to wear glasses when they have some defect of vision. 55. Why are spectacles better than nose glasses? 56. Relate the experience of Francisque Sarcey. 57. In all eye tests, why is it important to keep one eye covered while the other is being tested? 58. Why should the question of expense not delay us in having our eyes treated by an oculist? 59. Give some good rules to guide us daily in the use of our eyes. 60. State how weak eyes may be benefited. How may defective eyes be corrected? 


\section{Chapter XXIV}

1. Tell how good hearing contributes toward our usefulness and pleasure. 2. Mention the three divisions of the ear. 3. What is the auricle? The auditory canal? 4. What are the earwax glands, and what is their use? 5. Why should we not try to dig or swab out the earwax? 6. Describe the drumhead. 7. What is the Eustachian tube? 8. Tell how sound impressions get to the brain, page 265. 9. What is said about impacted earwax, pages 265 and 266 ? 10. State how a foreign body may be removed from the ear. How should it not be removed, and why? 11. Tell how the drumhead is sometimes punctured. 12. Explain why picking the ear with a pencil or any pointed instrument is dangerous. 13. Explain the danger of suddenly shouting into a person's ear; of boxing or striking any one on the ear. 14. Why is the stoppage of the Eustachian tube one of the gravest dangers to the ears? Tell why colds, catarrh, etc., cause this tube to become stopped up. 15. Why should an aurist be at once consulted if there is any derangement of hearing with or after a cold? 16. The stoppage of the Eustachian tube also often occurs after what two serious diseases of children? 17. Of what are unusual sounds in the ear a sign? 18. Why should little children's hearing be frequently tested? 19. Tell how earache may be relieved, page 269. 20. Explain why an aurist should be at once consulted when there is a discharge from the ear. 21. State why diving and jumping into the water are likely to injure the hearing. 22. How may our ears be protected when we are going where loud explosions will take place? 23. How may persons who work around noisy machinery protect their ears? 24. Mention a drug that is said to cause deafness. 25. What is 
one of the greatest dangers of deafness, page 273 ? 26. What is often the cause of pupils being stupid and disorderly in school? How may this cause be removed? 27. Tell how ears may be tested. 28. Mention several signs that are warnings of possible ear trouble, page 274 . 29. Why should deafness in only one ear be a matter of serious concern? 30. Mention some of the discomforts of deaf persons.

\section{Chapter XXV}

1. Tell some of the benefits of sleep. 2. How many hours of sleep should children have? Adults? 3. What benefit will sometimes come from a few hours' or a few days' rest in bed? 4. Tell why pure air is necessary to restful sleep. 5. What is said on page 277 about bed-clothing? Pillow? Mattress? 6. Why is "Early to bed and early to rise" a good motto? 7. Tell why it is well to have a regular time for retiring and rising. 8. What is said on page 278 about children's sleeping with an old person? 9. Mention some causes of sleeplessness, page 279. 10. How may we help to avoid sleeplessness? Why should persons doing mental work take special pains in these respects? 11. Tell why it is unwise to sit up late at night to prepare for next day's examination. 12. Mention the causes given on page 281 that often result in breaking down the health of school children. 13. If children attend dancing school or theater, it should only be on what nights? 14. What is said on page 281 about knowledge gained by cutting off needed rest at night?

\section{Chapter XXVI}

1. Tell why it is wise immediately to cleanse and cover cuts. 2. Why should a physician always be sent for in 
case of a severe cut? 3. Describe a Spanish windlass or tourniquet. 4. If a person receives a severe cut while out of doors alone, what is the best plan? 5. What will usually stop or retard the flow of blood from a cut, at least until the doctor comes? 6. How may bleeding from the nose usually be stopped? 7. What is said about a wide cut, page 286? 8. What is the simplest and best home remedy for a burn? 9. Why should a physician be at once summoned if more than a small surface is burned? 10. State the best thing to do when clothing accidentally takes fire. 11. How should burns from acid be treated? Burns from alkali? 12. Tell what is said about sunstroke; about heat exhaustion. 13. What is a good remedy when only a very small part of the body is frozen? 14. Tell how to treat a severely frozen person before the doctor comes. 15. Describe Sylvester's method for restoring respiration. 16. Tell what else may be done while artificial respiration is in progress. 17. What is one of the quickest ways of relieving a child who has got something in his windpipe? 18. Tell the usual cause of fainting, and state how to relieve this condition. 19. In cases of unconsciousness, what is a good rule to follow until a physician arrives? 20. As a rule, what is the best thing to do in a case of poisoning while awaiting a physician's arrival? 21. Mention some remedies that may be used if the poison is known to be an acid; if it is known to be an alkali. 22. Tell what is said of poison ivy.

\section{Chapter XXVII}

1. Mention some diseases that are caused by minute plants or animals. 2. In what kind of tissue do these usually not thrive? When are they likely to get a start in the body? 3 . Tell about the rapidity with which they 
increase. 4. In cases of consumption, pneumonia, etc., where are these germs? In cases of typhoid fever? In scarlet fever, measles, etc.? 5. How may disease germs get from one person to another? 6. Mention several ways of destroying disease germs, page 296. 7. Describe the patent spittoons for the use of consumptives. If an ordinary spittoon is used, what solution should it contain? 8. What should a patient be careful to do while coughing? 9. Why should rugs, pictures, etc., be removed from the room of a person ill with a germ disease? 10. Mention some of the duties of a city or village health officer. Why should his instructions always be carefully obeyed? 11. Tell the benefits of vaccination. 12. What disease is called "The Great White Plague"? 13. How did the deaths from tuberculosis alone in the United States in 1899 compare with the total number of deaths from diphtheria, smallpox, typhoid fever, and whooping-cough? 14. When do consumption germs usually get their start? Where is the usual beginning place? 15. Mention several of the usual symptoms of the beginning and progress of consumption. 16. Why should every house possess a clinical thermometer? 17. What is said about temperature on page 303 ? About the pulse-rate? 18. Tell three marked signs of consumption that are often given little attention, page 304. 19. Tell how consumption may be prevented from spreading in a family or neighborhood. Give some arguments in favor of this statement. 20. Explain why a fine is imposed for expectorating in street-cars, etc. Tell why all should obey such rules. 21. Why is it a great mistake for any one who may have incipient tuberculosis to try patent medicines? 22. What are the two things most useful in increasing a consumptive's vitality and power of resistance? 23. Name some foods that are excellent for tuberculosis patients. Why is olive 
oil especially good? 24. Mention some regions to which tuberculosis patients are sent. 25. Tell about the outof-door life of tuberculosis patients in such regions. 26. Are alcoholic drinks a help or a hindrance to persons ill with tuberculosis? 27. Mention some classes of people who are likely to have tuberculosis, page 310 . 28. Tell some special precautions that such persons should take. 



\section{GLOSSARY}

\section{KEY TO THE MARKINGS}

(From Webster's International Dictionary)

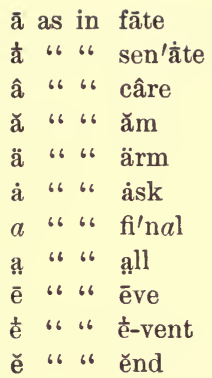

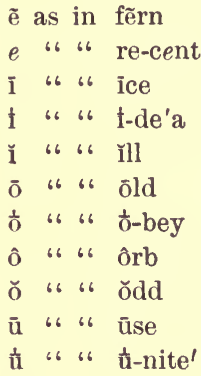

y as in rude

u $66 \quad 66$ full

$\breve{u}$ 66 66 ŭp

$\hat{u}$ 66 66 ûrn

y̆ 66 66 pit' $\breve{y}$

$\overline{\mathrm{OO}}$ 66 66 foOd

OO 66 66 foot

ou "6 66 out

oi "6 "6 oil

n (like ng) as in bank

I indicates primary accent.

" indicates secondary accent.

\section{A}

abnormally (ăb-nôr'mal-ly̆), adv., in a manner not normal or natural. absorb (ăb-sôrb' $b^{\prime}$, v.t., to take up like a sponge. abstainer (ăb-stān'ẽr), n., one who abstains. accidentally (ăk"sĭ-děn't $a$ l-ly̆), $a d v$., by chance. accommodate(ăk-kŏm'mō-dāt), v.t., to adapt or adjust. accommodation (ăk-kŏm'"mō-dā'shŭn), n., the act of adapting or adjusting. accomplish (ăk-kŏm'plǐsh), v.t., to complete or fulfill. accountable (ăk-kount'à-b’l), a., answerable.

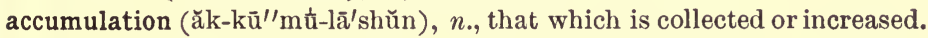
activity (ăk-třv'ĭ-ťy), n., the state of being active or lively. admiration (ăd"mĬ-rā'shŭn), n., wonder mingled with pleasure. admiringly (ăd-mīr'ı̌ng-ly̆), $a d v$., with admiration. adolescence (ăd"ō-lěs'sens), $n$., the state of growing from childhood to maturity; youth. adult (à-dŭlt' $), n$, a person who has reached his growth. 
advantage (ăd-vản'tâjj), n., gain or benefit.

aerate (ā'err-āt), v.t., to supply with common air.

Alhambra ( $\breve{l}$-hăm'brä), n., the palace of the Moorish kings at Granada, Spain.

alimentary (ăl'/î-mĕn't⿳亠口冋-ry̆), $a$., pertaining to food or to the functions of nutrition.

alternate (ăl'tẽr-nāt), v.t., to perform by turns or in succession. anxiety (ăn-zì' $’ \grave{e}-t \breve{y}), n$, care, uneasiness.

appreciate (ăp-prē'shĭ-āt), v.t., to value.

architect (är'kl̆-tĕkt), n., a person skilled in the art of building.

architecture (är'kǐ-těk"tutur), n., the art of building.

artery (âr'tẽr-y̆), n., one of the cordlike canals through which blood passes from the heart tc various parts of the body.

atmosphere (ăt'mŏs-fēr), n., the air of a place; any surrounding influence or condition.

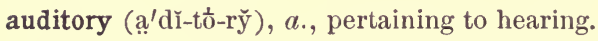

aurist (a $a^{\prime}$ řst), $n$., one skilled in treating disorders of the ear. authority (ạ-thŏr/Ǐ-ty̆), n., rightful power.

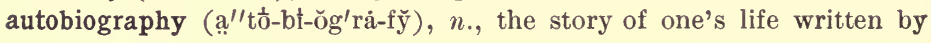
one's self.

bandage (bănd'âjj), n., a strip of cloth used in binding up wounds. banquet (băn'kwĕt), n., a feast.

benefactor (bĕn'lè-făk'tẽr), n., one who confers a favor.

beneficial (běn'"ē-fĭsh'al), a., helpful.

beverage (běv'ẽr-ăjj), n., drink.

blight (blit), v.t., to destroy.

blubber (blŭb'bẽr), $n$., the fat of whales and other large sea animals.

boisterous (bois'tẽr-ŭs), $a$., rough; noisy.

booty (bō'ty̆), n., plunder.

calculate (kăl'kỉ-lāt), v.t., to estimate ; to count.

cavity (kăv'ı́-ty̆), n., a hollow place.

ceaseless (sēs'lěss), a., without pause or end.

celebrated (sěl'ē-brä $\bar{a}^{\prime \prime}$ těd), $a$. , famous.

chafe (chāf), v.t., to rub; to wear by rubbing.

characteristic (kăr/'ăk-tẽr-ı̌s'tı̌k), n., a distinguishing quality.

chemist (kĕm'isst), n., a person skilled in chemistry.

coddle (kŏd'd'l), v.t., to treat with too much tenderness. 
companionable (kŏm-păn'yŭn-à-b'l), a., agreeable; sociable. comparatively (kŏm-păr'di-třv-ly̆), $a d v$., relative to other things. compartment (kŏm-pärt'ment), n., one of the parts into which an inclosed space is divided.

community (kŏm-mū'nĭ-ť̆), n., place or neighborhood. compel (kŏm-pěl'), v.t., to force.

completely (kŏm-plēt'ly̆), adv., fully. component (kŏm-pō'nent), n., one of the parts that make up a thing. comprehend (kŏm"prè-hěnd'), v.t., to understand. compulsory (kŏm-pŭl'sō-ry̆), $a$., enforced by law. concave (kŏn'kāv), a., hollow and curved. The opposite of convex. considerably (kŏn-š̆d'ẽr-à-bly̆), $a d v$., much. constipation (kŏn"stri-pā'shŭn), n., a state of the bowels in which the expulsion of waste is not regular or sufficiently frequent. construct (kŏn-strŭkt' ${ }^{\prime}$ ), v.t., to build; to make. content (kŏn-těnt' ${ }^{\prime}$, v.t., to satisfy. contestant (kŏn-těst'ant), n., an opponent; one who contests. continually (kŏn-tĭn't̀- $a$ l-ly̆), $a d v$., unceasingly ; without stopping. contrive (kŏn-trī' '), v.t., to plan; to devise. convex (kŏn'věks), a., rising or swelling into a rounded form. The opposite of concave.

counterbalance (koun"'tẽr-băl'ans), v.t., to oppose with an equal weight or power.

create (krē-āt' $)$, v.t., to cause to exist. cumbersome (kŭm'bẽr-sŭm), a., burdensome or hindering.

degrade (dé-grād $d^{\prime}$ ), v.t., to bring shame on ; to disgrace, to debase. derange (dè-rānj'), v.t., to disturb; to throw into disorder. derangement (dè-rānj'ment), n., disorder ; confusion. determination (dè-tẽ̃r'mĭ-nā'shŭn), n., decision. development (dè-věl'ŏp-ment), n., growth. $\operatorname{diet}\left(\mathrm{d}_{\mathrm{i}}{ }^{\prime} \breve{\mathrm{e}}\right), n$., what is eaten and drunk habitually. difficulty (dǔf'frù-kŭl-ty̆), n., a thing hard to do ; obstacle. dilute (dì-lūt'), v.t., to thin by mixing. disgust (diss-gŭst' ${ }^{\prime}$, v.t., to cause loathing; to provoke strong distaste. dispute (dǐs-pūt ${ }^{\prime}$ ), v.t., to question the truth of. distasteful (dǐs-tāst'fụl), a., unpleasant; offensive. distinctness (dǐs-tinnkt'něss), $n$. , state of being clearly seen. distort (dǐs-tôrt' $), v . t .$, to twist out of shape. 
divergent (dǐ-vẽr'jent), $a$, going farther and farther from each other. draught (dräft), $n$., a current of air moving through an inclosed place. dub (dŭb), v.t., to call.

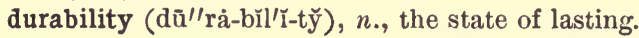

$\mathbf{E}$

effective (ĕf-fěk'třv), $a$., able to accomplish results.

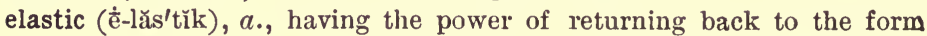
from which a substance has been bent or pressed; springy.

elasticity ( $\overline{\mathrm{e}}^{\prime \prime}$-lăs-tīs'⿳亠口冋-t $\left.\breve{y}\right), n$., quality of springing back. emergency (⿳亠े⿵-mër'jen-sy̆), $n$., an unforeseen happening. emotion (è-mō'shŭn), $n$., excitement of the feelings.

endurance (ĕn-dū $\left.r^{\prime} a n s\right), n$., the act of bearing or suffering. enduring (ĕn-dūr'ĩng), $a$. , lasting. energy (ĕn'ẽr-jy̆), n., force; power. enterprise (ěn'tẽr-prīz), n., project; that which is undertaken.

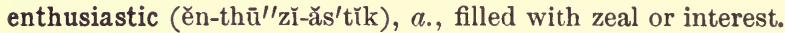
estimation (ěs" ${ }^{\prime \prime} \mathrm{ir}-m \bar{a}^{\prime}$ shŭn), n., opinion of the worth of anything. evaporate (è-văp'ô-rāt), v.i., to pass off in vapor.

excess (ěk-sěs' $\left.{ }^{\prime}\right), n$., that which goes beyond what is usual or proper. exertion (ĕgz-ẽr'shŭn), $n$., a laborious effort. exhilaration (ěgz-ĭl" à-rā'shŭn), $n$., joyousness; high degree of good feeling.

expand (ěks-pănd'), v.t., to spread out.

expansion (ěks-păn'shŭn), n., the act of spreading out.

experience (ĕks-pē'rĭ-ens), n., practical wisdom gained by personal knowledge, feeling, or action.

experiment (ĕks-pĕr'̌̌-ment), $n$., a practical test. expulsion (ěks-pŭl'shŭn), n., the act of expelling or sending out. extension (ěks-těn'shŭn), n., enlargement; increase. extract (ěks-trăkt'), v.t., to draw out or forth.

feasible (fé-'žl-b'l), a., capable of being done; practicable. fetid (fét/ıd), a., having an offensive smell.

fiber (fī'bẽr), n., the delicate, thread-like portions of which the tissues of plants and animals are in part constituted.

flavor (flā'vere), $n$., the quality of anything that affects the taste. focus (fō'kŭs), n., a point at which the rays of light meet and at which the image is formed. 
formaldehyde (fôr-măl'dè-hīd), n., a colorless liquid often used in preserving milk and other food.

fortify (fôr'tĭ-fĩ), v.t., to furnish with power to resist attack.

foundation (foun-dā'shŭn), n., that on which anything stands or by which it is supported.

frenzy (frěn'žy), $n$., any violent agitation of the mind. frequently (frē'kwěnt-ly̆), $a d v$., often ; repeatedly.

function (fŭnk'shŭn), n., the appropriate action of any special organ or part of an animal.

G

gallant (găl'lant), $a$. , brave.

general (jěn'ēr- $\alpha$ l), $a$. , cornmon to many.

girth (gërth), $n$. , the measure around the body.

gradually (grăd'ù-âl-ly̆), $a d v$., slowly, by steps or degrees.

$\mathrm{H}$

habitually (hả-bĭt'玄- $a$ l-ly̆), $a d v$., as a matter of habit.

handicap (hăn'dĭ-kăp), n., hindrance.

hardship (härd'shı̆p), $n$., that which is hard to bear.

hoard (hōrd), $n$., hidden treasure.

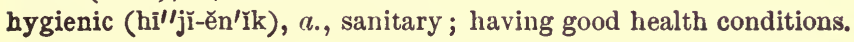

\section{I}

immune (ı̆m-mūn'), $a .$, protected from.

immunity (ı̆m-mū'nı̆-ty̆), n., freedom from.

impairment (Ĭm-pâr'ment), $n$., injury.

impetus (Ĭm'pè-tŭs), n., momentum; force.

impression (Ĭm-prěsh'ŭn), n., influence or effect on the senses or the

intellect.

improbable (İm-prŏb'á-b'l), $a$., unlikely to be true.

incipient (In-sı̆p'1̌-ent), a., beginning to be or to show itself.

incompetent (ı̆n-kŏm'pè-tent), $a$., incapable ; unfit.

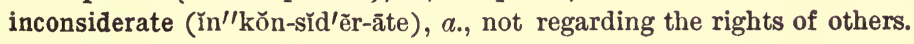

indefinitely (ı̆n-děf'î-nĭt-ly̆), $a d v$., not definitely.

indistinct ("̆n"'dǐs-tīnkt'), $a$., not clear.

induce (Ĭn-dūs ${ }^{\prime}$ ), v.t., to influence.

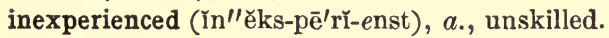

inflammation (Inn"flăm-mā'shŭn), n., the state of being swollen.

inflate (Ǐn-flāt'), v.t., to expand; to enlarge. 
ingredient (Ĭn-grēeld̆-ent), $n$., one of the parts that make up or compose a mixture.

inherit (Ĭn-hĕr'ĭt), v.t., to receive by birth; to come into possession of.

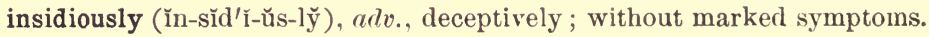

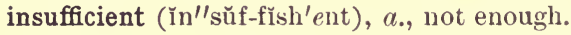

intelligently (Inn-tĕl'lî-jent-ly̆), $a d v$., with readiness of understanding. intense (inn-těns $\left.{ }^{\prime}\right), a$. , extreme in degree.

intentional (ĭn-těn'shŭn- $a$ l), $a$., done by design.

international (inn't'tẽr-năsh'ŭn- $a$ l), $a$.. between nations.

introduction (Ǐn"trō-dŭk'shŭn), n., formally making persons known to each other.

intrude (Ĭn-trụd $\left.d^{\prime}\right), v . t$. \& $i$., to enter without invitation or welcome. investigation (Ĭn-věs"t tr̆-gà'shŭn), n., the act of inquiring into or thoroughly examining.

investment (ĭn-věst'ment), $n$., that which is invested or put into something with a view of obtaining profit.

invisible (Ǐn-vǐz'lı-b'l), $a$., not able to be seen.

irregularly (ı̆r-rĕg'ū-lãr-ly̆), $a d v$., not natural ; not uniform.

irritable (ír'rî-tá-b'l), a., easily made out of temper or angry.

isolated ( (I'sō-lā-těd), a., separated from others.

\section{$J$}

justifiable (jŭs"'tĭ-fî̀'à-b'l), $a$. , in a manner shown to be just.

L

languid (lăn'gwĭd), a., not disposed to exert one's self ; not active. liberally (lĭb'ẽr-al-ly̆), $a d v$., generously.

listless (lıst'lěss), a., having no desire or inclination; spiritless. lubricate (lū'brǐ-kāt), v.t., to make smooth or slippery.

M

marvelous (mär'věl-ŭs), $a$. , wonderful ; astonishing. massage (măs'-săj), n., a rubbing or kneading of the body. menu (me-nụ' $), n$, bill of fare.

microscope (mī'krō-skōp), n., an instrument for making an enlarged image of a small object.

miser (mï'zẽr), n., one who lives miserably to increase his wealth. moderately (mŏd'ẽr-⿳亠口冋t-ly̆), $a d v$., in a manner not extreme or violent. moisture (mois'tūr), n., liquid in small quantities. multitude (mǔl'tǐ-tūd), n., a great number; a crowd. 
museum (mū-zē'ŭm), n., a collection of curiosities or works of art. mysterious (mǐs-tēerri-ŭs), a., difficult to understand ; containing mystery.

\section{$\mathrm{N}$}

necessitate (nèt-sẽs'sǐ-tāt), v.t., to make necessary ; to compel. nervousness (nẽrv'ŭs-něss), $n$., the state of being easily excited. normal (nôr'mal), a., according to established rule or regular form. nourish (nŭr/ ̌sh), v.t., to feed and cause to grow. nutriment (nū'trĭ-ment), $n$., that which nourishes; food. nutritious (nū-trǐsh'ŭs), a., giving nutriment.

O

obstruction (ŏb-strŭk'shŭn), n., that which bars or obstructa. obviate (ŏ $\mathrm{b}^{\prime}$ vĭ-āt), v.t., to make unnecessary. oculist (ŏk'tu-lisst), $n$., one skilled in treating diseases of the eye. odorless ( $\bar{o}^{\prime}$ dẽr-lěss), $a .$, free from smell.

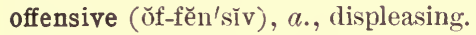
oil of vitriol (vĭt'rŭ-ŭl), $n$., strong sulphuric acid. opaque ( $\left.\bar{t}-p \overline{\mathrm{k}^{\prime}}\right), a .$, not transparent. ornamental (ôr $\mathrm{r}^{\prime \prime}$ ná-mĕn't $(l)$ ), $a$., that which ornaments or beautifies. overindulgence ( $\bar{o}^{\prime \prime}$ verr-ĭn-dŭl'jens), $n$., taking too much of anything. overwhelm $\left(\bar{o}^{\prime \prime}\right.$ vẽr-whělm $\left.{ }^{\prime}\right)$, v.t., to cover over completely ; to oppose overpoweringly. oxidize (ŏks'/̌-diz), v.t., to combine with oxygen.

\section{$\mathrm{P}$}

pallor (păl'lẽr), n., want of color.

papier-maché (pä́pyà-mä"shà'), n., a hard and strong substance made of a pulp from paper mixed with glue.

parallel (păr'al-lěl), a., extended in the same direction, and in all parts equally distant.

penetrate (pěn'è-trāt), v.t., to enter into.

percussion cap (pẽr-kŭsh'ŭn kăp), n., a small copper cap containing gunpowder.

peril (pěr'ǐl), n., danger.

persist (pẽr-sǐst), v.i., to keep trying ; to persevere.

physical (fǐz' $\mathrm{l}-\mathrm{k} a \mathrm{l}), a$., relating to the bodily structure.

physician (fĭ-ž̆sh'an), n., a person skilled in the art of healing; a doctor of medicine.

pirate (pí'ratt), n., a robber on the high seas, 
Pisa (Pé'zå), n., city in Italy, having a famous leaning tower. pollute (pŏl-lūt' ${ }^{\prime}$, v.t., to make unclean. porous (pōr'ŭs), a., full of pores or small openings. posture (pǒs'tür), n., position of the body. precaution (prè-kạ'shŭn), $n$., previous care. preëstablish (prē"/ĕs-tăb'lĭsh), v.t., to establish beforehand. preferable (prěf ẽr-à-b'l), $a$., worthy to be chosen before something else. preference (prěf'ẽr-ens), $n$., choice. preparation (prĕp"'à-rā'shŭn), n., a making ready. preserve (pré-zẽrv'), v.t., to keep or save from injury. prevalence (prěv'á-lens), n., the state of being widespread. preventive (prè-věnt'ivv), n., that which hinders. principal (prĭn'š̃-pal), $a$. , most important. process (prǒs'ěs), n., way of doing. prodigious (prò-dĭj'ŭs), $a$., very large. profuse (prò-fūs'), a., large in quantity. prohibit (pró-hĭb/it), v.t., to forbid. projection (prō-jěk'shŭn), n., a part jutting out. proportion (prò-pōr'shŭn), n., proper share. prosperity (prŏs-pẽr'Ǐ-ty̆), n., good fortune; success. puncture (pŭnk'tùr), n., a small hole made by a point. purification ( $p \bar{u}^{\prime \prime} r$ t-fĩ-kā'shŭn), n., the act of making pure or clean. putrid ( $\mathrm{p} \bar{u}^{\prime}$ trĭd), $a$. , foul, or decayed.

\section{$\mathrm{R}$}

radiate ( $\left.\mathrm{ra}^{\prime} \mathrm{d} \mathrm{i}-\mathrm{a} t\right)$, v.t., to send out in direct lines from a point or points. rancid (răn'sĭd), a., having a rank smell or taste ; musty. realize (ré-'al-iz), v.t., to understand to be real; to comprehend fully. rearrange (rē"l'ăr-rānj'), v.t., to place in a different way. reduce (rè-dūs's), v.t., to diminish; to lower. reflection (rè-flèk'shŭn), $n$., the act of thinking over or considering; state of being reflected. refrain (rê-frān'), v.i., to keep one's self from action ; to abstain.

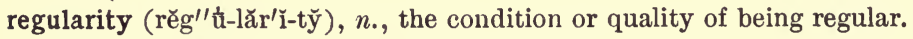
regularly (rĕg'tu-lẽr-ly̆), $a d v$., in due order or time. regulate (rĕg't̀-lāt), v.t., to direct by rule. relax (rè-lăks's), v.t., to loosen. reliable (rè-lī'á-b'l), $a .$, trustworthy; fit to be relied on. remote $\left(\mathrm{r}^{\mathrm{e}}-\mathrm{mō} \mathrm{t}^{\prime}\right), a$. , far away. repulsive ( $\mathrm{rt}^{\mathrm{t}}-\mathrm{pŭl} \mathrm{l}^{\prime} \mathrm{s} \mathrm{v} v$ ), $a_{\text {. }}$, forbidding; offensive. resident (rěz'⿳亠-dént), $n$, one who dwells in a place for some time. 
resistance (rte-zIst'ans), n., opposition; the act of withstanding. responsible (rê-spðn'sĭ-b'l), $a$., able to answer for one's conduct. rhythmic (rith'mǐk), a., having a regular succession of motion. robust (rò-bŭst' $)$, a., strong; vigorous.

\section{S}

sanatorium (săn"'à-tō'rĭ-ŭm), $n$., a resort for invalids. sedentary (sěd'ěn-tà-ry̆), a., inactive ; much sitting. sewage (sū'âj), n., the contents of a sewer or drain. shun (shŭn), v.t., to avoid; to keep clear of. solicitous (sô-lĭs'ĭt-ǔs), $a$., eager; anxious. solution (số-lū'shŭn), $n$., the state of being dissolved. sparingly (spâr'ǐng-ly̆), adv., savingly. spectacle (spěk'tà-k'l), n., a remarkable or noteworthy sight.

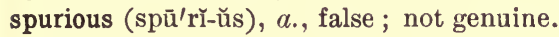
stagnant (stăg'nant), a., not flowing. staple (stā'p'l), a., regularly produced in large quantities. steerage (stēr'âj), n., the space in the after part of a vessel, under the cabin.

structure (strŭk'từr), n., arrangements of parts ; a building. stunt (stŭnt), v.t., to stop or to lessen.

substance (sŭb'st $\alpha \mathrm{ns}$ ), n., material. substitute (sŭb'stǐ-tūt), v.t., to put in the place of another person or thing. suffocate (sǔf'fō-kāt), v.t., to stifle ; to smother.

supplement (sŭp'plè-ment), v.t., to add something to. systematic (š̌s"těm-ăt'ǐk), a., proceeding according to regular method.

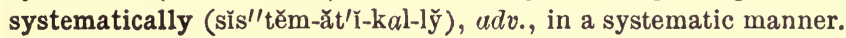

\section{$\mathrm{T}$}

tax (tăks), v.t., to lay a burden upon.

tedious (tēe'dĭ-ŭs), $a .$, tiresome.

temperature (těm'pẽr-ä-tùtr), $n$., condition with respect to heat or cold. temporary (těm'pó-rà-ry̆), a., lasting for a time only.

tenđency (těnd'en-sy̆), n., direction or course toward any place, object, effect, or result; disposition or inclination for.

testimony (těs'tǐ-mót-ny̆), n., evidence; proof of some fact.

threshold (thrěsh'öld), $n$., entrance, beginning.

thrive (thriv), v.i., to grow vigorously.

transmit (trăns-mít'), v.t., to cause to pass over or through. 
undefiled (ŭn-dé-fill'd' $\mathrm{d}^{\prime}$ ), $\alpha$. , pure ; not corrupted or unclean. undetected (ŭn-dè-těk'těd), $a .$, not found out. ungainly (ŭn-gān'ly̆), a., clumsy ; awkward. universal ( $\overline{\mathrm{u}}^{\prime \prime} \mathrm{nI}$-vẽr's $\left.a \mathrm{l}\right), a$. , unlimited; all-reaching. unnaturally (ŭn-năt't't-ral-ly̆), $a d v$., contrary to the order of nature. unnecessarily (ŭn' 'něs-ěs-să'rǐ-ly̆), $a d v$., needlessly. unpalatable (ŭn-păl '⿳亠丷⿵冂⿱八口𧘇-tá-b'l), $a .$, not agreeable to the taste. unquestionably (ŭn-kwĕs'chŭn-ä-b'ly̆), adv., without doubt. unwholesome (ŭn-hōl'sŭm), a., not tending to promote health.

\section{V}

variety (vä-rī'tety $), n$., the state of being different. various ( $v \bar{a} '$ rĭ-ŭs), $a$., different.

vein (vān), $n$., one of the cord-like canals through which blood passes to the heart.

vibration (vì-brā'shŭn), n., motion to and fro as a pendulum.

vigorous (vı̆g’ẽr-ŭs), a., strong; robust.

violence (vì ó-lens), $n$., force; highly excited action.

vision (vǐzh'ŭn), $n$., sight.

vital ( $\left.\mathrm{vi}^{\prime} \mathrm{t} a \mathrm{l}\right), a .$, necessary to life.

vitality (vît-tăl'î-ty̆), n., life; vital force.

vulnerable (vǔl'nẽr-ä-b'l), adv., capable of being wounded.

W

well-poised (wěl-poiz'd'), $a$., well-balanced. 


\section{INDEX}

Absorption, 28, 29.

Adenoids, 152.

Air, 7, 97-182.

Albumen, 43, 48.

Alcoholic drinks, 72-85, 309.

Alimentary canal, 17.

Almonds, 65.

Amherst College, 180.

Aorta, 108, 111.

Apples, 65, 66.

Aqueous humor, 235.

Arteries, 106, 284.

Artificial lights, 122, 240.

Artificial respiration, 289, 290.

Astigmatism, 253.

Athletic training, 79, 80 .

Atomizer, 156, 272.

Auditory canal, 263.

Bacilli, 301, 308.

Bacon, 47.

Bacteria, 35, 36, 67, 135, 136, 295.

Baked potatoes, 91 .

Bananas, 65, 66.

Baseball, 173.

Baths, 195-202, 309.

Beans, 64.

Beef, 46, 47 .

Between meals, 89, 90.

Beverages, 69-85.

Bile, 27.

Black Hole of Calcutta, 124.

Blood, 106-112, 147, 172, 196, 197, 198, 203-205, 215, 218, $222,228,241,279,283-285$, $291,292$.
Blood poisoning, 284.

Bones, 5, 143, 144, 264, 314.

Boracic acid, 156, 247.

Bowels, evacuation of, 29.

Brainworkers, 91.

Bread, 56-61.

Breathing, 143-157.

Broiled meats, 91.

Bronchial tubes, 105.

Broth, 90.

Burns, 286.

Butter, 41.

Cabinet bath, 199, 200.

Cake, 60.

Camera, 235.

Candling eggs, 45.

Candy, 86-89.

Canned fruits, 66, 67.

Canned vegetables, 64 .

Canning, 67.

Capillaries, 106, 111, 112.

Carbohydrates, 13.

Carbon dioxid or carbonic acid gas, 101-104, 111-113, 115-118, 121.

Cartilage, 163.

Cervantes, 282.

Chain of bones, 264 .

Cheese, 42.

Chicken, 46.

Chocolate, 70, 71 .

Choking, 291.

Choroid coat, 234.

Chyle, 28.

Chyme, 27, 28.

Cigarettes, 180. 
Circulation, 107-111, 197, 203, | Ear, 262-275. 205, 216, 218, 228, 241, 279, Earache, 269. $280,288$.

Clinical thermometer, 303.

Clothing, 209-220.

Cocoa, 70, 71.

Coffee, 69, 70, 90, 91.

Cohn, Dr., 249.

Colored glasses, 240.

Combustion, 100-103, 113, 115, 116.

Complexion, 195.

Concave glasses, 250.

Condensed milk, 40, 41.

Constipation, 63.

Consumption, 128, 295, 301-313.

Contagious diseases, 295-313.

Convex glasses, 253.

Corn, 55.

Cornea, 234.

Corpuscles, 111.

Cotton, 210-212.

Cream, 34.

Cross-eye, 255.

Crystalline lens, 235.

Custard, 91.

Cuts, 283, 284.

Daniel, 94, 96.

Deafness, 153, 262, 263, 269, 272275.

Deep breathing, 148, 149, 158.

Dental floss, 225.

Dermis, 192.

Diaphragm, 144, 145, 163.

Diaphragmatic breathing, 146 .

Digestion, 16-31.

Diphtheria, 298.

Doughnuts, 60, 91.

Draught, 122.

Dried beef, 47 .

Dried fruits, 66.

Drowning, 288-290.

Drumhead, 264.

Dusting, 137.

Ear-drum, 263, 264.

Earwax, 263, 264.

Eggs, 43-48.

Emergencies, 283-294.

Entire wheat flour, 58.

Epidermis, 192.

Esau, 88.

Esophagus, 22.

Eustachian tube, 264, 268, 269, 272.

Exercise, 163-176.

Expectoration, 295, 297.

Eyes, 233-261.

Farsightedness, 252.

Fat, 10-12.

Fireplace, 132.

Fish, 51-53.

Food, 6-96.

Food habits, 86-96.

Formaldehyde, 34, 296.

Franklin, Benjamin, 201, 202.

Freezing, 288.

Fruit, 65-68.

Gall bladder, 27.

Gastric juice, 23, 25.

Germs, 295, 296.

Ginger ale, 72.

Gladstone, William E., 21.

Glazed paper, 245.

Golf, 173.

Greeks, 94.

Hair, 214-217.

Ham, 47.

Harvey, Dr. William, 109.

Health officer, 298.

Heart, 106-109, 117.

Heat exhaustion, 287.

Hitcheock, Dr., 180.

Hodge, Dr. C. F., 77.

Horseback riding, 173. 
Humidity, 104.

Hydrochloric acid, 23.

Ice cream, 72 .

Influenza, 295.

Insensible perspiration, 193.

Insomnia, 278.

Insurance, 80, 178.

Intestinal digestion, 27, 31 .

Intestinal juice, 28 .

Intestines, 17, 22.

Intercostal muscles, 163.

Iris, 234.

Iron, 14.

Jacob, 88.

Jam, 66, 90.

Jamaica ginger, 248.

Japan, 56.

Japanese, 51, 191.

Jellies, 66.

Kane, Dr., 12.

Kidneys, 193, 194.

Lamb, 47.

Legumes, 64 .

Lewis, Dr. F. Park, 243.

Lime, 14.

Limewater, 32, 115, 226.

Liquid glass, 44 .

Liver, 22, 27.

Londonderry, steamer, 124.

Lungs, 105, 112, 117, 119, 145, 193, 194.

Magnesia, 14.

Mastication, 18-21, 228.

Measles, 269, 296, 298, 299.

Meat, 46-51.

Medicines, 30.

Melba, Madame, 174-176.

Milk, 32-41.

Mouth breathing, 150.
Mumps, 298.

Mutton, 47.

Nearsightedness, 241, 250, 251.

Nebuchadnezzar, 94.

104, Nervous system, 205-208.

Night sweats, 304.

Nitrogen, 9, 101, 115.

Nitrogenous foods, 9.

Nose, 150.

Nosebleed, 285.

Nose breathing, 150-157.

Nose glasses, 258.

Nuts, 64, 65 .

Oatmeal, 55.

Oil glands, 192, 194.

Oleomargarine, 41, 42.

Olive oil, 11, 308.

Olympic games, 79, 80 .

Optic nerve, 235.

Oranges, 66.

Oxygen, 99-101, 106, 111, 112, 114-117, 132.

Oysters, 53.

Pancakes, 60, 90.

Pancreas, 22, 27.

Pancreatic juice, 27, 28.

Pasteurized milk, 39.

Pastry, 60, 61.

Patent medicines, 133, 187.

Peanut butter, 65 .

Peanuts, 65.

Peary, Commander R. E., 74, 182

Peas, 64.

Pepsin, 23.

Perspiration, 193.

Perspiratory glands, 192.

Phosphorus, 14.

Pickles, 90.

Pie, 60, 91.

Plants, 113.

Pneumonia, 295.

Poisoning, 292. 
Poison ivy, 293.

Polypi, 152.

Pop, 72.

Pores, 193.

Pork, 49, 50.

Potatoes, 62.

Preserving fruit, 68.

Proteid, 9.

Pryor, Dr. John H., 149.

Ptomaine, 52, 293.

Pulmonary artery, 107, 110.

Pulmonary vein, 108, 111.

Pulse, 110, 304 .

Pupil, 235.

Quinine, 272.

Railroad employees, 82.

Raspberries, 66.

Rennin, 23.

Respiration, 112.

Respirator, 156.

Rhythmic breathing, 148, 149, $158,163$.

Ribs, 144, 145.

Rice, 55, 56.

Roosevelt, Theodore, 168, 169, 172,174 .

Russian baths, 198.

Rye, 55, 56.

Saliva, 18.

Salivary glands, 18 .

Salt, 14, 25.

Sarcey, Francisque, 258.

Sausage, 50, 91.

Scarlet fever, 269, 296, 298, 299.

Schoolrooms, 137.

Sclerotic coat, 234.

Scott, Sir Walter, 169-172, 174.

Seaver, Professor J. W., 178-180.

Shoes, 218.

Silk, 210-212.

Sixth-year molars, 229.

Skating, 173.
Skin, 192, 309.

Sleep, 276-281.

Smallpox, 296, 298, 299.

Snoring, 155.

Soda, 14.

Soda water, 72 .

Soups, 49.

Spanish windlass, 285

Spartans, 94.

Spectacles, 257.

Squint, 255.

Starch, 13.

Sterilized milk, 39 .

Stewed fruits, 66 .

Stews, 49.

Stomach, 22, 23.

Stomach digestion, 22-27.

Suffocation, 291.

Sugar, 13, 14.

Sugar habit, 86-89.

Sunshine, 136.

Sunstroke, 287.

Tartar, 227.

Tea, 69, 70 .

Teeth, 221-232.

Temperature, 138, 139, 194, 303.

Tennis, 173.

Thermometer, 139.

Thirst, 184.

Thorax, 143-145.

Toast, 59, 60, 91 .

Tobacco, 177-182.

Toothpowder, 225.

Trachea, 22.

Trichinæ, 49.

Turkish baths, 199 .

Type, 245.

Typhoid fever, 190, 295, 297.

Unconsciousness, 292.

Vaccination, 299.

Valves, 109. 
Veal, 50.

Vegetables, 63.

Veils, 242.

Veins, 106, 107, 284.

Ventilation, 118-134.

Villi, 28.

Vitreous humor, 235.

Walking, 173.

Walnuts, 65 .

Water, 183-202, 309.
Watery vapor, 98, 103, 104, 112, 126, 193.

Wheat, 54.

Whittier, 282.

Whole wheat flour, 58 .

Whooping cough, 298.

Wind pipe, 22, 291.

Wood alcohol, 247.

Woolen, 210-212.

Yale University, 21, 178. 



\section{Source Readers in American History}

SELECTED AND ANNOTATED BY

ALBERT BUSHNELL HART, of Harvard University

IN FOUR VOLUMES. ILLUSTRATED

No. I. Colonial Children = - = Price 40 cents, net No. II. Camps and Firesides in the Revolution. Price 50 cents, net No. III. How Our Grandfathers Lived = Price 60 cents, net No. IV. Romance of the Civil War - Price 60 cents, net

\section{Source Book of American History}

FOR SCHOOLS AND READERS

Edited by ALBERT BUSHNELL HART, Ph.D. Editor of "American History told by Contemporaries," etc.

Cloth. 12 mo. 60 cents, net

"A volume that we have examined with close attention and can commend with confidence. In about four hundred pages of text, it finds room for something like one hundred and fifty examples of the original material of our history, from the voyages of Columbus to the Spanish-American War. The selections are judiciously made, edited, and annotated; the introductory chapters for teachers are of the most helpful sort; and the book is sold at so low a price that no secondary school in which American history is taught can find a reasonable excuse for not employing it as an adjunct to the regular manual." - The Dial.

\section{THE MACMILLAN COMPANY}

\section{4-66 FIFTH AVENUE, NEW YORK}




\section{PIONEER HISTORY SERIES}

\section{By CHARLES A. MCMURRY}

Designed as a complete series of early history stories of the Eastern, Middle, and Western States, suitable as an introduction for children to American History. Illustrated and equipped witb maps.

Cloth I2mo 40 cents each

\section{Pioneers on Land and Sea}

The first of the three volumes deals with the chief ocean explorers, Columbus and Magellan, and with the pioneers of the Eastern States, Canada, and Mexico, such as Champlain, Smith, Hudson, De Leon, Cortes. These stories furnish the gateway through which the children of our Atlantic States should enter the fields of History. The attempt is to render these complete and interesting stories, making the experiences of pioneer life as graphic and real as possible.

\section{Pioneers of the Mississippi Valley}

Such men as La Salle, Boone, Robertson, George Rogers Clark, Lincoln, and Sevier supply a group of simple biographical stories which give the children a remarkably good introduction to History. Teachers are beginning to believe that children should begin with tales of their own home and of neighboring states, and then move outward from this centre. For eastern children these stories form a very suitable continuation to "Pioneers on Land and Sea," and vice versa.

\section{Pioneers of the Rocky Mountains and the West}

In some respects these western stories are more interesting and striking than those of the states farther east, because of their physical surroundings. Children of the Western or Mountain States should enjoy these stories first. The various exploring expeditions which opened up the routes across the plains and mountains are full of interesting and instructive incidents and of heroic enterprise. The chief figures in these stories are men of the most striking and admirable qualities, and the difficulties and dangers which they overcame place them among the heroes who will always attract and instruct American children. Incidentally, these narratives give the best of all introductions to western geography. They are largely made up from source materials furnished by the explorers themselves.

\section{THE MACMILLAN COMPANY}

64-66 FIFTH AVENUE, NEW YORK

BOSTON CHICAGO SAN FRANCISCO ATLANTF













Sivo

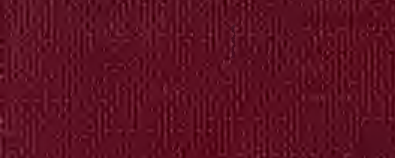

(1)

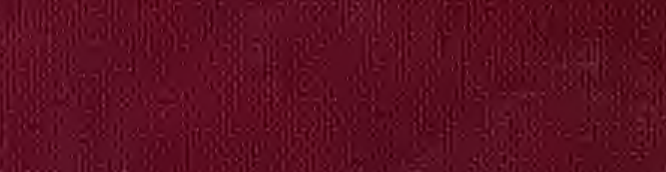

25

(3)

3.

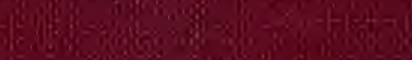

(1) 5

$\operatorname{lig}_{0}$

af

5.

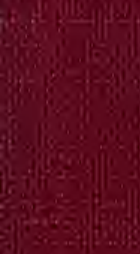

